Golden Gate University School of Law GGU Law Digital Commons

1907

\title{
The San Francisco Earthquake and Fire April 18, 1906 and Their Effects on Structures and Structural Materials
}

US Department of the Interior

Follow this and additional works at: https://digitalcommons.law.ggu.edu/federal_documents

Part of the Environmental Law Commons

\section{Recommended Citation}

US Department of the Interior, "The San Francisco Earthquake and Fire April 18, 1906 and Their Effects on Structures and Structural Materials" (1907). Federal Documents. 16.

https://digitalcommons.law.ggu.edu/federal_documents/16

This Federal Document is brought to you for free and open access by the Government Documents at GGU Law Digital Commons. It has been accepted for inclusion in Federal Documents by an authorized administrator of GGU Law Digital Commons. For more information, please contact jischer@ggu.edu. 
DEPARTMENT OF THE INTERIOR UNITED STATTES GEOLOGICAL SURVEY GEORGE OTIS SMITH, DIRECTOR

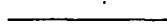

TIIE

、

SAN FRANCISCO EARTHQUAKE AND FIRE

$\mathrm{OF}$

APRIL 18, 1906

AND THFIR EFIECIS ON STRUCTURES AND STRUCTURAI MATERIATS

REPORTS BI

GROVE KARL GILBERT, RICHARD LEWIS HUMPHREY, JOHN STEPHEN STWELL, AND. FRANK SOULÉ

WITH PREFACE BY

JOSEPH AUSTIN HOLMES

In Charge of Technologic Branch

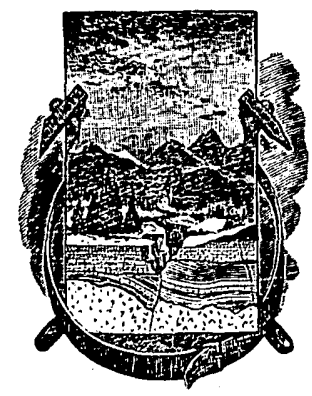

WASHINGTON

GOVERNMENT PRINTING OFEICE

1907 



\section{CONTENTS.}

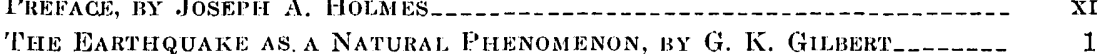

Introduction -..._- 1

The fault triace

Cracks -_._-_. 7

Dislocations of surface material___._._._- 7

Motions constituting the earthquake_. 10

Distribution of intensity

The Effects of the İarthquake and Fire on Various Structures ani

Structural Materials, by Richard L. Humphrei

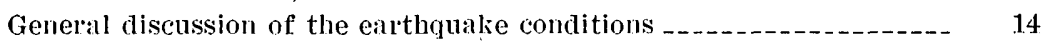

Effects on structures outside of San Francisco ____________ 17

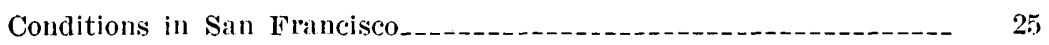

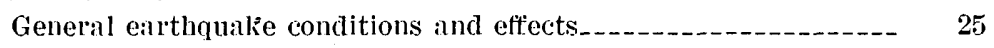

Behavior of individual structures_-_- 30

General statement___._. 30

Academy of Sciences building

Atna (Young, or Commissary) Building

Appraisers' warehouse (United States custom-house) _....... 32

Aronson Building

Bekins Van and Storage Company's building-_-_-_-_-_---_ 33

Bullock \& Jones Building

California Casket Company's building-_._-_-_-_-_-_-_-_ 33

Call (Claus Spreckels) Building 34

Chronicle buitdings..... 35

City hall and hall of records________ 35

Crocker Building

Emporium _._.

Fairmount Hotel__._. 37

James Flood Building-_- 37

Grant Building-_-_-_-_._-_._- 37

Hotel Hamilton_-_-_-_-

Hibernia Savings and Loan Society's building

Hobart Building

Jackson Brewing Company's building $\quad 39$

Hall of Justice

Kamm Building-_._..-_-_- 39

Kobl (Hayward) Building

Majestic Thenter-_.....- 40

Mercantile Trust Company's building 
The Effects of the Earthquake and Fire on Various Structures, ETc.-Continued.

Conditions in San Francisco-Continued.

Bebavior of individual structures-Continued. Page.

Merchants' Exchange building________._._._._._. 41

Mills Building_____-__- 41

United States mint

Monạdnock Building

Murphy Building

Mutual Life Building_____._. 43

Pacific States Telephone and Telegraph Company's building- 43

Post-oftice building__-_-__- 44

Rialto Buildingr. 45

St. Francis Hotel____. 45

Scott Building _._. 46

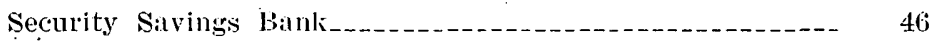

Shieve Building _._._. 46

Sloane Building _._- 47

- Spring Valley Water Company's building_..._._._._._._._. 47

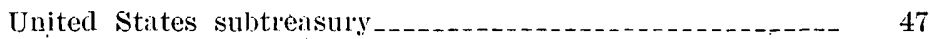

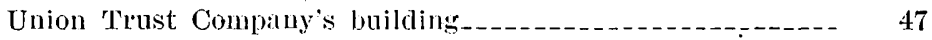

Volkman Building _..... 48

Wells-Fargo Building _._. 48

Aspects of the fire disister.

Fire history and recommenditions of insurance boards__._._. 49

Fire-resisting qualities of structures and structural materials_-_ $\quad 51$

Water supply and other methods of fighting fire

Genernl lessons of the earthquake and fire

Obstacles to the reconstruction of San Francisco___________ 59

Statistics and general information

The EFfects of the Earthouake and Fine on Bulloings, Gngineering

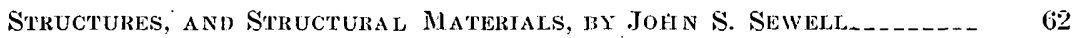

Introduction _._. 62

Scope of the investigation 62

Acknowledgements _._. 63

Extracts from the rejort of a committee of the National Board of Fire Underwriters on San Francisco conditions_-_._._._.-.

Some features of the earthquake and fire

Amount of destruction due to the earthqualie and file, respectively

Fire-fighting operations; the use of dynamite...................

Temperatures of the Baltimore and San Francisco fires._._....

Earthquake- and fire-resisting qualities of structures and structural materials _._.

Effect of fire on Government and class A commercial buildings--

Vaults and safes_____-_.

Behavior of structural member's and materials___________ 71

Behavior of individual structures

Academy of Sciences building

Atna (Young, or Commissary) Building

Appraiser's' warehouse

Aronson Building._._. 78 
The Erfects of the lirthquake and Fire on Rullotas, etc.-Continued.

Earthquake- and fire-resisting qualities of structures. etc-Continued.

Behavior of individual structures-Continued.

Bullock \& Jones Building

Call Buildingr._. 81

Chronicle buildings__.__._. 83

City hall and hall of records_._. 54

Cowell Building 89

Crocker Building

Crocker Istate Building__._._._._._. 90

Dewey monument._. 90

Emporium _... 90

Fairmount Hotel_._. 92

James Flood Building

Grant Building

- Hall of Justice

Kamm Building

Kohl Building

Merchants' Exchange building____._._._. 94

Mills Building_-

United States mint._. 95

Monadnock Building

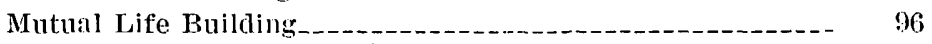

Facific States 'lelephone and 'l'elegraph Building_______- of

Palace Hotel___a 97

Post-office building _t

Rialto Building

St. Finncis Hotel____ 108

Shreve Building

Sloane Building _._.

Spring Valley Water Company's building

Union Ferry Building 105

Union Trust Company's building

Miscellaneous structures.___._. 108

General discussion__. 108

Ordinary buildings and residences.._._. 110

Chimneys _... 111

Brick smokestacks._._. 112

Conditions outside of San Flancisco_____ $\quad 112$

Oakland _. 112

Palo Alto

Other: towns _ _

Fortifications _. 114

Reservoirs, pipe lines, and other structures along the fault

line _._. 114

General conclusions._-____ 116

The rebuilding of San Francisco_______- 116

Distribution systems for: waterworks______ 117

Sewer's _._.

Fire-resisting features of buildings in "congested districts" _._ 119 
The Effects of the Earthquake and Fire on Buildings, etc.-Continued.

General conclusions-Continued.

Fireproofing Page.

Protection of openings_._.

Fireproof vaults._._._.

Constructions and materials recommended for earthquake localities

The minimizing of fire losses

Earthquake insurance

Summary

The Earthquake and Fire and their EFFects on Structural Steel and

STEel-Frame BuLldings, BY Frank Soulé.

The earthquake

Geologic features._.

A study of the effect of natural features on the intensity of destruction

Distance from the fault line Soil formation

The fire

General description

Abstract of report of engineers' committee of the National Board of Fire Underwriters.

Extracts from a San Francisco fire expert's report to the British fire-prevention committee

Effect of the layout of the city and the character of the buildings.

Behavior of structural steel and steel-frame buildings subjected to the earthquake and fire

Effects due primairily to the earthquake

Introduction -.

Foundations -

Structural-steel frames exposed to vibratory motion

Masonry walls and stonework

Reliability of structural steel

Effects of the fire

Buildings

Concrete -..-

Plister and metal work

Reenforced concrete

Lessons from the various types of buildings._.

Fire-fighting apparatus and fire-resisting materials_._._._.

Final conclusions _._.

Earthquake protection

Fire protection _. 157

Acknowledgments _._.

List of Papers Relating to the Eartheuake and Fire_.

INDEX _. 


\section{ILLUSTRATIONS.}

(All the plates will be found at the end of the bulletin.)

Flate I. Earthquake effects along the fault trace: $A$, Road crossing fault trace near Point Reyes station; $B$, Fence parted by earthqualke fault.

Il. Redwood tree on line of fault south of Fort Ross, showing earthquake effect along the fault trace.

III. Fault trace near Point Reyes station.

IV. A, Secondary cracks, shore of Bolinas Lagoon; B, Secondary cracks, with settling, Bolinas.

V. Results of earth flow, Ninth street, San Francisco.

VI. Earthquilke effects on " made ground:" $A$, Settling on Dore street; $B$, Buckling caused by earth flow, Howard street.

VII. Shifted bottom of Tomales Bay: $A$, General view; $B$, Edge of new shoal.

VIIl. A, Earthquake ridges on tidal that, 'Tomales Bay; $B$, Slipping of alluvial soil toward a river.

IX. Dimage to Pilarcitos 30-inch pipe line by earthquake.

X. A, Collipsed 30 -inch wrought-iron pipe near trestle crossing the fault; $B$, House on line of fault, torn asunder by earthquake.

XI. A, Racking and spalling of concrete pier due to earthquake movement; $B$, Endurance of concrete dam near fault trace at Crystal Springs Lake, San Mateo.

XII. A, Effect of earthquake on a brick building near Salinas (Spreckels's sugar mill); $B$, Earthquake wreck of Hall of Justice, San Jose.

XIII. $A$, Comparative earthquake endurance of dissimilar structures near San Jose; B, Earthquake effect, high school building, San Jose.

XIV. A, Comparative behavior of reenforced concrete and brickwork under earthquake vibration; $B$, Complete wreck by earthquake at Santa Rosi.

XV. Endurance of steel framework as affected by method of support, Leland Stanford Junior: University: $A$, Undamaged steel framework supporting dome of library $; B$, Collapse of brick walls causing destruction of steel skeleton dome of gymnasium.

XVI. Memorial arch, Leland Stanford Junior University: A, Before the earthquake; $B$, Earthquake effect.

XVII. $A$, Collapse due to lack of tie between walls and frame; $B$, Collapsed tower and general earthquake wreckage.

xvili. A, Earthquake damage due to lack of tie and bracing; $B$, Earthquake effect on arches.

XIX. Earthquake effects on cement-block walls: $A$, Endurance of walls tied together with steel rods; $B$, Wall thrown down by earthquake vibrations of roof trusses which were not tied to wall. 
I'LATE XX. A, Loosening of arch stones and spalling of colunns ly earthquake: $B$, Undamiged reenforced-concrete structure.

XXI. A., Racking of newly constructed building; B, Gool earthquake endurance of buttressed walls.

XXII. A, X cracks in brickwork, calused by rocking; $B$, slip of foundation of cyclorama, causing collapse of the structure.

xxili. A, Earthquake effect on structure of reenforced concrete of poor quality; $B$, Effect of earthquake on adjacent buildings of dissimilar type and construction.

XXIV. A, Failure of cast-iron shell of coucrete-filled cast-iron columns by fire; $B$, Spalled granite, Market street entrance of Atna Building, San Francisco.

XXV. A, Subsidence of street in ftont of Attna Building; B, Fire endurance of concrete.

XXVI. A, Buckled columns and collapsed floor panel; $B$, Incipient failure of naked cast-iron column in city hall.

XXVI1. A, Earthquake endurance of reenforced-concrete building; $B$, Failure of terra-cotta column coverings, resulting in buckled columns.

XXVIII. A, Earthquake endurance of a well-constructed brick building; $B$, Failure of ornamental terral cotta.

XXIX. A, Earthqualke cracks in walls of vault; $B$, Collapse of floor panel caused by fall of load from floor above.

XXX. A, Earthqualke damage minimized by special construction, Dewey monument, Saln Francisco; $B, \dot{X}$ cracks in walls due to rocking of building by earthquake, Chronicle Building, San Francisco.

XXxi. Ruin of the seven-million-dollar city hall, San Francisco.

XXXII. Complete failure of slow-burning wood construction.

XXxil. A, Behavior of steel frame; $B$, Earthquake damage to stone piers.

xxxiv. Buckling of columns due to failure of plastered metal-lath fireproofing.

XXXY. A, Incipient buckling of columns from heat; $B$, Fiture of suspended ceiling.

XXXvi. A, Granite columns spalled by fire; $B$, Buckling of columns due to failure of wire-mesh and plaster fireproofing.

XXXVII. A, Stonework spalled by fire; $B$, Earthquake damage due to light walls and bad construction.

Xxxvili. A, Good earthqualie endurance of a building of the monumental type; $B$, Spalling of stonework by fire.

XXXIX. A, Wrecked tower and spalled stonework; B. Complete wreck by earthquake, due to joor design.

XL. A, Spalling of enameled brick in light well and failure of fireproofing of window-frame separators: $B$. Buckling of basement column due to failure of terril-cotta covering in fire.

XI. A, Endurance of a well-protected huilding subjected to severe radiant heat; $B$, Warping of plastered metal-lath covering.

XLII. A, Roof trusses damaged by heat, through failure of terra-cotta covering; $B$, Effect of settling of ground subjerted to earthquake vibrations.

XLIII. A, Cracks in masonry, pavilion of post-office; $B$, Effect of slip, Mission street, San Francisco.

XLIV. A, Cracks in masonry and settling of outer terrace, post-office building, San Francisco; $B$, Effect of earthquake in loosening stonework. 
Prate XLV. A, Failure of hollow-tile fireproofing; $B$, Failure of terra-cotta tile protection and spalling of lower webs of floor tiles.

XLVI. A, Brickwork thrown down by earthqualke vibration; B, Elfect of severe shaking on well-bonded brickwork filled with good mortar.

XLVII. Sheared rivets, tower of Union Ferry Building, San Francisco.

XLVIII. A, Bucliling of basement column due to failure of plastered metallath fireproofing; $B$, Damage said to have been caused by dynamite.

XLIX. A, Failure of basement column due to fire; $B$, Failure of terracotta tiling and metal-frame wire-glass windows by fire.

L. A, Collapse of building due to buckling of columns; $B$, Failure of terri-cotta tile covering in fire.

LI. Effects of he:t on steel work.

LII. A, Endurance of brick vault; B, Absolute failure of so-called fireproof salfes.

LIII. A, Earthquake damage to brick stack: B. General earthquake effect on firame huildings.

I.IV. Destruction by fire, San Françisco; view westward from 'l'elegraph Hill.

LV. Destruction by fire, San Francisco; panorama from corner of. Pine and Powell streets.

LVI. Map of San Francisco, showing burned district.

LVII. Map of San Francisco and vicinity, showing relation of burned district to entire city.

Fig. 1. Map of the fault trace, page 3 .

2. Diagrans illustrating the nature of the earthquake-making fault, page 4 . 



\section{PREFACE。}

By Josepi $\Lambda$. Holmes.

Immediately after the San Francisco earthquake and fire of April 18,1906 , it was decided to arrange for an investigation of their effects on buildings and materials of construction. Accordingly, on April 19 Richard L. Humphrey was sent to San Francisco for this purpose, as secretary of the National Advisory Board on Fuels and Structural Materials and representing the structural materials division of the United States Geological Survey. At the request of the President, Capt. John Stephen Sewell, Corps of Engineers, United States Army, was sent to San Francisco on a similar errand by the War Department under order of April 23, 1906. Frank Soulé, dean of the college of civil engineering of the University of California, was asked late in the fall of 1906 to prepare a report on the general earthquake and fire conditions. G. K. Gilbert, of the United States Geological Survey, also a member of the California earthquake investigation commission, who was near San Francisco at the time of the disaster, was asked to prepare a brief special report on the phenomena of the earthenake.

Mrr. Gilbert has brought into his paper only the salient features and results of the earthquake, for the reason that the subject is being treated more fully in the report of the California earthquake investigation commission.

Mr. Humphrey, who during the last two years has had charge of the structural materials laboratories of the United States Geological Survey, has had many years' experience in the investigation of structural materials, especially with regard to their fire-resisting qualities.

Before going to San Francisco Captain Sewell had studied carefully the effects of fire on buildings and materials, especially as inclicated by the results of the conflagration at Baltimore in 1.904 .

Professor Soulé has had the advantage not only of a large experience, but also of being thoroughly familiar with the conditions in San Francisco prior to the earthquake and fire, and of being on the ground during their occurrence. He has had subsequently every opportunity for studying, at first hand and in great detail, the effects of both the earthquakè and the fire. 
The investigations of these three engineers were conducted independently, and their reports have been prepared without collaboration. Under these circumstances there are necessarily some differences of opinion as to matters of detail, but as to the more important features the writers are in hearty accord. About four hundred illustrations were submitted with the original reports; many of these do not appear with the printed reports because their use would have involved duplication, but wherever a view given by one author was rejected because of its similarity to a view by another author showing the same engineering features, a reference to the accepted view has been inserted. The legend appended to each illustration indicates whether the original view was actually taken by the author or was procured from another source.

Persons interested in this subject are advised not only to read each of these papers, but also to consult a number of other important papers on this subject which have appeared in the different technical journals and the proceedings of technical societies during the last several months. (See list at end of bulletin, pp. 159-161.) 


\section{THE SAN FRANCISCO EARTHQUAKE AND FIRE OF APRIL 18, 1906, AND THEIR EFFECTS ON STRUCTURES AND STRUCTURAI MATERIALS.}

By G. K. Gilber', R. L. Humphrey, J. S. Seweld, and Frank Souré.

\section{THE EARTHQUAKE AS A NATURAL PHENOMENON.}

By G. K. Gilbert.

\section{INTRODUC'TION.}

The investigations to which the San Francisco earthquake has given rise are of two classes-the study of the natural phenomena constituting or associated with the earthquake, and the study of the relations of the San Francisco earthquake and future earthquakes to human activities.

The principal studies of the earthquake as a natural phenomenon . are under the direction of the California earthquake investigation commission, which was appointed by the governor of the State. three days after the occurrence of the shock. The human or economic aspects of the subject have been studied chiefly by engineers and architects, of whom a number have acted in private capacity, while others have acted as the representatives of governmental or private organizations. In many of the architectural studies the earthquake and fire have been considered together, as the destructive effects of these two sources of danger were closely associated in the San Francisco disaster.

This volume is devoted to certain economic aspects of the subject, and the present chapter on natural phenomena of the earthquake selects those features which seem contributory to an understanding of the papers which follow. A fuller account of the earthquake may be found in the preliminary report of the State commission 
above referred to; and a monographic report is to be expected when the labors of this commission shall have been completed. ${ }^{a}$

An earthquake is a jar occasioned by some violent rupture. Sometimes the rupture results from an explosion, but more commonly from the sudden breaking of rock under strain. The strain may be caused by the rising of lava in a volcano or by the forces that make mountain ranges and continents. The San Francisco earthquake of April 18, 1906, had its origin in a rupture associated with mountainmaking forces. A rupture of this sort may be a mere pulling apart of the rocks so as to make a crack, but examples of that simple type are comparatively rare. The great majority of ruptures include not only the making of a crack but the relative movement or sliding of the rock masses on the two sides of the crack; that is to say, instead of a mere fracture there is a geologic fault. After a fault has been made its walls slowly become cemented or welded together; but for a long time it remains a plane of weakness, so that subsequent strains are apt to be relieved by renewed slipping on the same plane of rupture, and hundreds of earthquakes may thus originate in the same place.

A faulting may occur far beneath the surface and be known only through the resulting earthquake; but some of the quake-causing ruptures extend to the surface, and thus become visible. The New Madrid and Charleston earthquakes are examples of those having deep-seated origins; the shocks at Inyo and San Francisco, of those whose causative faults reached the surface of the ground.

The San Francisco earthquake had its origin, wholly or chiefly, in a new slipping on the plane of an old fault. The trend of the fault is northwest and southeast, and it is known through a distance of several hundred miles. Visible evidence of fresh slipping-a surface trace, to be described presently-does not appear through its whole extent, but has been traced from San Juan at the south to Point Arena at the north (fig. 1), a distance of about 180 miles. Because the earthquake was severe in Priest Valley, 60 miles southeast of San Juan, it is thought that subterranean slipping on the old fault plane extended beyond San Juan. At Point Arena the visible fault trace passes under the ocean, and the line of its trend does not again touch the coast, so that its northwestern course and extent are in doubt. A fault trace which appears at Point Delgada, 75 miles to the north, may be part of its continuation or may represent a separate fracture. In a general way the intensity of the shock was greatest near the

\footnotetext{
a The California earthquake investigation commission is composed of Andrew $C$. Lawson (chairman), A. O. Leuschner (secretary), G. K. Gilbert, H. F. Reid, J. C. Branner, George Davidson, Charles Burkhalter, and W. W. Campbell. Its work is organized under. three committees-a committee on isoseismals, A. C. Lawson, chairman; a committee on coseismals, A. O. Leuschner, chairman, and a committee on the geophysics of the earthquake, H. F. Reid, chairman.
} 
fault trace and diminished with distance therefrom; but to this rule there are important exceptions, and it has been noted especially

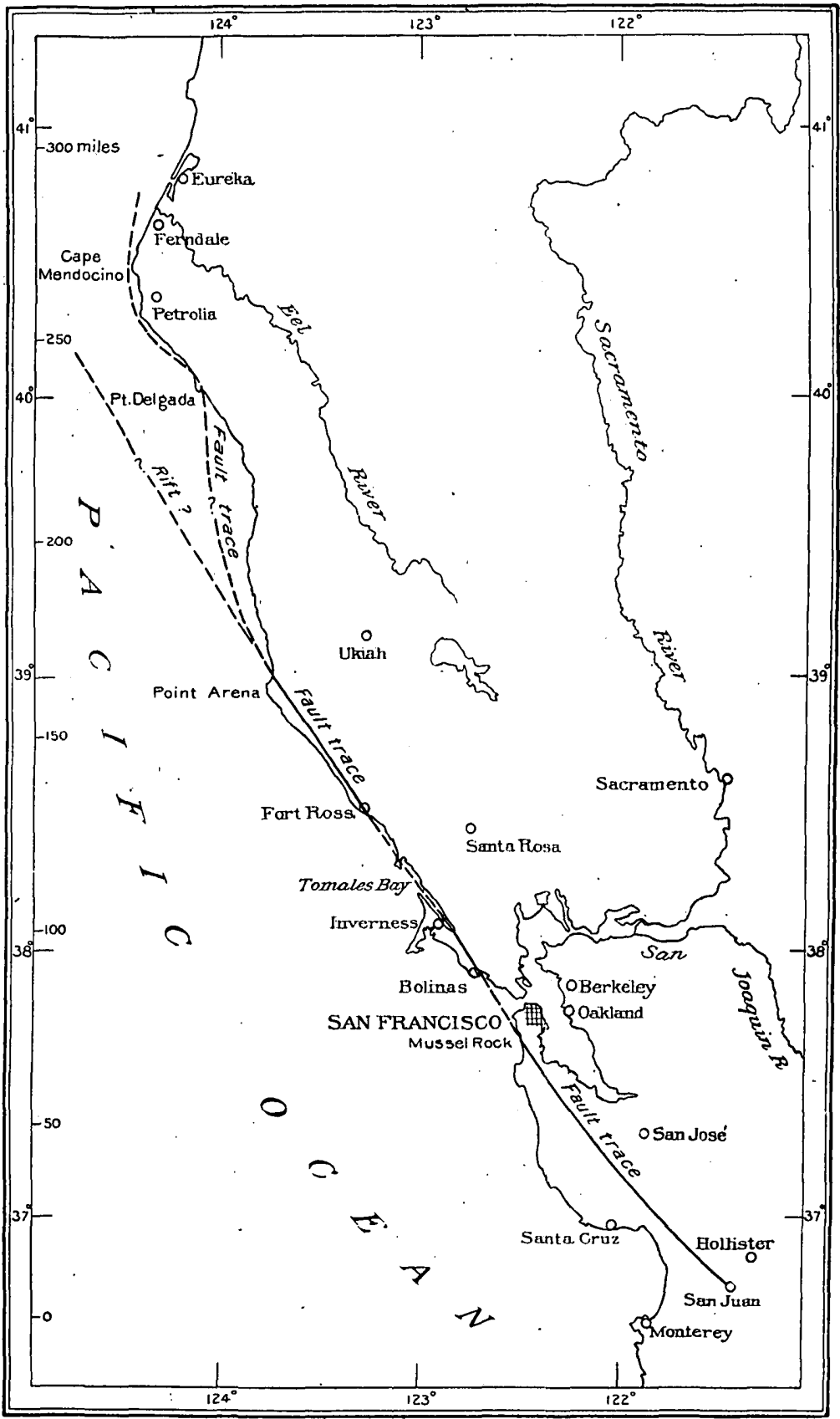

Fic. 1.- Map of the fault trace. Broken lines indicate alternative hypotheses as to its extension north of Polnt Arena.

that an area of high intensity coincided approximately with the Santa Rosa Valley, which trends northwestward, parallel to the main 
fault. As the ridges of the neighboring Coast Range have the same northwesterly trend, it is thought probable that a subterranean slipping here occurred on a fault associated with the valley. In that case the geologic event causing the earthquake included coincident or nearly coincident yielding on more than one fault plane of the Coast Range system, and various other peculiarities in the distribution of intensity may be ascribed to local faulting.

The region of high intensity, to which most of the destruction was limited, is a belt 20 to 40 miles wide, extending from the mouth of Eel River at the northwest to Priest Valley at the southeast (fig. 1). This belt includes the surface expression of the principal fault-a feature distinctively known as the fault trace-a large number of cracks, and many local and superficial dislocations of soil and rock variously characterized as landslides and slumps.

\section{THE FAUL'T' 'TRACE.}

The plane of the earthquake-causing fault, where it appears at the surface, is approximately vertical. The movement which took place along this plane was approximately horizontal.
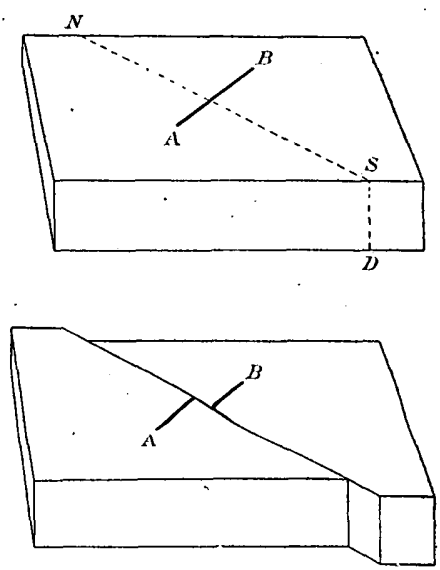

Frg. 2.-Diagrams illustrating the nature of the earthyuake-making fault.

As the statement of these relations is sometimes found confusing, they are here illustrated diagrammatically. The upper diagram in fig. 2 represents a rectangular block as if cut from the land, the thickness being 25 feet, the length east and west (right to left) 150 feet, and the width 100 feet. The dotted line NS indicates the surface outcrop of the old fault plane, trending northwest and southeast, this plane cutting the face of the block in the vertical line SD. AB stands for any straight line on the surface of the land-such as would be defined by a road, a fence, or a row of trees-crossing the fault outcrop at right angles. The lower diagram represents the same 
rectangular block after the earthquake, its two parts dislocated by sliding horizontally along the fault plane, and the line $\mathrm{AB}$ made discontinuous by an offset.

To return, now, from the ideal to the actual, the sides and bottom of the earth block disappear. The depth to which the fault penetrates is indefinite and unknown, and so is the extent of the lands on either side affected by the displacement. For nearly 200 miles there is a fracture on the face of the land, and everything traversed by the fracture is dislocated, the part on the southwest side having apparently moved toward the northwest and the part on the northeast side having apparently moved toward the southeast. The total horizontal offset ranges in general from 2 to 16 feet, but at one place, affected by abnormal conditions, reaches 20 feet (Pl. I, A). The effect is also shown by a redwood tree (Pl. II), which was situated at a place where the displacement was slight. The average offiset is 10 to 12 feet. Associated with the horizontal dislocation are vertical dislocations of minor and variable amount. This line of fracture, with the associated dislocation, is the surface expression of the fault which occurred on April 18, 1906. It is the visible trace of the fault across the surface of the land, and in the following pages will be called the "fault trace." a

The fault trace itself is in some places inconspicuous, as in the flat meadow represented in $\mathrm{Pl}$. I, $B$, where one might readily walk across it without noticing that the ground had been disturbed. Its ordinary phase, however, includes a disruption of the ground suggestive of a huge furrow, consisting of a zone, between rough walls of earth, in which the ground is splintered and the fragments are dislocated and twisted. This phase is shown in Pl. III. In many places the fault trace sends branching cracks into bordering land, and locally its effect in dislocation is divided among parallel branches.

The views of the fault trace given in Pl. VII represent it at a point not far from the head of Tomales Bay, where it traverses a hillside having a general slope toward the southwest. In the upper view we look toward the northwest; in the lower, toward the southsoutheast. The horizontal displacement is here about 16 feet, the ground at the left, in each view, having moved from us, and the

\footnotetext{
$a$ In the case of an earthquake fault with important vertical displacement the surface expression is a small cliff or scarp, and to such a feature the name "fault scarp". has been given; but this name does not serve to characterize the feature produced by the horizontal displacement of April 18, 1906. In default of an appropriate and established name the geologists who first traced the feature made tentative use of "furrow" and "rift;" and the word rift was employed in the preliminary report of the California commission, in a popular article by the present writer, and probably in other places. The commission, however, in giving more deliberate attention to terminology, has determined to reserve the word rift for a meaning more in consonance with earlier geologic usage and to substitute "fault trace" for the surface expression of the fault. The present paper conforms to the nomenclature accepted by the commission.
} 
ground at the right toward us. There is also a vertical displacement, the ground on the southwest side having been relatively lifted 1 or 2 feet, and the expression of the vertical change is exaggerated in the lower view by the relation of the horizontal change to the local slope of the hillside. There is nothing in the pictures to show the amount or even the direction of the horizontal displacement, but measurements were made at neighboring points where the fault trace intersects. a road, a trail, and a small gully. The nature of the evidence as to displacement is illustrated by Pl. I, $B$, which shows a dislocated fence. The locality is on the farm of E. R. Strain, near the head of Bolinas Lagoon, and the camera was directed toward the northeast-at right angles to the trend of the fault trace. The main branch of the fault trace (which is here divided) crosses the foreground from left to right, touching the dissevered ends of the fence, but the shear is at this point so smooth that its surface trace is concealed by the grass. The fence, which before the earthquake was straight and continuous, was broken across and offset to the distance of $8 \frac{1}{2}$ feet.

Between Point Arena and Fort Ross the course of the fault trace (see fig. 1, p. 3) is approximately parallel to the coast, passing to the east of all the coastal towns. From Fort Ross to the head of Tomales Bay it traverses the water, except at Bodega Bay and Preston Point, where for short distances it crosses the land. It again enters the water at Bolinas Lagoon, passing several miles outside the Golden Gate, and returning to the land at Mussel Rock, whence it follows a nearly direct course to San Juan. It does not touch any large town, but passes within a mile of Manchester, Plantation post-office, Fort Ross, Bodega, Inverness, Point Reyes station, Olema, Woodville, Bolinas, Woodside, Portola, Wrights, Chittenden, and San Juan.

On the east and west sides of the fault trace, respectively, the right-line distances to various places are as follows:

Distances from the fault trace to near-by prominent points.

EAST SIDF.

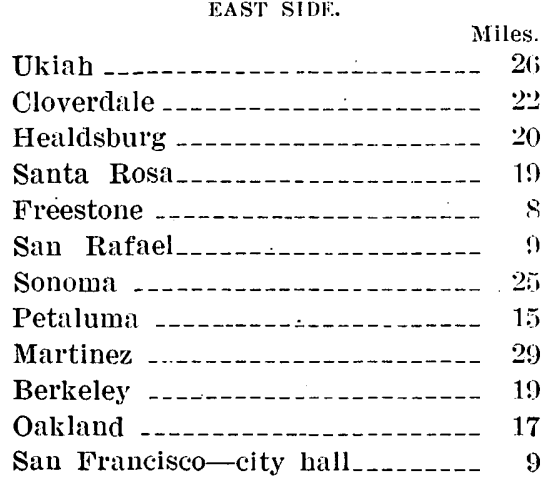

EAST SIDE-continued.

Miles.

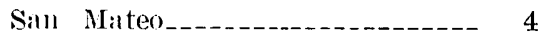

Stanford University_-_-_-_-_ 5

San Jose_-_-_-_-_- 13

WEST SIUE.

Point Reyes light-house__._._._. 11

Halfumoon Bay

F'escadero _...... 10

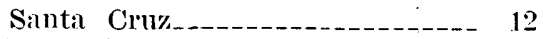

Salinas _-__-__- 13 


\section{CRACKS.}

All through the area of high. intensity cracks were made, and these were specially numerous near the fault trace. The cracks were also more numerous in soft alluvium than in hard. ground, but the number which deeply penetrated the bed rock was large. Perhaps this feature is better expressed by saying that the bed rock was generally and profoundly shattered, but without important dislocation except on the old fault plane. The wide prevalence of shattering is shown by the derangement of the underground circulation of water. In every farming district within the main earthquake belt persons familiar with the springs noted changes in the flow of water, ranging from moderate diminution or increase to complete stoppage or to the breaking out of new springs. In some places the derangements were temporary only; but more commonly a permanent change was reported.

At the surface the cracks had great variety of expression. Some were barely perceptible as partings; others gaped so widely that one might look down them several yards. Some were mere pullings apart; others showed small differential movements of the nature of faulting. Some were solitary; others, especially those exhibiting faulting, were in groups. Some straggled and branched irregularly; others were nearly straight for hundreds of feet. Theoretically, some cracks were primary as regards the earthquake and others secondary; that is to say, some were caused directly by the preexistent stresses which produced the main fault and others were caused by the waves constituting the earthquake.

Pl. IV shows two types of secondary cracks. In $A$ the cracks are crooked and without faulting. They traverse tidal mud near the head of Bolinas Lagoon and are near the main branch of the fault trace, which follows the base of the bluff seen at the right. The cracks seen in $B$ are in Bolinas, within half a mile of the supposed position of the fault trace. The greater part of the village lies in a narrow valley dividing a plateau. The valley floor is of alluvium, the surface of which curves upward at the sides. As a result of the earthquake the alluvium settled somewhat toward the middle of the valley, thus forming along the bases of the hills a system of cracks associated with faulting.

\section{DISTOCATIONS OF SURFACE MATERTAT.}

The district most strongly affected by the earthquake is one in which landslips are normally of frequent occurrence. On many hill slopes were masses of earth or rock, the descent of which was sure to take place whenever conditions became favorable. The shaking of 
the earth on the morning of April 18, 1906, supplied the lacking factor, and they were all loosened at once. In the simplest case, a poised rock toppled over and rolled down a slope. In other cases adhesion was overcome, with resultant sliding. In yet others strains occasioned by the sapping of cliffs were reinforced by kinetic strains and cohesion was overcome, with resultant fracture. Elsewhere an unconsolidated formation, even though in a dry condition, was made to flow by simple agitation. Hillside bogs and other bodies of wet earth lost coherence and flowed as mud. Slips of this character grade into those of wet alluvium or "made ground" resting upon gentle slopes-ground which under ordinary conditions flows or creeps at an almost imperceptible rate, but which by shaking was made to move several feet or yards in a few seconds. The filled districts of San Francisco afford several examples, and two of these are illustrated by Pls. V and VI, B. The view shown in Pl. V is northwestward on Ninth street, near Brannan. Before the earthquake the car tracks and curb line were straight and approximately level, and this condition was not disturbed on the relatively firm ground shown in the distance. In the nearer part of the view the street crosses a tract of made ground created by filling a valley tributary to a narrow tidal inlet called Mission Creek. The descent of this valley was southwestward; and the made ground flowed in that direction, carrying street and buildings with it. In taking the photograph reproduced. in Pl. VI, $B$, the camera stood on ground made by the filling of Mission Lagoon, an expansion of Mission Creek, and was pointed northward, commanding a portion of Howard street. The made ground here flowed northeastward and the buckling of street-car tracks was caused by its motion. Where the same earth flow crossed Valencia street the horizontal movement amounted to 6 feet.

In the various cases of dislocation enumerated the motive force appeared to be gravity, and the apparent function of the earthquake was to initiate movement by overcoming equilibrium, adhesion, or cohesion, or else to increase mobility by agitation, and thereby temporarily convert a quasi solid into a quasi liquid. While I do not doubt that this explanation is ordinarily adequate, there is at least one dislocation of surface material for which it is inadequate, and this raises the question whether in various other instances it may not require qualification. I refer to an extensive shifting of mud on the bottom of Tomales Bay. At the head of the bay and thence for a distance of several miles northwestward the soft mud was moved bodily westward. It not only descended from the northeast shore, so as to cause deeper water, but ascended toward the southwest shore, creating a broad shoal (Pl. VII). The horizontal change of position near the southwest shore was in places more than 25 feet, and 
the vertical change as much as 2 feet. As the ascending movement can not be ascribed to gravity, it must be referred to the earthquake, even though the way in which the earth waves produced the effect is not evident. The locality is adjacent to the fault trace, the position of which is along the bottom of the.bay, east of the shoal.

The illustrations may require a few words of explanation. The upper view of Pl. VII looks northward from the southwest shore of the bay. Tide being low, the newly formed shoal or mud bank is broadly exposed, but the receding tide has left a lane of water to mark the separation of the mud bank from the firmer ground that withstood the quaking. Immediately after the earthquake the mud was rigid, as in the tract shown in Pl. VIII, $A$; but before the view of Pl. VII, $A$, was taken (April 28,1906) the surface had been largely smoothed by the action of wind waves. A single ridge which escaped that action appears at the left in the upper view of Pl. VII and in the foreground of the lower view.

A permanent disturbance of the ground also resulted in many instances from compacting. Just as sand or grain that has been poured into a measure can be made by shaking to settle down and occupy less space, so various loose formations, and especially artificial fillings, were shaken together by the earthquake and the ground surface lowered. In such compacting the particles making up the aggregate are readjusted so as to fit more closely together and the voids are reduced. In dry formations compacted by the earthquake the reduction of voids was opposed only by the elasticity of the contained air. In wet formations it encountered the effectual resistance of the contained water, and could be accomplished only by the extravasation of some of the water. Ordinarily it was impossible to measure the settling due to compacting, or even to determine its occurrence as a phenomenon independent of ground flow, but it was clearly seen in various localities in San Francisco where those parts of graded streets which retained their simple shapes and straight lines served as reference planes for neighboring parts that were disturbed. (Compare the distance and foreground of $\mathrm{Pl}$. V. Another example of the effect on the filled-in land in this part of the city is shown in Pl. VI, A, a view of Dore street between Bryant and Brannan streets. The settling of the soft ground caused the street to drop at least 5 feet at this place.)

The only notable water waves generated by the shock were in Tomales Bay, where a group of waves estimated to be 6 or 8 feet high came to the northeast shore. The automatic tide gage at the Presidio showed a depression of about 4 inches, with subsequent oscillations of similar amount. Water was spilled from tanks, etc., and in at least one place was thrown from a pool out on the land. 


\section{MOTIONS CONSTITUTING THE EARTHQUAKE.}

The earthquake occurred between 10 and 15 minutes after 5 o'clock a. m., standard time of the one hundred and twentieth meridian. As time was consumed in the propagation of the shocks, the moment of beginning at any place depended in part on the distance of the place from the zone in which the disturbance originated. As this zone was hundreds of niles in extent it is probable that the time of beginning was not the same at all points along. it. For similar reasons the character and sequence of the motions constituting the earthquake were not the same at any two localities, and the differences in the vicinity of the zone of origin may have been very great. In and near San Francisco the principal part had a duration of about one iminute; it was preceded by comparatively faint tremors for several seconds, and it was followed by minor tremors. During the stronger part the motion was chiefly in horizontal directions and oscillatory, but its rhythm was irregular in period and emphasis. On firm ground in the same region the range of motion is believed to have been more than 2 inches, but was not measured, there being no seismograph capable of recording it. On soft ground the range of oscillatory motion may

have been several times greater, and it was also. greater in the immediate vicinity of the fault trace.

The following paragraphs present my conception of the essential character of the motions constituting the earthquake in the region of its destructive intensity. In the endeavor to make a brief and clear statement the conception is expressed somewhat badly, with little reference to the various uncertainties of fact and theory by which it is actually qualified.

The earthquake fault has a length of 300 miles, possibly 400 . Nothing is known of its depth. It coincides with a plane of earlier faulting, on portions of which there have been movements within a few decades. The fact of recurrence on the same plane shows that the rock faces in contact had not become welded, so that the molecular force which there resisted motion was less than the cohesion of solid rock and may have been little stronger than adhesion. A tract of the crust including the fault plane had come to be affected by a system of slowly increasing shearing strains, and the associated stresses were the forces directly causing the fault. When the stress component coincident with the fault plane at some point became greater than the adhesion (or cohesion) a local slipping took place. This caused a redistribution of strains and stresses, the local relief of strain being followed by increase of strain and stress in all adjoining tracts of the fault plane, with the result that the adhesion was overcome in those tracts and the area of incipient faulting thereby. enlarged. Thus from the initial tract the lesion was propagated as a sort of wave through all the fault plane. 
At the initial tract a small movement sufficed to relieve the local strain, and the motion was then arrested by friction, but the movement was renewed by reaction from other tracts, and it alternately started and stopped till the accumulated stresses had spent themselves. There was a similar rhythmic sequence in other parts of the fault, the frequency of the alternations depending on local conditions; and the total movement of dislocation at each point was accomplished by a series of steps and not by a single leap.

The time consumed in these reactions was not infinitesimal. The rate of propagation of changes in strain was of the same order of magnitude as that of earthquake waves in general, and the rate of propagation of the initiation of movement on the old fault plane may have been somewhat slower because of the necessity of accumulating a certain amount of stress increment to overcome the adhesion. It is probable that the completion of the fault required more than one minute, and it may have required more than two minutes. It is even possible that the displacement had been completed at the initial point before it began at the most remote.

In the succession of slippings and stoppings at any point of the fault plane each separate slip communicated a jar or pulse to the surrounding rock, and this pulse was propagated in all directions. The earthquake at any locality in the neighborhood of the fault consisted of such pulses from different directions. The general distribution of intensity indicates that the pulses weakened in transmission somewhat rapidly, whence it may be inferred that the particular pulses constituting the dominant elements of the local earthquake were those from the nearer parts of the fault.

If this conception of the earthquake is correct, the rhythm observed in the region of high intensity was a phenomenon distinct from the rhythm of harmonic waves. It was essentially a frictional rhythm, dependent on the relation of certain rock strains and rock stresses to the resistances afforded by adhesion and sliding friction. It was irregular not only because the intervals of local starting and stopping. were unequal, but because it was derived from a considerable area of the fault surface, in which the local rhythms were neither harmonious nor synchronous.

The compounding of unevenly spaced pulses from different points of the fault plane caused both reinforcement and interference, introducing a character analogous to beats in music, but without the regularity of musical beats. It also at times made oscillatory motions swifter in one direction than the other, so that reciprocative accelerations were not always symmetrically arranged. In less technical language, the motion was jerky and included abrupt phases that were almost blows. The compounding also introduced variety in the direction of motion, especially at the end, when for a short time the 
pulses from remoter parts of the zone of origin ceased to be overpowered by those from the nearest parts. The motion in that closing phase of the violent part of the earthquake has been compared by an observer to the motion of a vessel in a choppy sea; and I conceive that this comparison is the expression of a veritable analogy.

\section{DISTRIBUTION OF INTENSITY.}

When the isoseismal curves for this earthquake are drawn those for the higher intensities will show a remarkable elongation in the northwest-southeast direction. They will also show irregularties expressive of high intensity in the Santa Rosa Valley and other outlying areas. These features are related to the position and form of the zone or zones of origin. If drawn in detail they will show also the great influence of peculiarities of geologic formations. Detailed surveying has been attempted by the State commission only in San Francisco, partly because the results will there have the greatest practical value, and partly because the data are there most available. Notwithstanding the abundance of cracks, landslides, and broken trees in the region of high intensity, it is nevertheless true that natural structures in general are much less sensitive to earthquake violence than artificial structures, and for that reason grades of intensity are most easily mapped in cities.

The word "intensity" has various meanings as applied to earthquakes. As technically defined, it is the acceleration of the earth particle and is a quantity to be measured by the seismograph. But the field of instrumental observation is so limited that another definition practically obtains-that of power to destroy, a property which depends on the duration and direction of the motion as well as its acceleration, and which may have other factors:

It has long been known that buildings and other structures on ground of certain kinds are more susceptible to earthquake injury than on ground of other kinds, and these differences were strikingly illustrated in San Francisco. The general fact appears to be that the amplitude of vibration and the acceleration are greater in loose, unconsolidated formations than in solid rock. The firmer and more elastic a rock formation, the less the intensity of the earthquake shocks it transmits to buildings standing on it; and there is a gradation in this quality from the firmest bed rock to the loosest gravel, sand, and mud. For strong shocks, at least, the intensity is greater in loose formations saturated with water than in those that are dry.

Closely related to the control of intensity by the peculiarities of formations is the subject of surface undulations. Observers of strong earthquakes sometimes report visible progressive undulations of the ground, similar to water waves, and such observations are usually 
made where the formations are alluvial. Doubtless many of the observations are fallacious, depending on a subjective illusion as to the direction of verticality, which arises from the horizontal movements of the observer's support; but some of them may also be objective. Not only is there a gradation in physical condition from dry earth through mud to water, but the shaking of a loose formation, whether wet or dry, overcomes the adhesion of particles and thereby imparts for the time being a mobility analogous to that of liquids. It is therefore conceivable that gravity waves, altogether analogous to those of water, may be produced by a violent earthquake on the surface of a loose formation. Certain ridges on soft ground caused by earthquakes in Japan are inferred by Omori and Kikuchi to represent such soil waves and to indicate a wave length (crest to crest) of 20 to 40 meters. The San Francisco earthquake produced a similar ridging on tidal mud in Tomales Bay, the average ridge interval being not more than half that of the Japanese examples. The Tomales Bay ridges are roughly parallel to the fault trace (which is close at hand), have about the same irregularity as wind waves, and originally ranged in height from 1 to 3 feet. They were observed chiefly, but not exclusively, on the body of mud already mentioned as having been shifted toward the southwest shore. The tract shown in Pi. VII lies so low as to be submerged much of the time, and the ridges had been so nearly obliterated when the views were taken that little remained besides an obscure indication of their ground plan; but an area nearer the head of the bay, and probably lying somewhat higher, not only seemed to have preserved its character when photographed (April 28; see PI. VIII, $A$ ), but showed little change when visited nine months later.

Notwithstanding the persistence of the ridges at the last-mentioned locality, there is no reason to question the statement that the whole mud plain had the smooth surface common to tidal flats until it was disturbed by the earthquake. Nor. do I find any room for doubt either that the ridges originated as waves on the surface of the mud while it was rendered quasi liquid by violent agitation, or that they persisted because the mud promptly resumed its normal coherence when the agitation ceased. It is by no means equally clear that the arrested waves were true gravity waves rolling across the mud plain. Whatever their mechanism and history, they illustrate a mode of response of wet, unconsolidated material to powerful earth tremors, they suggest an explanation of certain wavelike ridges produced on areas of made ground in San Francisco, and they contribute to an understanding of the peculiar destructiveness of the earthquake in such areas. 


\section{THE EFFECTS OF THE EARTHQUAKE AND FIRE ON VARIOUS STRUCTURES AND STRUCTURAL MATERIALS.}

By Richaido I. Humphrey.

\section{GENERAL DISCUSSION OF 'THE EARTHQUAKE CONDITIONS.}

On the 18th of April, 1906, the whole civilized world stood aghast at the appalling destruction which visited the city of San Francisco and vicinity. Three weeks later, for the purpose of studying the effect of the earthquake and fire on structural materials, the writer began the investigation herein described, lasting six weeks and cov-. ering the entire affected territory. It would be impossible, however, to describe the extent of the damage adequately or comprehensively in a report of this character. When we consider the terrific destruction wrought in the surface of the earth by the first movement or "slip," which developed structural weaknesses, it is not surprising that this movement and the resulting vibrations should prove so fatal to the structures of man.

In the fire that followed hundreds of thousands of people were rendered homeless and dependent on public bounty for shelter and the necessities of life. This phase of the disaster appealed to popular sympathy and drew spontaneously from all parts of the country contributions of food, clothing, household furnishings, and money for the relief of the destitute.

To the user of the materials of building construction the study of the behavior and relative efficiency of the various classes of such materials under the unusual and rigorous conditions imposed by the earthquake and fire is most interesting and instructive. The test was one of such violence that only structures of first-class design and materials and honest workmanship could survive. Flimsy and loosely built structures collapsed like houses of cards under the terrific wrenching and shaking, and many of the structures which withstood the earthquake were subjected to a second test in a fire which surpassed all the great conflagrations of recent years. Some of these structures 
which successfully withstood the first test failed signally under the second, by reason of inadequate fireproofing. A very few withstood both tests successfully.

It is a generally accepted fact that no structure could have withstood the stresses produced by the movement of the earth at the "fault trace," along which the maximum intensity of disturbance was localized. The stresses produced by the vibrations at other points, however, could have been resisted with safety if proper design, firstclass materials, and honest workmanship-constituting the whole secret of earthquake-resisting power-had been employed in the structures so located. In tall structures rigidity of construction, attained by adequate diagonal and portal bracing, is absolutely essential. In such buildings, owing to the inertia of the mass of the upper portion, the maximum bending moment exerted by the earthquake was applied at some point between the foundation and the top-generally just below the middle. While reenforced-concrete structures were few in the zone of seismic disturbances, these few stood the test by earthquake and fire in a highly satisfactory manner. Rigidity and stiffness and a high fire resistance are inherent qualities of concrete, and this material proved admirably suited to resist these extraordinary tests.

The destruction was greatest in structures built on filled ground, or on alluvial soils in the valleys of rivers, with foundations which did not go through to solid ground, the settling of the earth caused by the vibrations resulting in permanent displacement or distortion of such structures. At many places where great destruction took place, as at Palo Alto, San Jose, Salinas, Santa Rosa, etc., the structures were built on soft ground. In structures built on solid ground or rock formation the action was much less severe and was confined to shaking, producing a maximum oscillation in the upper portions of the structure.

In order to understand properly the conditions under which such destruction as that caused by the earthquake could occur, one should study the geologic conditions prevalent just prior to the earthquake.

The history of the Pacific coast is replete with records of seismic disturbances, the entire region being in a condition of unstable equilibrium and cut by long rifts in the surface, called "faults," which have produced a series of long, narrow valleys. The forces which produce elevations and subsidence of the surface also produce stresses, which finally overcome the adhesion of the opposing rift walls, and earthquakes take place in the slipping of these walls, through a few inches or a few feet, in the effort to adjust the stresses. These earthquakes are of two classes-volcanic and tectonic. The former occur in regions of volcanic activity, are shallow in extent, 
and affect comparatively small areas; the latter not only extend to a much greater depth, but also affect much greater areas. The region north and south of San Francisco is regarded as particularly susceptible to earthquakes of the latter type.

A. C. Lawson has traced several of the "faults" referred to, and about ten years prior to the San Francisco earthquake he indicated the location of the present fault trace south of the Golden Gate. His relief map of California serves to show the lines of known faults by the parallelism of the ridges and valleys. In following these valleys one finds evidence of faulting on every hand-the scars and markings on the earth and rocks, and the presence of little lakes or ponds without visible source of supply other than the watershed of the adjacent ridges. According to Lawson, the coast of California is rising, and the seismic disturbances whose record is found in the rocks have been produced by movements in the process of upheaval and subsidence, of folding and faulting, which are, perhaps, greater along the coast of California than in any other part of the world. Whatever may be the causes of these movements, it is apparent that the resultant stresses relieve themselves by producing these faults or rifts in the earth's surface.

The average Californian becomes accustomed to the earthquakes which produce "temblors" of sufficient intensity to rattle windows. Prior to the great earthquake of April 18, 1906, these temblors were of frequent occurrence, but occasioned no alarm and, indeed, scarcely excited a passing interest. Over two hundred earthquakes were recorded during the period from 1850 to 1886, being more prevalent in the vicinity of San Francisco Bay than elsewhere. The writer is informed that during the period just prior to April 18 few if any noticeable temblors occurred. It is fair to assume, therefore, that the great earthquake resulted from an accumulation of stresses which would ordinarily have been relieved by smaller movements.

The relative intensities of earthquakes are indicated, on the RossiForel scale, by Nos. I to X. All under V produce no visible destruction, and from $V$ the destruction increases up to $\mathrm{X}$, which represents those in which complete destruction takes place. The writer understands that the earthquake of April 18 is rated at IX on this scale.

This earthquake, the most severe in the history of the State, took place at 5 hours 13 minutes and 38 seconds a. m., Pacific time, the main shock lasting one minute and five seconds. Between this time and $7 \mathrm{a} . \mathrm{m}$. about thirty minor shocks were recorded. A zone of destruction 50 miles wide was produced, extending for a distance. of 150 to 200 miles north and south of San Francisco (see the map, fig. 1, p. 3), beginning at Point Arena, paralleling the coast to Fort Ross, 
passing under the ocean bed just west of the Golden Gate, reappearing on the land at Mussel Rock, and following the Pilarcitos and San Andreas pipe lines of the Spring Valley Water Company in a direct line to Hollister. The zone included San Francisco Bay, Russian River, and the Sonora, Santa Clara, and Salinas valleys. The first movement was along this zone in a southeasterly direction, and the vibrations set up on all sides produced a continuous twisting, rocking, wrenching movement that brought down chimneys, walls, towers, etc. In the opinion of the California earthquake investigation commission the slip commenced at the northwest end of the zone, and the force which occasioned the rupturing or shearing: movement was a progressively decreasing one to the southeast end. As in the earthquake of 1868 , the destruction was greatest in proportion to the nearness to the fault trace, and in parts built on soft or alluvial soil, or on " made ground." The earthquake as recorded by the seismographs showed a horizontal movement of about 3 inches and a vertical movement of about 1 inch, the velocity of propagation being about 2.1 miles per second. The wave movement was long and slow in hard soil and rock and comparatively short and incoherent in soft ground.

\section{EFFECTS ON STRUCTURES OUTSIDE OF SAN FRANCISCO.}

In considering in detail the damage wrought by the earthquake one must look for evidence in the country surrounding San Francisco, since the fire in that city obliterated most of the signs of the damage.

The greatest loss in the city of San Francisco was principally the result of the fire, which was rendered uncontrollable owing to the wrecking of the water-supply system by the earthquake. (See the maps of the city and vicinity, Pls. LVI and LVII.) An examination of the damage to the system at once suggests itself, especially as some of the main conduits are located on or near the fault line.

The city is supplied principally by gravity from three main distributing reservoirs, viz, University Mound, College Hill, and Lake Honda; there are also two supplementary sources-Alameda Creek, on the east side of the bay, and Lake Merced. The University Mound reservoir, having a capacity of $33,000,000$ gallons, is supplied from Crystal Springs Lake through 17 miles of 44-inch wrought-iron pipe, carried for a considerable distance on trestles over the marshes. The College Hill reservoir has a capacity of $15,000,000$ gallons and is supplied from San Andreas Lake through 14 miles of 44-inch, 37-inch, and 30 -inch wrought-iron pipe. The Lake Honda reservoir, with a capacity of $31,000,000$ gallons, is fed from Pilarcitos Lake through 16 miles of conduit, $1 \frac{1}{2}$ miles of which is wooden flume and the remainder cast-iron and wrought-iron pipe and brick tunnel. Of the two supplementary supplies, the water from Alameda Creek is car- 
ried 27 miles, crossing San Francisco Bay through submarine pipes, and thence passing through the Crystal Springs conduit to the city; that from Lake Merced is pumped into the Pilarcitos conduit and thence to the city.

In company with Herman Schussler, chief engineer of the Spring Valley Water Company, the writer made a detailed examination of the principal conduits and reservoirs. On the San Bruno marsh the 44inch line to the University Mound reservoir had been thrown off the trestle for a distance of 1,300 feet; and, while the pipe was readily repaired, the trestle had to be rebuilt, as many of the timbers had rotted. Near Baden the line had been telescoped 42 inches, shearing off an 8-inch gate valve. The reservoir itself was undamaged, yet its three days' supply was rendered useless by the breaks in the cast-iron distributing mains.

The only damage done to the conduit between San Andreas Lake and the College Hill reservoir was at Baden, where the slip joint had been broken, tearing out the four cast-iron lugs-an effect indicating a force of at least $2,000,000$ pounds.

The principal breaks in the Pilarcitos conduit, which was so badly damaged that the company decided to abandon it, were examined. This conduit had been located for convenience in one of the long, narrow valleys, and therefore on the line of an old fault. It is evident that it would be futile to attempt to build this conduit strong enough to withstand a slip on the fault line. The brealss in this 30-inch wrought-iron pipe ranged from 30 inches to 6 feet in length. At other points it was telescoped and twisted beyond repair. (See Pl. IX.) The Pilarcitos conduit crosses Frawleys Gulch on a trestle. The movement of the earth produced a compression in the pipe line at this point, which threw it off and wrecked the trestle, and the water in the conduit leading to the trestle line was released so rapidly that it formed a vacuum, which caused this conduit to collapse, as shown in $\mathrm{Pl}$. X, $A$. The conduit crosses and recrosses the fault for a distance of 6 miles south of Frawleys Gulch. The 30-inch wroughtiron pipe line was torn and twisted at each crossing, while the earth dam of Pilarcitos Lake was uninjured.

The San Andreas earth dam lies across the fault, the crossing being about 100 feet from its east end, and the dam shows a disturbance for a distance of more than 100 feet. One of the worst cracks runs diagonally across a culvert 4 feet 6 inches in diameter, which appears to be uninjured. Although San Andreas Lake had considerable water in it, no appreciable loss of head was observed. There is a roadway over the dam, along which runs a fence. Both were offset at the fault line'about $3 \frac{1}{2}$ feet. A wooden flume used for diverting storage water to the reservoir lines crosses the fault, and was wrecked at that 
point for 50 feet. A brick conduit used for waste purposes extends across the fault. All the four rings, of hard-burned brick, are laid in first-class Portland-cement mortar, making a first-class piece of work in every way. This conduit, which is 9 feet 6 inches in diameter, was crushed together at the crossing.

The Searsville dam, a structure similar to the San Andreas earth dam, 1 mile east of the fault line and parallel to it, was also found to be uninjured.

Very little damage was done to the pumping stations, and the steel standpipes of this company were not injured. The Lake Honda reservoir was slightly damaged by a crack in its concrete lining. No damage was done to the Alameda Creek supply, except to the connection at the Belmont pumping station.

The concrete dam near San Mateo, at the lower end of Crystal Springs Lake, parallel to the fault line and a few hundred feet east of it, was undamaged. This dam, a view of which is given in Pl. $\mathrm{XI}, B$, is built of large blocks of concrete, thoroughly keyed together and molded in place, each block containing between 200 and 300 cubic feet. The dam is 680 feet long, with a present height of 146 feet. When completed it will be 170 feet high, 176 feet thick at the base. and 25 feet thick at the top. It is arched upstream to a radius of 637 feet.

The clay-core earth dam of the upper Crystal Springs Lake lies across the fault line at nearly right angles. This dam is now maintained as a county causeway, equalizing pipes having been placed through it. At the time of the earthquake the water was at the same height on each side, and the absence of any "head "made it impossible to tell the extent of the damage. The dam moved about 6 feet, however, this fact being shown clearly by an offset of that amount in the fence which runs across it. The roadway over the dam also shows the same offset, although not so clearly.

The water supply of San Francisco, as compared with that of other cities, was fairly good and had a rated capacity of $36,000,000$ gallons per day. The failure to control the fire by reason of the crippling of the water supply was not due to the failure of the system outside of the city, but to the breaks in the distributing mains within the city, which rendered unavailable about $80,000,000$ gallons of water stored within the city limits. These breaks occurred (see the map, Pl. LVI) wherever the pipes passed through soft or made ground. No breaks occurred where the cast-iron pipe was laid in solid ground or rock. It is evident that in earthquake countries water-supply pipes, at least, should be so laid as to avoid the action of slips, settling, and ground movements of all kinds. The pipe lines should also be arranged with gates and by-passes, making it possible to cut 
out any portion of the system which may become crippled: There should also be some means of preventing the loss of water which is occasioned by breaks in the house service pipes.

While one of the main conduits was badly damaged wherever it crossed the fault, this damage was no greater than that done to any other structure that was situated at the fault line. Structures so located were torn apart, the gap in the case of a fence (PI. I, $B$ ) or road (Pl. I, A) being from 6 to 20 feet, according to local conditions. In the country around Fort Ross there were many trees located on the fault that showed the effect of the slip. Great redwood and pine trees were either twisted out of normal position or split (Pl. II) from the roots up for distances of 35 feet or more, even when perfectly sound. This splitting action was due to the earth on the west of the line of faulting moving the roots on that side, a motion which tended to pull the tree apart. Where the tree had some defect or was unsound (as from dry rot) the action was even more marked and the destruction much greater. Redwood trees grow to great heights and are perfectly straight, and to find one out of plumb is very unusual.

Another interesting example of the effect of the slip along the line of the fault is afforded by the Southern Pacific Railroad bridge over Pajaro River near Chittenden station. This bridge crosses the fault obliquely at a very acute angle-about $10^{\circ}$. It consists of two girder shore spans of 50 feet each and three Pratt truss river spans of about 100 feet each. The piers and abutments are built 'of concrete, with granite coping and bridge seats (Pl. XI, $A$ ). The bridge was badly racked by the movement of the earth, which dragged the piers and abutments. The movement of the south abutment was about 24 inches, a distance sufficient to leave the girder without support. The ground also moved a greater distance than the abutment-perhaps 8 or 10 inches farther. The movement of the earth tending to pull the piers from under the trusses was resisted by the anchor bolts, resulting in a cracking of the piers, apparently on the lines marking the different daily batches of concrete used in constructing them. The granite caps were moved out of position and many of them cracked, and the anchor bolts were twisted and bent. The bridge was put into service by the construction of a timber support.

In the vicinity of Los Gatos, where the line of faulting passes through the Santa Cruz Mountains, it crosses the first tunnel of the narrow-gage railroad to. Santa Cruz near Wrights. In this tunnel a portion of the loose roof, of shale on a layer of serpentine or soapstone, caved in, completely closing the tunnel. A house on this fault line near Wrights was split in twain, the movement of the earth throwing the west side of the house from its foundation ( $\mathrm{Pl} . \mathrm{X}, B$ ). 
The Saratoga reservoir of the San Jose Water Company lies in a saddle of the Santa Cruz Mountains between Saratoga and Los Gatos, and the fault line crosses it at right angles, the cracks extending through the body of the dam. The reservoir was full at the time, but there was no apparent loss of head.

As already stated, in the country bordering the line of faulting the damage done was greater in soft or alluvial soil or made ground. Most wooden water tanks on low supports were wrecked, not only in the vicinity of the fault line but throughout the affected zone, the failure being due to a lack of lateral bracing of the trestle support. Chimneys generally collapsed, the cause being the unequal movement of the inelastic brickwork and the usually elastic frame structure surrounding it. Wooden buildings on good foundations stood well, the chief damage being to the chimneys and plastering. The alluvial or soft soil forming the banks of rivers generally moved toward the river under the earthquake vibrations, the settling of the ground being most marked (Pl. VIII, $B$ ). The country in the vicinity of Salinas River presented interesting features of this character. The county road crosses the river near Salinas on a wooden bridge, and the slipping of the banks carried the south abutment 6 feet toward the river. The ground was badly cracked and there were a number of slips in the neighborhood. The road leading to Spreckels's sugar mill, 4 miles south of Salinas, was also greatly damaged by the slips. Spreckels's sugar mill (Pl. XII, $A$ ) is located on soft alluvium. . The main building, which is 500 feet long, is said to be the largest sugar mill in the world. The vibrations of the earth jarred the brickwork loose at the end of the building, which buckled in the middle, where there were no floors above the second floor. The damage to other buildings was also extensive. The town of Salinas itself was severely shaken. 'The high-school building and some of the buildings on the main street were damaged, chimneys were thrown down, and a water tank of the Southern Pacific Railroad, supported on a steel trestle near the station, collapsed.

Along the Bay of Monterey the whole shore slipped about 12 feet into the bay, the movement buckling the rails on a railroad trestle and the cars dropping about 5 feet. A frame house and surroundings moved 12 feet, still maintaining their relative positions. In Monterey the principal damage was in the loss of chimneys and cracking of plaster.

At San Jose, located on the soft alluvium of the Santa Clara Valley, the destruction was extensive. The post-office, a very substantial building, lost its tower, which was laid up in lime mortar, and was deficient in lateral bracing. The walls were of brick with a 4 -inch or 6 -inch stone veneer, and there was a wooden-framed slatecovered apex. The collapse of the tower damaged the pavement, and 
to some extent the building itself. The damage to the hall of records, along the end walls, was due entirely to defective construction. The Hall of Justice (Pl. XII, $B$ ), which was completed in 1905 , had the wall along the cornice line thrown down. The reenforced-concrete roof contributed no little to the support of the walls of the building, and had the stonework been less heavy and of better quality the damage probably would not have been so extensive. The high school (Pl. XIII, $B$ ), a flimsy structure of brick with wooden frame, was so badly wrecked that it had to be torn down as a matter of safety. The destruction of the buildings along First street, the principal business thoroughfare, was also extensive. Lime mortar, flimsy framing, poor design, and lack of tie between floor and roof members and walls were the causes of these failures.

Perhaps the worst example of poor design, bad workmanship, and poor materials in the earthquake territory, except in the city of San Francisco, is the insane asylum at Agnew, about 6 miles northwest of San Jose, consisting of a main building surrounded by a number of others-all flimsily constructed brick structures with timber frames. The construction of these buildings, with their thin walls (in many places devoid of mortar) and light, insufficient wooden framing, indicates a criminal negligence that is appalling. One'hundred and seventeen patients and attendants lost their lives, principally from the fall of the central tower of the main building. The brick stack of the power plant and the towers of surrounding buildings collapsed. In the farmyard near by is a water tank supported on a wooden trestle. This tank moved about 10 inches, while less than a stone's throw away are four water tanks supported by a diagonally braced steel trestle, which were undamaged ( $\mathrm{Pl}$. XIII, $A$ ).

The most interesting ruins are those of the Leland Stanford Junior University, at Palo Alto, 6 miles east of the fault line. These buildings were on a soft soil and were therefore subjected to the severest earthquake conditions; and as they represent several different types of construction they afford a profitable study in the earthquakeresisting power of various structures and structural materials. The destruction was very great, most of the buildings being wholly or partially destroyed.

Three types of wall construction were represented-(1) solid stone, (2) brick and stone veneer, and (3) reenforced concrete. The buildings of the first-mentioned type, which were erected by Senator Stanford by day labor, were examples of good substantial work, and the damage to them was not so great. The stone-veneer buildings represent a later type, resorted to as a matter of cheapness, and suffered the most. The third type, of reenforced concrete, sustained practically no damage. 'The stone-veneer buildings have a 4 -inch or 
6-inch face of stone, poorly bedded, containing a large percentage of spalls, the lime mortar being of good quality. The construction is fairly common in other parts of the country. The roof trusses were not anchored to the walls, but to a great extent were butted against the walls; the floor joists rested in the walls and were not tied. Under the vibrations the walls were pushed out of plumb and, having no proper connection with the floor and roof members, collapsed.

The gymnasium and library presented interesting features. The dome of the library was supported by a skeleton of steel, and although the surrounding walls collapsed, this dome was not damaged (Pl. XV, $A)$. The gymnasium dome rested on intermediate brick walls, which collapsed with the dome (Pl: $\mathrm{XV}, B)$.

The boys' dormitory (Encina Hall) was built of stone, and was one of the buildings erected by Senator Stanford. The chimneys of this structure collapsed and crashed through the roof and floors, killing one student and injuring several others. The walls themselves were but slightly cracked. The girls' dormitory (Roble Hall) had walls of reenforced concrete with wooden floors. The chimneys on this structure also collapsed, but no other damage was done, the walls being left intact, without any cracks.

The memorial arch (Pl. XVI) was a poorly designed structure, 100 feet high, with stone-veneered walls. The structure above the arch ring was hollow, and an attempt had been made to stiffen it by the use of a number of I beams. These beams were not tied to the stonework, but simply rested upon it, and under the action of the earthquake they became battering rams and helped to accomplish the destruction of the arch. The arch as first designed was 75 feet high, and it will be noted that the earthquake reduced it to the height originally intended (Pl. XVI, $B$ ).

The memorial chapel, one of the most beautiful buildings in this country, was almost completely wrecked (PI. XVII, $B$ ) by the collapse of the tower. A platform of steel beams had been placed under the clock as a precaution against the chance falling of the pendulum, and this platform saved the clock. The damage done to the mosaic work and the interior decoration is probably irreparable.

The chemical laboratory was damaged by falling chimneys, and gable walls were pushed out and suffered considerable damage by the collapse of the assay stack. The plastering was also badly cracked. Great damage was also wrought in the power plant of the mechanical engineering department by the falling of the stack.

The quadrangle, or main academic portion of the university, was built by day labor and was a fair piece of work. The cloister (Pl. XVIII, $B$ ) suffered considerably, the bases and caps of the columns being spalled and chipped, indicating that they must have been subjected to a rocking motion. The arches apparently opened up, for in 
a number of them the arch stones had dropped partly out of place. The department of geology (Pl. XVIII, $A$ ), the newly completed end of the quadrangle, suffered the greatest damage; many of the walls will have to be rebuilt, having been either cracked very badly or destroyed entirely. The plastering was badly cracked and showed the outline of each sheet of metal lath. Where reenforced concrete was used the ceilings were free from cracks.

The most interesting building is the museum (Pl.oXIV, A), which consists of a central pavilion of reenforced concrete and wings of brick plastered with cement mortar. The columns of the central pavilion are solid concrete, having been cast in place. This building had wooden floors. The wings were wrecked by the earthquake, but the central pavilion escaped injury, although its contents were more or less damaged, principally by being shaken from their positions.

Although the destruction at Stanford University was very great, the character of construction was fair and did not suffer by comparison with that used in other parts of the country. The excellent qualities of reenforced concrete and its ability to withstand earthquake shock were strongly demonstrated.

The town of Palo Alto suffered considerably from the earthquake. Chimneys were generally thrown down. A number of buildings were wholly or partly wrecked, the causes of the failures being similar to those in other sections, consisting largely of defects in design, lack of adequate bracing, poor mortar, and bad workmanship. Three concrete-block buildings were either wholly or partly destroyed and have especial interest, since they have been cited as evidence of the failure of concrete blocks. Two of these buildings are located on Alma street opposite the station and on opposite sides of University avenue-the Thiele Building (Pl. XVII, $A$ ), a partially completed three-story structure, which was entirely wrecked; and the Fuller Building, a two-story structure, which also collapsed. The concreteblock walls, 13 inches thick, laid in cement mortar, were not braced in any way - the joists, $1 \frac{1}{2}$ by 13 , simply resting upon the wall. When the building vibrated, the wall was pushed out and collapsed because there was nothing to restore it to its normal position. This defect was more clearly shown in the one-story building of Vandervoort Brothers (Pl. XIX, $B$ ), in which the roof truss was simply butted against the block wall without tie or other connection.

At Santa Rosa the destruction was greater than in any other section affected by the earthquake, and the fire that followed completely wiped out the business section. of the town, which suffered a greater proportionate total loss than San Francisco. A concrete-block building (Pl. XIX, A) in this town escaped with slight damage at the cornice only, where the blocks were thrown down, the reason being that the walls were tied to the roof timbers by tie-rods which 
held the walls and roof together and made them move as a unit. The cornice was rebuilt before the view was taken. While buildings of brick and stone collapsed all around this one, it received practically no damage and demonstrated that structures that will successfully withstand earthquake shock can be built of concrete blocks. The other buildings at Santa Rosa did not present any interesting features, as they were mostly defective in design and workmanship and the material. was generally poor. The city hall, the court-house (PI. XIV,$B$ ), the Masonic Temple, the Keegan-Brush Building, and the St. Rose Hotel were all completely wrecked, and added their testimony against poor mortar in brickwork, light wooden frames, and insufficient bracing.

Towns like Berkeley and Oakland did not suffer as greatly from the earthquake as many neighboring towns, the reason lying in the fact that these towns are built on solid ground or on rock. In Berkeley, while chimneys were shaken down, there was no extensive earthquake damage. The Greek Theater, a massive structure of concrete, was uninjured. 'In Oakland, however, greater destruction occurred. Just outside of Oakland is located the Mills College for Girls. 'The science building had brick walls plastered with cement mortar, and was considerably damaged by the shaking it received and the falling chimneys. The building had wooden floors and was considerably racked, the walls being pushed out slightly. Within a few feet is the bell tower ( $\mathrm{Pl}$. XX, $B)$, a reenforced-concrete structure 80 feet high with walls 4 inches thick, which was not damaged in the slightest degree.

\section{CONDITIONS IN SAN FIRANCISCO.}

\section{GENERAL EARTHQUAKE CONDITIONS AND EFFECTS.}

Within the city of San Francisco (see the map, Pl. LVI) the havoc wrought by the earthquake depended on the character of the construction and its foundation. Bordering San Francisco Bay, from Telegraph Hill to Mission Creek, the land consists of mud flats, which have been gradually filled in, and on this land many large commercial buildings had been erected, among others being the Union Ferry building, the post-office, the mint, and the custom-house. Adjoining this filled land was comparatively level ground composed of sand and clay formed by the wearing away of the hillsides and by the incoming sand from the seacoast-a fringe of soil on which were located many of the principal buildings. From Telegraph Hill southwestward along Russian Hill to Sutro Heights runs a ridge of rocky hills composed of indurated clay shale, with serpentine and other rocky formations on their highest summits. 
The signs of destruction wrought by the earthquake in the city of San Francisco were more or less obscured or: in many places entirely obliterated by the fire. The best evidence of the earthquake can therefore be obtained outside the burned district, and the following notes cover the most important examples of damage due to the earthquake alone.

As in districts outside of San Francisco, the greatest damage was done to those structures having insufficient foundations built on soft alluvium or filled ground. The settling of the ground in the mud flats along San Francisco Bay and of the filled ground in old water courses was accompanied with great destruction. It was in such ground that the greatest number of breaks occurred in the cast-iron gas and water mains and the sewers. The breaks in the sewers were not so evident as those in the gas and water mains, for the reason that the latter were under pressure and breaks in them resulted in breaks in the streets themselves. The most noticeable destruction resulting from the settling of soft or filled ground occurred in Howard and Shotwell streets between Seventeenth and Eighteenth streets, Bryarit street betwen Ninth and Tenth streets, Dore street between Bryant and Brannan streets (Pl. VI, $A$ ), and at the corner of Seventh and Mission streets. The settling was greatest in Howard, Dore, and Bryant streets, being in Dore street at least 5 feet.

On solid ground the earthquake had a rocking effect which produced $\mathbf{X}$ cracks (Pl. XXII, $A$ ) in the brick or stone walls of those buildings which were deficient in diagonal bracing. This was especially true in the upper stories of tall buildings, the cracks generally appearing in the piers between windows or around doorways. The brick curtain walls of buildings well braced diagonally, brick walls reenforced with band iron, and well-buttressed brick walls, as in such old structures as the Palace Hotel, Sailors' Home, St. Mary's Hospital, Synagogue Emanuel (Pl. XXI, $B$ ), and others, and walls of reenforced concrete proved best adapted to withstand this rocking action. The Palace Hotel was stiffened with cross walls in addition to the band-iron reenforcement in the brickwork, and is in good condition as far as earthquake effects are concerned. It was completely gutted by fire, however (Pls. XXX, $B$; LII, $B$ ), being a nonfireproof structure with wooden floors and roof which yielded readily.

Weak and flimsy framing, insufficient bracing, and poor mortar were the cause of most of the failures in San Francisco. 'The Albert Pike Memorial, a recently completed building on Geary street west of Fillmore, was seriously damaged, and so also was the adjoining Jewish synagogue (Pl. XXI, $A$ ), which had not been quite completed. Both buildings are examples of defective design and workmanship. In the girls' high school the damage to the brick walls resulted from a lack of proper tie between the floor and roof timbers and the walls 
and the poor quality of the mortar used in the brickwork. Again, in the Hahnemann Medical College, on California street near Maple street, the destruction of the end walls was the result of bad design, the roof trusses butting against the walls and the floor timbers resting upon the walls without adequate tie. The poor quality of the mortar permitted a ready disintegration of the brick-veneered walls, although some'band iron had been used for the purpose of strengthening them. The Cathedral of St. Dominic, with its high, unbraced brick walls and its peculiar wood-sheathed spires, also proved a victim of poor design and workmanship; the sheathing on the spires was shaken off and the collapse of the walls resulted in extensive damage to the interior.

In interesting contradistinction to these failures was the Sailors' Home, erected in 1858 for use as a marine hospital and condemned as unsafe after the earthquake of 1868 . Its heavy brick walls, reenforced with band iron and further stiffened by cross walls thoroughly bonded, are in excellent condition. The building rests upon rock and the framing is excellent; the rafters are fastened to a wall plate which ties the walls, causing the structure to move as a unit. The only cracks occurred where partition walls which had been added were shaken loose from the main walls and around the archways leading to the main stairway on the second and third floors, where no extra stiffening of the walls had been provided. The building in all other respects suffered no damage, there being no new cracks apparent in the exterior walls.

The old red-tiled Spanish Mission Dolores (Pl. XXIII, $B$ ), built in 1777 , with its adobe walls and wooden frame, was not injured, while its more modern successor was greatly damaged. The complete collapse of the tower of the new Mission Dolores was not brought about directly by the.earthquake, but the damage was such that the tower had to be taken down, as shown in Pl. XXIII, $B$.

The group of buildings comprising the plant of the San Francisco Gas and Electric Light Company, built on the soft ground along San Francisco Bay just west of Fort Mason, was badly shaken, and none of the buildings escaped damage. The collapse of the stack wrecked the light slate-covered iron roof of the power house and started the fire that destroyed the roof of the boiler house. The ground settled very considerably under the vibrations of the earthquake, and further destruction was caused by the unequal settling of the building. The main shock appeared to come from the north, and the north walls received the greatest damage. The end wall of the retort house was pushed out 1 foot at the center, but was saved from collapse by the tie-rods which held it to the roof truss. The walls were cracked at the northwest and northeast corners. The scrubber and gas-tar holder houses were wrecked, the heavy wooden 
wof trusses collapsing. Nearly évery wall was moved slightly, but the brickwork was generally very good, and apparently had cement in it. The exhaust house had three intermediate walls, 18 inches thick at the top. The north wall and the next one fell into the building, the side walls being pushed out 6 inches. The building had wooden roof trusses and the north truss cracked at the conter mortise. The flonr settled badly around the condensers. The gas holder collapsed from the sudden release of the gas due to a break in the mains. The trestle pier extending into the bay also collapsed.

Most of the structures built on. piles along the bay suffered considerable damage, especially the frame sheds on the wharves. The. Union Ferry Building (Pl. XLVI, $A$ ), the terminus for all the ferries plying on the bay, is built on piles. It was more seriously damaged by the earthquake than would appear at first sight, and barely escaped the fire also. It is of interest to consider in some detail the behavior of this structure under the action of the earthquake. The ten-story tower was so seriously damaged as to require the removal of the masonry walls, and will probably have to be rebuilt. This tower consists of a steel frame which was inclosed with heavy sandstone walls backed with brick for several of the lower stories, and with sheet metal above. The floors above the masonry part were of stone concrete reenforced with expanded metal between $\mathbf{I}$ beams. The brick walls were badly shattered, and a large section was thrown out just below the clock on the west front, while on the east front a large mass fell through the skylight onto the upper story of the main building. There were but few cracks in the north and south walls. The steel time-ball staff was badly bent, indicating a considerable movement of the top of the tower, probably resulting from the first shock. The steel work was severely racked, the greatest damage being just below the middle. Some of the diagonal braces were sagged, having been stretched beyond their elastic limit (Pl. XLVI, $B$ ). In the southeast corner of the third story the bottom and top loops of one of the 2-inch square diagonals were pulled apart, and several of the rivets in the angle connection were sheared off; in the southwest corner also the top diagonal loop pulled apart, the diagonal being considerably bent; in the northwest corner seven of the eight $\frac{3}{4}$-inch rivets in the angle of the connection for the diagonals were sheared off (Pl. XLVII, $B$ ); and in the northeast corner all but 2 inches of the top angle was sheared, and the north diagonal was bent, the loop having been pulled apart. On the second floor; in the northeast corner; the top east diagonal connection pulled away, shearing the rivets; in the southeast corner the top angle of the diagonal connection sheared for about 2 inches, and four of the 1-inch rivets holding the cover plate of the southwest column (Pl. XLVII, $A$ ) were sheared, as were also 
two of the rivets holding the clip support for the west girder. The floor of the main building consisted of groined arches of stone concrete springing from concrete piers supported by cluster piles. The self-supporting walls of sandstone backed with brick were more or less shaken, and the piers of the driveways were badly cracked; the floors were of stone concrete reenforced with expanded metal between I beams and supported by cast-iron columns. The concrete in this building appeared to be undamaged.

Most of the entrances to the cemeteries were wholly or partially wrecked, and the burial vaults and gravestones were all more or less disarranged. It has been estimated that perhaps 60 per cent of the monuments, vaults, etc., in cemeteries were overturned or moved.

In Golden Gate Park nearly every stone or brick structure was damaged. The emergency hospital, a single-story brick and stoneveneered building, lost its gable walls and was damaged in the same manner as other structures having improperly bonded walls laid in lime mortar, and deficient in proper ties between the masonry and the other structural parts. The gable walls of the restaurant in the children's playground were thrown down by the earthquake, but the greatest damage resulted in the settling of the foundation of one of the columns, which caused the collapse of the structure. The music stand, a stone-veneer brick-backed structure, was racked and shaken. Part of the pediment was shaken loose, and many of the columns were spalled and moved. Some of the walls of the museum were thrown down, and its contents were more or: less damaged. All the monuments were damaged. The Francis Scott Key monument $(\mathrm{Pl} . \mathrm{XX}, A)$ was racked so badly that the arch stones were shaken loose, the columns spalled at cap and base, and the monument as a whole moved on its foundations.

The most interesting structure in Golden Gate Park is the cyclorama (Pl. XXIII, A), on the top of Strawberry Hill, built about fifteen years ago. The top of the hill had been leveled off in order to - form a foundation. The cyclorama consisted of circular walls of reenforced concrete, the aggregate of which was a hard shale crushed to concrete size. This material was very inferior and yielded a poor concrete. The reddish-brown effect was obtained by means of a veneer ( $1 \frac{1}{2}$ to 4 inches thick) of a concrete consisting of crushed brick, sand, and cement. The reenforcement in the base consisted of four $\frac{7}{8}$-inch cables of thirty strands each. The reenforcement of the columns consisted of $\frac{3}{4}$-inch twisted bars and $\frac{1}{2}$-inch stirrups. The entrance, with its very heavy, massive top, should have been of hollow-construction reenforced concrete. The settling of the foundation or fill under the vibration of the earthquake caused the structure to collapse. The slip (PI. XXII, $B$ ) occirred principally on the northeast side, the movement being 4 or 5 feet. The principal crack in 
the base was about 11 inches wide, with a half-inch horizontal crack leading from it along the reenforcement. The floor is in good condition, except the pavement, which broke into blocks, most of the planes of fracture coinciding with the actual joints between the different sections. Under the circumstances-the undermining of the foundation by the slip as described-the structure developed remarkable strength. No brick or stone structure could have stood the shock so well. The rustic.railing around the outside of the walk (Pl. XXII, $B$ ), which was of wrought-iron pipe covered with wire mesh and plastered with Portland-cement mortar, was distorted by the slip, but otherwise uninjured.

At the bottom of Strawberry Hill is a bridge crossing over Stow Lake. This bridge is made of concrete, and showed no signs of cracking, although the banks of the lake slipped into the water.

\section{BEHAVIOR OF INDIVIDUAL STRUCTURES.}

\section{GENERAL STATEMENT.}

The numerous fires that broke out all over the city were doubtless caused by the collapse of chimneys and the breaking of electric connections. These fires were at first confined to the territory south of Market street, and it is said that by $8 \mathrm{a} . \mathrm{m}$. on the morning of April 18 more than fifty fires were recorded. The early failure of the water mains rendered the city helpless and placed it at the mercy of the flames, the fury of which for three days threatened to complete one of the greatest disasters of recent years and to obliterate one of the most beautiful cities in the country. The conflagration was finally checked, at the barrier presented by a wide avenue, by a change in the direction of the wind and through the efforts of the fire department, using water pumped from the bay at the foot of Van Ness avenue.

San Francisco consisted principally of frame and brick structures, with perhaps forty or more so-called "fireproofs," a few buildings of slow-burning construction, and the substantial Government buildings. Many of the buildings contained mercantile stocks, and most of them were exposed to exterior fire conditions of maximum severity. Since every type of construction was represented, the ruins afford a most excellent opportunity for comparative study, although the scope of the information obtained is incomplete, as a water test is lacking.

In comparing the behavior of the various structures and structural materials it has been thought best to describe the condition in which certain individual buildings were left by the earthquake and fire, and to present the salient features of these buildings by illustrations with descriptive legends. The following descriptions, which for 
convenience are arranged in alphabetical order, cover the structures not previously mentioned that were inspected by the writer, the total number embracing nearly every building that was left standing in the burned district. The locations of these buildings can be found by reference to the map, Pl. LVI, and to the panorama, Pl. LV.

\section{ACADEMY OF SCIENCES BUTLDING.}

The Academy of Sciences building, 819 Market street, views of parts of which are shown in Pls. XXIV, $A$, and XXV, $B$, wais of ordinary concrete construction and six stories high, and was completely destroyed.

A six-story annex having brick walls, concrete-filled cast-iron columns, and reenforced-concrete floors, was connected to the main building on the rear. The brick walls of the annex were badly cracked by the earthquake, and the building was subsequently completely gutted by fire. The structure itself passed through a fairly hot fire successfully, although surrounded by buildings which were completely wrecked. Plaster of Paris was used on the concrete-filled cast-iron columns and seemed to stand fire much better than lime mortar. These columns are: shown in $\mathrm{Pl}$. $\mathrm{XXV}, B$, a view taken from the third floor looking southeast. An interesting feature of the building was the concrete-filled cast-iron column that supported the south wall. Owing to the unequal expansion of the cast iron and the concrete the cast iron failed, bulging from the heat and cracking on cooling, as shown in PI. XXIV, A. The $\frac{3}{4}$-inch or 1 -inch thickness of concrete which covered the reenforcing bars proved insufficient in the basement, where the fire was fairly hot. The heat expanded the bars, thereby ripping off the concrete layer and leaving the rods exposed.

\section{AETNA (YOUNG, OR COMMISSARY) BUILDING.}

The five-story Atna Building (Pls. XXIV, $B$; XXV, $A$; XXIX, $B)$, on the southwest corner of Spear and Market streets, was occupied by the Sellers Brothers Hardware Company. It was built on piles and had self-supporting walls of gray granite, pressed brick, and teira cotta. The steel columns and girders were fireproofed with expanded metal, plastered. The expanded-metal reenforced-concrete floors rested upon steel girders with intermediate ribs of concrete supported by 5 -inch by $\frac{1}{2}$-inch bands of steel without fireproofing which hooked onto the top flanges of the girclers.

One panel of the fifth floor, which was rather heavily loaded with tin plate, collapsed because of the expansion of the above-mentioned steel bands from the heat, which was sufficient to volatilize the tin even from the middle sheets of the pile. The fall of the load of tin 
plate caused the failure of the third floor, as shown in Pl. XXIX, $B$. The plaster protection of the columns was in fair condition, and the columns were uninjured. The principal damage from earthquake was to the brick walls, the south and west walls showing a number of cracks. The granite trimmings around the doorway and the terracotta trimmings of the building were badly spalled by the fire, as shown in Pl. XXIV, $B$. The basement floor, which was of concrete 7 or 8 inches thick, was pushed up under the sidewalk, reducing the headroom at this point from 8 feet to $3 \frac{1}{2}$ feet, approximately. This bulging was probably caused by settling ( $\mathrm{Pl}$. XXV, $A$ ), as the foundation piling did not extend under the sidewalk.

APPRAISERS' WAREHOUSE (UNITED STATES CUSTOM-HOUSE).

The four-story custom-house building, on Jackson, Washington, and Battery streets, shown in Pl. XXVIII, $A$, passed through both earthquake and fire without injury, although located on the alluvial flats. All the buildings around it were burned, but the fire did not gain a foothold in this building, and there was, therefore, no fire test. As an example of successful resistance of the earthquake test, however, this building stands as a favorable testimony to first-class materials and workmanship. The walls were of brick, with granite ornamentation, and the roof was slate covered. The partitions and cross walls were all of solid brickwork, and the only damage that they sustained consisted of a few cracks in the archways near the stairways on the upper floors.

\section{ARONSON BUIIDING.}

The ten-story Aronson Building, on the corner of Third and Mission streets, had a steel skeleton with hollow-tile partitions and fireproofing for the columns. The floors were of concrete reenforced with expanded metal.

Two of the columns on the first floor buckled by reason of the failure of the hollow tile (PI. XXVII, $B$ ), the columns being shortened about 10 inches. Columns also buckled in the basement and on the fifth, eighth, and tenth floors. 'In the basement two columns were fireproofed with concrete, and remain in first-class shape, but near them are two badly buckled columns which were fireproofed with terra cotta. This result is an excellent object lesson on the merits of the two systems of fireproofing. The sandstone was badly spalled by fire, and the walls were badly racked by the earthquake. The castiron stairways were very much damaged. The fire in this building was not severe. 
BEKINS VAN AND S'IORAGE COMPANY'S BUILDING.

The building in process of construction by the Bekins Van and Storage Company, at the corner of Thirteenth and Mission streets, was the only example of the pure type of reenforced concrete in the city (Pl. XXVII, A). Two of the six floors were erected, the walls being made of brick laid in lime mortar and the floors and columns of reenforced concrete.

The walls were badly cracked by the earthquake, but the reenforced concrete was not injured. Considerable furniture stored in the building was burned, and the heat slightly blistered the under surface of the concrete floor, which was still green at the time of the disaster.

\section{BULLOCK \& JONES BUILDING.}

The Bullock \& Jones Building, on Sutter street west of Montgomery street, is an eight-story steel skeleton with floors of reenforced cinder concrete, hollow-tile partitions and column protection, and bearing walls of ornamental terra cotta and terra-cotta pressed brick. The reenforced-concrete floor arches were haunched between steel girders, but were not continuous over the girders.

The earthquake damaged the outside very considerably. The building is of rather flimsy construction, and it is a wonder that the fire did not wreck it. The terra cotta was badly spalled by the fire, especially around the windows, and the hollow tile failed badly, both in partitions and as column protection. The 3-inch terra-cotta partitions failed generally, and several columns buckled on the third and eighth floors (PI. XXVI, A). The elevator inclosure, which was plastered on expanded metal, failed, as did also the cast-iron stairways. The wood covering of the floors and the wooden nailing strips were burned. The concrete floor is in excellent condition. A few panels collapsed where the steel girders were displaced. The distorted unprotected beams and girders around openings show strikingly the folly of unprotected steel work.

Californta CaSket COMPANY'S BUILDING.

The building which was in process of construction on Mission street between Fifth and Sixth streets by the California Casket Company was seven stories in height and had a steel skeleton and floors of reenforced cinder concrete. The self-supporting walls were built on the sides and rear of brick and on the front of brick faced with sandstone, which was spalled by the heat, although there was no stock and little combustible material in the building. The columns 
were fireproofed with concrete. The brick protection around many of the columns was jarred loose, and the brick vaults on the first, second, and third floors were badly cracked around the archways of the openings into them, as shown in PJ. XXIX, $A$, a view of a vault in the second story. The stairways were constructed of concrete with steel channel horses and were cracked in a number of places, especially at the landings. Some of the wooden window frames were burned, but the fire was not very severe either in the building or surrounding it, the greatest damage resulting from the earthquake. The partitions inclosing stairways and elevator shafts were of the usual flimsy metal lath and plaster type. The walls were so badly cracked as to require partial rebuilding, especially at the southwest and northwest corners.

\section{CALL (ClaUS SPRECKELS) BULLDING.}

The Call Building (fifteen stories besides the dome), corner of Third and Market streets, was one of the best-designed skeleton buildings in San Francisco. It was fairly well braced laterally, and the workmanship was first class. It stood the earthquake shock well because of its excellent foundation, which extended 25 feet below the sidewalk and consisted of a grillage of steel beams embedded in concrete. The main defect was in the fireproofing of the floors and columns, in which terra cotta was used, and the greatest damage to the building was from fire. Although some of the diagonal braces were bent and had apparently been stretched so as to take a permanent set, the general behavior of the structure demonstrates that high buildings subject to earthquake can be erected with safety even on sand foundations.

The floors were of reenforced concrete up to the seventh story and of hollow-tile arches above, topped with cinder concrete. The partitions were principally 3 -inch hollow tile, and these failed very generally. The terra-cotta fireproofing around the columns proved ineffective, and although the steel did not buckle, the paint had been burned off the metal. Wood floors laid on wood nailing strips were used in all offices and were all destroyed by fire. The marble tiling and wainscoting of the corridors was either shaken down by the earthquake or destroyed by the fire. The stairways had cast-iron horses and marble treads, most of the latter being calcined. The suspended wire lath and plaster ceilings were generally destroyed because of the lack of proper fastenings. The curtain walls of granite and sandstone were not damaged by the earthquake, but were considerably spalled by the fire. 
The Chronicle buildings, corner of Market and Kearney streets, comprised an old ten-story structure and a new fifteen-story annex that was in process of construction, both shown in Pl. XXX, $B$. The old building consisted of steel beams and protected cast-iron columns, with self-supporting walls, which had a brownstone front up to the second story and were ornamented with terra cotta above. The floor was of hollow tile, filled with cinder concrete and covered with wood. The cast-iron columns were fireproofed with 3 -inch hollow tile, and 4-inch hollow tile was used for the partitions. The terracotta partitions and fireproofing entirely collapsed. The building appeared to have stood the earthquake shock, and received its principal damage through the fire. The collapse of the western section of the building was probably due to the buckling of the cast-iron columns.

In the annex terra-cotta hollow tile was used for the floor construction, 4-inch hollow tile for the partitions, and 3-inch hollow tile for fireproofing the columns and girders. The curtain walls were built of. sandstone, with terra-cotta trimmings for the front walls of the first and second stories, and brick and terra cotta for the remainder. The building was racked considerably by the earthquake, the front walls developing the characteristic $X$ cracks (a number of which may be perceived by a close inspection of $\mathrm{Pl}$. $\mathrm{XXX}, B)$, due to a lack of diagonal bracing of the steel skeleton. The tiling failed extensively, the lower webs spalling off and the columns buckling in the southwest corner on the upper floors above the roof of the old Chronicle Building. There was little combustible material in the building, and the trim had not started; a few of the wooden window frames only burned; so that the fire test was not great.

\section{CITY HALL AND HALL OF RECORDS.}

The city hall (Pl. XXXI) was a brick building, at City Hall avenue, Larkin street, and McAllister street, consisting of steel floor. beams and corrugated-iron arches with cinder-concrete filling. It was wrecked by the earthquake and subsequently gutted by the fire. A prominent feature was a central tower, surmounted by a dome built over a structural steel skeleton. Grouped around the dome were a number of cast-iron columns of half-inch metal filled with brick concrete supported on brackets. Some of these columns in falling broke into small pieces. The brickwork was completely shaken from the central tower. The cement-plastered brick walls were laid in lime mortar of generally poor quality and without adequate tie to the steel work. In some places there was an absence 
of any mortar, but in others it was very good, the brick walls falling in large masses and the broken bricks showing the mortar to have been the stronger. The massive architectural ornamentations were top-heavy and lacked adequate bracing. The ceiling was formed of corrugated metal against which the mortar plaster was pressed, with intermediate brick partitions where the span of the beams was too great. The expansion of the corrugated-iron arches by the heat produced a rise at the crown, and the softening of the iron caused the arches to fail; they would have been much stronger without the unprotected corrugated iron. In the treasury department a granite column was badly spalled by the fire. The building was a monument of bad design and poor materials and workmanship, and was. not, therefore, of such a character that it could be expected to resist successfully the effect of earthquake or fire.

The damage done to the hall of records by the earthquake was not serions, and consisted of the falling of a small section of brickwork from the third story on the west side and other cracks in the walls. The fire, however, destroyed the contents of the building, leaving only the shell standing.

\section{CROCKER BUILDING.}

The ten-story Crocker Building, corner of Powell and Market streets, was a steel-skeleton structure, with hollow-tile floor arches, partitions; and fireproofing for columns and girders. The first two stories of the self-supporting walls were granite, and the remainder buff brick with terra cotta.

On the ninth and tenth floors the light Phonix columns buckled through the failure of the hollow-tile fireproofing. The fire was only moderate, however, and except on the ninth and tenth floors the steel appeared to be in good condition. The weakness of hollow floor tiles for carrying heavy loads was demonstrated in a number of places where the tile floors had been broken by the fall of safes. The lower webs of the floor tiles had failed over extensive areas. The stairways, with their cast-iron horses and slate treads, were nct damaged to any great extent. The floors were topped with cinder concrete and covered with wood in the offices and with mosaic in the corridors.

\section{EMPORIUM.}

In the building known as the "Emporium," $825-855$ Market. street, west of the Academy of Sciences, the first two stories were fireproofed" with terra cotta. Slow-burning wooden construction was used above the second floor. As shown in Pl. XXXII, very little of this structure save the exterior walls was left standing. 
The six-story Fairmount Hotel, California, Mason, Powell, and Sacramento streets, was nearly completed, and the only combustible in it was the lumber used in construction. It consisted of a steel skeleton with floors of cinder concrete reenforced with expanded metal. The walls were self-supporting and were constructed of granite backed with brick up to the third floor and of light-colored terra cotta in the upper stories. The ceilings were of the suspended type plastered on metal lath. The original plans called for the columns to be fireproofed with concrete, but because of the greater. expense of this material the plans were changed and the expanded metal and plaster partitions were molded around these columns. The result was that even under the moderate heat to which the building was subjected about 40 of the columns buckled, including 23 on the third floor alone (Pl. XXXIV), and the partitions were completely wrecked. The effect of the earthquake shock was principally confined to the west end of the north front. The terra cotta was spalled considerably and the granite only slightly by fire. The exterior damage was not very great.

JAMES FTOOD BUILDING.

The steel-frame twelve-story James Flood Building, on the northeast corner of Powell and Market streets, was constructed with segmental hollow-tile floor arches topped with cinder concrete and suspended ceilings plastered on metal lath. The columns were constructed of $\mathbf{Z}$ bars and were filled with common brick to the outer edge of the section and the whole inclosed with 3 -inch hollow tile. This tile failed ( $\mathrm{Pl}$. XXXV, $A$ ), although the fire could not have been very severe, for the wooden floor in the offices was only partly burned and there were a number of wardrobes and switch boxes of wood, besides the door and window frames and wainscoting, which were not burned. The stairways, which had cast-iron horses and marble treads, were in fair condition. The corridors were tiled with marble. The stonework was very slightly spalled by fire, and the principal damage by earthquake was a cracking of the sandstone at several of the entrances (Pl. XXXIII, $B$ ).

GRAN'T BUILDING. .

The lower floor of the Grant Building, at the southeast corner of Seventh and Market streets, was used for a bank, the upper floors for offices. It was eight stories high and had a steel frame with cinderconcrete floors, the beams and girders being of solid concrete. The first story had self-supporting walls of sandstone, and the remaining 7171-Bull. $324-07-4$ 
stories walls of pressed terra-cotta brick, trimmed with sandstone. Hollow tile was used to fireproof the columns and for the partitions.

The cast-iron stairways with marble treads were damaged but slightly. The hollow-tile partitions were badly wrecked, most of them being thrown down. The building was injured considerably by dynamiting, which partly disguised the damage caused by the earthquake.

\section{HOTEL HAMTILTON.}

The twelve-story apartment house known as the Hotel Hamilton, on the north side of Ellis street between Mason and Powell streets, was a steel-skeleton structure with floors of reenforced concrete and girders and beams of solid concrete. Plastered wire lath served as a fireproofing for the columns, and the suspended ceilings were of the same material. This construction may be seen in Pl. XXXVI, B. Four-inch hollow tile was used in the partitions.

The marble treads of the cast-iron stairway were to a large extent calcined. A number of the columns buckled on the first, sixth, and seventh floors, the wire lath being entirely insufficient. This buckling caused the floors throughout the building to settle. The damage by earthquake to the curtain walls was slight. The sandstone finish of the first four floors spalled but little from the heat; the terra cotta above, however, was considerably spalled.

\section{HIBERNIA SAVINGS AND LOAN SOCIETY'S BUILDING.}

The two-story bank building of the Hibernia Savings and Loan Society, on the northwest corner of McAllister and Jones streets (Pl. XXXVII, $A$ ), was constructed with two street fronts of granite and rear walls of brick. The gallery and a portion of the second floor were constructed of brick and concrete arches. The ceilings and ornamental work were plastered wire lath. The dome was sheathed with copper. The granite fronts, especially around the doors and windows, were badly spalled by fire; other damage to the structure was confined almost entirely to the roof.

\section{HOBAR'T BUILDING.}

The five-story Hobart Building, on the north side of Market street near Post street, had bearing walls of brick faced with granite up to the second story and of brick trimmed with terra cotta for the remaining stories. The framework consisted of cast-iron columns with steel girders and beams; the floors of segmental arches of plain concrete. The cast-iron columns were fireproofed with brick in the basement, and with wire lath and plaster on the first floor. The partitions were of 4-inch hollow tile. The ceilings were plastered wire lath attached to the lower flanges of the beams. 
The granite columns were spalled practically to destruction by fire, as shown in Pl. XXXVI, A. The fire in one section appeared to be very hot and caused a collapse of one of the floors, which was followed by the failure of the other floors of that section of the building.

JACKSON BREWING COMIPANY'S BUTIDING.

The plant of the Jackson Brewing Company, on the southeast corner of Eleventh and Folsom streets (Pl. XXXVII, B), was in process of construction and was wrecked by the earthquake, the damage by fire being but slight. The brick walls were laid in lime mortar of poor quality. The steel beams and girders were supported by cast-iron columns. Many of the various steel members were bolfed together with an insufficient number of bolts, the girders and beams resting upon the walls without any tie; the columns, girders, and beams were not fireproofed, and in the eastern half the concrete floor slabs, 6 inches thick, were without reenforcement. Several persons were killed by the collapse of the tower. That this building should have been wrecked is not surprising, as the design was bad and the material and workmanship were very poor.

HALL, OF JUSTICE.

A steel frame and floors of cinder concrete reenforced with expanded metal were used in the Hall of Justice, at the corner of Kearney and Washington streets. The earthquake largely wrecked this building (Pl. XXXIX, $A$ ). The cupola of light steel angles collapsed from the heat after being racked by the earthquake. The walls were laid in lime mortar, and the floor panels were stiffened, as in the Aitna Building, with 5 by $\frac{1}{2}$ inch steel bands. The floors were wood covered and were burned. The suspended ceilings were of plastered expanded metal lath, the partitions of 3-inch expanded metal, plastered, while the columns had a double layer of plastered expanded metal with a $1 \frac{1}{2}$-inch dead air space between. The suspended ceilings failed, as shown in $\mathrm{Pl}$. XXXV., $B$, a view taken on the second floor. One of the central basement columns buckled and collapsed 18 inches, presenting the appearance of having punched a hole in the floor. Two of the six-cell prison cages fell through the floors into the basement. The cast-iron stairways with marble treads are in fair shape.

\section{KAMM BUILDING.}

The seven-story L-shaped Kamm Building, on Market street, west of the Call Building and adjacent to it on two sides, had a steel skeleton and self-supporting sandstone walls. The floors were of reenforced stone concrete, covered with wood, with hollow partitions and sus- 
pended ceilings of plastered wire lath, the steel columns, beams, and girders being also fireproofed with plastered wire lath.

The rear structure collapsed when a number of columns in the basement buckled under the intense heat produced by the burning. wall paper, of which there was a large quantity stored in the basement.

\section{KOHL (HAYWARD) BUILDING.}

The Kohl Building, on the northeast corner of California and Montgomery streets, which presented a number of interesting features, is of a modern type of steel-skeleton construction, 11 stories in height. The floors were of concrete, reenforced with expanded metal, and the columns were incased with expanded metal, plastered: The partitions were made of hollow tile, with metal-covered frames, doors, and windows. The suspended ceilings were of plastered expanded metal.

The earthquake did but little damage, breaking a few panes of glass and loosening the marble wainscoting. 'There were also a few cracks in the stone facing at the southwest corner of the first floor. The first, second, third, fourth, and part of the seventh floors were burned, the remainder of the building being undamaged. The structure was surrounded by a series of rather low buildings, and the fire was not severe either on the outside or inside. The character of the inside trim prevented to a considerable degree the spread of the flames. One defect in the construction was in the use of plate glass instead of wire glass for the doors and windows.

\section{MAJESTIC THEATER.}

The Majestic Theater, at the corner of Ninth and Market streets (Pl. XXXIX, B), although one of the largest and best of the San Francisco theaters, was particularly bad in design. The roof trusses, of about 80 -foot span and perhaps 75 feet above the ground, were carried on 18-inch walls insufficiently reenforced by pilasters.

The common brick bearing walls were completely wrecked by the earthquake. The roof trusses over the stage collapsed. The walls still show extensive earthquake cracks, as will be seen from the illustration. The building was subsequently gutted by fire.

\section{MERCANTILE TRUST COMPANY'S BUILDING.}

The three-story Mercantile 'Trust Company's building, on California street east of the Kohl Building, like most of the low structures, appeared to be immune from the earthquake and fire. The principal damage was caused by the falling walls of adjacent buildings, which smashed in the steel roof with its heavy glass and started a fire in the interior. The granite facing around the windows spalled to a slight extent, but the building was not badly damaged. 
MERCHAN'T' EXCHANGE BUIIDING.

The recently constructed modern office building known as the Merchants' Exchange, on California street between Montgomery and Sansome streets, caught fire from the outside and its contents were destroyed. The edifice was 13 stories in height, with steel skeleton, fireproofed with plastered wire lath and reenforced-concrete floors. The floors of the rooms were of wood; the corridors were floored and wainscoted with marble. The fireproofing of the columns consisted of two layers of quarter-inch wire lath with a dead air space between, except those which were bricked into the outside walls. The suspended ceilings and partitions were likewise of plastered wire lath, and the same material formed the walls of the "fireproof" vaults. The curtain walls were of brick on the sides and rear; on the front the first two stories were of granite, the remainder being pressed lerra cotta with terra-cotta trimmings. The heat of the fire was sufficient to calcine a large portion of the wainscoting and the marble treads of the cast-iron stairways. Though not completely destroying it, the fire burned the life out of the plaster, all of which will have to be renewed. The rear walls were cracked by the earthquake. The enameled brickwork of the light well (Pl. XI. A.) also shows earthquake cracks, and is badly spalled by the fire. The stonework was slightly spalled by the heat. The metal frames between the windows opening into the court were buckled, the cinder-concrete fireproofing being insufficient. The terra-cotta trim in the light well was also badly spalled.

MILLLS BUILDING.

The eleven-story Mills Building; at the northeast corncr of Bush and Montgomery streets, had a steel skeleton with hollow-tile fireproofing and hollow-tile partitions. The floors were also of hollow tile topped with cinder concrete and covered with wood in the offices; the tiling and wainscoting of the corridors were of marble.

The walls were racked by the earthquake. The hollow tile failed and left the steel skeleton exposed to the fire. Just how seriously it was damaged is problematical; four of the basement columns buckled (Pl. XL, B), the lower webs of the floor tiles failed over large areas (Pl. XLV, $B)$, and the partitions and the marble treads of the cast-iron stairways were destroyed. In the light well the window casings were distorted by heat because of insufficient fireproofing, and the terra cotta, granite, and exterior trim of the wall were badly spalled. Owing to the failure of the floor tile many safes fell through the several floors. The building should be rebuilt. 
UNITED STATES MINT.

The massive three-story (iovernument building occupied by the United States mint, at Fifth and Mission streets (PI. XXXVIII), which was not damaged to any appreciable extent by the earthquake, was inspected in company with the superintendent, Mr. Leach. One of the interior walls was weakened by a break in the sewer which ran under it, and one of the chimneys was cracked at the top. This structure, which is located at the intersection of two wide streets, is built on soft alluvium, but rests upon a substantial pile foundation. The bearing walls were of solid brick faced with granite, the northwest face of which was badly spalled by fire (Pl. XXXVIII, $B$ ). The floors consisted of brick arches between steel beams, finished in cement. They were supported by cast-iron columns, which were unprotected except where they were incased by the heavy brick wall partitions. The doors and windows were of wood glazed with plate glass, the windows on the first and second floors being fitted with folding inside iron shutters. The roof and northwest side of the third story caught fire from without, but as an artesian well provided an independent supply of water the fire was prevented from gaining a foothold, and the building was but slightly damaged.

\section{MONADNOCK BUILDING.}

The ten-story Morradnock office building, on the south side of Market street between the Palace Hotel and the Call Building, was in process of construction and was damaged by the earthquake and by dynamiting in the vicinity, besides being gutted by fire.

The west wall was not erected, as that section was incomplete, pending the satisfactory-purchase of the land. The structure had a steel skeleton frame, reenforced-concrete floors, with a ceiling of plastered expanded metal. The columns were incased with two layers of plastered expanded metal, with a dead air space between them. The partitions were 3 inches thick, plastered on wire lath. The floors were topped with cinder concrete and covered with tile in the corridors and with wood in the offices. The corridors were to have been wainscoted with marble also. The building was not adequately braced diagonally. Large areas of the exterior were damaged and will have to come down. Two unprotected columns in the basement collapsed, settling the floors for 7 inches. The building is to be repaired by jacking up the floors and replacing the buckled columns. What effect this will have on the reenforced-concrete floors is problematical. Certainly their factor of safety is reduced, and in the judgment of the writer the building is materially weakened, for the reason that the buckling of the columns, which resulted in the settling of the floor, cracked the floor beams at their points of connection with the 
columns. While the jacking up closes the cracks, it can not restore the original strength of the connection, which although not entirely gone has been reduced to a very small percentage of its former value.

\section{MURPHY BUILDING.}

The.columns of the five-story Murphy Building, at the corner of Kearney and California streets, were constructed of corner angles latticed and filled with cinder concrete, the whole being incased with plastered metal lath, with a dead air space between. The floors consisted of cinder-concrete arches between channels.

This building was completely gutted by the fire, although the structure itself was left in fair condition. The metal-lath ceilings and partitions stood the test fairly well, though some of the partitions were buckled out of shape. A view of this damage on the third floor is shown in Pl. XLI, $B$. The terra-cotta trimmings and the copper work around the bay windows were badly damaged by fire.

\section{MUTUAL LIFE BUILDING.}

The nine-story Mutual Life Building, at the southeast corner of Sansome and California streets, was fireproofed throughout with terra-cotta hollow tile, with hollow-tile partitions. The treads of the cast-iron stairways and the wainscoting and tile of the corridors were of marble. The office floors were constructed of cinder concrete covered with wood.

The damage to this building from the earthquake was very slight. The fire in the building, while not severe, was sufficient to cause the failure of the tile fireproofing of the roof trusses, which collapsed from exposure to heat (Pl. XLII, $A$ ).

PACIFIC STATES TELEPHONE AND TELEGRAPT COMPANY'S BUILDING.

The recently completed eight-story building of the Pacific States Telephone and Telegraph Company, on Bush street between Grant and Kearney streets (Pl. XLI, $A$ ), embodied many good and a few bad features of construction. 'The side and rear walls were of brick, and the front was of terra-cotta pressed brick and terra-cotta trimmings. All the walls were self-supporting. The floors were of reenforced concrete between steel beams, and the ceilings for all floors above the basement were suspended metal lath, plastered.

The walls were cracked somewhat by the earthquake, and the pilasters on the exterior were spalled. The girders and columns supporting the floors were fireproofed with concrete and were in excellent shape after the fire. The window protection was excellent; the front was provided with Kinnear rolling shutters, with plate-glass metal-covered windows, while the side windows had: 
metal-covered sash and frames, with wire glass, and tin-covered sliding shutters. The earthquake racked the front sufficiently to prevent the shutters from working. The heat produced by the burning insulated wire and other supplies was high and protracted. The reenforced-concrete beams of the roof were weakened by heat and will have to be replaced. The concrete in general, however, stood this trial exceedingly, well in view of the protracted high temperature. The fire caught through an unprotected rear door in the southwest corner, and the break in the roof made possible a very hot fire, which melted glass and even welded nails. The concrete floors and the column protection were not damaged in the slightest. If the methods of fire protection had been consistent throughout, it is probable that this building would have escaped without damage.

\section{POST-OFFICE BUILDING.}

The writer made a thorough examination of the post-office building, on Mission street between Sixth and Seventh streets, in company with J. W. Roberts, superintendent of construction, of the Supervising Architect's Office. This three-story structure rested on a foundation consisting of steel beams incased in concrete, carried through the soft alluvium to a hard gravel, the depth varying from 30 feet at Seventh and Mission streets to 12 and 14 feet at the opposite corner. The building had a steel frame, expanded-metal and concrete floors, and plastered expanded-metal suspended ceilings. All partitions or interior walls were of terra-cotta hollow tile, laid with full joints of Portland-cement mortar, the terra-cotta work being first class in every particular. The corridors were tiled and wainscoted with marble. The exterior walls were of granite and were thoroughly anchored, each stone being fastened to the steel work and doweled and pinned to the adjacent stones. The outer facing of granite is carried on the steel work and is not backed with brick, there being an inner wall of terra cotta, with a dead air space between, which serves as a passageway for pipes, flues, etc.

The ground at the corner of Seventh and Mission streets settled about 5 feet (Pl. XLIII, B.). The floor of the building was slightly cracked at that point, and Mr. Roberts stated that there was a settling of about $1 \frac{3}{4}$ inches. The outer walls were considerably racked (Pls. XLIII, A; XLIV) by the earthquake, many stones having been shaken entirely loose from the steel work in some places, while । in others a number of stones were started from their beds, and the anchorage was broken. There were also many cracks, especially in some of the exterior pilasters, which were formed of two steel columns, 12 feet apart, without diagonal bracing, the hollow space being used for heating and ventilating apparatus. These pilasters were badly racked. 
The worst damage appeared to be in the interior walls of hollow tile, which were very extensively cracked, especially on the first and second floors. The plaster finish on the hollow-tile partitions strengthened them very considerably. One portion of the mosaic ceilings of the corridors on the main floor was laid in Portlandcement mortar on a flat tiled arch and was badly cracked; another portion, laid in Portland cement against wire lath plastered, was undamaged. In the mail-handling room the end wall was moved out of plumb by the earthquake, and the enameled-brick covering of several columns was shaken off. The only damage done by fire was in the district-court room, in the north corner of the third floor, which caught from without and was burned out, together with two adjacent rooms on the northwest front. On the northeast end of the first floor the exterior stonework was also spalled by fire.

A very considerable amount of damage was done by the dynamiting of near-by buildings, which was so severe as to smash the glass and blow out the window and door frames. In many places the marble wainscoting on the opposite side of the corridor was shaken loose. Probably 20 per cent of the injury done to the building is in the glass, marble, and finish. The building is substantial, and the materials and workmanship are first class.

\section{RIALTO BUILDING.}

The eight-story Rialto Building, at the southwest corner of Mission and New Montgomery streets, had a steel frame and reenforced cinder-concrete floors. The partitions were of hollow tile and the ceilings of suspended expanded metal, plastered. The columns were fireproofed with two layers of plastered expanded metal for all floors except the basement, where only one layer was used. The corridors had mosaic floors, and the stairways were of cast iron with marble treads.

The building was considerably racked by the earthquake and was further damaged by fire and dynamiting (Pl. XLVIII, $B$ ). The fire was only moderately hot, but was sufficient to destroy the fireproofing of two columns in the northeast corner of the basement, so. that they failed by buckling (Pl. XLVIII, $A$ ), causing extensive wrecking of the upper floors. The failure of the column protection was caused by the expansion of a pipe inside of it. The terra cotta around the entrance to the building was cracked by the earthquake.

\section{ST. FRANCIS HOTEL.}

The twelve-story St. Francis Hotel, in West Union square, at the corner of Geary and Powell streets, was of a modern type, having a steel skeleton, reenforced-concrete floors, with suspended ceilings plas- 
tered on wire lath. The fireproofing of beams and girders in the basement and first floor was concrete; in the upper floors it was wire lath and plaster. 'The columns of the first floor were fireproofed with concrete, those in the basement with brick, and on the upper floors 4-inch hollow tile was used. On the first floor the concrete was omitted for 18 inches at the top and a cap of plaster of Paris used; this was a serious mistake and might have caused trouble.

The stone was slightly spalled by fire and on the front was slightly damaged by the earthquake. The enameled bricks of the light well were badly spalled by heat. Two columns failed by buckling. The fire was not severe, and the damage was not very great.

\section{SCO'T'I' BUILDING.}

The Scott Building, on the south side of Mission street between First and Fremont streets, was a four-story structure with a mansard roof. Machinery sales rooms occupied the two lower floors, printing and lithographing offices the upper. The building was constructed of steel girders and beams, with reenforced-concrete floors, suspended ceilings plastered on metal lath, and unprotected castiron columns. The curtain walls were carried on steel work which was unprotected over the windows.

The mansard roof and the upper part of the walls were destroyed by the earthquake. The western section was wrecked by dynamite. The ceilings failed, and the stonework spalled slightly. The fire was not severe, to judge from the appearance of the undamaged naked cast-iron columns.

\section{SECURITY SAVINGS BANK.}

$\nabla$

The Security Savings Bank, a two-story building on Montgomery street between California and Pine streets, received its principal. damage from the falling walls of an adjacent building. The granite and marble front was slightly spalled by the earthquake.

\section{SHREVE BUILDING.}

The eleven-story Shreve office building, at the northwest corner of Post and Grant.streets, was constructed with steel frame, reenforcedconcrete floors; and suspended ceilings plasiered on metal lath. The columns above the second floor were fireproofed with 3-inch hollow tile; those below with concrete. This latter protection, as well as the concrete floors, is in first-class condition. The difference in efficiency between the concrete and hollow-tile protection for columns is clearly demonstrated, the former being in excellent shape, whereas the latter failed, resulting in a number of buckled columns. 
The seven-story Sloane Building, on Post street between Grant and Kearney streets, had bearing walls of terra cotta, brick and terracotta trimmings, and a framework of cast-iron columns and steel beams and girders. The partitions and fireproofing were of expanded metal, plastered, and the floors were of concrete, reenforced with expanded metal. All columns except those in the basement were fireproofed with expanded metal, plastered.

There is every indication of a very hot fire in the basement, which buckled several of these unprotected columns, causing a collapse in the central portion of the building (Pl. XLIX, $A$ ).

SPRING VALLEY WATER CONIPANY'S BUILDING.

The City of Paris Dry Goods Company occupied the two lower floors of the Spring Valley Water Company's building, at the southeast corner of Geary and Stockton streets, the remaining four stories being used for office purposes. The building, a general rear view of which is shown in Pl. $\mathrm{L}, A$, had a steel skeleton, the partitions, column protection, and floor arches, the lower web of which spalled off extensively, being of hollow tile. The floor arches were topped with cinder concrete and covered with wood. The columns in the southeast corner of the basement buckled, and the upper stories collapsed. The hollowtile partitions were in bad condition, and the 2-inch tile on columns failed generally. Where the tile ceilings were unprotected the webs spalled extensively; where there was a suspended ceiling remaining in position the tiles were in fair condition. The cast-iron stairways with marble treads were also damaged. There were a few slight earthquake cracks along the Stockton street side, and the south wall had a vertical crack.

UNITED STATES SURTREASURY.

The four-story brick subtreasury building, on Montgomery street between Commercial and Clay streets, had rolling shutters on the lower front windows and a combination of wood and concrete floors. The wood burned, causing the collapse of that portion of the building. The remainder of the concrete-floor portion seemed to be in fitir condition.

UNION 'TRUS'T COMPANY'S BUILDTNG.

The Union Trust Company's ten-story office building, on the corner of Market and Montgomery streets, was constructed with a steel frame. The front walls of the first two stories were granite; the 
remaining walls were of pressed terra-cotta brick, with terra-cotta trimmings. The floors and partitions were of hollow tile, and the girders, beams, and columns were fireproofed with the same material. Thre floors were topped with cinder concrete covered with wood, except in the corridors, where cement finish was used. The cast-iron stairways had marble treads. The granite walls were spalled around the openings by fire. The hollow-tile partitions failed extensively, and the lower web of the floor tile spalled over large areas. The fire was not intense, and the steel appeared to be in fair condition except on the ninth and tenth floors. The extent of the damage can be seen in Pl. $\mathbf{L}, B$, a view on the ninth floor. The steel trusses on the tenth floor were very much distorted by heat, owing to the failure of the hollow-tile fireproofing.

YOLKMAN BUILDING.

The lower floor of the Volkman Building, on the north side of Jackson street between Montgomery and Sansome streets, opposite the unburned block near the appraisers' building, was occupied by a branch of the post-office. The structure was surrounded on the sides and rear by completely gutted buildings, and its escape was probably due to its protected openings. The windows were glazed with wire glass and the sash and frames were metal covered. The rear doors were equipped with Kinnear rolling shutters. A few windows were so badly damaged that they will have to be replaced, but the building was only slightly injured, for the fire did not gain a foothold.

WELILS-TARGO. BUILDING.

The six-story Wells-Fargo Building, on the northeast corner of Mission and Second streets, is devoted exclusively to Wells, Fargo \& Co.'s express business. It has a steel skeleton, self-supporting walls, and reenforced-concrete floors. The ceilings are of plastered wire lath, as are also the hollow partitions and the fireproofing on the columns. The outside walls are of granite for the first two stories and pressed brick and terra cotta for the remaining stories. The openings into the air and light well were of metal frame, glazed with wire glass.

This building shows, especially in the Mission street front, the racking effect of the earthquake. The marble treads of the castiron stairways were considerably damaged by the fire, and the marble wainscoting of the corridors was thrown down by the earthquake. The window frames in the light well (Pl. XLIX, $B$ ) were warped by the fire, which also spalled the terra-cotta trim. 


\section{ASPECTS OF' THE FIRE DISASTER.}

The San Francisco fire, which lasted three days, was one of the greatest conflagrations of recent times. The loss by fire was greater than it should have been, by reason of the failure of the cast-iron water mains in the city; although the loss must necessarily have been great because of the character of the buildings, 90 per cent of which were frame. This disaster demonstrated that the lessons from the Chicago and Baltimore fires are still unlearned. The same faults in construction continue to be repeated. The only sure way to remedy grave defects of this character is to enact strict building laws which will compel an observance of the essentials for fireproof structures.

The conditions at San Francisco were unusual, and even had not the water supply failed it is doubtful whether they could have been controlled, for the reason that it would have been impossible for the fire department to handle efficiently so many fires at a time, especially as there were so many nonfireproof structures. Large conflagrations demonstrate that there is no such thing as a fireproof building. To label one as such is bad practice, since it gives a false sense of security and induces a relaxing of necessary precautions.

\section{FIRE HISTORY AND RECOMMENDATIONS OF INSURANCE BOARDS.}

It is claimed that the recorded destruction by fires in San Francisco up to 1899 was excessive, showing an average loss between two and three times that expected in cities having ordinary fire protection. In every year since 1899, except 1903, although the number of fires increased materially, the average loss per fire remained moderate. In any of these years the number of fires involving losses of $\$ 40,000$ or more did not exceed two. In 1903 there were ten large fires, each involving a loss of more than $\$ 40,000$, thus bringing the total up to: a high figure; and at each of these fires the greater portion of the loss was to the contents rather than to the buildings.

In October, 1905, a board of fire-insurance experts presented the report of an examination made under the direction of the National Board of Fire Underwriters on the fire-hazard conditions of San Francisco. This report is extremely interesting and shows clearly how a body of trained experts can accurately locate defects and predict the consequences likely to result from them. The criticisms and recommendations embodied in the report are particularly pertinent to San Francisco; and when the conditions prior to the great fire are considered, the conclusion must be inevitable that no other result of these conditions-a general conflagration which swept the citycould reasonably have been expected. Attention was called to the following principal features of construction affecting the fire hazard 
in the business district: (1) Bad exposures and unprotected openings; (2) poor construction; (3) an absence of sprinklers or of any of the modern protective devices; and (4) excessive height in nonfireproof structures. It is stated that in the congested district about 2.2 per cent were fireproof, 68.3 per cent were wooden joisted brick, and 29.5 per cent were frame buildings. A very bad feature lay in the fact that a large number of so-called "fireproofs" were surrounded by nonfireproofs. The mixture of dwellings and minor mercantile buildings surrounding the congested-value district also greatly increased the hazard.

The board recommended the municipal ownership of the water supply. They considered the present supply ample in amount for the existing requirements, but subject to a decided probability of local iailure in emergencies, owing to faults in the distribution system. They deemed it very desirable to increase the capacity of the existing system and to install at the earliest possible date a separate fire-main system, and recommended that all dead ends of pipe mains be connected with the network wherever practicable. They advised that the system of distribution be equipped with a sufficient number of gate valves, so located that no single case of accident, breakage, or repair to the pipe system would necessitate the shutting from service of a length of main greater than the side of a single block (a maximum of 500 feet) in important mercantile manufacturing districts, or than two sides of a single block (a maximum of 800 feet) in other districts.

The building code was found to be satisfactory on the whole, but the board recommended that it be so amended as to limit floor areas, provide for the protection of exposed openings in fireproof buildings, and encourage the use of modern protective devices and constructions, such as sprinkler equipments, automatic fire doors, wire glass, etc. They recommended that prompt measures be taken to relieve the hazardous conditions in narrow streets by widening the streets or enforcing adequate window protection, or both, and advised that automatic sprinkler equipments be required in all buildings which by reason of their size, construction, or occupancy, singly or combined, might act as conflagration breeders. The potential hazard was considered very severe, in view of the exceptionally large areas and great heights of many buildings and of their highly combustible nature by reason of sheathed walls and ceilings, numerous ur:protected openings and light wells, and the general absence of fire breaks, taken in conjunction with the presence of interposed frame buildings and the comparatively narrow streets. These numerous and mutually aggravating conflagration breeders, considered in connection with the almost total lack of sprinklers and general absence 
of modern protective devices, and the prevailing high winds, made the probability feature alarmingly great.

They advised that the inadequate force of four building inspectors be at least doubled, and that the building laws be rigidly and impartially enforced.

They found the fire department to be an efficient force, well organized under an exceptionally competent chief, and though weak in powerful engines, otherwise fairly well equipped, the number of engine companies being particularly large.

In their report the board summarized the situation in San Francisco as follows:

While two of the five sections into which the congested-value district is divided involve only a mild conflagration bazard within their own limits, they are badly exposed by the others, in which all the elements of the conflaglation liakild alre present to a mirked degree. Not only is the hazard extreme within the congested-value district, but it is angmented by the presence of a compalct surrounding, greatt-height, large-area, frame-residence district, itself ummanageable from a fire-fightirg standpoint by reason of adverse conditions introduced by the topograply. In fact, San Francisco has violated all underwriting traditions and precedents by not burning up; that it has not done so is largely due to the virilince of the fire department, which can not be relied upon indefinitely to stave off the inevitable.

\section{FIRE-RESISTING QUALITIES OF STRUCTURES AND STRUCTURAL MATERIALS.}

The fire which has practically destroyed San Francisco has more than fulfilled this prophecy. The destruction was greater than in the Baltimore fire because the fire was hotter, owing, as has been pointed out, to the inflammable surroundings and the unprotected openings, and to the unchecked sway of the flames. The heat was so intense that sash weights and glass melted and ran together freely. In some places the edges of broken cast-iron columns softened, the tin coating in piles of tinned plate volatilized, even in the middle of the piles, and nails were softened sufficiently to weld together. (See also Pl. LI, A.) The maximum temperature, lasting for a few minutes in each locality, was probably $2,000^{\circ}$ or $2,200^{\circ} \mathbf{F}$., while the average temperature did not exceed $1,500^{\circ} \mathrm{F}$.

Nearly all the so-called "fireproofs" were gutted and their contents destroyed, the fire damage done to these buildings being fully 60 per cent. The early collapse of protected steel frames owing to the failure of the fireproofing was of common occurrence. The extent of the damage to a building from fire can be determined only after the débris and wreckage have been removed and will then be found to be much greater than was at first supposed. This is particularly true of steel structures in which the effect of fire is partly hidden by the débris. 
Of perhaps thirty fireproofs of good height with reenforcedconcrete floors, all but two had steel frames. Steel beams and columns were generally protected with metal lath and plaster, cinder concrete, or terra-cotta tile. Practically all floor construction consisted either of hollow terra-cotta tile or reenforced concrete. Ceilings of light angles and metal lath, plastered, suspended from floors, served as additional means of fireproofing, by keeping the fire from coming into direct contact with the flooring material. Steel beams in many buildings had no protection, even where concrete filled, except this subceiling. The lower webs of floor tile came off to perhaps a greater extent than in the Baltimore fire. It is said to be impossible to procure a suitable hard-wood sawdust on the Pacific coast, such as is required in the manufacture of porous terra-cotta tile. The tile used is therefore denser and of poorer quality. The behavior of reenforced-concrete floors was most excellent.

Partition walls were in a very few buildings of brick. As a rule, however, they were either of 3-inch hollow terra-cotta tile or metal lath, plastered.

The matter of column protection is very important, as the number of failures in the San Francisco fire was particularly large, especially in the Fairmount Hotel (Pl. XXXIV). Unprotected cast-iron columns failed as a result of unequal expansion caused by the lugs. A few light cast-iron columns filled with concrete came through without damage, and at the Academy of Sciences (Pl. XXIV, $A$ ), as already described, cast iron failed around a concrete core, which carried the load. Brick-filled columns gave fair satisfaction, but concrete-protected columns afforded the best results. The question of fireproofing, however, is one of degree, being dependent on the intensity and duration of the fire. A column may be fireproofed sufficiently for an office building, but entirely too little for a warehouse; or a column which may be suitable for the upper stories may fail in the basement, as in the Kamm Building (p. 40). Again, the practice of running piping back of the fireproofing on columns, especially if the fireproofing is of hollow tile, is extremely bad. Many failures were caused by the expansion of such piping throwing off the terra-cotta tile. Concrete is probably the best fireproofing material, because, as shown by experience, its stiffness will enable it to support not only the steel within, if the latter is softened by the heat, but perhaps the structure itself. The following types of column protection were used in San . Francisco buildings: (1) Plaster on wire lath, both single and double layers, the latter having a dead air space; (2) single terra-cotta tile; (3) concrete; (4) concrete covered with terra-cotta tile; (5) brick.

Of the fire loss, perhaps 75 per cent was in the trim and ornamental work. Inflammable woodwork in the corridors, doors, and windows proved a source of great loss, and should be eliminated for orna- 
mental purposes. The behavior of the metal-covered woodwork in the Kohl and other buildings was satisfactory and immensely better than that of the naked wood. It is certain that a building may be finished and trimmed and even decorated with noninflammable materials. Although the additional security of such materials in case of fire does not appeal to owners and architects as compensating for their extra cost in comparison with wood or other inflammable materials, the building laws should nevertheless compel this type of construction.

The loss in ornamental stonework was particularly great, especially in the case of marble, which in many structures was completely calcined. Brickwork suffered most from the earthquake and least from fire, and sandstone splintered less than granite, which suffered severely, a number of badly spalled columns showing how futile this material is for other than ornamental purposes. Concrete proved superior to brick as a fireproofing medium.

It is estimated that over 80 per cent of the so-called "fireproof" safes failed. Many valuable records and much other property were thereby destroyed. An ordinary fireproof safe was of absolutely no value, and the contents of nearly every one were destroyed. In many office buildings so-called fireproof vaults were constructed of hollow tile or plastered metal lath, being formed partly by the partitions of the rooms, and were so flimsy that they yielded readily to the flames. In Pl. LII can be seen groups of so-called "fireproof safes," many with walls 20 inches or more thick, which failed to serve the purpose for which they were designed. Pl. LII, $B$, shows part of a collection of over 50 of these "safes" whose contents were destroyed. In a number of jeweler's safes silver and other precious metals were melted. The warping of the doors also resulted in the loss of the contents in many vaults, even where they were otherwise well designed. In short, fireproof vaults and safes behaved in the San Francisco fire very much as they did in the Baltimore fire. Little progress seems to have been made toward the production of a satisfactory fireproof safe. The only really fireproof vault is one with brick or concrete walls not less than 10 inches thick. The cementfilled metal safe proved to be a very good type of fireproof. Even in well-designed safes and vaults, great care must be exercised in opening them after they have been exposed to fire. Time should be allowed for the temperature in the interior to become reduced to somewhere near the temperature of the surrounding air, as otherwise the contents may be destroyed by spontaneous combustion on exposure to the air. Pl. LII, $A$, is a view of one of the oldest vaults in San Francisco, that of the old Wells, Fargo \& Co.'s Express, which passed the fire test satisfactorily.

The writer is of the opinion that the present commercial hollow 7171-Bull. 324-07-5 
terra-cotta tile is largely, if not entirely, devoid of merit for fireproofing purposes. Even when it is of the best grade and workmanship it can hardly be considered a first-class building material. At a comparatively low temperature the tiles fail, the thin webs spalling from unequal expansion. A more porous tile, with thicker webs keyed together and laid in Portland-cement mortar with tight joints, would unquestionably be more suitable for the purpose. It may be true that in case of repairs after a fire damaged tile of the usual commercial type can readily be detected and renewed. Terra-cotta tiling may, however, allow sufficient heat to pass through it to soften slightly the steel member which it encases and still remain in position, thus hiding the defect. Several examples of this condition were found.

The advocates of terra-cotta tile contend that concrete may be seriously damaged by dehydration without noticeable change in its appearance. While this contention may be justified, it should be noted that any weakness or softness may be as readily detected and repaired in concrete as in terra cotta. Concrete, moreover, has the great advantage of being a nonconductor of heat, and so will withstand a prolonged heat before the damage extends to any great depth; and it usually remains in place, maintaining its protective qualities. The value of a structure or of a method of fireproofing is determined largely by ascertaining what portion of the structure is left available for use after the fire. The word "fireproof" is of course a misnomer, for no building is absolutely fireproof; and the resistance offered to fire is one of degree only, for if the heat be sufficiently high and prolonged, nothing can withstand it. The best materials are nonconductors of heat, having high fusing points. At high temperature concrete loses its, water of crystallization, but the depth to which this dehydration goes and the rate at which it takes place are the factors that determine the effectiveness of the material. The heat insulation afforded by concrete is of a high order, and to obtain the best results a sufficient thickness must be applied. This required thickness is naturally a variable quantity; 2 inches, or even 1 inch, may be sufficient for an office building, but would be inadequate for a warehouse. These remarks concerning concrete also apply to all other forms of fireproofing. The prime point on which information should be procured is the thickness of the insulation for proper protection against fire.

Perhaps the most important problem is that of protecting a building from fire from without. To do so means the protecting of all openings and the making of the roof equally as resistant as the other parts of the structure. Buildings should be self-contained-that is, protected against exterior fires and capable of fighting fire from the inside; and in earthquake countries, where the outside water service 
is likely to fail through rupture of the steel mains, it is highly desirable to have an independent supply, as from an artesian well, with the necessary pumps and service pipe.

In the matter of fireproofing, certain definite recommendations may be deduced from the San Francisco conflagration, as follows:

1. Exterior openings should be protected by the use of metal frames or metal-covered frames with wire glass, or exterior iron shutters or interior metal-covered shutters, or both exterior and interior shutters.

2. The structural members, especially the columns, should be better protected, preferably with solid concrete; they may be filled with brick and covered with terra cotta or with a double layer of cementplastered metal lath, with an air space between.

3. There should be a better type of partition, the present plastered metal lath.or hollow terra-cotta tile being inadequate. Reenforcedconcrete partitions are much more efficient.

4. All combustible trim should be eliminated. The fire loss from, this item is high, and it should be so designed as to be replaced readily and cheaply.

5. Attic floors and roofs should be designed to resist fire. In many buildings the roof members were not fireproofed and their failure caused great damage.

6. Buildings should be so arranged that the fire could be confined to a single room.

\section{WATER SUPPLY AND OTHER METHODS OF FIGHTING FIRE.}

In connection with the matter of the fireproof construction of buildings above referred to, certain suggestions may be made in regard to private and public facilities for fighting fire, as follows:

1. An independent water supply and other facilities for fighting the fire from either within or without should be provided.

2. Another very important problem, at least so far as San Francisco is concerned, is that of the public water supply. 'The failure of a gridiron system of cast-iron pipes seriously cripples a water supply, no matter how large may be the storage. It is also evident that greater care must be exercised in the laying of these mains, especially in filled ground or alluvial soil, where failures are likely to occur. A system of by-passes should be provided, so arranged as to permit the cutting out of portions which are broken or otherwise damaged, and some system should be installed for quick repairs under emergency conditions.

3. A high-pressure service operated from the bay, using salt water, would also be an essential feature. This service might necessitate a floating pumping station, as recommended by the National Board of Fire Underwriters, 
4. The use of explosives, such as dynamite, for fighting a fire should be greatly restricted and intrusted to experts only, or else abandoned. It is extremely doubtful whether the progress of a fire can be checked by dynamiting in advance of the fire without the removal or thorough wetting of the débris. Such procedure would have been impossible in San Francisco, as the water supply was unavailable and it was impossible to carry away the wreckage. The indiscriminate dynamiting did more harm than good, for the reason that the concussions injured the surrounding buildings, as shown, for example, by the extensive damage done at the post-office. Back firing would have been equally bad, because to apply this method successfully plenty of water for controlling the fire is necessary. A fire stop is the best way of checking a conflagration, and a fireproof structure makes the best fire stop if it has well-protected openings.

\section{GENERAL IESSONS OF THE EARTHQUAKE AND FIRE.}

In considering the results of the destruction which was wrought by the earthquake and fire there appear certain salient features from which conclusions may be drawn. In regard to the possibility of the erection of an earthquake-proof structure, it is apparent and universally admitted that it would be impossible to build on the fault line a structure which could withstand the effect of a slip. Furthermore, it is realized that in building near the fault on soft or alluvial soil extra precautions must be taken; for example, location of the San Francisco water mains in ground of this character was unwise, since it is difficult to design a waterworks system capable of resisting the effect of settling of the ground. The importance of proper construction and distribution of the water mains in districts liable to earthquakes is demonstrated by the fact that the greatest damage in San Francisco, fully 85 per cent of the total, was by fire. The action of the earthquake in starting the fires which grew to a great conflagration seems insignificant compared to the breaking of the water mains, which left the city defenseless against the flames.

The comparatively great destruction wrought by the earthquake to structures located on filled ground or alluvial soil has already been pointed out. The destruction in San Francisco was confined largely to buildings located on the alluvium of the flats or on the filled ground of old watercourses. That structures can be built, however, which will satisfactorily meet even such conditions when adequate foundations are provided, extending through the soft material to a solid base, is demonstrated by the behavior of such buildings as the Leland Stanford Junior Museum (Pl. XIV, $A$ ) and Roble Hall, at Stanford University ; the Government buildings (Pls. XXVIII, $A$; XXXVIII; XLII, $B$; XLIII ; XLIV), and the Call and other buildings in San Francisco. 
The structures which suffered most from the earthquake were-

1. The municipal and county buildings. The greatest destruction was sustained by these buildings, which were generally badly designed and poorly constructed of inferior materials, while the wellbuilt, substantial Government buildings suffered less.

2. Lightly and flimsily constructed wooden buildings. Well-constructed wooden buildings generally withstood the shock, but those that were flimsily built, resting upon posts or equally insufficient foundations, collapsed, even where they were fairly well designed. The essentials of earthquake-resisting power are vertical continuity, adequate diagonal bracing, and first-class foundations.

3. Improperly built brick and stone structures. The brick walls which failed, either by being shaken down entirely or by shattering, were laid in lime mortar with few header courses, and generally had wooden frames with little or no bracing and no tie to the walls. Stone and brick masonry cracked diagonally in the form of an $X$. Hollow-tile partitions and masonry of brick or stone were similarly cracked, although this injury was small where Portland-cement mortar was used. Where the walls were laid with hard brick, with plenty of headers and in Portland-cement mortar, and were properly tied to the floor and roof members there was little, if any, damage. Chimneys collapsed most generally, breaking about halfway up, and destroyed in part at least the structures upon which they fell. While the evidence was by no means conclusive, it appeared to the writer that brick stacks of circular section proved more substantial than square ones. The stack of the Valencia street power plant, which was of eight-pointed star section, collapsed, the part which remained standing showing cracks at one of two opposite reentrant angles almost to the base (Pl. LIII, $A$ ). It is quite evident that brick stacks and similar tall structures built of brick or stone without reenforcement against flexure, or without being guyed, are unsuitable for use in countries liable to earthquake shock. They should be constructed either of steel, guyed, or, if self-supporting, of steel or reenforced concrete. (See also Pl. XIII, A.)

4. Insufficiently braced and loosely constructed steel structures. In structures which were deficient in diagonal bracing the effect of the earthquake was localized in the piers between openings and curtain walls in characteristic $X$ cracks. In tall structures like the Call Building, the tower of the Union Ferry Building, and others, the diagonal bracing that had been installed proved insufficient, and the diagonals at about the middle distance between the top and base were strained beyond the elastic limit of the material, acquiring a permanent set, which was indicated by a slight buckling. It is assumed that the effect of earthquake shock on diagonal bracing is equivalent to a heavy wind pressure, variously estimated at 30 to 50 pounds 
per square inch. The writer believes that the higher figure should be used, because the essential in satisfactory earthquake-resistant design is rigidity; whereby the structure moves as a unit. Unless there should be earthquakes of greater severity than the one under discussion, no fear need be felt for tall buildings. It has been fully demonstrated that a steel frame well braced diagonally upon an adequate foundation successfully meets the earthquake requirements; not even the masonry being injured to any great extent.

Concrete, especially reenforced concrete, because of its great adhesive strength and reenforcing metal, proved more satisfactory than any other material. Its solid monolithic structure produces a successful earthquake-resisting material, inasmuch as it moves as a unit; moreover, it offers a maximum resistance to fire. The great concrete dam of the Crystal Springs Lake at San Mateo (Pl. XI, $B$ ) gave abundant proof of the substantial qualities of concrete in a mass, for although it lies within a few hundred yards of the fault, it suffered no damage. Solid concrete floors proved satisfactory, though concrete in San Francisco was of a very poor quality, and flimsy concrete stiffened with light metal passed as reenforced concrete. Cinder concrete was used extensively for floors and elsewhere, and was of a very inferior grade. Much of it was high in sulphides, which had a deleterious effect on the embedded material, especially in floors where slight cracks permitted air and moisture to come in contact with these sulphides and the metal. For a proper earthquakeproof structure, everything - the design, the materials used, and the workmanship-must be first-class. Most of the failures resulted from bad design, poor workmanship, and poor materials. If reenforced concrete of the quality described could give such satisfactory results in meeting the extraordinary conditions of the San Francisco earthquake and fire, it is evident that much greater satisfaction would have been given by the use of first-class material.

The causes of the failures in San Francisco may be summarized as follows:

1. The effort on the part of those qualified to design and advise on building construction to meet the owners' demands by planning structures so that they can be erected for the least possible cost, a practice which tends to a departure from the principles of correct design, the result being a structure that will carry ordinary loads, but that fails when subjected to unusual conditions. Such was the case at Stanford University, where the poorly constructed stoneveneered buildings met ordinary conditions, but failed in the earthquake; while the more substantial structures, like the dormitoriesone of reenforced concrete and the other of solid stone masonrysurvived.

2. Actually dishonest design and construction. 
The following requirements should be adhered to in structures for earthquake countries:

1. Location on or near the fault should be avoided.

2. Foundations and superstructures should be so built that they will move as a unit.

3. Wooden structures should be rather heavily framed, with continuity in the vertical members, adequate diagonal bracing, and substantial foundations.

4. Steel structures should rest upon an adequate foundation and be thoroughly braced diagonally. This feature is a most important one, as rigidity is absolutely essential.

5. Brickwork and stonework should be thoroughly bonded with full header courses laid in Portland-cement mortar.

6. Masonry should be thoroughly tied to the steel or other framing members.

7. Buildings should have no unnecessary material in their super- $C$ structures, and heavy ornamentation should be omitted.

8. Flimsy floors and partitions should be avoided; reenforced con- $L$. crete is an excellent material for both.

Professor Omori, chairman of the Japanese earthquake commission, and other earthquake authorities, have stated that great earthquakes are followed by a settled condition in the earth's surface and that there is an interval of fifty or one hundred years during which no earthquakes occur. The general fear which prevailed during the first days following the earthquake has been quieted by these assurances, which have also created a feeling of security that has led to a relaxation of the precautions necessary in the work of reconstruction. The lessons taught by the great calamities such as have befallen San Francisco, Baltimore, Chicago, and other cities are not regarded. It is very probable that the new San Francisco to rise on the ruins will be, to a large extent, a duplicate of the former city in defects of construction.

\section{OBSTACLES TO RECONSTRUCTION OF SAN FRANCISCO.}

The actual loss by fire in San Francisco was much greater than in the Baltimore fire, for the reason that many insurance companies have taken advantage of the earthquake clause in the policies and failed to pay their claims, while others without the requisite funds were unable to pay the large claims in full. This failure to pay a very considerable percentage of the fire losses and the delay in adjusting them have proved serious setbacks in the progress of reconstruction.

The new building code is also operating against the best interests of the city. The arbitrary classification of buildings based on the 
type of construction is one which will result in more harm than good. Those interested in its preparation directed their attention principally to office and other large buildings, apparently not realizing that the greater proportion of reconstruction will consist of small three or four story buildings. The fact that a structure is built of steel and fireproofed does not make it superior to those representing other. types of construction, for poor materials and workmanship may produce inferior quality, whatever the type.

The proposed code discriminates against reenforced-concrete buildings in designating them as class B structures. While not intentional, this conveys the impression that such buildings are next in order of superiority to structures of class A. Class A should embrace buildings so well designed and constructed of such first-class materials that they afford the maximum resistance to fire, and should represent the best method of fireproof construction regardless of type.

That there was only one reenforced-concrete building of the modern type in San Francisco was due in part to the opposition of the labor unions. The exorbitant demands for wages, coupled with the high cost of materials, have proved a serious handicap. The cost of all construction work is excessive at the present time, and business interests will suffer from the shrinkage in value which will follow the fall in price of labor and materials. This policy of the labor organizations is materially interfering with and checking the work of reconstruction.

In addition to these labor difficulties, the questions of widening and extending old streets and opening new ones, for the purpose of carrying out the plans for the new and greater city, are still undecided, and most of the business men are unwilling to begin the work of reconstruction until these points are settled.

\section{STATISTICS AND GENTRAL INFORMATION.}

The defects of construction which are so strongly condemned by reason of the failure of the structures were no worse than those generally existing throughout the United States. The same defects are common, and it is evident that the same result would follow an earthquake of equal intensity in another part of the country. A moment's consideration will show that the loss of life and property in New York, for example, under similar conditions, would be enormous. The damage to property in San Francisco is estimated at $\$ 250,000,000$, but this sum, large as it is, is exceeded by the total annual expenditures for new construction in New York.

The loss of life from earthquakes is usually very great. That it did not exceed 500 in San Francisco is explained by the fact that at the time of its occurrence, during the early hours of the morning, 
most of the inhabitants were in houses, 90 per cent of which were of frame. Structures of this type withstood the earthquake shock particularly well, which accounts for the minimum loss of life. Had the earthquake occurred four or five hours later, when the people were performing their daily tasks, in offices, schools, etc., or on the streets, the loss of life must have been very great. The writer saw a view of a drove of cattle buried under the ruins of a fallen wall while passing through Mission street, which graphically told the story of what might have occurred had the shock come later in the day. Although the loss of life was small, more than 200,000 people were rendered homeless and dependent on the authorities for even the necessaries of life.

In three days the tremendous area of more than 2,593 acres was burned, destroying entirely 490 city blocks and in part 32 blocks. (See Pls. LIV-LVII.) Of this area, 314 acres constituted the congested district, on which there was $\$ 250,000,000$ insurance, probably representing a value of at least $\$ 500,000,000$.

In the Baltimore fire (February, 1904) 1,343 buildings were destroyed, having an assessed value of $\$ 12,908,300$. In two years these burned buildings were replaced by 570 buildings, whose assessed value is $\$ 20,000,000$. These new buildings are larger than the old, and the widening of the streets has eliminated 700 building lots. It is expected that when the reconstruction within the burned district is complete there will be fewer than 800 buildings, of which the assessed value will be fully $\$ 25,000,000$. It is therefore quite reasonable to suppose that the assessed value of the reconstructed San Francisco will be at least double that at the time of the catastrophe. 


\section{THE EFFECTS OF THE EARTHQUAKE AND FIRE ON BUILDINGS, ENGINEERING STRUCTURES, AND STRUCTURAL MATERIALS.}

By Jofn Stephen Sewel.

\section{INTRODUCTION.}

\section{SCOPE OF THE INVESTIGATION.}

The following pages contain the matter of a report dated July 5, 1906, to Brig. Gen. Alexander Mackenzie, Chief of Engineers, United States Army, of an inspection made by me of the ruins of San Francisco, in accordance with Special Orders No. 97, dated War Department, Washington, April 23, 1906.

I arrived in San Francisco on the morning of May 8, 1906, and remained until the night of May 19. My orders directed me to investigate the effect of the fire and earthquake, on buildings and engineering structures in the territory affected by the earthquake, and authorized me to visit such points in addition to San Francisco as it might be necessary to observe. As soon as possible after my arrival, I called on the various military and civil authorities, and procured from the latter permits authorizing me to enter and inspect the damaged structures.

It appeared that in the territory affected by the earthquake, in addition to buildings of various types, there were the works of the Spring Valley Water Company and fortifications, light-houses, and railroad structures. Some rumors of collapsed tunnels on the coast division of the Southern Pacific Railroad had been circulated in the East before I left Washington. I found on inquiry, however, that no tunnels had collapsed, and whatever damage had been done, except to buildings along the line, had been wholly or partly repaired before I reached California.

Inquiry among engineers and others competent to speak disclosed the fact that the dams of the Spring Valley Water Company were practically not injured by the earthquake. Considerable damage was done to some of their conduits and to the pipes of the distribution system. Inquiry in reference to these items disclosed the fact that a 
personal examination would consume a great deal of time. It also disclosed the fact that an examination was in process by competent engineers, and Major McKinstry undertook to get for me a report of the results of this examination. As a matter of fact, I have been allowed to see a copy of such a report made by Charles D. Marx and Charles. B. Wing, which the authors prefer not to have published as yet. However, certain essential facts as to the condition of dams, conduits, etc. (see Pls. IX; X, $A ; \mathbf{X I}, B$ ), are taken from it and embodied further on in my own report; although the photographs and certain other features of the report itself, which seem to be peculiarly the property of its authors, are not submitted herewitî. In view of the fact that the results of the examination of the waterworks were promised to me, it seemed superfluous for me to visit the dams and conduits, except as a matter of personal interest, and as my time was very short, I decided not to do so.

The light-houses and fortifications are in charge of competent officers, whose duty it is to report the nature and extent of the damage done to them by the earthquake. As an inspection of the light-houses would have involved a great deal of time, I decided not to attempt to visit them, and made only a superficial examination of the fortifications.

As my own experience has been mainly in the line of fireproof buildings, however, I made a very careful inspection of the ruins of San Francisco itself, and also visited Oakland and Palo Alto, with a view to inspecting damaged buildings at those points. I found, as a result of those trips and by inquiry among competent witnesses, that, with one exception, there was no type of building in the affected district which was not well represented among the buildings of San Francisco. The exception was the concrete work at Leland Stanford Junior University, near Palo Alto, to which specific reference is made on page 113. The greater part of my time, for the reasons above outlined, was spent within the limits of San Francisco itself, and much of it within what had been the congested district of the city.

\section{ACKNOWLEDGMENTS.}

Acknowledgment is due to Capt. M. L. Walker, Corps of Engineers, commanding officer at Fort Mason, who not only entertained me at his quarters during my stay in San Francisco, but rendered very material assistance in the way of transportation when needed, and especially in placing at my disposal the services of Private William. $\mathrm{H}$. Hughes, of the First Battalion of Engineers, a very efficient photographer, who accompanied me and took such views as seemed desirable for the purposes of my report. I was also much indebted to Maj. C. H. McKinstry, Corps of Engineers, who gave me much 
valuable information that made it possible to avoid useless expenditure of time, and who was also of great service in procuring for me the necessary permits from the local civil authorities.

\section{EXTRACTS FROM THE REPORT OF A COMMITTEE OF THE NATIONAL BOARD OF FIRE UNDERWRITERS ON SAN FRANCISCO CONDI- TIONS.}

San Francisco before the earthquake and fire consisted mainly of frame and brick buildings of ordinary construction. A few adobe buildings still remain, but there were not many of these. There were about 45 so-called fireproof buildings in the city, and a small number of so-called slow-burning buildings, modeled more or less loosely along the lines of the New England mills. A fair idea of the general nature of the city, so far as buildings are concerned, is given in the following quotations from a report on San Francisco issued by the committee of twenty of the National Board of Fire Underwriters in October, 1905:

CONTLAGRATION HAZARD.

Potential.-In view of the excessively large areas, great heights, numerous unprotected openings, general absence of fire breaks and stops, highly combustible nature of the buildings, many of which have sheathed walls and ceilings, frequency of light wells, and the presence of interspersed frame buildings, the potential hazard is very severe.

Probability feature.-The above features, combined with the almost total lack of sprinklers, and absence of modern protective devices generally, numerous and mutually aggravating conflagration breeders, high winds and comparatively narrow streets, make the probability feature alarmingly severe.

Summary.-While two of the five sections into which the congested-value district is divided involve only a mild conflagration bazard within their own limits, they are badly exposed by the others, in which all the elements of the conflagration hazard are present to a marked degree. Not only is the hazard extreme within the congested-value district, but it is augmented by the presence of a compact surrounding, great-height, large-area, frame-residence district, itself unmanageable from a fire-fighting standpoint by reason of adverse conditions introduced by the topography. In fact, San Francisco. has violated all underwriting traditions and precedents by not burning up; that it has not done so is largely due to the vigilance of the fire department, which can not be relied upon indefinitely to stave off the inevitable.

In another portion of the same report the following occurs:

The principal features affecting the conflagration hazard in the business section are bad exposures, poor construction, lack of proper protective devices, excessive height in nonfireproof buildings, large floor areas, and the large percentage of frame construction present.

The mixed dwelling and minor mercantile section which immediately surrounds the congested-value district, and extends from it in all directions with more or less uniformity, is alarmingly compact.

* * The security resulting from a combination of redwood and such dampness as exists in San Francisco is regarded by the national board engineers as fancied merely. 
In addition to the frame, ordinary joisted brick, so-called fireproof, and mill buildings, there were in San Francisco four buildings of a monumental type, so far as weight of construction was concerned. These were the new city hall (Pl. XXXI), the new post-office building (Pls. XLIII and XLIV), the United States mint (Pl. XXXVIII), and the appraisers' stores, or custom-house (Pl. XXVIII, $A$ ). The few mill buildings which existed were not of a standard type, according to the report of the National Board of Fire Underwriters. The fireproof buildings had been erected in accordance with the building laws of San Francisco, which provided for three principal types of commercial buildings, known as class $\mathrm{A}$, class $\mathrm{B}$, and class $\mathrm{C}$.

The general requirements for buildings of these classes and for mill buildings are as follows:

\section{BUILDINGS IN FIRE LIMITS.}

SECTION 96 . Every building hereafter erected within the fire limits shall be constructed in accordance with the requirements of this ordinance for the construction of buildings of either class A, class B, or class C.

BUILDINGS OF CLASSES A, B, AND C.

Sectron 97. Class A, termed "fireproof," or "skeleton construction," shall include all buildings wherein all external and internal loads and strains are transmitted from the top of the building to the foundation by skeleton or framework of steel, and the beams or girders of which are riveted to each other at their respective juncture joints. A building of this class must be constructed of noninflammable material throughout, and all interior constructive metal work, with the exception of the framing for elevators and staircases, shall be protected from fire by brick or terra cotta at least $1 \frac{1}{2}$ inches thick, or by plastering three-fourths of an inch thick applied to metal lath. The face of the plastering shall be $1 \frac{1}{2}$ inches from the metal. Wood may be used only for window and door frames, sashes, standing finish, hand rails for stairs, and for the upper and under floors and their necessary sleepers. Wood may also be used for isolated furring blocks, but this class shall not permit the use of laths or furrings of wood.

Class B. A building of this class shall be constructed with all its exterior walls and piers of masonry, or of masonry and steel, and all exterior surfaces other than masonry shall be covered with noninflammable materials. All partitions, furred walls, or other plastered surfaces throughout shall be metal lathed. All interior: metal work shall be protected as in class $\mathbf{A}$, and in addition the floor and ceiling joists, posts, roof boards, and partitions may be of wood in such places as does not violate the requirements of any section or clause of this ordinance.

Class C. A building of this class shall be constructed the same as class B in every respect, except as to the requirements for interior lathing.

Section 98. Limit of height of buildings of classes $A, B$, and $C$ :

Class A, limit of beight

Class B, limit of height 220

Class C, limit of height 100

(As amended by Ordinance 1297.) 
SLOW-BURNING OR "MILL" CONSTRUCTron.

SECTION 99. A building of the slow-burning or "mill" construction type is a building whose outside walls are built of masonry, concentrated in piers or buttresses, between which is a thin wall containing the door and window openings, and whose floors and roof are constructed of heavy timbers, covered with plank of a suitable thickness; the girders being supported between the walls by posts.

\section{SOME FEATURES OF THE EARTHQUAKE AND FIRE. ·}

\section{AMOUNT OF DESTRUCTION DUE TO THE EARTHQUAKE AND FIRE, RESPECTIVELY.}

Within the burned area all frame buildings and practically all buildings with timber floors were totally destroyed, with all their contents. This classification includes mill buildings and those of every other type in which the floor construction is combustible. Practically all the so-called fireproof buildings were gutted, and their contents were a total loss. The average loss on the buildings of class A was, in my judgment, considerably in excess of the average loss on the "fireproof" buildings in Baltimore. This statement can not be made with absolute positiveness, however, in the absence of a detailed estimate of the cost of repairing each building, which $I$ had not time to make. I am quite sure, however, that the damage in San Francisco was greater than it was in Baltimore.

From what was left of the ruins themselves, and from the testimony of competent observers, including engineer officers who were ordered into the business district of San Francisco immediately after the earthquake and before the fire had destroyed the evidences of earthquake damage, I think it is quite certain that the earthquake damage was extensive and severe. There were no available data on which to base an accurate estimate, but I formed a general impression that the damage done by the earthquake alone was at least as great as 10 per cent of the total damage by fire and earthquake combined. The damage from the earthquake, however, was localized in a remarkable degree. In places a group of buildings were almost totally destroyed, and buildings almost in contact with them on all sides escaped practically without damage, although I feel quite sure that miany of the wrecked buildings were superior in every way to their neighbors which escaped. Owing to the remarkable variation in the intensity of the shock from point to point, thus demonstrated, the measure of damage done to an individual building is by no means a measure of the excellency or inferiority of its construction. "Some specific evidence on this point is presented elsewhere in this paper.

FIRE-FIGHTING OPERATIONS-THE USE OF DYNAMITE.

The fire, of course, completed the work begun by the earthquake. (See Pls, LIV-LVII.) The interruption of the water supply, due 
to the breaking of the conduits and mains, left the fire practically in control of the situation. Some attempts were made to stop its progress with dynamite, but from what evidence I was able to obtain I doubt very much whether a great deal was accomplished by this means. It is probable that at one or two points where the fire had become much less fierce its progress was entirely stopped by the use of dynamite, but even this much is not certain: I am personally of the opinion that dynamite might be used so as to check the progress of a conflagration, but it has never been properly applied to that purpose as yet. It seems probable that if a strip of property, a whole city block in depth, extending across the entire front of the fire, were selected sufficiently far in advance to enable it to be completely razed by dynamite before the fire reached it it would prove an effectual barrier, especially if there were water available to keep the ruins thoroughly wet. In the absence of the water the only way to make sure of the result would be to have an enormous number of men ready, as soon as the buildings were demolished, to move the débris to the side nearest to the approaching fire. It is probable that the ruins would be set on fire by the dynamite itself, but with a sufficient number of men, properly handled, the amount of combustible matter along the side next to unburned property might be so materially reduced that the fire would not be able to cross the gap. I rather think that unless such heroic measures are applied the use of dynamite is just as likely to do harm as good in resisting the advance of a conflagration. It will readily occur to anyone at all familiar with such things that to get together the requisite number of men and properly direct their work would require full military control of the situation; otherwise the measures described, while not impossible, would hardly be practicable.

One or two attempts were made, apparently with not a great deal of judgment, to dynamite steel-frame buildings that were on fire. I understand that the explosive was simply placed in the basement loose, practically without any tamping, and detonated. The only result was to knock a few basement columns off their foundations and bring down a portion of the floor construction above. I doubt whether any good results could be obtained by trying to dynamite a steel-frame building as a means of stopping the advance of a fire. If, in a strip of property such as that described above, any steel-frame buildings exist, especially if the frames are protected with any sort of fireproofing, it is probable that more good would result from allowing them to stand, while dynamiting their combustible neighbors.

It would be practically impossible in the time available to demolish a steel frame so completely that all of the combustible débris could be properly handled. It would, burn more freely and more disas- 
trously after dynamiting than if the building were left intact. A good plan in such a case would be to remove all the combustible contents of the building before the fire reached it, throwing them out, if no other course were open, on the side next to the advancing conflagration. Under such circumstances the average fireproof building, while it might be ruined itself, would probably act as a barrier to the spread of the flames beyond it, although, of course, it could not prevent the fire from working around the sides if neighboring combustible buildings were not removed.

A certain amount of damage in addition to that caused by the fire and earthquake was done in San Francisco by the dynamite used to blow down dangerous walls. More specific data on this point are presented in the detailed descriptions.

\section{TEMPERATURE OF THE BALTIMORE AND SAN FRANCISCO FIRES.}

The apparently more complete destruction by fire at San Francisco than at Baltimore immediately raises questions as to the probable temperature of the San Francisco fire. I noted everything coming under my observation which would seem to give an idea as to the probable temperature prevailing, and I am personally of the opinion that the San Francisco fire was appreciably hotter than that at Baltimore. Thus, in places which had been occupied by hardware stores I saw kegfuls of nails with the wood all burned away, but with the nails still standing up in a compact mass, retaining the shape of the keg, owing to the fact that they had been partially welded together. In other places kegfuls of nails which had evidently fallen at least one story, and possibly several stories, into the basement of an adjoining building, had nevertheless retained the form and size of the keg, although some of the nails were loosened. I also saw a number of cast-iron radiators that were partially melted and some cast-iron soil-pipe fittings that had been melted to such an extent that it was not possible to tell what sort of fittings they had been. In some cast-iron columns which had been softened and broken in the fire the raw edges of the break were appreciably rounded and blunted, due to the incipient fusion of the metal. In the basement of an iron warehouse I saw a number of racks of steel bars which had apparently been precipitated from the first floor and which were to a considerable extent welded together. The weld was not perfect, of course, but. at some of the points where the welds occurred it would have been impossible to separate the bars without considerable damage.

Glass of all kinds melted and ran freely. Lead sash weights melted and ran out of the window boxes before the timber of the boxes was entirely consumed. Several witnesses, among them an engineer officer, told me that they had observed this phenomenon in a number of places. The sheet-metal cases of typewriters and similar articles of 
sheet metal, though they showed no evidence of melting, had been almost completely burned up, so that they were full of holes, and the metal itself presented the same appearance as iron that had been burned in a blacksmith's forge. In the warehouse of the Waterhouse \& Lester Company, on Howard street, some racks of steel bars were precipitated into the basement when the building collapsed. These bars were partially welded together by heat. (See also Pl. LI, B.) In the ruins of glassware and china stores the glass, as a rule, was completely melted, and many articles of porcelain ware had become softened and distorted in all manner of shapes, indicating a high temperature, as porcelain is made of very refractory material.

All things considered, I am inclined to think that temperatures considerably in excess of $2,000^{\circ} \mathrm{F}$. were not at all uncommon in the San Francisco fire, although there were manifestly, in the burned area, places where no such temperature was reached. Very few office buildings were subjected to such intense heat, except here and there in individual rooms, where there was evidence of the storage of records or other combustible matter in large quantities; but the department stores, dry goods stores, and other buildings of mercantile occupancy evidently suffered from temperatures at least as high as $2,000^{\circ} \mathrm{F}$. In mercantile buildings these high temperatures seemed to be the rule and not the exception.

\section{EARTHQUAKE- AND FIRE-RESISTING QUALITIES OF STRUCTURES AND STRUCTURAL MATERIALS.}

\section{EFFECT OF FIRE ON GOVERNMENT AND "CLASS A" COMMERCIAL BUILDINGS.}

So far as resistance to the fire is concerned, the only buildings that presented anything of interest were naturally the monumental public buildings and the commercial fireproof buildings of the better class; that is, practically of class A. The fire did not succeed in entering the mint nor the appraisers' stores. It got into the upper story of the new post-office building at one corner, and cleaned out a court room and its adjoining offices; but it was held at this point, and the post-office building itself was not involved in a fierce conflagration such as that which ruined many of the commercial buildings. The fire got into the new city hall, and succeeded in wrecking the portion which was not ruined by the earthquake.

\section{VAULTS AND SAFES.}

In many of the office buildings in San Francisco suites of offices were equipped with vaults, some of which were fairly capacious and provided with doors of more or less efficient appearance, a number of them having the ordinary vestibule, with both inner and outer doors. Where the interior partitions of the building consisted of metal 
furring, lathing, and plaster, the walls of the vaults were likewise of these materials. Where the interior partitions consisted of hollow tile, the walls of the vaults wiere of hollow tile also. Although I examined a great many, I did not see a single vault partitioned off either with metal lathing and plaster or with hollow tiles that preserved its contents. I was informed by some gentlemen, who were apparently connected with the Spring $\cdot$ Valley Water Company, that on the top floor of their building a vault walled off with hollow tiles had protected its contents, but that the corner of the building in which it was situated had not been completely gutted, so that the vault did not receive a severe test.

In the Baltimore fire there were a number of vaults walled off with hollow tiles, and all that I happened to see during my inspection of the ruins in Baltimore had failed. The same thing was in evidence everywhere in San Francisco, and it is my opinion that this result could have been predicted with absolute certainty at the time these vaults were built, from data then available. To all external appearances, no doubt, the vaults looked like secure places in which to keep valuables; as a matter of fact, they were the flimsiest kind of shells, not capable of resisting any sort of determined attack from either fire or burglars. The tenant would have been better off withcut the vault, for in that case he would probably have carried his papers to some other point where they would have had a better chance to escape the fire.

The only vaults I saw that came through a really fierce fire without damage were those built of brickwork (Pl. LII, $A$ ). Even these vaults did not always protect their contents, however. I saw a number of them opened in which the contents had been totally destroyed. As they seemed to be fairly good vaults, this result was a matter of more than ordinary interest. I therefore carefully examined a number of them and discovered that the fire had gained access through cracks due to settling, or to the earthquake, or else through unfilled joints, due to poor workmanship in the original construction of the vault. It appeared that probably the contents of the building were burning fiercely around the vault before the floor above had burned out or collapsed, so as to give full vent to the gases of combustion. Some pressure must have been generated by the great heat thus confined, and under this pressure the incandescent gases resulting from the fire found their way through the smallest and most tortuous passages in the brickwork. In several cases it was apparent that the contents had probably been ignited by a small tongue of flame (probably not thicker than a lead pencil) penetrating into the vault as a result of such conditions.

A few vaults failed owing to the fact that the outer door warped and pulled away from the frame. Whether this warping could have 
been prevented with an adequate number of bolts I do not know, but in an important vault it would seem worth while to have the outer door at least filled in the same manner as the door of a fireproof safe. If it were built in this way it would probably not warp-at least not enough to let the fire in.

To judge from the safes which I saw opened, very nearly threefourths of the safes in the San Francisco fire failed to protect their contents (Pl. LII, $B$ ), and as a result the loss of valuable papers and records must have been very, extensive.

\section{BEHAVIOR OF STRUCTÚRAL MEMBERS AND MATERIALS.}

The commercial fireproof buildings in San Francisco, in my judgment, suftered considerably more damage than corresponding buildings in the Baltimore conflagration. In the San Francisco fire, for the first time, the collapse of protected steel frames, due to the destruction of the fireproof covering at a comparatively early stage in the fire, was a matter of common occurrence. Practically all of the floor construction in fireproof buildings in San Francisco consisted either of hollow terra-cotta flat arches or of reenforced-concrete slabs, carried on steel floor beams. In a few buildings steel columns and girders were used, with reenforced-concrete beams and slabs covering the space between the girders. Steel girders were more generally protected with metal lathing and plaster, or with solid concrete filling, than with anything else, but terra-cotta covering was also used to a considerable extent. The lower flanges of beams were in some buildings unprotected; in others they were covered with metal lathing and plaster; and in still others (a rather general practice), there was a ceiling composed of light furring angles and metal lathing, fastened below the floor construction and plastered. Most of the steel beams and girders in the floor construction had no other protection for their lower flanges than this furred ceiling, even where the webs were protected by a solid concrete filling.

Columns were generally protected in one of three different ways, as follows:

1. With hollow tiles adapted to either a circular or square section, the webs being about five-eighths of an inch thick, and the total thickness of the tile, including webs and hollow space within, being about $2 \frac{1}{2}$ or 3 inches. The tiles were from 12 to 18 inches in length and about 12 or 15 inches wide.

2. With metal lathing and plaster surrounding the column, so as to leave an air space of about 1 or $1 \frac{1}{2}$ inches.

3. With a solid covering of concrete from 2 to 4 inches thick.

In addition to this protection the columns in the walls were generally covered with 4 inches of brickwork, and in one building there was a double covering of metal lathing around isolated columns, the 
inner covering having one coat of plaster applied and the outer covering having the full two or three coats required for the finishing, as the case might be.

In a general way, practically none of the column protection in San Francisco, except the 4-inch brick covering, was adequate. The coverings of terra cotta and of metal lathing and plaster failed absolutely. Although there were a great many individual columns protected with other coverings which suffered only small damage, the number in which the protection completely failed was so great that the statement is entirely justified that practically all the coverings were wholly inadequate to resist any real fire test. The wall columns covered with 4 inches of brickwork were, except in one building, fairly well protected, so far as I was able to determine. None of the columns covered with cinder concrete suffered any serious damage, but there were not many columns protected in this way. Of the three buildings in which I particularly noticed such covering, two had evidently not experienced any great heat. In the third a column covered with 4 inches of cinder concrete had undoubtedly been subjected to a heat that was very intense. The concrete covering was seriously damaged; the column, however, had not suffered. This case is described on page 79 .

Interior partitions in San Francisco were built almost entirely of hollow tiles similar to those used for making square coverings on columns, or else of light metal studs covered with metal lathing and plaster. A few were built of brickwork. In a general way it may be said that practically all the interior partitions that were not built of brickwork were a total loss, being absolutely inadequate. In my judgment, the burning of the contents of a single well-filled office room would have developed in the majority of buildings enough heat to get through the surrounding partitions.

The furred ceilings already described were also very largely a loss. In buildings that had been occupied for ordinary office purposes, probably not more than 20 per cent of the furred ceilings absolutely came down; the remaining 80 per cent stayed in place, with complete loss of the plaster, the metal furring and lathing, however, being in shape to use again with only minor repairs. But wherever the amount of combustible matter was evidently greater than that ordinarily found in offices, the entire furred ceiling-metal lathing, furring strips, and all — came down bodily and was a total loss.

. So far as I was able to determine, the earthquake did not cause the collapse of any of the floor construction or partitions in any of the fireproof buildings, but it must have shaken a good many of the partitions badly, so that their destruction by fire was rendered somewhat more easy: The earthquake damage, however, only hastened the result. Partitions of the kind that were used in San Francisco 
are not fireproof, and a very hot fire will invariably destroy them, notwithstanding the fact that they are made of noncombustible material. I had rather expected to find that some damage had been done by the earthquake to floors made of hollow tiles or brick arches. That no such damage occurred was a matter of some surprise, and indicates that the vertical component of the undulation was not very great. It is probable that the earthquake caused some cracks to appear in the floors, but I did not see any which could with certainty be ascribed to this cause. It was also a matter of some surprise that some of the partitions were not shaken down by the earthquake, considering the ease with which the fire destroyed them.

So far as fire damage was concerned, the floor systems in San Francisco stood better than any other portion of the fireproof buildings, although they did not stand very well, at that. The lower webs came off from the hollow-tile floor arches in the same way that they did at Baltimore, but to a very much greater extent. The cinderconcrete floor slabs in many buildings were protected for a time by the furred ceilings previously described. Where the ceilings failed at an early stage, or where there had been no such ceilings, the damage to the concrete floor slabs was very apparent. The concrete was dehydrated to a certain extent on its lower surface, and in many of the slabs the reenforcement had become so hot that there was a permanent deflection of greater or less extent, accompanied by cracks on the lower side in the middle of the span.

Just how much damage was done by the fire to cinder-concrete slabs was a little difficult to determine, for the reason that most of the cinder concrete used in San Francisco was evidently a very inferior article in the first place. There was no doubt in my mind, however, that the concrete near surfaces which had been exposed to the fire showed deterioration, as compared with that which had not been exposed to the fire, although it was all so poor that there was not much room for difference in quality. I saw reenforced-concrete floor slabs, some of cinders and some of stone, which were on the point of collapse from heat alone, although they had not quite let go.

I also saw a number of terra-cotta floor arches which had totally collapsed. Some of these showed evidence of damage by masses falling from above, but in others the collapse seemed to have been due to heat alone.

Girder and beam protection was a little more efficient than the column coverings, but it was not adequate. Its weakness was not fully developed, because, in many places where the necessary heat existed, the columns failed first and let down the floors, so that it was not possible to say how much of the damage to the floor members was due to heat alone. In a general way, however, it may be said that girder coverings of metal lath and plaster. were wholly inade- 
quate, those of hollow tiles suffered serious damage, and those of solid concrete failed a little more commonly than they should, although they were the best of all. Many girders that had been covered with metal lath and plaster were badly warped and deflected, and some wholly collapsed, from the heat alone. Many beams were seriously deflected from the heating of exposed lower flanges.

I was not able to learn that any. serious damage had been done to column coverings by the earthquake. In some buildings columns which had not been exposed to much heat happened to be standing with their covering absolutely intact, while another column not far away in the same story of the building and evidently subjected to an intense heat had not only lost its covering, but had itself been practically destroyed by the fire. In no such case was I able to discover any evidence of earthquake damage in the covering that was intact, and there was nothing to indicate that one column might have had its covering damaged by the earthquake, while its neighbor escaped. More detailed information rèlative to fire damage is presented in the discussion of the individual buildings (pp. 76-108).

The earthquake did a great deal of damage, which could easily be differentiated from that due to the fire. As a rule brickwork in San Francisco was laid in lime mortar or in lime mortar gaged with a small amount of Portland cement. Wherever such masonry was subjected to serious earthquake shocks it was very badly shattered. Much of it came down in the ruins, and much of that which remained in place was reduced to a loose pile, without any adhesion between the mortar and the bricks. The bricks in general were more or less misplaced even where they did not come down, and many of them were broken. Where brickwork was solidly laid up in good Portlandcement mortar, if the earthquale shock induced stresses sufficient to damage it, the damage generally appeared in the form of well-defined cracks, which could have been easily pointed up, so as to leave the wall almost as good as it was before.

Well-executed stone masonry subjected to earthquake shocks showed, in many places, considerable slipping of the individual stones, the adhesion between the stones and the mortar having been destroyed. Here and there, where the strength of the mortar approached that of the stone, the stone itself was badly shattered and cracked. Where the wall ran in the direction in which the undulation seems to have been propagated, it generally showed an $\mathrm{X}$-shaped crack (Pl. XXII, $A$ ), the legs of the $\mathbf{X}$ crossing the affected area in a diagonal direction. Where the masonry was very good these cracks were the only apparent damage, but where it was not so good the individual stones, bricks, or tiles, as the case might be, had been loosened from their beds and broken, so that the entire mass was shattered, although in many places still standing. 
In steel-frame buildings put up in the ordinary way, without any special bracing, most of the earthquake effect was localized in piers between windows, as if a horizontal force had been applied to the floor above, tending to slide it with reference to the floor below. As this effect occurred in both. directions, the piers referred to were generally marked with $\mathrm{X}$-shaped cracks, and in addition the masonry was apt to be very much shattered. There seemed to be no general rule as to the place where this shattering effect occurred. In some buildings the piers in the one or two stories near the middle of the height of the building seemed to have suffered the most; in others, the piers nearer to the roof. One tall building, which extended far above its neighbors, was seriously damaged in practically every story above the neighboring buildings.

It was apparent that in some buildings the shock was so severe that probably no structure, however well built, could have withstood it absolutely without damage. It was equally apparent, however, that such great exhibitions of energy were confined to small areas, and that it would be possible to put up buildings in San Francisco which would come through a similar earthquake with very little damage except to individual buildings here and there.

Hollow-tile work seemed to be badly shattered by the earthquake in a great many places. Well-executed stone masonry, as a rule, stood better than brickwork. Brickwork built with good hard bricks, laid in Portland-cement mortar, stood better than that built with inferior bricks or inferior mortar.

Of all the structures which were manifestly exposed to severe shock the concrete buildings at Palo Alto stood best. It would seem to be a general rule that increased tensile strength, even in a brittle material, greatly increased the resistance to earthquake shock. The height above the ground at which the damage was greatest appeared to be largely a function of the distribution of mass in the structure itself, combined with the distribution of the bracing. If the base of a tall steel-frame building were subjected to a vibration tending to tilt it, manifestly some time would be required to set the upper part of the building in motion. As the vibration evidently occurred in both directions, there would be a reversal of motion before the upper part of the building had responded to the first impulse. Under these circumstances there would be established somewhere a center of oscillation, where very severe stresses, due to the acceleration of the superincumbent mass, would be largely concentrated.

It might have been supposed that most of the destructive effect of such action would be manifested at the joints in a steel-frame building; but around the joints are concentrated the ends of the floor beams and girders, together with the floor construction, and at the level of these joints is the only portion of the walls which is per- 
fectly solid. The shafts of the columns at about midstory height are therefore less efficiently braced than the portions on a level with the floors. Moreover, it is probable that the play in the connections of the steel work at the floor level would permit a little motion here without any damage, provided, in the meantime, the bracing at midstory, due to the masonry, is sufficient to preserve the structure from collapse; thus the connections would escape without material damage. As a matter of fact, some such action seems to have taken place. There was very little damage at the points where the steel work was fastened together; at least, very little that was apparent.

The failure of the masonry in the piers seems to have prevented the columns from being broken across in the middle or permanently deflected. It is an interesting speculation how near some of the unbraced steel-frame buildings were to total collapse under the stresses above described. In my judgment many of them were a little too near for safety. I saw a number of field bolts or rivets that I thought had probably been sheared by the earthquake, but as to most of them I was not sure that they had ever been in place. In one or two instances, however, the earthquake effect was indisputable.

As it is very difficult to discuss the earthquake effect in a general way, however, it will be taken up further in connection with the subjoined detailed description of the effect of the earthquake and fire on individual buildings in San Francisco. .

\section{BEHAVIOR OF INDIVIDUAL STRUCTURES.}

\section{ACADEMY OF SCIENCES BUILIDING.}

The Academy of Sciences building, on Market street, was interesting because of its interior construction. This building had castiron concrete-filled columns and Ransome reenforced-concrete floor construction. So far as it was possible to ascertain, no damage was done to the reenforced concrete or to the columns by the earthquake. The building was gutted and the floors considerably damaged by the fire, but the columns were not damaged, and on the whole the building stood very well. A very good view of this building was given in the Engineering News of June 7, 1906, page 623. (See Pls. XXIV, $A ; \mathrm{XXV}, B$.)

AETNA (YOUNG, OR COMMISSARY) BUILDING.

The steel-frame structure at the corner of Spear and Market streets, locally known as the "commissary building," because it was said to have been erected originally with a view to furnishing offices for the Commissary Department of the Army, rests upon piles, and suffered relatively small damage from the earthquake. Pl. 
$\mathrm{XXV}, A$, shows the corner of the building and the subsidence of the street at this point. The inlet at the corner indicates the original level of the street. There was a vault under the Market street sidewalk, immediately behind the wall at the curb line. The basement floor in this vault was of concrete and had a total thickness of 7 or 8 inches. The earthquake caused the earth to bulge up in the portion of the basement under the sidewalk, rupturing the concrete floor and turning it up on its edge, so that where there had previously been a clear headroom of $7 \frac{1}{2}$ feet the highest point of the bulge was within $3 \frac{1}{2}$ feet of the beams carrying the sidewalk. The columns were of steel, protected with expanded metal and plaster. The girders were of steel and the space between them was spanned by reenforced-concrete construction. The reenforced-concrete beams were formed on the lower edge by a curved piece of flat steel (Pl. $\mathrm{XXIX}, B)$. The concrete floor construction was damaged by the heat to such an extent that a heavy load of sheet iron on the third floor broke through, though it did not fall through bodily. The expanded metal that was used for reenforcing the slabs from rib to rib evidently got hot and was ruptured at this point.

The cinder concrete used in the floor construction of this building was badly damaged by the heat; although the heat could not have been very intense, as otherwise the ribs, with their exposed metal reenforcement, must have failed. Moreover, the girders did not have their lower flanges protected, yet they remained straight. A great many of the ribs, however, were deflected very considerably, but, owing to the fact that they were curved to begin with, this deflection, due to the fire damage, was not very apparent. The columns themselves were practically uninjured, although the column covering was severely damaged and will probably have to be totally renewed. There were some terra-cotta partitions, terra-cotta furring, and furred ceilings in this building, all of which totally failed. The brick wall at the west side of the building exhibited some earthquake cracks, and at a number of places the brickwork spalled under the heat.

\section{APPRAISERS' WAREHOUSE.}

The appraisers' warehouse was a very heavy structure, built on the old-fashioned monumental plan. (Pl. XXVIII, A.) It was entirely of brickwork, with some stone trimmings, and the exterior brickwork was laid with full header courses. It was practically undamaged by the earthquake, the chimney even being left standing, and the fire did not get into it. It is probable that the shock. at the site of this building was not so severe as it was at some other places, or the chimneys, at any rate, would have been thrown down. The building itself shows a very few slight cracks, which may have been due to 
ordinary settling and not at all to earthquake. Mr. Roberts, the local representative of the Supervising Architect's Office, informed me that rluring the construction of the building there had been some unequal settling, so that one end was about $1 \frac{1}{4}$ inches lower than the other, but that this settling had been at a uniform rate from one end to the other, so that it had caused practically no damage. On the interior there were many solid brick partitions, with some unprotected castiron columns. The floor construction was of steel or iron beams and segmental brick arches with a span of 3 to 6 feet.

It is worthy of note that immediately after the earthquake and fire three of the very few buildings in the burned district which were absolutely open and ready for business in every particular were the post-office, the mint, and the appraisers' warehouse. The massive construction used in these Government buildings would appear to have been a very good investment.

\section{ARONSON BUILDING.}

The ordinary ten-story steel-frame structure at the corner of Third and Mission streets known as the Aronson Building had terra-cotta column coverings and partitions and cinder-concrete floors, all of which were of the types described in this paper as common in commercial buildings. The building seems to have been occupied for light commercial purposes, and the fire test to which it was subjected was therefore somewhat more severe than that prevailing in office buildings.

A column in the basement was buckled, and two of the columns on the first floor were badly buckled near the ceiling, as shown in $\mathrm{Pl}$. XXVII, $B$. These results, so far as the condition of the fireproofing is concerned, are typical not only of the other stories of the Aronson Building, but of similar work in other buildings throughout the burned district. Some of the work in the Aronson Building was not severely tested by the fire and was still intact. An examination of it shows that it was as well done as similar work in any other commercial building in San Francisco. Where the fire was not very hot this kind of fireproofing protected the steel and suffered not more than 10 or 15 per cent of damage itself; where the fire reached the average temperature the fireproofing suffered a loss of 50 to 100 per cent, and where the fire was a little hotter than the average the total loss of the fireproofing and serious damage to the steel work was not at all uncommon. Damage to fireproofing such as that here described occurred in the James Flood Building, the Emporium Building, the building of the Spring Valley Water Company, the Mills Building, and every other building in which hollow tiles were used.

The buckled column in the basement was about the worst example of this sort of damage that I discovered, although I am inclined to 
think that in one or two other buildings in which there was a general collapse of the steel superstructure worse columns than this one could have been found under the débris. The débris was not cleared away while I was in San Francisco, so I had no opportunity to see the condition of many columns that had evidently failed.

The basement of the Aronson Building was divided into several rooms by hollow-tile partitions. The room in which the buckled column was located had evidently contained an enormous amount of paper in some form or other, and the heat generated must have been very intense. The fire broke through the hollow-tile partition which separated this room from the adjacent one, but there was very little that was combustible in the latter, and the column standing there had its fireproof covering entirely intact. Examination showed that the work in this building was neither better nor worse than the average of similar work anywhere else in the. San Francisco commercial buildings. A plain and inevitable inference is that wherever such work was practically undamaged the fire test was not at all severe.

In the same part of the basement as that in which the abovementioned column was situated-that is, under the Third street wall of the building - there were two columns covered with cinder concrete. The concrete covering on one column made a very large and heavy pier; on the other it was about 4 inches thick. It was apparent that the heat in this front portion of the room was not quite as severe as it was farther back, where the buckled column was. Not only was there very much less evidence of fire in the way of ashes, etc., but the general indications pointed to a considerably lower temperature-although the heat at this point was very severe, nevertheless. The larger cinder-concrete pier was evidently damaged to some extent by the heat. The cement had apparently been dehydrated to a depth of one-fourth to three-eighths of an inch on the flat surface, and to a greater depth at the corners. The other pier showed more evidence of intense heat. It stood opposite the middle of the room, where there seems to have been the greatest accumulation of combustible matter. When I first saw this column the cinder concrete was dead and friable to a depth of nearly an inch. How much of this was due to original poor quality and how much to the action of the fire was difficult to determine, but fire damage was very evident. This pier showed on the surface a number of longitudinal cracks running from top to bottom, indicating that there had been a tendency for the concrete to fail and come off under the expansion stresses. At a later inspection a part of the concrete covering of this column had been knocked off, and it then became apparent that the cracks above referred to had extended entirely in to the surface of the column itself, and enough heat had got in to partly burn off the paint along the inner edges of the cracks. 
The stairways in this building had apparently been partitioned off by hollow-tile partitions, but these were totally wrecked, and the stairways were in such condition that it was only with great difficulty and by going on all fours that they could be used to reach the upper story. In the west wall of this building I saw the remains of a wire-glass window, with metal sash and frame, which had been practically destroyed by the heat-probably, however, as a result of a simultaneous attack by the fire from both sides. Wire glass seems to have done some good service in other buildings in San Francisco, although in the Merchants' Exchange, as in the Aronson Building, it failed completely, so that a constructing engineer, who had drawn his conclusions entirely from what he saw in the Merchants' Exchange, was disposed to condemn wire glass outright.

BULLOCK \& JONES BUILDING.

The steel-frame Bullock \& Jones Building was faced with ornamental terra cotta, with hollow-tile column covering and reenforcedconcrete slabs which were haunched on the beams, the slab reenforcement apparently not being continuous over the tops of the beams. Some of the floor slabs collapsed, and the column coverings failed entirely. Two columns in the third story had buckled in the same way the columns buckled in the Aronson Building. This building was rather more flimsy even than the average commercial building, and the fire nearly brought it down. Pl. XXVI, $A$, is an interior view showing the buckled columns in the second story. It will be observed that pipes were run up inside of the column coverings. Where similar conditions existed in Baltimore it was maintained by those interested in the particular system of column covering used that the pipes had got hot, expanded, and thrown the covering off. My own opinion was and is that the covering must have failed first, otherwise the pipe would not have become hot. It may be that after the covering had partially failed, the pipe got hot and completed the destruction, but if the covering had been efficient to begin with, there would have been no trouble with the pipe.

A comparison of the conditions in the Bullock \& Jones Building with those shown in other views for example, in the illustrations of the Aronson Building-is sufficient to justify the opinions herein expressed. P1. XXVI, $A$, shows that one of the panels of the floor system had collapsed. My examination of the Bullock \& Jones Building indicated that the reenforced-concrete floor construction was haunched on the lower flanges of the floor beams. The photograph confirms this observation, as will be seen by examining the naked floor beam which appears in the lower left-hand portion of the view. The reenforcement of a floor slab should always be con- 
tinuous over the top of the beam; otherwise the construction is nothing but an arch, and develops the thrust to be expected of an arch. Moreover, as a rule, tie-rods are omitted when reenforced-concrete floor slabs are used, and it was naturally to be expected that reenforced-concrete floor slabs of this type would collapse to some extent; the wonder is that they did not collapse to a greater extent in the Bullock \& Jones Building. The fire damage to ornamental terra cotta in this building was very conspicuous.

\section{CALL BUILDING.}

Of all the commercial buildings in San Francisco, by far the most interesting was that known as the Call (or Spreckels) Building, at the corner of Third and Market streets. This building is remarkable for the care and skill shown in the design of its steel work. It is a steel-frame building, all the walls, floors, partitions, etc., being carried on steel work. It has 15 main stories, in addition to the stories in the dome, or cupola, and rests upon a continuous foundation composed of concrete reenforced with steel beams. The building proper is about 75 feet square, but the foundation is about 90 by 110 feet, and was carried to a depth of about 25 feet below the sidewalk level. A fairly complete and satisfactory description of this building was published in the Engineering Record of April 9 and 16, 1898.

In the first four stories above the street the bents of the steel work adjacent to the four corners of the building on each side were braced with solid portal braces. In - addition, eight interior bents were braced with diagonal tiebars from top to bottom. At all junctions of girders and beams with columns knee braces were used. The design of this steel work is well worthy of study by anyone interested in such structures. It is probably, on the whole, the best-designed piece of such work in the United States. Another remarkable thing about it is that the execution was apparently as good as the design. In a number of places where the fireproofing had come off the connections were exposed, and the workmanship here seemed to have been practically as good as it could well be made. I particularly noticed the column bearings, and they seemed to be absolutely close and true. Inaccurate column bearings in building work are so often seen that one is almost justified in saying that they are the rule rather than the exception; but in the Call Building such connections as were exposed to view had been put together with extreme accuracy.

The column covering in this building was of hollow tiles, about 3 inches thick, with very thin webs. Partitions were built of the same material. The floor construction was of reenforced cinder concrete. Some furred ceilings composed of wire lathing and light furring strips were also used. The outer walls were furred with 2-inch 
hollow tiles. When I saw the building the column coverings and partitions throughout were either down or so badly shattered that nearly all of them would have to be taken down and rebuilt, and the furring had fallen from many of the outer walls. The chief engineer of the building stated that it was practically undamaged immediately after the earthquake, and that the fire which subsequently gained access did not damage it very much, but that a large part of the ruin of the partitions and column coverings was due to the concussions from the dynamite used in demolishing dangerous walls in the neighborhood.

The hollow-tile covering of the steel work came down pretty generally throughout the building. Whether or not this failure resulted from the fire, close examination of the steel work proved that the tile covering was totally inadequate, because in many places there had been heat enough to burn the paint entirely off the steel and to leave indications of high temperature on the metal itself. Photographs taken of the Call Building during the progress of the fire indicate that the fire was not very fierce, yet, in my judgment, some of the steel members were very close to serious damage as a result of it. So magnificent a piece of steel work deserved better fireproof covering than it had; but, as a matter of fact, the steel itself was observed to be fire blackened in many places. The furred ceilings in this building in general suffered so.much damage that they should be taken down altogether. The marble finish throughout, while not absolutely destroyed, was so damaged as to be worthless. The reenforced-concrete floor slabs stood fairly well, but some of the concrete looked as if it had suffered appreciably from the heat.

On the exterior the Call Building showed absolutely no damage from the earthquake except in the story immediately above the main cornice, where, in the parts adjacent to the four corners, a few stones had evidently slipped so that the joints had opened up for possibly half an inch or more. The exterior of the building was faced with the grayish-green sandstone which is used for so many buildings in San Francisco. This stone, wherever the fire struck it, not only spalled very badly, but had its color very largely burned out, so that what remained was a dull and lifeless buff gray, the green having totally disappeared.

Examination of the Call Building from the exterior produced the impression that it was slightly out of plumb to the southeast, but later information showed that this estimate of the direction in which the building leaned was incorrect. Captain Kelly kindly sent a man with a plumb line to verify the observation. He plumbed the building from the tenth floor, as its dimensions were reduced somewhat above this point. He found that the building leans uniformly toward Market and Third streets; at the tenth floor the building overhangs 
Market street by 8 inches and Third street by 10 inches. This indicates clearly that it is not safe to trust the eye in the matter of a building out of plumb, because when previously examined-not only once but several times-the Call Building presented the appearance of leaning away from Market street instead of toward it. In my judgment the deviation from the vertical in this building may have been due in whole or in part to the earthquake, but it is not at all impossible that it may have been built out of plumb. With the rigid type of connections used in the Call Building, strict mathematical accuracy of construction at all points would be essential to insure the exact perpendicularity of the building. As this accuracy is practically unattainable, it is ordinarily necessary to accept slight deviations from the plumb line and probably, in the majority of cases, a certain amount of torsion in the frame itself. So far as these deviations are kept within reasonable limits they make no serious difference, and the building is just as good for all practical purposes as if it were perfectly plumb and true.

On the whole, the foundations and steel frame of this building were admirably designed. The bracing of the steel work seems to have taken up the vibration due to the earthquake, so as to preserve the masonry of the outer walls. As long as there is no deflection sufficient to crack the masonry, there.can be no doubt that the building is safe. It is a question whether other buildings which were not so well braced, and in which the piers between windows were badly shattered, were not dangerously near collapse, and it may well be doubted whether there is not serious damage to the steel work as it is. This matter could be determined only by uncovering the steel and making a detailed inspection.

The only safe plan in the construction of steel-frame buildings is the one followed in the Call Building-that is, to brace the steel work so that by itself it is able to resist the stresses due to the vibration. The engineer who designed the foundations and steel frame of this building may well be gratified at the admirable manner in which his structure fulfilled its purpose: Had the building been as well designed to resist fire as to resist earthquake, it is probable that the total damage would have been very much less than it was.

CHRONICLE BUILDINGS (OLD AND NEW).

The old Chronicle Building ( $\mathrm{Pl}$ XXX, $B$ ) seems to have been built in two parts-a west and an east wing. The west wing had protected cast-iron columns, rolled beams, and terra-cotta fireproofing. The interior structure had entirely collapsed, apparently from the heat. It was impossible, with the débris piled around it, to determine just what the cause of the failure was, but it was probably 
due to the buckling or rupture of a lower-story column by the fire. In the east wing of the old building the terra-cotta fireproofing had suffered, to a considerable extent, the typical damage which is described in connection with the Aronson Building (p. 78) and in the general discussion of the subject (p. 72). Many floor tiles had lost their lower webs.

The new Chronicle Building (also shown in $\mathrm{Pl}$. XXX, $B$ ) was badly racked by the earthquake from the point where it rose above the neighboring buildings to the top. It seems to have been provided with knee braces tending to stiffen it in a direction parallel to the Kearney street front. In the first story, at any rate, there were some diagonal braces in the steel work of the north wall. The worst damage was to the masonry of the Kearney street front; the shattering of this masonry can be observed by a close inspection of Pl. XXX, B. This building was unfinished. It had hollow-tile fireproofing, including partitions. The burning out of the window trim and of whatever combustible matter may have been in the building, caused a good deal of damage to the hollow-tile floors, especially near the windows, where the lower webs came off almost completely.

The old Chronicle Building seems to have suffered very little from the earthquake, notwithstanding it must have acted as a buttress for the new building.

CITY HALL AND HALI OF RECORDS.

The new city hall in San Francisco (Pl. XXXI), together with the hall of records, which adjoins it and which formed practically a part of one and the same structure, was a massive brick building with steel floor beams. This building had corrugated-iron floor arches, leveled up with concrete. There were some naked cast-iron columns where the span from wall to wall was too great for the beams. All interior partitions of any importance were of brick and rather heavy. In the basement and subbasement the corrugated-iron arches were left exposed. Everywhere else there was a ceiling carried on a form of metal lathing consisting of sheets of metal crimped so as to form dovetailed grooves or ribs; the plaster, being pressed up against this lathing and into the dovetailed grooves, was enabled to hold on by the key thus formed. The girders in the building were protected by a wrapping of this metal lathing finished on the exterior with plaster. The brickwork in the city hall was made of a very good quality of common bricks. The mortar appeared to be lime mortar gaged with cement, and was distinctly superior to lime mortar pure and simple. The workmanship was also above the average. The bricks were not as well laid as they might be, yet it was not poor 
work by any means. I found a few places where joints were not well filled, but not a greater number of such places than one would expect to find even in fairly good work. On the exterior the building was finished with stucco, which was tinted to imitate the grayishgreen sandstone so much used for building purposes in San Francisco.

The city hall was of an irregular plan, as it was built on a triangular lot. The building contained in the western part an interior court, in which a nonfireproof structure had been erected prior to the earthquake and fire to accommodate the fire-alarm headquarters. On the southeast front of the building a little to the east of the center was a rotunda with a tower and dome above it. This tower was built of brickwork up to the base of the upper of two peristyles of free pillars around the outside of the tower. This peristyle was composed of steel columns covered with hollow tiles, so as to form a pillar of circular section with an entasis. The walls of the tower from the base of this peristyle up also seem to have been of hollow tiles. At the base of the dome was a floor composed of terra-cotta flat arches. It was reported that the masonry of the building had been reenforced to a great extent with embedded steel bars for the purpose of increasing its resistance to earthquake. I did not notice any such bars myself, but it was very difficult to get such access to the débris as would have permitted the verification of this point.

In a general way it may be said that the southwest half of the building was practically destroyed by the earthquake. The heavy masonry was thrown down, so that the entire southwest half of the tower was left entirely exposed, the dome standing on the steel work alone. The remaining half of the building showed considerable damage from the earthquake, but the principal damage here was due to the fire. Pl. XXXI gives a fair idea of the earthquake damage in the southwest half of the building.

It will be observed that some of the projecting pilasters on the exterior of the wall were badly cracked. A singular action of the earthquake, as exhibited here and in other places, was the tendency to shear off projecting pilasters even though they were built of the same material as the wall and well bonded to it. In my judgment this action was due to the fact that the earthquake caused the wall to rock slightly sidewise. When it rocked toward the side from which the pilasters projected, the entire weight would be for an instant concentrated on the base of the pilaster in such a way as to tend to shear it loose from the wall, which actually happened in many cases, the wall presenting no other evidence of damage whatsoever. Instances of this damage are pointed out in the discussion of other buildings.

Examination of Pl. XXXI, especially with a reading glass, will show that many of the diagonal braces in the steel work of the tower

7171-Bull. 324-07-7 
were stretched beyond their elastic limit. I found, on personal examination in the fleld, that many of the wind struts had almost slipped from their seats on the columns. The bolt holes or rivet holes intended for bolts or rivets to hold the struts in place between their seats were not filled. Whether this was due to the fact that they had been sheared by the earthquake or whether they had been omitted in erection, I could not determine definitely. The latter will seem a plausible supposition to anyone familiar with the way in which the average erecting gang does its work. A few of the wind struts had absolutely slipped from their seats and fallen down; but it was not possible to determine from the visible evidence whether this damage was due to the earthquake or to the precipitation of the mass of masonry upon the struts as a result of the failure of the outer walls. Examination of the diagonal tie-rods made it apparent that some of them may have been stretched and bent by the mass of masonry falling upon them, but that others had very clearly been stretched beyond the elastic limit by the vibration of the tower during the earthquake. In inspecting the inside of the rotunda I observed considerable earthquake damage to the tower, including the stretching of a pair of diagonal tie-rods in the dome by the impact of the falling material. The terra-cotta floor at the base of the dome was absolutely intact, so far as could be determined. I made an effort to get out upon the steel work of the tower to climb it, but could only get as high as the gallery in the rotunda on a level with the upper floor of the main building. The means of access to the higher points had been evidently destroyed by the earthquake. The portion of the tower above this point, however, was carefully examined through a very good field glass, which enabled me to see a great many. details practically as well as if I had been able to climb the tower itself. Among other things, it indicated very clearly that this terracotta floor was of a much better type than those ordinarily put into commercial buildings.

Around a portion of the rotunda there was an inner wall, built of hollow tiles, which the earthquake had so shattered that practically the entire wall would have to be taken down in order to make adequate repair. It will be noted by an examination of Pl. XXXI that the brickwork of the building fell and broke up into large masses. If it had been very poor brickwork it would have broken up, for the most part, into individual bricks, and the fact that it did not do so is proof that it was not of a kind to call for serious censure of the architect or contractor. There was practically no fire in the rotunda of the tower of the city hall. Opposite the main corridor connecting with the portion of the building to the north the varnish on the hand rail in the upper galleries was scorched, but on the main floor 
a temporary platform covered with bunting, which had evidently been used on the occasion of some meeting, was practically undamaged, except for the material which had been precipitated upon it.

The main structure of the building itself, to the southwest of the tower, as shown in the foreground and to the left in Pl. XXXI, was badly racked by the earthquake. There was very little damage from fire in this part of the building. Either the vibration due to the earthquake or the impact of falling material removed a good deal of plaster from the walls in the part of the building immediately behind the two columns that are still standing, with the portion of the entablature that they supported. A large part of the building was entirely gutted by the fire, so that, in my judgment, it would cost about as much to remove the débris and restore this building as it cost to put up the building originally.

. In the northwest corner of the building there was a pavilion which had a row of free columns still standing. In the middle of the west front of the building there had been a pavilion with a similar row of columns, all of which, with their entablatures, were precipitated into the street. These columns were composed of drums of cast iron with annular rebates which enabled them to be securely seated and centered on each other. The interior of each shaft was filled with broken-brick concrete of a very good quality. The columns were very heavy and massive, and it must have required an extremely severe shock to detach their entablatures from the rest of the building and then to throw the whole mass into the street.

The effect of the fire on the interior of the city hall was very interesting. Some parts of the ceiling remained in place sufficiently long to protect the corrugated-iron arches from damage; in fact, some of the ceiling did not come down at all. Such a case is presented in Pl. XXVI, $B$, which shows the incipient failure of a naked cast-iron column and a ceiling that was evidently on the point of coming down. Where the fire was intense it brought the ceiling down in time to permit serious damage to the corrugated-iron arches and their concrete filling. Wherever these arches were exposed directly to much heat the first-effect was to cause them to expand and rise at the crown, which generally resulted in shattering the concrete filling immediately over the crown. Further application of the heat caused the corrugated-iron arch to soften and come down altogether. When it did, the concrete followed it, the portion at the crown being too much shattered to act as a key. In this way the total collapse of large areas of floor construction in the city hall was brought about. The concrete arch would have stood better alone than it did with corrugated iron underneath it; indeed, it is doubtful whether any of the concrete arches would have collapsed but for the damage done by the expansion of the corrugated iron. The concrete was of a very fair 
quality and the arches were very heavy. Many of the floor beams were 24 inches deep, and that was consequently the depth of concrete at the haunches. The thickness at the crown seems to have been not less than 5 or 6 inches, and the span between floor beams was not more than 6 or 7 feet. A concrete arch of such dimensions and such span, even though it had been made of very poor concrete, should have stood perfectly well had it been depending on its own power of resistance alone. In a number of places where the floor did not collapse the effect of heat on the exposed lower flanges of the 24-inch beams was sufficient to produce a deflection of 6 or 7 inches on a span of 25 or 30 feet. This result indicates clearly the necessity of protecting the exposed flanges of all beams.

Pl. XXVI, $B$, shows some unconsumed papers about the base of the cast-iron column. These papers came from a vault which opened into this room and the contents of which were charred, but not destroyed; all the combustible contents of the room proper were destroyed. The dark splotches on the wall in the background are due to spalling of the brickwork at the surface under the influence of the fire. This phenomenon was noticed in a number of places in San Francisco, just as it was in Baltimore; but as a rule the spalling did not penetrate to a greater depth than half an inch, and the wall itself was practically as good as before. In the fire at San Franciseo, as in every other large fire, the right kind of brickwork proved to be more resistant than any other material.

A good deal of the plaster on the interior walls in the city hall was on wooden furring studs and wooden laths. Why this kind of work should have been done is beyond comprehension. Many of the corridors would have suffered practically no damage but for this one circumstance. As the fire burned out the wooden trim of openings between the corridors and the rooms it gained access to the wooden furring and burned it out behind the plaster, thereby bringing most of the plaster down. There were, however, many square yards still standing, although the wooden furring studs and laths had been burned out behind. There would appear to have been no reason for furring these interior walls; the plaster could just as well have been applied to the brickwork itself. As a matter of fact, in many parts. of the building it was so applied, though in other parts the walls were furred with metal lathing and studs. Why a uniform treatment was not adopted is not apparent.

The halls of the building were generally floored with marble tile. Even where the heat had apparently not been very intense these tile floors expanded and came up, and the marble was rendered chalky, while the color was completely ruined.

In this building a number of girders or lintels rested upon stone templates, which were exposed at the face of the wall. All such 
templates that were subjected to the heat were badly spalled and shattered, and one or two of them had failed sufficiently to permit the ends of the girders to settle an inch or more. I also noticed a number of places in the walls of the building where the fire had evidently found its way into the interior of unfilled joints through very small and tortuous passages.

The hall of records was connected with the city hall by means of an arcaded corridor. The building was circular and all the floors above the first were pierced so that they practically formed galleries. The beams supporting these upper floors or galleries were of steel, set radially and supported at their inner ends by girders carried on a peristyle of 12 circular cast-iron columns, which had no fireproof covering of any sort. The floor arches were segmental arches of common bricks. The lower flanges of the beams were exposed, but the evidence indicated that there must have been a suspended ceiling of some sort below the fireproof floor construction, although it was impossible to determine its nature. It is probable that it was carried on combustible supports of some kind, which have totally disappeared. As the records had been carried away from this building before the fire reached it the heat within it was not very intense and the interior: of the structure was standing in a comparatively undamaged condition, except for finish. The exterior walls, however, were badly shattered by the earthquake. The window shutters were of iron, and if they had remained in place, considering the situation of this building, would probably have kept the fire out. As indicated in the view, however, the earthquake wrenched some of these shutters, with their surrounding masonry, entirely out of the wall, thereby, of course, leaving easy access for the flames.

As previously stated, it is my opinion that to remove the débris and restore the city hall, including the hall of records, to its original condition would cost as much as the entire building cost in the beginning. As it was so badly damaged by the shock it would apparently be wise to remove it altogether and build a structure of another type designed to resist earthquakes.

COWELI, BUILDING.

No special interest attaches to the Cowell Building, except that it seems to have been more flimsy than the average. It had unprotected steel work and girders and wooden-joisted floors. The effect of fire on the unprotected steel work is well illustrated in Pl. LI, $B$.

\section{CROCKER BUILIIING.}

The Crocker Building had a steel frame and hollow-tile fireproofing. Some of the tile arches had totally collapsed, and over large 
areas-probably at least 30 per cent of the whole-they had lost their lower webs. There was nothing of special interest in this building more than has been described with other buildings. The damage seemed to be about as great as the average-probably more than 60 per cent.

\section{CROCKER ESTATE BUILDING.}

Pl. XXVIII, $B$, shows the kind of damage to ornamental terra cotta which is typical of both earthquake and fire action. This particular view was selected because it was possible to take it from a point near by so as to show the damage in detail. The Crocker Estate Building, a part of which is shown in the view, had cinderconcrete floor slabs, rolled beams and girders, and naked cast-iron columns. The fire was evidently not very hot in this building. The lower flanges of the beams and girders were covered with expanded metal and plaster. The webs of the beams were protected with cinder concrete built out solid from the webs to the edge of the flange. The rear portion of this building and a building of similar construction. on the east had largely collapsed, apparently as a result of the action of the fire on the naked cast-iron columns. At this and every other point where exposed cast-iron columns had failed it was often noticed that the heads of the columns broke off and remained attached to girders and beams by means of the lugs and bolts. This result confirms conclusions derived from certain experiments made a number of years ago, to the effect that the lugs, ribs, etc., at the heads of castiron columns are the source of severe shrinkage stresses, with consequent weakness in the column.

\section{DEWEY MONUMENT.}

The Dewey monument, in Union Square, is shown in Pl. XXX, $A$. Careful examination indicates that the upper stone of the shaft has slipped to the left by an appreciable amount-apparently about an inch. The second stone has slipped about three-fourths as far, and the third stone from the top about one-fourth of an inch. I was informed that there is a steel bar running up through the center of the shaft. This construction, if it was used, explains why the monument was not thrown to the ground, as it otherwise must have been.

\section{EMPORIUM.}

The Emporium was a large department store on the south side of Market street, between Fourth and Fifth streets (Pl. XXX.II). The only portion of its interior structure which remained had been carried by a steel frame. It is reported, however, that mill construction had been used for the upper stories in a portion of the building. It is also 
reported that this building was dynamited three times during the progress of the fire, although I was assured by a policeman, who claimed to have been on duty during the whole time, that this report was not true. Under the circumstances, it is a little difficult to draw a reliable conclusion from the state of affairs in the Emporium. However, examination of the ruins indicated very strongly that much of the trouble was due to the inadequacy of the fireproof protection to the steel work.

Pl. XXXII, $A$, is a general view of the collapsed portion of the building and illustrates the failure of the terra-cotta column covering in various stages. The hollow-tile end-construction arches in the mezzanine floor had collapsed over considerable areas, under the influence of heat alone, as the evidence plainly indicated that nothing could have been precipitated upon them and that they were not subjected to an explosion. A considerable portion of the rear wall of the Emporium, which had been thrown down, probably partly by earthquake and partly by the fire, presented one case of very excellent mortar used in a commercial building. The mortar was better than the bricks, and both were of good quality. The fireproofing in the lower part of the building was quite as good as that ordinarily found. in similar structures throughout the country. In fact, it would be easy to point out department stores not so well fireproofed as the lower part of the Emporium.

I have always been of the opinion that the Horne store in Pittsburg, which was the first large fireproof department store to be tested by fire, was really closer to collapse from the heat than is generally believed. After the covering has been stripped from a steel column, the time and heat required to bring it down are not very great. The fact that the covering comes off during a fire is . absolute proof that it is wholly inadequate. If the steel column stands up, notwithstanding the loss of its covering, it is due to good luck and not at all to good fireproofing. In the Forne store the covering was stripped from a number of columns; in the Emporium Building the same thing happened, but the heat continued a little longer, and there is no doubt in my mind, after an examination of the ruins, that at least a portion of the collapse was due to the failure of the columns under heat. The floor tiles in the Emporium Building lost their lower webs in large quantities, where the arches themselves did not collapse; and tiles in the column covering which did not come off bodily also lost their exposed webs in considerable quantities. The ruins of the Emporium were in a very dangerous condition, so that a detailed inspection was not practicable; and it is doubtful whether any useful results would have followed, because the fireproofing was of the ordinary commercial type which has often enough been proved inadequate to resist a serious fire. 
The lower two stories of the Fairmount Hotel (Pl. XXXIV) were of concrete. The next story, the first, was built of granite, apparently backed with brickwork, and above that the building was faced with ornamental terra cotta. The earthquake damage to this terra cotta was severe. Neither the granite nor the concrete walls of this building seemed to have suffered materially from the earthquake, but the granite was badly damaged by the fire. The building was surrounded by a wide open space, and the fire must have been very fierce in its vicinity to have ignited it. I was informed that considerable damage was done to the steel work and fireproofing in this building; but as the owners, or at least those in charge, objected to having it inspected, and as it was an unfinished building, I made no examination of its interior. If, under the circumstances, it suffered seriously from the fire, the only conclusion that could have been drawn was that the fireproofing was very poorly done.

\section{JAMES FLOOD BUILDING.}

The new James Flood office building, situated on the north side of Market street, opposite the Emporium Building, had a steel frame, segmental hollow-tile floor arches, terra-cotta column covering and partitions, and furred ceilings of metal lath and plaster. The hollow-tile column covering and partitions failed in this building in the same manner as in others, and to about the same extent as in the average building. The lower stories seem to have been occupied for mercantile purposes, and here the fire damage was greater than it was above. Pl. XXXV, $A$, is a view taken in the first story. of the Market street wing. The second and third columns from the front are slightly buckled to the right. They were covered with hollow tiles in about the same way as the columns shown in the Aronson Building. The columns in the James Flood Building were Z-bar: columns and were filled in solidly with brickwork, in addition to the hollow-tile covering shown in the view. In my judgment, this construction was the only thing that saved the Market street wing of this building from collapse, because there was every evidence that the columns which were found slightly buckled had reached a dangerous temperature, and would probably have come down and wrecked all of the building above them had it not been for the stiffening effect of the brick filling.

Pl. XXXIII, $B$, shows a doorway in the west front of the James Flood Building illustrating the damage by earthquake to the sandstone piers. The stone used in this building was the same grayishgreen sandstone that is described in connection with other buildings, 
and at each principal entrance there was a groined-arch ceiling made of it. These ceilings were so badly cracked and damaged that they will probably have to be taken down and rebuilt.

\section{GRAN'T BUILDING.}

The structure at Seventh and Market streets known as the Grant Building illustrated the capricious variation in intensity of the earthquake shock within short distances. This building was separated from the post-office by a very narrow street, hardly wider than an alley. The building had cinder-concrete floor slabs, furred ceilings in the upper stories, and terra-cotta partitions. Although it was a commercial building of very ordinary type, it was only slightly damaged by the earthquake, but was gutted by fire. It was entirely outside the area of surface disturbance, the streets in its vicinity showing no signs of settlement or upheaval. The fire was not very hot apparently, but was just about able to take the plaster off the under part of the floor construction without seriously damaging the latter. The terra-cotta partitions were all down. There was no evidence of superiority of construction, however, as everything pointed to moderate tests by both earthquake and fire.

\section{HALL OF JUSTICE.}

The Hall of Justice was one of the municipal buildings which was seriously damaged by the earthquake. A general view is shown in PI. XXXIX, $A$, but does not bring out the damage that really occurred. In the basement of this building was another example of buckled columns. The columns were covered with expanded metal and plaster. This covering failed at a point near the floor, and the columns buckled and sank, producing the same effect as if they had been punched into the ground. The column coverings throughout this building failed very generally from the fire.

\section{KAMM BUTLDING.}

The Kamm Building was situated on Market street, west of the Call Building. The rear portion was extended eastward by a short ell, so that it was wider than the front. It was occupied in the first story and basement by a wall-paper establishment. The columns were protected by metal lathing and plaster.

The burning of the wall paper in the basement caused general buckling of the basement columns to such an extent as to result in the collapse of all the interior framework of practically the entire rear portion of the building. A good view of this building is to be found in the Engineering Record of May 26, 1906, on page 645 . 


\section{KOHL BUILDING.}

The Kohl Building was of steel-frame construction faced with the grayish-green sandstone which is referred to so often. It had reenforced-concrete floors with furred ceilings and partitions of metal lath and plaster. The window frames and sash were metal covered, and there was very little combustible matter in the finish. The doors, with their frames and jambs, were of wood covered with sheet metal. It is manifest that this building was not subjected to very intense heat, as the windows above the fourth story were unbroken and the stone was comparatively undamaged. The first, second, and third stories were burned out, and there was some damage in both the fourth story and the attic.

The metal-covered doors in this building, however, prevented to some extent the spread of the fire within the building itself, so that where one room burned out, the fire coming in through a front window, an adjacent room was not burned because of the resistance offered by the door. The building could hardly have been subjected to a very fierce heat, however, for, if it had been, the light partitions would have failed, in which case the metal-covered doors would have been of no avail. Where the heat was really intense, the wood of doors, frames, and windows burned out under the metal anyway, but of course the metal covering delayed the ignition of the wood and later prevented it from burning freely.

\section{MERCHANTS' EXCHANGE BUILDING.}

The structure known as the Merchants' Exchange was a steelframe building with Roebling cinder-concrete flat floor slabs, double wire-lath and plaster protection for the columns, and partitions made of light furring irons, wire lath, and plaster. In some places wire lath and plaster were applied to both sides of the furring strips; in others the furring strips with the wire lath were simply plastered on both sides. This was one of the buildings in which the vault walls were made of the same materials as the partitions. Every vault in the building failed. All the partitions in the building were a total loss; not only did the plaster have to come off, but the metal framework had to come down also. The floor construction had a furred ceiling below it. The plaster had come down because of the heat on nearly all the ceilings, and probably as much as 20 per cent of the furring rods and wire lathing were down.

Large -areas of the face bricks were shaken from the wall of this building, owing to the fact that they were laid without bond. The rear wall was also damaged by the earthquake. The adhesion of the bricks and mortar seemed to be largely destroyed throughout the wall, 
without, however, producing any very large cracks. It is doubtful whether the wall is really safe in its present condition. On the inside of this building some of the wall columns were covered with 4 inches of brickwork projecting from the inner face of the wall as a pilaster. Some of these brick coverings had cracked almost entirely away from the main walls, besides being cracked vertically at other points in a manner similar to the cinder-concrete column coverings in the basement of the Aronson Building described on page 7.9. The brickwork in these places seemed to have been rather below the average in quality. It is not entirely certain whether the fire or the earthquake caused the cracks, but all the columns seem to have been uninjured, although the brickwork of one or two was so badly damaged that it ought to be taken down and rebuilt. Some enameled bricks were practically ruined by the fire, which stripped off the enamel face (Pl. XL, A).

MILLS BUILDING.

The large steel-frame Mills Building was without special bracing. The floors were of hollow tiles on the end-construction system, and the remainder of the fireproofing was likewise of hollow tiles. The tile arches lost their lower webs to a great extent, and some of them collapsed, apparently from heat alone; the column coverings failed very generally, and the girder coverings to a somewhat less extent (Pl. XLV , B). One basement column buckled under the action of the heat (Pl. XL, $B$ ). The conditions in the Mills Building as to column coverings and partitions were similar to those in the Aronson Building.

\section{UNITED STA'TES MINT.}

The mint was an old-fashioned monumental structure with granite walls and segmental brick-arch floor construction, carried on iron beams. A general view, showing the southwest front, is presented in Pl. XXXVIII, $A$. The building seems to have been practically uninjured by the earthquake, the only damage visible being at the base of the right-hand brick stack. It is probable that the shock at the locality of the mint was not so severe as it was at the new post-office building, although the two are only a few blocks apart; yet the result may be an indication that the solid old-fashioned monumental walls with the stonework solidly backed up by brickwork constitute after all one of the best types for resisting earthquake shocks.

It is somewhat surprising that the brick stacks were not overthrown, but I am informed that the thickness of the masonry in.these stacks was very great, which probably explains their stability. The northwest (Pl. XXXVIII. $B$ ) and northeast faces of the mint were 
considerably damaged by the fire, but the fire was kept out of the building proper by means of water from an artesian well equipped with fire pumps, located in the building.

\section{MONADNOCK BUILDING.}

The structure known as the Monadnock Building was an ordinary steel-frame office building, which was in process of erection. It was badly racked by the earthquake. Every one of the piers in which the earthquake cracks appeared was so badly shattered that no repairs short of tearing down and rebuilding would suffice. As a matter of fact, it is probable that adequate repairs to the masonry in the front wall of this building would involve reconstructing more than half of it. It would appear that there must have been rather severe vibration to shatter the brickwork so badly. Whether the steel escaped injury is a question of considerable interest, which can not be settled until the masonry covering is taken off.

\section{MUTUAL LIFE BUILDING.}

The Mutual Life Building was a steel-frame structure of the same general type as the Mills Building, and it suffered in the same general way, though possibly not quite so much. Some of the floor arches had collapsed, apparently from falling weights of some sort. (See Pl. XLII, A.)

\section{PACIFIC STATES TELEPhONE AND TELEgRAPH BUILDING.}

The Pacific States Telephone and Telegraph Building, on Bush street, illustrated the tendency of the earthquake to shear off projecting pilasters (Pl. XLI, $A$ ). This building had a steel frame, stoneconcrete floor arches, furred ceilings above the basement, and concrete column and girder coverings. The front windows were of plate glass in metal-covered sash, with rolling steel shutters on the outside. The side and rear windows were of wire glass in metalcovered sash and frames, with sliding tin-covered wooden shutters on the inside.

The window protection seems to have prevented the entrance of fire from the outside, but in some other way an interior fire was started which completely gutted the building. The interior fire practically destroyed the plate glass, but not the rolling steel shutters. It seriously damaged the tin-clad shutters, but did not damage the wire glass appreciably. Had the interior fireproofing been as efficient as the window protection it is doubtful whether this building would have been burned out, for the interior fire should have been confined to the place of its origin. For these probable facts as to the 
history of the fire in this building I am indebted to S. A. Reed, consulting engineer for the committee of twenty of the National Board of Fire Underwriters. Mr. Reed states, however, that the history of the fire here must be largely surmise, because reliable evidence was not obtainable.

This company had also a building with reenforced-concrete floor construction and wire-glass protection for its windows for: one of its branch exchanges. The exposure of this building was probably not very severe. It was three stories high and the fire got into the upper story and cleaned it out; but the floor construction prevented the fire from extending into the stories below, which suffered practically no damage to structure or contents. A part of the third-story wall was thrown down either by the earthquake or by some other means, and this damage may have opened a way for the entrance of the fire.

\section{PALACE hómet.}

All of the interior and the exterior walls of the Palace Hotel, on the south side of Market street, were built of brickwork. It is reported that the brickwork was reenforced with embedded iron bars. The structure stood remarkably well, and there is little indication of earthquake damage. The building was nonfireproof, and was, of course, completely burned out, but the walls still stand almost as good as ever. (See Pl. XXX, B.)

\section{POST-OFFICE BOILIDING.}

The steel-frame and granite post-office building (Pls. XLII, $B$; XLIII; XLIV) was carried on isolated grillage foundations, each column having its own footing. The diagonals of the building ran nearly north and south and east and west, the south corner being at Seventh and Mission streets. To the south and west of Mission street was an elongated, narrow, curved area in which the earthquake damage was very severe. It was commonly reported that this area, which was not far from the south corner of the post-office building, was a stream bed or ravine that had been filled within the recollection of the older inhabitants of San Francisco. Through the courtesy of J. W. Roberts, the local representative of the Supervising Architect's Office of the Treasury Department, I was enabled to make a detailed inspection of the building, and he also gave me very complete information as to the history of the building and the causes of the various items of damage which were in evidence at the time of my inspection. Mr. Roberts, who is evidently a cool and accurate observer, seemed of the opinion that the material under the building was a natural deposit, and not an artificial fill. But toward 
the south it was not of a nature to inspire confidence in its carrying power at the depth shown on the foundation plans. He accordingly obtained authority to lower the footings wherever the material at the depth shown on the plans seemed unreliable, so that the footings of the south half of the building were lowered-some of them, as I remember his statements, to a depth of 20 feet or more below the basement-floor level. At any rate, he carried them to a point where the material, in his judgment, was sufficiently hard and compact. All this underlying material is very sandy; but at considerable depths, I understand, gravel appears, and the combination is almost as hard as hardpan.

The walls, floors, and all parts of the post-office building proper are carried on the steel frame. The outer walls consist of a granite facing, carried on the steel work at each floor level. The granite is not backed up in the usual way, the backing having been omitted to save weight. Some distance behind the granite an inner wall was built of hollow terra-cotta blocks. The space between the granite and the terra cotta was used for the passage of pipes, air flues, etc. The granite was heavily anchored to the steel work. In a number of panels of the steel work corner braces made of a pair of channels were used, and they were fastened as far down on the columns and as near to the center of the wall girder that spanned the space between the columns as the window openings would permit. There was also some portal bracing in a part of the building over which it had been intended to erect a tower. This intention was afterwards abandoned, but I understand the bracing was in place. In a general way, panels of the outer wall in which the corner bracing was used suffered less than adjacent panels-especially in projecting pavilions, where there was no bracing.

Practically all the interior walls of the building above the basement were built of hollow tiles. The tiles were of excellent quality, with webs nearly 1 inch thick. The floor and roof construction was of clinker concrete, reenforced with expanded metal. Suspended ceilings of metal lath and plaster were very generally used. In the mail-handling room there were a number of isolated columns filled solid with clinker concrete and covered with 4 inches of enameled brickwork. The column covering was circular, the bricks having been made radial for this purpose.

The lower part of the column, however, was incased in a circular cast-iron covering made in halves and put together around the column. This casing took the place of the enameled brick up to a point above which injury from blows and abrasion was not likely to occur. There were also in the mail-handling room a number of circular shafts of enameled birickwork, with stairways inside, leading to the inspectors' galleries. 'The corridors of the building and the 
more important rooms had a great deal of expensive and beautiful marble finish; there was much marble-mosaic ceiling work, and the finished woodwork was of extraordinary richness. On top of the buildings were a number of chimneys built of granite blocks with terra-cotta linings.

All the materials entering into the construction and finish. of this building were the best of their kind, and the workmanship, under the efficient supervision of Mr. Roberts, was as nearly perfect as it is possible to make it. I have never seen work better done, and have rarely seen it so well done. To one who knows and appreciates good work it is a continual pleasure to see everywhere in the San Francisco post-office the record of sleepless vigilance and skilled labor. Where the structural parts were laid bare by the damage due to the earthquake, the same story was told by the minutest details as well as the roughest parts of the work-everything was the best of its kind. It is therefore of great interest to study the effect of the earthquake on this structure, for the care with which it was built must have made it fully as good as its designers could have hoped. Moreover, I am inclined to think that it received a more severe shaking than any other building in the congested district of San Francisco that was at all comparable with it. The city hall was badly racked, but, to judge from the condition of the adjacent street surfaces and the surrounding ruins, the shock was much less severe than that to which the post-office was subjected. For instance, there was a partially erected steel frame (Pl. XLII, $B$ ) on the southwest side of Seventh street, near the post-office. Before the earthquake all the columns were plumb and in true alignment. As a result of the shock there was a lateral shifting of the column bases-the relative movement being almost 2 feet in some places-at the cellar-floor level. The basement walls of the incomplete building were also shifted horizontally; at the east corner, where the walls had met at a right angle, they had been ruptured by a vertical crack and moved laterally in such a way that the angle between them was reduced to about $75^{\circ}$, as nearly as I could estimate it without taking measurements.

The south corner of the post-office building is shown in Pl. XLIV, $A$. Mr. Roberts states that accurate measurements show that the building proper settled a little at this point, but not more than oneeighth inch relative to other parts of the structure. The general appearance of the building bears out this statement. The result is remarkably gratifying when the great extent of the near-by surface disturbance on Mission street is considered. The street went down about 4 or 5 feet at this point as a result of the earthquake (Pl. XLIII, $B$ ). The molded granite shelf surrounding the building, shown with small timber props under it in Pl. XLIV, $A$, was set into a rebate in the main wall of the building... When the sidewalk and 
the supporting granite curb settled away from the shelf, it remained in position, as a cantilever, but the props were put under it to keep it from being broken. In the basement no evidence of the earthquake could be found, except a few insignificant cracks in the concrete floor, which Mr. Roberts says were not there before the earthquake.

On the whole, I think it is fair to say that the post-office was subjected to an extraordinarily severe test. About half of the chimneys were thrown down. One of them either rocked on its base or was thrown upward far enough to cause the counterflashing, which lapped the flashing about 3 inches, to clear the flashing and come down inside of it. The chimney remained upright, but with a slight horizontal displacement. In the exterior walls a good many stones were started from their beds, and some were cracked. Two or three fell from the wall. At least one anchor was exposed, and it had been broken. Whether the steel work was damaged or not could not be determined, as it was not sufficiently exposed. The damage to the exterior walls is fairly well shown in Pls. XLIII, $A$, and XLIV.

Pl. XLIII, $A$, shows damage on the southwest side of the west corner of the building; the surface of the window reveal and the adjacent return of the upper molding on the sill, at the point indicated by the arrow, were separated at least three-fourths of an inch, yet during the earthquake they were jostled together with sufficient force to abrade the reveal and spall the sill. That this effect should have taken place without shattering all the masonry around the window opening is one of the many inexplicable phenomena that seem characteristic of earthquakes.

The two sides of the pavilion on the Mission street side at the east corner showed cracks in the masonry and a disturbance of the sidewalk. A window arch on the northeast front, where the outer wall of the mail-handling room adjoins the main building, was damaged (Pl. XLIV, B). The building is $\mathrm{U}$-shaped in plan, the mail-handling room being in the court and closed in on the northeast by a wall. This wall was seriously shaken and was shored up at the time of my inspection.

With the exception of one window at the north corner, the exterior masonry of the building practically escaped damage from the fire. According to Mr. Roberts, the damage on the northwest front was somewhat increased after the fire as a result of the demolition of some neighboring walls by dynamite because of their dangerous condition.

On the interior some of the marble slabs used for dadoes and wall coverings were shaken off by the earthquake, and some marble columns used in connection with ornamental mantels and doorways were thrown down. 
A great many marble slabs were thrown down by the concussion due to the dynamiting of dangerous walls at Seventh and Market streets, less than half a block away. The clamage to marble finish from this cause was much greater than that due to the earthquake. Although the slabs brought down by the dynamite may have been loosened by the earthquake, they could have been taken down and reset if the dynamite had not caused their total loss. In one sense much of the loss was irreparable, for adjacent slabs were beautifully matched by being sawed from the same block and then so set in groups of two or four that the veining was symmetrical about the joints. Where one slab of a group was destroyed the only way to restore the finish to its original beauty would be to renew the whole group. In addition to injuring the marble finish, the dynamite did much damage by blowing windows, transoms, and doors from their frames, and by blowing panels out of doors and glass out of windows. With the kind of woodwork used in this building and with plate glass in all the windows, this item of damage was very heavy. Débris from the demolished buildings, also, was thrown across the street and came down through one or two skylights in the post-office building. It was only owing to good luck that some of the employees were not killed or seriously injured. As it was, the interiors of one or two expensively finished rooms were almost wrecked. All the items of damage which Mr. Roberts ascribed to the dynamite were of the same general type as those due to the concussion in mortar batteries, etc. The chief engineer of the building stated that he and some of his subordinates, although down in the basement, were thrown to the floor by the force of one of the dynamite explosions, and that the electric lights were extinguished for several seconds, although the engines kept running. Probably the concussion lifted the brushes from the commutators of the generators. It seems probable, from what evidence I was able to gather, that at first the dynamite was used in rather large quantities without tamping; but later it was used in a more tentative way and tamped with sand bags. By this policy those in charge of the later blasting operations finally got the work down to a system whereby a wall was brought down within a distance of 20 feet from the base on either side without any dangerous hurling of débris beyond that distance. So far as I was able to learn, after the work had reached this stage no one noticed any damage to neighboring structures, and, in fact, very few perple were aware that blasting was in progress.

Some of the mosaic ceilings in the post-office building were planted on a terra-cotta base, others on a furring of metal lathing and plaster. The former were seriously damaged by the earthquake, but the latter remained intact. As previously stated, the interior walls 
in the post-office were built of 6-inch terra-cotta blocks, with webs nearly 1 inch thick. They were beautifully built, every joint being absolutely filled with cement mortar that was much harder than the tiles, though the latter were of exceptionally good quality. None of these walls were thrown down, but many of them showed the intersecting diagonal cracks that are characteristic. of earthquake action. The tiles along the lines of the cracks were so badly shattered that many of them will have to come out. As a contrast, reference is made to $\mathrm{Pl}$. XLVI, $B$, showing earthquake damage to good brickwork. In the tile wall the same cracks appear, but the tiles are badly shattered for some distance on either side. In addition, in much of the flimsy tile work in the commercial buildings the adhesion of the mortar in the entire partition, if there was any, was destroyed. In the concrete walls at Palo Alto a few cracks appeared here and there as a result of the earthquake; but they were even sharper and narrower than the crack shown in Pl. XLVI, $B$, and there was no shattering effect whatever.

The column coverings in the mail-handling room, described above, were absolutely uninjured, but the circular brick walls around the spiral stairways developed many rather ugly spiral cracks. Such cracks were very conspicuous also in circular smokestacks, where the damaged work was not thrown down entirely.

The floor construction in the post-office was absolutely undamaged by the earthquake. This was one building where "cinder concrete" was made as it should be-of well-burned clinker only. In the court room which burned out a part of the furred ceiling came down, exposing the floor slab above. It may not have received a very severe test, for when work is done as well as it was in this building even a furred ceiling will exhaust the fury of a fairly hot fire. Be that as it may, the floor slab showed no signs of damage whatever, and it was the only case I saw where the heat had evidently reached the floor slab without leaving some degree of damage behind. The fire did not get through the 6-inch hollow-tile walls either, and it took off very few exposed webs. Here again it is probable that the plaster finish was so well done that it prevented the tiles from getting the full effect of the fire. The fire was stopped at the entrance to another court room, where there was a double wooden door, consisting of one door on each side of the partition. Water and wet blankets sufficed to stop the fire at this point, and it is reasonable to suppose that the extra resistance of a second door, even though it was of wood, was a material factor in the result. From a purely technical point of view it is to be regretted that the post-office building was not more seriously involved in the fire, for its fireproofing was of a commercial type-in its best possible form, however. Such a test would have yielded more interesting results than all the rest of San Fran- 
cisco combined. It is my personal opinion that the results would have indicated to private owners the availability of a desirable form of fire insurance at moderate cost on which but one premium would have to be paid.

The post-office building was so carefully and intelligently designed and so well executed, and, all things considered, gave so good an account of itself', that it seems a little presumptuous to suggest wherein it could be made better. Yet I believe that if the granite had been solidly backed with good brickwork and even more heavily anchored to the steel frame, if the frame had been more completely and heavily braced, and if all the interior partitions had been of solid brickwork, the structural damage would have been much less; and even the greater weight on the foundations might have been an advantage rather than otherwise. Mr. Roberts estimates the total damage as about $\$ 400,000$. Of this damage more than one-fourth, much of which was caused by the dynamite, is charged to marble finish and plate glass. The cost of the building was about $\$ 2,500,000$.

RIALTO BUILDING.

The Rialto Building was a steel-frame structure, with expandedmetal and cinder-concrete slabs, expanded-metal and plaster column covering, and furred expanded-metal ceiling. It had two main wings, in each of which it is said attempts were made to dynamite the building, the explosions causing the collapse of a portion of the interior structural work. A hole in the roof was produced by the same cause. Pl. XLVIII, $B$, a view of the southeast corner of the building, shows a portion of this damage at close range, and is submitted to show the effect of dynamite on a steel-frame building.

The fact that the building was dynamited makes it impossible to draw any useful conclusions as to,its fire-resisting qualities; but there seems to have been only a moderately hot fire in this building, and the fireproofing, while seriously damaged, was not a total failure as a result of the fire alone. The north front was badly racked by the earthquake, resulting in many cracks in the walls. The south front of this building was also damaged by the earthquake; the intersecting diagonal cracks in the walls were plainly visible. A considerable amount of face brickwork was thrown off on this front, probably owing to the fact that it was laid without bond.

\section{ST. TRANCIS HOTEL.}

The new St. Francis Hotel, which had been occupied but a short time, had a sandstone front and was supported by columns protected with cinder concrete. These columns were entirely undamaged, although a section near the upper end of each column which 
had apparently been covered in by a furred beam, or other architectural feature, since destroyed, was entirely devoid of protective covering. A great many people in San Francisco regarded the behavior of these columns as a substantial recommendation of cinder concrete, but the whole building bears evidence of having been subjected to only a moderate heat.

SHREVE BUILDING.

The columns in the first and second stories of the Shreve Building were covered with cinder concrete; those in the upper stories with hollow tiles. All the evidence in this building points to a moderate heat. The plastering on the columns was not seriously damaged, and such plastering never stands an intense heat. The hollow tiles on the columns came off very generally, but it is probable that the heat was more intense in the upper portion of the building than in the lower portion. This theory is supported by the fact that the damage to the masonry adjacent to the windows was most severe in the upper stories.

This building, like the St. Francis Hotel, is cited as an example of the excellent behavior of cinder concrete as a column covering, but in this case also there is every reason to believe that the concrete did not receive a severe test. The only cinder-concrete covering I saw that had evidently received an extreme test was in the basement of the Aronson Building, as described on page 79 .

\section{SLOANE BUILDING.}

The mercantile structure known as the Sloane Building, at 114 Post street, had cast-iron columns, protected with expanded metal and plaster. The floor slabs were of expanded metal and cinder. concrete. The basement of this building was subjected to an extremely fierce heat. At least six or eight of the columns had their covering destroyed, and the columns themselves either buckled or failed to such an extent that a large portion of the framework above was knocked down afterwards as a matter of safety. In the rear of the basement two rows of columns across the entire width of , the building had practically all failed in the same way, but the débris was piled around them to such an extent that views could not be obtained.

\section{SPRING VALLEY WATER COMPANY'S BUILDING.}

The Spring Valley Water Company's Building, at Post and Geary streets, was used for office purposes in the upper stories and for mercantile purposes in the first and second stories. The southeast corner had totally collapsed (Pl. L, $A$ ), apparently from the failure of the 
basement or first-story columns under the action of the heat. Pl. $\mathrm{XLV}, A$, is a view taken in the first story of this building, which had been occupied by the City of Paris Dry Goods Company. This view is submitted as illustrating a typical but rather bad example of the loss of lower webs from hollow-tile floor arches. The column coverings shown in the view had suffered about as little as any others. The coverings of other columns in the same building were practically destroyed, as were also the partitions. The same sort of damage as that shown in Pl. XLV, A, was plainly visible in some of the upper stories of this building, especially the second story.

A stairway carried on unprotected cast-iron strings was destroyed by the heat in this building. The same thing occurred in a number of other buildings in San Francisco, even where the stairways had been walled off by hollow-tile partitions or by partitions made of light studs, metal lathing, and plaster. It has generally been considered-in commercial work, at any rate-unnecessary to protect a stairway carried on cast-iron strings, but the San Francisco fire showed that some form of protection is very essential. Where the inclosing partitions did not fail, the stairways were of course not seriously damaged, but as a matter of fact the partitions failed almost everywhere in San Francisco.

\section{UNION FERRY BUILDING.}

The Union Ferry Building (Pl. XLVI, $A$ ) is a large structurepractically of monumental proportions-which forms the terminus of all the ferry lines plying between San Francisco and various other points on the bay. It is built on piles, with heavy stone walls, backed with brickwork. The stone is the grayish-green sandstone elsewhere described. The floor construction consists of steel beams and girders, with stone-concrete slabs reenforced with expanded metal. The lower flanges or girders and beams were not protected. Near the center of the west front a high tower rises to a considerable distance above the building. The fire did not gain entrance, but the building was very seriously racked and damaged by the earthquake. The damage was not at all of a fatal nature, however, and the building was kept in . practically continuous operation as a ferry terminus. The tower, which was built with a braced steel frame, inclosed to a height of several stories with a heavy wall composed of sandstone backed with brick, and closed in with wood and sheet metal above the masonry part, was so badly damaged that the masonry walls were being removed at the time of my inspection. To judge by the effects on this tower, the greatest intensity of the earthquake vibration must have been from northwest to southeast. The bracing was badly strained, 
and in this case there can be nc question that the effect was entirely due to the earthquake. The masonry in the tower was of an admirable quality.

In Pl. XLVI, $B$, is shown a crack in the brick masonry on the inside of the tower, together with a part of a diagonal tie-rod which had been stretched beyond the elastic limit and was hanging with a noticeable sag. It will be noted that the brickwork was well bonded and that the joints were well filled. The mortar 'was much harder than the bricks, but both were of good quality. It is also evident from this view that there was no general shattering of the entire mass; there was a well-defined crack, but nothing else.

At the northwest corner of the tower, about halfway from the roof of the main building to the top of the masonry walls of the tower, a diagonal tie-rod had been fastened to the wall girder by means of a gusset plate, with eight rivets in it. Seven of these rivets were sheared under the action of the earthquake, leaving the plate hanging by the eighth rivet at the time I saw it (Pl. XLVII, $B$ ).

One detail of the bracing in the ferry-building tower, of which a satisfactory photograph could not be procured, was as follows: The wall girders at the different floor levels were utilized for the wind struts of the bracing. In the lower part of the tower the diagonal tie-rods were fastened directly to the wind struts. The ends of the wind struts rested between upper and lower seats attached to the columns, and were, as a rule, bolted to each of those seats with nothing but two $\frac{7}{8}$-inch bolts, the idea evidently being that, as the struts resisted compression only, it was not necessary to fasten them to the columns with anything designed to resist any considerable force tending to separate them from the column. The upper seat was evidently designed to take the vertical component of the stress in the diagonal, and the lower seat to take this load in addition to the ordinary load which the wind strut transmitted to it in its capacity as a girder. The bolts fastening the ends of several of the wind struts to their seats had been sheared, and the struts had almost slipped out from between the seats.

In the upper part of the tower a different method was adopted, the diagonal tie-rods being fastened to bent plates that passed around the outside of the columns opposite the ends of the wind struts. No shearing of the bolts or slipping of the struts was noticeable at these points. It is plainly apparent that ordinary assumptions made in designing wind struts will not apply when it is desired that the bracing shall resist earthquakes. There is evidently a tendency for the columns at the ends of a wind strut to buckle outward, and thereby also a tendency to pull the strut out from between its seats. In fastening bracing to resist earthquake shock, therefore, the struts should be fastened to the columns at their ends much more securely than 
is ordinarily done. . In fact, if the diagonal is to be fastened directly to the wind strut, there should be a connection between the strut and the column capable of taking up the horizontal component of the stress in the diagonals. Knee braces, such as those used in the Call Building, possess a manifest superiority over ordinary bracket seats in construction of this sort. An examination of the condition of the bracing in the ferry-building tower can leave no doubt whatever that the tower was just on the point of total collapse. Conditions. were so bad that the superintendent of the contracting firm that was taking the masonry down evidently felt a little uneasy about what would happen when the masonry covering was removed from the portion of the steel work where the bracing was most seriously damaged. He was proceeding with great judgment and caution, however, and no doubt succeeded not only in removing the damaged masonry with safety, but in so tying together the steel work as- to avoid all danger of collapse.

A part of the masonry in the east front of the tower was precipitated from its position (Pl. XLVI, $A$ ) and fell through the skylight and onto the floor of the corridor in the upper story of the main building. This floor consisted of stone concrete, reenforced with expanded metal, and carried by steel beams with spans apparently of 7 or 8 feet. The contractor's superintendent, already mentioned, told me that he thought the amount of masonry so precipitated on this floor amounted to 30 or 40 tons. It punched in the floor one small hole not much larger than a man's fist, but nothing of any size got through. It is doubtful whether any form of floor arch or slab except reenforced concrete and possibly solid brick would have stood this test so successfully. Certainly no hollow-tile floor such as those in ordinary use would have stood it for a moment; the falling mass would have gone on through to the ground.

Along the west front of the ferry building, about halfway up the second-story window piers, most of the stonework had slipped about an inch. Some of the first-story piers were so badly shattered by the earthquake that they had to be boxed in to prevent the loose stone from falling. There were in the floor construction of the tower and of the building proper a few cracks which I thought might be due to the earthquake, although it is possible that they may have been shrinkage cracks. I was not able to get any convincing testimony on this point, but I have seen a good many shrinkage cracks and am of the opinion that most of these cracks were due to the earthquake and not to shrinkage. On the whole, the ferry building stood the shock remarkably well. It would seem to be the part of wisdom, however, to tear the tower down altogether and not to rebuild it. 


\section{UNION TRUST COMPANY'S BUILDING.}

The ordinary steel-frame Union Trust Building, with terra-cotta fireproofing, came through the earthquake in about the same condition as the average fireproof building in Baltimore after the fire. From the exterior it presented the appearance of having stood the ordeal about as well as any other building in San Francisco that - was completely gutted. The damage, however, was probably at least as great as that suffered by such buildings as the Continental Trust in Baltimore. Lower webs were off in many places, and column and girder coverings were damaged to a considerable extent (Pl. L, B).

\section{MISCELLANEOUS STRUCTURES.}

\section{GENERAL DISCUSSION.}

A number of buildings of fire-resistant construction in San Francisco, such as the Mutual Savings Bank, the Hibernia Bank (see Pl. XXXVII, $A$ ), and several others, have not been specifically mentioned in this report, but they presented nothing of more than ordinary interest. Detailed descriptions have been given of at least one example of everything that was typical, and practically everything described in detail was typical of many other cases of the same general class.

A building at First and Natoma streets had naked cast-iron columns, steel girders, reenforced-concrete beams from girder to girder, and reenforced-concrete slabs from beam to beam. The reenforcement of the concrete beams consisted of plain round rods passing through the webs of the girders and fastened with nuts in the same way as tie-rods. The aggregate of the concrete, in the beams at least, seems to have been of stone. Some of the slabs looked as if some cinders had been used in them, but this appearance may have been due to damage by the fire. At any rate the concrete was very badly damaged, as will be seen in some of the rear bays of the upper ffoor. Where the deflection was worst there may have been something precipitated upon the floor, but even at other points considerable deflection was apparent, together with serious damage to the concrete. It was evident, from the beams hanging down in the front, that in erecting this building the forms for the beams were filled first and the slabs were put on afterwards, so that there was no adequate bond between the beams and the slabs. The reenforcement of the slabs in this building was a very light twisted-wire mesh, and the only wonder is that it held as well as it did. The remains of a furred wire-lath ceiling were visible, and the failure of this ceiling is typical of what occurred in many other buildings. 
It will be noted that there was no reenforced-concrete construction, pure and simple; in San Francisco. The warehouse of the Bekins Van and Storage Company (Pl. XXVII, $A$ ), in process of construction, had reenforced-concrete columns and floor construction and brick walls. The walls were badly damaged by the earthquake, but the reenforced concrete was absolutely uninjured. This building, however, was unfinished, and the lower portion of it was not subjected to the stresses which would have resulted had it been complete, with all its contents. In that case the energy due to the vibration of the greater superincumbent mass might have produced effects which were not produced in its unfinished condition.

One-half of the circular observatory on Strawberry Hill, in Golden Gate Park (Pl. XXIII, $A$ ), was thrown down by the earthquake. I did not make a personal examination of it, except from a distance, but was informed that it had been reenforced with heavy iron rods bedded in the masonry. It was reported to me that these rods were broken at the point where the collapsed portion had separated from the part still standing. The general effect of the earthquake on hollow circular structures of all sorts seems to have been a tendency to increase their diameter. Where this tendency was very marked, it naturally caused their collapse.

Practically all the other photographs submitted and not specifically referred to in the foregoing pages were taken with a view of showing earthquake damage. The tower of the church next to the old Mission Dolores was dangerously near being thrown down, and had to be pulled down later, as shown in Pl. XXIII, B. Pl. XXXVII, $B$, is a view of a brewery which had been four stories high, with a tower at the corner extending to a considerably greater height than the building. The damage was due to earthquake alone. Pl. XXI, $A$, shows a case of earthquake damage pure and simple. It will be observed that the face bricks were not bonded, and were thrown down in large quantities. None of the brickwork in this building seems to have been of a very good quality.

An old-fashioned brick building of ordinary construction near Fort Mason appeared to have survived the earthquake absolutely undamaged. This example indicates the variation in the intensity of the earthquake within relatively short distances.

Pl. XXXIII, A, shows a building, known as the Butler Building, which was partially completed at the time of the earthquake. When I first saw it the side wall, which appears in the illustration as nearly torn down, was standing at about the same height as the front wall (shown at the right side of the picture). This side wall had a few earthquake cracks in it which were plainly visible, but it was a matter of surprise to see, a few days later, that the wall had been practically torn down; for if this wall was damaged sufficiently to 
justify its destruction, a great many walls of other steel-frame buildings ought to have come down also. This building was of the ordinary steel-frame type, without any bracing. The walls were very light, and on the principal fronts they were pretty well shaken to pieces. A superficial examination indicated that they were much more seriously damaged than the side wall which had been torn down. This building appears in the background of the view of the Dewey monument (Pl. XXX, $A$ ). At the time this view was taken a considerable amount of the masonry in the front wali had been removed, but there was still a great deal which, in my judgment, was too badly damaged to be safely left.

$\mathrm{Pl}$. LV is a panorama taken from Pine and Powell streets. The building on the left side of the street at the left is the Merchants' Exchange. To the right, just behind the high ground and trees, is the Mills Building, and farther to the right is the Union Trust Building. The other buildings will probably be recognized by persons who are more or less familiar with the city; the names of the chief ones are given on the plate. It will be observed that this panorama covers an arc of nearly $180^{\circ}$. The Twin Peaks appear some distance to the right of the city. hall.

\section{ORDINARY BUILDINGS AND RESIDENCES.}

The effect of the earthquake on miscellaneous buildings of the cheaper class was more or less interesting. There were a number of brick dwellings in San Franciseo faced with arch bricks laid in Flemish bond. These bricks, of course, are considerably harder and stronger than ordinary red bricks. Though they make a very rough wall, it is interesting and attractive, like the old colonial brickwork in the East. Apparently these houses were very strong. Whether it was good luck in all cases, or whether this brickwork really was much superior to the average brickwork used in San Francisco, I saw not a single example of earthquake damage to any house built in this way. I noticed eight or ten of these dwellings, and not one of them was damaged. 'The same fact had been noticed by the enlisted man who accompanied me as a photographer. He apparently had seen a greater number of buildings of this kind of brickwork than $I$ had, and he stated that not one of them seemed to have suffered any injury, although, in many cases, their neighbors had been seriously damaged.

A considerable number of frame buildings had practically collapsed under the earthquake; some of them were thrown bodily from their foundations. Plaster was generally shaken loose from wooden lathing, but, so far as I saw, none that was applied to good metallic lathing, such as heavy wire lath or expanded metal, had been shaken down. 
As a result of my observations, I am inclined to think that a building of the following type would be very desirable for residential purposes in an earthquake country:

The frame should be of timber, rather heavy and thoroughly braced, with all the vertical members continuous from bottom to top, or else thoroughly spliced. The horizontal members should be made as nearly continuous as possible-preferably by full splices. Horizontal and vertical members should also be fastened together as rigidly as possible, diagonal braces being used wherever conditions will permit. The frame should be covered on the outside with expanded metal and this metal plastered on both sides, a good deal of cement being used in the plaster. The exterior can be finished in stucco or pebble dash, as desired. The interior of the frame should be covered with expanded-metal lathing and the ordinary interior plaster-finish put on. The ceilings also should be finished with expanded metal and plaster. In my judgment, a building of this sort could be put up for very little more than the cost of an ordinary frame dwelling, and would not only come through an earthquake much better, but would be very much more difficult to set on fire and would burn much more slowly after it was on fire.

CHIMNEYS.

Chimneys seemed to be shaken down by the earthquake everywhere; even where there was no other damage this result was almost universal. The chimneys, as a rule, were built of bricks laid in lime mortar, and generally broke off at the point where they came through the roof. Reenforced-concrete chimneys with a terra-cotta lining would be very little more expensive than the kind that were ordinarily used in San Francisco, and would have suffered very much less damage. If any chimney projects a considerable distance above the roof, it would be advisable to brace it near its upper end to the roof in some way, so that it would not be free to vibrate. It seems probable that this plan might have saved some of the chimneys that failed. Appearances seemed also to warrant the conclusion that in the vibration some chimneys were brought up short against the roof framing and thus caused to break off at this point. If there had been a little more room for relative vibration between the chimney and the framing, it seems possible that some of these chimneys would not have fallen. The best way to prevent such damage is to build the chimneys of reenforced concrete or of some other material that has both rigidity and great tensile strength, Such chimneys would not ordinarily break off, even though they jostled against the roof timbers. 
BRICK SMOKESTACKS.

There were a great many brick smokestacks in San Francisco, nearly all of which suffered more or less damage. For some reason circular stacks seemed to suffer more than square ones, but the number of square stacks in evidence was not sufficient to justify general conclusions.

The views of brick stacks speak for themselves to a great extent. The stack of the Valencia street power station (Pl. LIII, A) was of some interest because of its peculiar cross section-an eight-pointed star. At the vertices of two diametrically opposite reentrant angles the stack was split practically from top to bottom. The ruins of a circular stack, situated near San Jose, are shown in PI. XIII, $A$.

\section{CONDITIONS OUTSIDE OF SAN FRANCISCO.}

OAKI.AND.

I made one trip to Oakland and went through the greater part of. the town. A good many chimneys had been shaken down and the front walls of a number of ordinary brick buildings had been precipitated into the street. Several steel-frame buildings faced with sandstone were badly racked, and in places some of the stone had been shaken into the street. Some of the steel-frame buildings showed the same kind of damage as the Monadnock and new Chronicle buildings in San Francisco. The damage in Oakland in general was not different in type from that in San Francisco, but it was much less extensive, and individual cases were, as a rule, much less marked.

\section{PALO ALTOO.}

I visited Palo Alto, and through the courtesy of President Jordan, of the Leland Stanford Junior University, was enabled to mạke a satisfactory examination of the damaged buildings at the university. These buildings represented in a general way three different types. Among them were some old buildings faced with yellow sandstone, which had been built in the early days by hired labor, under the supervision of Governor Stanford himself. All the sandstone used at the university was of a light yellow-buff color, rather soft, and apparently not very strong. In these older buildings, however, the cut stone had good wide beds, was carefully laid, was well bonded to the backing, and was solidly backed up with brickwork. These buildings were damaged seriously, but by no means beyond repair.

In addition to these older buildings there were some newer ones of the same general design, but the sandstone facing was thinner and the beds not so well cut nor so wide. The backing was not so good. 
Much of it consisted of rubble made of very small pieces of stone, apparently gathered up where stonecutters had been working. Many of these spalls were not larger than a man's fist, and in places 4 or 5 square feet of the wall was entirely backed up with this material. The bonding of the stone facing to the backing seemed to be less thorough in the new buildings than in the old. In short, the newer buildings conformed rather to the modern commercial standard of building construction; the old ones approached the monumental. The newer buildings suffered materially more than the old. They were not, however, of a type that would indicate culpable negligence or incapacity on the part of anyone connected with their design and erection, although they were distinctly inferior in type to the older buildings. The mortar used was not by any means poor. It seems to have been lime mortar gaged with cement. I tried it at a number of points where the buildings had suffered very severely, and it was distinctly better than the average mortar found in ordinary commercial work, although not as good as straight cement mortar would have been.

The buildings of the third class at Stanford University were built of concrete. The girls' dormitory had concrete walls and timber interior construction, and in the central portion of the Leland St:anford Junior Museum, the oldest part of the building, the walls and interior construction were of reenforced concrete. There were two wings, built of brickwork, with reenforced-concrete floor construction. It is reasonable to suppose that the intensity of the force applied to this building by the earthquake was nearly uniform over the entire structure. The two brick wings were practically shaken down, suffering, I should judge, considerably more than 50 per cent damage. The reenforced-concrete central portion, vierved from the exterior, seemed absolutely undamaged. In the interior a few cracks had opened up, but they were not of serious consequence. I should judge that a thousand dollars would easily cover all the repairs to this part of the building. Its valuable contents were, to a large extent, thrown to the floors and smashed, involving a considerable loss; but the structure itself suffered almost no injury. The only damage to the girls' dormitory was caused by a chimney that toppled over and crashed down through the roof, doing some damage on the inside. By good luck, no one was hurt in this building. The concrete wall showed one or two cracks, which, however, were said to be shrinkage cracks that had appeared soon after the building was finished. The earthquake apparently had caused no visible damage of any sort in the exterior walls.

It was noticed that those buildings which had completely trussed roofs suffered much less than those in which the walls had to take 
the thrust of the rafters. This result was naturally to be expected, and indicates that in earthquake countries walls should not be subjected to the thrust of the raitters at all. The damage at the university also indicated clearly the necessity of thoroughly tying all the walls to the roof construction, gable walls as well as others. The university post-office building was said to be of reenforced concrete and undamaged. Very good illustrations of the damage at Stanford University can be seen in the Engineering News for May 10, 1906, and in the Engineering Record for May 12, 1906. (See also Pls. $\mathrm{XIV}, A ; \mathrm{XV}$; XVI ; XVII, $B$; XVIII.) A concrete-block building in the town of Palo Alto was totally demolished.

\section{OTHER TOWNS.}

Concrete-block buildings elsewhere were also reported as totally destroyed. The various structures of the Southern Pacific Railroad along the coast division had suffered more or less damage. One or two stations faced with a sandstone similar to that used at the Leland Stanford Junior University, and built in the ordinary style, had been very seriously damaged. One station, which seemed to have been built a little more carefully and with larger stones than the rest, was in very much better condition than most of them. The city hall at Redwood had a central circular tower, with a dome supported on steel work, much as in the city hall at San Francisco (Pl. XXXI), though on a smaller scale, and suffered almost exactly the same kind and degree of damage.

\section{FORTIFICATIONS.}

I visited the old brick fort at the Presidio and also most of the batteries along the face of the cliff. There were a few cracks in the old brick fort, but nothing to indicate that they might not have been due to settling as well as to earthquake. An inspection of the new emplacements from the exterior showed no visible signs of damage whatever. As reports on these matters are made by officers especially in charge of the work, I did not attempt to make a detailed inspection of the fortifications.

RESERVOIRS, PIPE LINES, AND OTHER STRUC'TURES ALONG THE FAUL'T LINE.

The following details were derived from a perusal of the report by Professors Marx and Wing, already mentioned (p. 63).

The Spring Valley Water Company had among its reservoirs two known as Crystal Springs Lake and San Andreas Lake. The line of the fault that caused the earthquake is said to run directly through both of these reservoirs. - Crystal Springs Lake has a large and high concrete dam; it is also subdivided by an old earth dam that was 
formerly the main dam, when the reservoir was smaller than it is now. The concrete dam, which was parallel to the fault and of course very near to it, was absolutely uninjured (Pl. XI, $B$ ); the earth dam, which lay across the fault approximately at right angles, showed definite signs of disturbance and lateral displacement. Longitudinal and transverse cracks appeared on top of the earth dam, and some of the former were reported to have extended to a depth of at least 3 or 4 feet. The transverse cracks were said to be less well defined and to indicate rather a general disturbance on each side of the fault line, about one-fourth of a mile away, and was absolutely to which it was damaged could not be ascertained.

San Andreas Lake is retained by a high earth dam. The fault ran under the east end of this dam and produced considerable disturbance over a strip about 150 feet wide, though the dam was not seriously injured: A concrete culvert inlet was connected with this dam, and one of the worst transverse cracks noted ran diagonally over the culvert, but the culvert itself was uninjured. Besides the high concrete dam of Crystal Springs Lake, the water company had another smaller concrete dam at Searsville. This dam also was parallel to the fault line, about one-fourth of a mile away, and was absolutely uninjured.

The Spring Valley Water Company had three main conduits running into San Francisco. One of these, known as the Pilarcitos conduit, consisted largely of 22 -inch and 30 -inch riveted pipe and 24-inch cast-iron pipe; some feeders were built of wooden flume: The conduit crossed and recrossed the line of the fault, and was so badly wrecked that the company has decided to abandon it-no doubt a wise decision, because the location along the line of the fault was a very bad one. Wherever the conduit crossed the fault line it was destroyed. In some places there was a longitudinal displacement of as much as 84 inches, which either telescoped the pipe or pulled it apart, as the case might be. (Views of these effects are given in Pl. IX.) It made no difference whether the conduit was in firm ground, or in soft ground, or carried on a trestle over marshy ground; the result was the same wherever it crossed the fault. In many places where the conduit was carried on trestlework the timber showed considerable decay. Whether sound timber structures would have withstood the shock seems open to question. (See also Pl. $\mathrm{X}$, A.)

Within the city proper the reservoir known as Lake Honda was damaged by the cracking of its concrete lining. It is reported that this cracking was due to the displacement of a retaining wall by a sliding bank set in motion by the earthquake.

The distributing mains of the Spring Valley Water Company, wherever they passed through soft or made ground, suffered in the 
same way as the conduits and pipes which crossed the fault line. (See the maps, Pls. LVI and LVII.) Some subaqueous „pipe lines crossing the bay seem not to have been injured.

Two interesting earth dams are those at the San Jose Water Company's Saratoga reservoir, which lies in a saddle in the mountains and is retained by an earth dam at either end. The fault runs directly through the reservoir, crossing both dams approximately at right angles. It was reported that near the east end of the north dam transverse cracks were formed, which extended through the body of the dam. There was also a longitudinal crack on top and some settling of the upstream half of the dam. The reservoir seems to have been full at the time of the earthquake, but no evidence was found that any water had escaped through this dam. At the south end of the reservoir the fault line intersected not only the dam but the 10-inch outlet pipe, which was broken by the earthquake. Considerable damage seems to have been done to the dam by the water escaping through this broken outlet pipe. Whether the dam itself would have been seriously injured by the earthquake but for this pipe can not probably be determined.

Professors Marx and Wing also noted in the vicinity of the fault a number of monolithic concrete bridges, all of which were uninjured; none of them, however, absolutely crossed the fault line. (Cf. Pl. XI, A.) These observers also report that a small concrete reservoir, built partly in embankment and partly in excavation, was wrecked by the earthquake, and seem to think that such structures would better be built in excavation. They found that some high timber frames carrying water tanks, as well as similar structures supporting steel standpipes, were intact. A steel water tower at Santa Clara was wrecked. The engineer who designed this tower gives an explanation of its failure, howéver, in the Engineering News for May 10, 1906. Very probably his explanation is correct, and if so, there is no reason why steel towers should not be used. Doctor Jordan told me of one tower that he saw which had collapsed as a result of the earthquake, and in which the nuts on the upper ends of the anchor rods stripped the threads so as to allow the tower as a whole to be thrown over.

\section{GENERAL CONCLUSIONS.}

\section{THE REBUILDING OF SAN FRANCISCO.}

Unless future earthquakes are very much more severe than any that have occurred, there is no reason why the rebuilding of San Francisco should not be a successful commercial enterprise. It seems highly improbable that there will ever be earthquakes more severe than that of April 18, 1906. There is no doubt that the city can be rebuilt 
so that, although it will suffer damage from future earthquaikes, this damage will not be at all fatal, and the city will not burn up as a result of it.

\section{DISTRIBUTION SYSTEMS FOR WATERWORKS.}

In a city subjected to earthquakes it seems practically impossible to suggest any method of construction which will make the mains and distributing pipes at all times perfectly secure. In my judgment the only remedy is to have within the city itself a large storage capacity, distributed among various reservoirs, and to have a more than ordinarily complete gridiron of mains with gate valves to cut out any main at every intersection. Further, the mains should be larger than would ordinarily be required, so that if a portion of the gridiron were shattered it could be cut out, but the water could be brought in undiminished quantities to the perimeter of the shattered area from all undamaged parts of the gridiron; that is, the mains should be so large that, although the water would have farther to travel in this case, there would be an adequate supply for fighting fire, if necessary, in the area where the mains were shattered.

It would seem that in a city like San Francisco a special system of high-pressure salt-water mains, supplied from a pumping station, would be the best solution of the fire-fighting problem so far as the congested district is concerned. This plan has been recommended by the National Board of Fire Underwriters, and it is probably the wisest one under the circumstances. The pumping station should, of course, be protected from earthquake damage in every possible way. Perhaps it should be a floating station. The salt-water mains should be so laid out and so interconnected that nothing short of general destruction of the entire system could wholly shut off the water from any considerable area.

In a city like San Francisco, where there is practically no damage from freezing, it would seem worth while to run the mains exposed everywhere, so that brealss could be located almost immediately. As these breaks would ordinarily occur only in scattered localities, and would not be very great in extent themselves, it ought to be possible to repair them in time to prevent any general destruction of the city by fire. Running the mains exposed would, of course, introduce difficult problems at street crossings, but there is little doubt that such problems could be solved successfully if they were seriously studied. All this means greatly increased expense in the distribution system, but in a situation such as that of San Francisco it seems to be required.

The earthquake effects at San Francisco also indicate clearly that a special study should be made of the problem of promptness in emergency repairs to the conduits and mains. It seems certain that,

$7171-$ Bull. $324-07-9$ 
in the immediate vicinity of existing faults and near areas including any considerable amount of made ground, both conduits and mains may be expected to suffer serious damage. At one point on Van Ness avenue (see B, Pl. LVI), where I happened to see the mains uncovered, a heavy water pipe, apparently about 20 inches in diameter, had been broken into pieces not more than 2 feet long. The total length of the break, however, was not more than 40 or 50 feet, so far as I could judge from what I' saw uncovered. It would seem that this main might have been spliced in a few hours had there been some means of rapidly plugging the broken ends on either side of the break and making a number of taps in the undamaged parts with parallel lengths of fire hose of large size. With gate valves at short intervals it ought to be possible to cut out any damaged portion of the system by connecting through with fire hose in such a way as to maintain at least a partial supply of water for fire-fighting purposes. Some similar plan on a larger scale might be devised for repairing conduits.

It would also seem desirable, wherever an important conduit or main crosses filled ground or material soft enough to suffer consolidation as a result of thorough shaking, to carry the main on piles or other foundations reaching to firm material below. Wherever there was filled ground the vibration due to the earthquake seemed to have much the same effect as would be produced in a vessel that had been loosely filled with sand and then subjected to vibration; as is well known, the sand, under such circumstances, will suffer consolidation to a very appreciable extent, which naturally lowers its surface by an amount corresponding in a general way to the intensity of the vibration. Where a large area and volume of made ground is subjected to similar vibration, subsidence occurs, and not only are buildings on the surface thrown down and destroyed, but water mains, sewers, etc., running through the filled material are subjected to a deflection which necessarily shatters them.

\section{SEWERS.}

The effect of the earthquake on sewers seemed to be practically the same as on conduits and water mains, except as varied by difference of material, where such difference existed. The necessity for firm foundations for sewers running through made ground is clearly indicated. The need of rapid repairs to the sewers is not quite so great as in the case of the fire mains, because a city can get along with inadequate sewerage facilities, if necessary. It would seem desirable, however, that all important sewers passing through made ground should be constructed of the heaviest iron or steel pipes, and be provided with an adequate foundation. Of course, sewers are not 
under pressure, and therefore can not be repaired with fire hose, as suggested for water mains. There seemed to be some fear in San Francisco that the breaking of the sewers and the water mains would cause the water to be contaminated by the sewage; but evidently if means were devised to maintain a good pressure in the water pipes this pressure in itself would protect a leaky main from such contamination.

\section{FIRE-RESISTING FEATURES OF BUILDINGS IN "CONGESTED DISTRICTS."}

\section{FIREPROOFING.}

The Baltimore and San Francisco fires, as well as many other fires and fire tests, have proved conclusively that commercial meth- ods of fireproofing are inadequate to stand any severe test. In most buildings the steel work is fairly well protected, but the number of failures is sufficiently great to show that the factor of safety against fire is not by any means what it should be.

For" the protective covering itself to suffer complete destruction, or almost complete destruction, in any one fire is in itself a failure, because under such circumstances the steel work is very near destruction and the margin of safety is altogether too small. It is more than probable-almost certain, in fact-that a detailed investigation of all the buildings in San Francisco would reveal many "protected" columns, not indicated in this report, that buckled as a result of the failure of the covering. In my judgment, columns should either be covered with 4 inches of brickwork, laid in Portland-cement mortar, and have all of the interior space filled with concrete, or else they should be inclosed in an expanded-metal jacket and the entire interior filled with concrete, so that the minimum thickness of the concrete would not be less than 4 inches. Exposed flanges of girders and beams should be protected by the equivalent of $1 \frac{1}{2}$ to $2 \frac{1}{2}$ inches of solid porous terra cotta, according to circumstances. If concrete is to be used, this thickness should be increased by about half an inch. The protection for lower flanges should always be inclosed in a basket of expanded metal or heavy wire lath, securely anchored into the side protection of the webs. The San Francisco experience showed that, even in a hot fire, such metal-mesh basket work will largely retain its tensile strength, and thus hold in position the fireproof covering inside even though the latter should be shattered by expansion stresses or otherwise. The webs of the girders should be covered by 4 inches of brickwork or concrete, built up on the lower flanges. Girders should be completely covered from bottom to top before the floor systeps are put in, so that the collapse of the latter will not expose the girder. Floor beams should have heavy, solid protecting 
skew backs, not less than $1 \frac{1}{2}$ inches thick, or be covered with at least 2 inches of concrete. In an important work the protection of the lower flanges of the floor beams should also be incased in expanded metal or wire lath. The furred ceilings so much used in San Francisco are a valuable addition to the fire-resisting qualities of floor construction, and if the furring rods were more firmly secured the total loss here, as a rule, would be measured by the value of the plaster alone.

Hollow-tile partitions should not be less than 6 inches thick. The tiles should have webs at least 1 inch thick, and all interior angles should be well filleted. The tiles themselves should be carefully laid in Portland-cement mortar, with all joints absolutely filled. Timber studs running to the top of the partition, to frame a door or window opening, should be absolutely prohibited. The webs of floor tiles should not be less than an inch thick, and their interior angles also should be well filleted.

The results at Baltimore and San Francisco did not, by any means, indicate that either hollow tile or concrete is altogether a failure or altogether a success. Both fires indicated very clearly that commercial methods of applying both materials are inadequate, but also that successful results can be attained with both materials.

A conflagration never yields reliable comparative results, but judging from such comparative results as are available, I think that there is no question that the best fire-resisting material available at the present time is the right kind of burned clay-that is, a good, tough, refractory clay, almost as refractory as fire clay, made into proper shapes and properly burned. Some commercial hollow-tile work is made of good material, but, as a rule, that is the only good thing that can be said about it. There can be no question that good clinker concrete; made of well-burned clinker, Portland cement, and sand, is a very efficient fire-resisting material. It is better than anything except the better types of burned-clay products; but the cinder concrete commercially applied is, on the whole, no better than the flimsy hollow-tile work with which it competes; in fact, it is not certain that it may not be worse. The only way to determine this point would be to go through all the floor construction in a place like San Francisco and make tests of the load-carrying capacity, etc., after a fire. It is very doubtful, of course, whether such tests will be made.

If a hollow-tile floor, for instance, loses its lower webs, the damage is very apparent, yet most of such floors remain true and capable of carrying considerable loads. A cinder-concrete floor which is even more seriously damaged is very likely to remain true, for the reason that the fire which damaged it also removed its superimposed load before the damage was fully accomplished. A hollow tile which comes through a fire without losing any of its webs is as good as it 
was before; whereas concrete of any kind which has come through a fire in which the temperature has exceeded $700^{\circ}$ or $800^{\circ} \mathrm{F}$. is inevitably damaged in all cases, owing to the dehydration of the cement, although it may appear uninjured to the casual observer. This property of concrete, of maintaining a good face in spite of real and serious damage, is likely to lead the layman into dangerous conclusions, and consequently into equally dangerous practice. It would seem that wherever reenforced-concrete floor construction is used a furred ceiling below it should be absolutely required.

The furred ceilings ordinarily used are too light; the furring rods are not quite heavy enough and they are not adequately secured to the floor construction above. If they were made a little heavier, and were more firmly secured, it is probable that, as a rule, no loss would occur except that of the plaster. Even if the furred ceiling comes down bodily, this failure is not apt to occur until so late a stage in the fire that the floor construction above will be practically undamaged, because there will not be enough left of the fire to raise the temperature of the concrete to the point where dehydration of the cement will begin. The presence of a furred ceiling, however, no matter how good, should never be accepted as an excuse for omitting the protection of the lower flanges of the floor beams and girders. A hollow-tile floor that would be fully equivalent to a reenforced-concrete floor, with a furred ceiling, could be made by using tiles in which the minimum thickness of the webs is 1 inch, and of which the material itself is tough, refractory clay, made porous by the addition of sawdust; such tiles should, however, be burned to a point where the clay itself is just short of vitrification. All the interior angles, where the webs of the tiles join each other, should be rounded to a radius of at least 1 inch or $1 \frac{1}{2}$ inches. If necessary to secure proper burning, a small hole three-eighths to five-eighths of an inch in diameter: might be allowed through the mass of clay at the intersection of the webs.

Tests recently made of a pattern of tile used at.the War College indicate that floor tiles subjected to a fire test will stand better if there is but one interior hole through the tiles, all the material which would otherwise be used in the interior webs being concentrated in the outer webs, and the opening in the tile being of circular or elliptical shape, depending on the height and width of the tile. For floor arches between steel beams such a tile as this one would have to be used on the end-construction plan. A specially heavy skew back should be designed to go with it, or else the end tiles should be cut to fit the profiles of the beam. The tiles themselves being so heavy, the latter method of obtaining a skew back would probably make the arch more than strong enough to carry its load, and where carefully done might afford adequate fire protection to the beams, 
although for that purpose a specially designed extra heavy sideconstruction skew back would be better, and should on the whole be recommended even in connection with the heavy end-construction arches described. It is probable that either a good concrete floor with the right kind of ceiling below it, or a heavy tile floor such as that herein described, would come through almost any fire with no damage except the loss of the ceiling plaster. These two types may therefore be taken as equivalent in efficiency; they will probably be about equal, also, in first cost.

It should be added that attic floors and roofs should be as carefully designed to resist fire as any other part of a building. This is a thing that has rarely been done, and the experience of both Baltimore and San Francisco shows that it is absolutely necessary.

PROTECTION OF OPENINGS.

While there is no doubt that commercial standards of fireproofing are dangerously inadequate, the greatest trouble of all is the fact that so little attention is paid to protecting the exterior openings in a building. Even a very inefficient type of fire shutter would probably have saved some of the buildings in San Francisco, which were, as a matter of fact, burned out. A light metal shutter combined with a window sprinkler would probably resist a rather fierce fire for a long time. Although the failure of the water supply in San Francisco might be urged as one reason why a window sprinkler would have been of no avail, it is a fact that water can be obtained by driving wells into the sand which underlies the business portion of San Francisco almost everywhere. Under these circumstances, if the fireproof buildings had been fitted with metal shutters, even no better than those in the windows of the hall of records, and if each window had been provided with a sprinkler and the building itself with its own well and fire pump, it is probable that the fire could have been kept out of a large number of the buildings. The protection of external openings is by all odds the most important constructive problem involved in the efforts to make cities proof against conflagration, and it seems probable that at the present time adequate protection of windows and doors is available at a reasonable cost. In my judgment, windows protected in the following way, even without sprinklers, might keep out the fire, though the buildings were shut up and abandoned.

1. The outer opening should be protected with some form of rolling steel shutter or, preferably, with a shutter composed of sheets of steel sliding in very deep rebates in the walls. The sheets of steel should be anchored in these rebates by means of angle irons or rivets driven so as to interlock with a bead to be placed in position after 
the sheet of steel is itself in position. By providing a pocket in the masonry just above the window head and making these shutters in three or four parts, overlapping and interlocking at the overlap, the whole shutter could be slid up into the wall practically out of sight. This arrangement would necessitate window openings slightly lower than those used in many commercial buildings, but the loss of light would not be very serious. The metal shutters when closed should overlap the window opening in all directions by at least 6 inches. This overlapping could be accomplished at the sill without making a pocket to catch water and dust, by forming a step in the sill itself.

2. The windows should be made entirely of wire glass, with sheet metal or metal-covered sash, hung in metal or metal-covered frames. Clear wire glass can be used if desired.

3. On the inside of the window there should be a sliding shutter, either of wood covered with sheet metal or of sheet metal such as that described for the outside. If the outer wall is furred, a pocket could be made between the furring and the wall, so that the inside shutters could be slid sidewise.

It is probable that under a fairly bad exposure to fire the outer shutters here described would be so damaged that they would have to be removed. In a conflagration they would probably be warped to such an extent as to let the heat in, and possibly to soften the wire glass and damage the windows themselves, so that they also might have to be renewed-at least so far as the sash were concerned. But it is very doubtful if any conflagration would ever get through the sash, much less through the inside shutters. Any damage to the window protection, however, would be a very small matter compared with the total destruction of the contents of the building and a damage of 65 to 80 per cent to the building itself.

Window protection of the kind just described could be so designed that it would not be objectionable even on the principal fronts of buildings. The San Francisco and Baltimore fires have demonstrated that all the exterior openings of even fireproof buildings need protection. It would seem that the time has arrived when building ordinances should require it.

If to the triple window protection described above a window sprinkler with adequate water supply is added, a defense which will probably not only be adequate for its purpose, but which will suffer small damage itself, will be provided. This system of protection, while it has never been applied, can be applied at a cost which is not prohibitive, especially if unnecessary and expensive finish is omitted.

Practically all the fireproof buildings in. San Francisco were unshuttered. Many nonfireproof buildings were partially shuttered, but no building, except that of the Pacific States Telephone and Tele- 
graph Company on Bush street, was completely shuttered. Although every opening in this building was protected, it is not certain that the fire did not find its way into the building through some of them in spite of the protection. The protection of individual openings apparently was not quite heavy enough. ${ }^{a}$

The view of the main front of this building (PI. XLI, $A$ ) shows plainly that it was not severely attacked by the flames, yet it probably would have resisted such an attack a good deal better than the façades of many other buildings. The exterior architraves of most of the windows are of solid molded brickwork, and the amount of hollow terra cotta in the exterior front is reduced to a minimum, so that this building would probably not have suffered quite as much as the average, even if the fire test from the outside had been fully as severe.

\section{FIREPROOF VAULTS.}

It would seem that the question of so-called fireproof vaults in commercial office buildings should also receive some attention. The failure of such vaults in San Francisco is absolutely inexcusable. The fact that they were so flimsy was not due to any lack of available knowledge as to how a fireproof vault should be built; the only motive that can be imagined for the erection of such vaults is parsimonious and criminal economy. (See Pl. LII.)

\section{CONSTRUCTIONS AND MATERIALS RECOMMENDED FOR EARTH- QUAKE LOCALITIES.}

For every tall building the best type of construction is undoubtedly a steel frame, but it should be thoroughly braced in much the same way as in the Call Building, where the steel bracing undoubt-

\footnotetext{
a Since the above was written the following information bas been received from California, through the courtesy and cooperation of Capt. M. L. Walker and Capt. William Kelly, both of the Corps of Engineers :

The rolling shutters on the Busb street building of the Pacific States Telephone and Telegraph Company were made of interlocking slats crimped out of beavy sheet iron, the shutter as a whole sliding at the sides of the opening in heary iron guides. Captain Kelly thinks they were made of No. 22 iron. I do not believe, personally, that these shutters withstood the direct impact of fierce flame for a great length of time; they would have warped and pulled apart so as to let the flame in. The view of the Bush street front of this building. (shown in PI. XLI, A) would indicate that there was no dicect attack by the flame from the outside, and there is every reason to believe that the plate glass on the inside stood long enough to prevent the shutters from receiving any serious attack from the flames of the interior fire. It is probable, however, that these shutters are fully as efficient as the rolling shutters made by other manufacturer's out of continuous sheets of corrugated iron riveted together along the edges. The continuous. sheets have to be of rather light metal, in order to make them practicable; and when subjected to any great amount of heat they invariably pull apart along the lines of rivet boles-a weakness which was clearly illustrated in the Baltimore fire. There would seem to be no doubt, however, that rolling shutters of eitber type used on the outer windows of a huilding would effectually prevent ignition from radiant heat due to a fire in a neighboring building. They would also; of course, resist for a time the actual impact of flame, but I am personally of the opinion that they could not resist this form of attack for very long.
} 
edly saved the masonry. In such buildings as the new Chronicle and the Monadnock the effect of the vibration was really resisted by the masonry, which was much shattered. Some of it was precipitated into the street from the new Chronicle Building, the Rialto Building, and others. It is not at all certain that the steel frames of these buildings have not also been seriously damaged by the earthquake. Naked steel frames of the same type came through without serious damage, but they did not suffer the additional stresses due to the vibration of a great load of masonry, floor construction, and contents in the upper stories, as did the finished buildings. It is not right to run the risk of precipitating the masonry into the street on the heads of passers-by, as would have happened at the unbraced steel-frame buildings had the earthquake occurred at a later hour in the day. Besides, if the strength of the building is dependent on the masonry, which is seriously shattered by the stresses that it is expected to resist, the factor of safety against general collapse is manifestly too small. The steel-frame construction should therefore be thoroughly braced. In my judgment, to obtain the best results it should also be inclosed with walls of reenforced concrete, in which case it would be almost impossible to throw the walls off. The proper artistic treatment of this material in a place like San Francisco would - seem to be a very important problem for the architects. The great utility of reenforced concrete in earthquake shocks can not be denied. Where steel-frame buildings are to be finished with ordinary masonry walls, however, complete bonding of all face bricks with full header courses should be absolutely required. No other form of bond is adequate. Nothing but Portland-cement mortar should be allowed in any part of the structure. The masonry should be tied to the steel frame in the very best possible way, and much more securely than is ordinarily the case.

For buildings of moderate height, say up to 125 feet as an extreme limit, reenforced concrete alone can undoubtedly be so designed as to give very good results when subjected to either earthquake or fire. But the bracing of a reenforced-concrete building of any height to resist earthquale is a matter for serious study. The problem can be solved, but it has not been solved yet.

Any building of considerable height, in an earthquake country, should have as little mass in the superstructure as possible, consistent with other necessary qualities. But this limiting of mass does not mean that the flimsy floors and partitions heretofore in use should be continued. In fact, to make the buildings proof against both earthquake and fire it is probable that they will have to be at least as heavy as they have been, but changes in distribution of the mass could. advantageously be made. 
For the ordinary commercial building, where brick walls and wooden joists would ordinarily be used, I am of the opinion that the use of reenforced concrete would be the safest and most practicable solution in a place like San Francisco. Where reenforced concrete is used throughout, whether the building is very tall or not, great care should be taken with the design and execution of the connections between the columns and the members of the floor system. There should be heavy knee braces for the connection of all girders and beams, and, wherever possible, portal bracing in the shape of reenforced-concrete arches should be introduced. Of course the amount of this work that needs to be done depends on the circumstances in each individual case, such as the height of the building, its horizontal area, the kind of material, the dead weight in the upper stories, etc.

The opposition of the bricklayers' union and similar organizations has hitherto prevented the use of reenforced concrete in San Francisco for all parts of buildings. This action of the labor unions has probably cost the city a good deal, and, should it be continued, will cost a great deal more in the future.

From the effect on the fortifications, and on monolithic and massive concrete structures elsewhere, as indicated by the details taken from the report of Professors Marx and Wing, it seems justifiable to conclude that a solid monolithic concrete structure of any sort is secure against serious damage in any earthquake country, unless it should happen to lie across the line of the slip; in that case the damage might be fatal, or it might not, depending altogether on the amount of the slip and the intensity of the forces that accompanied it.

It would seem that earth dams of ample size and with good foundations are also secure against fatal damage unless they are traversed by the slip. Even in the latter case the damage would appear to be not always fatal; that it would never be fatal, however, would be a rash assertion to make. It is unsafe to say that any sort of structure could be built so that geologic faulting could occur immediately underneath it without doing serious damage. As a matter of fact, however, most structures in an earthquake country would not lie on the line of a fault, and it seems quite certain that in such cases well-constructed earth dams and solid monolithic masses of concrete, whether large or small, would escape serious injury.

\section{THE MINIMIZING OF FIRE LOSSES.}

A study of the results of the Baltimore and San Francisco fires, especially in connection with the statements of adjusted losses at Baltimore, readily discloses the following facts:

In the first place, the contents of the fireproof buildings were a total loss. In many buildings the contents might probably be worth 
more than the structure itself, especially if any attempt is made to fix the value of records and papers that can not be duplicated. In the second place, the buildings themselves suffered a damage exceeding 65 per cent, and in San Francisco probably amounting to almost 80 per cent. A study of the items entering into this damage discloses the fact that a very large proportion of it is due to the loss of the architectural finish, such as face brickwork, ornamental terra cotta, and stonework on the exterior; marble dadoes, columns, and other finish on the interior; wooden door and window frames, wooden doors and windows, ornamental grillworl, etc. If the fireproofbuilding problem is to be solved in such a manner that conflagrations will not cause serious losses, it would seem that radical revision of the method of finish is necessary. As the finish must practically be a total loss anyway, it should be so devised that it can be replaced at small expense. This requirement, however, makes it impossible to adopt a material for the construction which, as the architects say, finishes itself-because, if the exposed surface is destroyed, the material becomes a total loss. It would seem that for the exterior of the structure, walls well built of good, common brick, laid in Portland-cement mortar, or else of reenforced concrete, could be finished on the outside with stucco, pebble dash, or some similar: material: The opportunity for the effective use of colors here would be very great. If the buildings were exposed to a fire, the exterior finish would probably be a total loss, but its value in dollars and cents is small. The fire might even strip it off and cause serious spalling to the main wall underneath, but, even so, the operation of renewing the finish would furnish adequate repairs for the main wall itself. On the other hand, if face brick or stone or ornamental terra cotta be spalled, the loss is total; the original finish can not be renewed, except by tearing the wall down and rebuilding it. On the interior, combustible trim of all kinds should be eliminated and marble or stone finish should. be securely protected from the access of fire. Enameled bricks and enameled tiles should also be made secure against not only the direct access of fire but the effects of high temperatures however applied. Instead of marble wall finish or enameled bricks or tiles, wall plaster of a good quality, finished with enamel paint, furnishes a perfectly satisfactory substitute, so far as utility and sanitary qualities are concerned. If such finish is destroyed by fire, its renewal is a matter of relatively small cost.

All interior partitions should be so solidly constructed that there would be no question whatever of a fire ever getting through them. That ought to be absolutely impossible. Stairways, stairway halls, and other places where elevator grills, ornamental balustrades, etc., might be used should be so located that no fire would ever get into them, and they should be kept absolutely free of combustible matter 
of all sorts and descriptions. Wooden floor finish should not be allowed in any portion of the building. All doors, door frames, window frames, and window sash should be of metal or of wood covered with metal. All important openings should have doors on both sides of the wall, the idea being to so design the interior of the building that a fire starting in any one room could be left to burn itself out not only without being communicated to other rooms or to the corridors, but also without causing any great money loss to the building itself in the room or rooms where the fire occurs. The interior construction of the building should be such that, should a fire by any chance be introduced from the outside, it could be confined absolutely to the room or rooms to which it finds access. Such a thing as a conflagration sweeping through a building can be made impossible at reasonable expense, provided unnecessary architectural finish is omitted and the money ordinarily expended on it is applied to other things.

Even such a building, however, might have a shutter left partly open, or some other of the various fire-resisting devices might be left in such condition as to defeat the purpose for which it was installed; so that if the building contains a large amount of combustible contents, it should still be provided with sprinklers. The municipal water supply should be under sufficient pressure to supply the sprinkler system. In a city like San Francisco an artesian well and fire pump in each building should be provided for the same purpose, if possible. Even then, if there, is a conflagration raging, the mechanical staff of the building and as many more men as can be obtained should be kept on duty inside the building, watching for points of weakness and extinguishing fires should any begin. A small amount of water and a small force of men would suffice for this duty in a building constructed as described.

It appears that in San Francisco a number of owners who were organizing forces for the active defense of their buildings were driven out by the police and military authorities in accordance with instructions from the municipal authorities-no doubt to prevent looting and also with a view of saving people from the effects of the dynamiting. It would seem, however, that in some cases proper judgment was not exercised, and that some buildings might have been saved themselves and might also have acted as barriers to the further progress of the flames if their occupants had been permitted to carry out their plans. For good illustrations of what can be done in this way one need point only to the post-office building, the mint, and the appraisers' stores. There is also every reason to believe that a more or less active defense was carried on in the Kohl Building; otherwise it must have suffered more severely than it did. As it was, however, this building was saved with slight damage. 
A fire-resisting building is, in one sense, exactly analogous to a fortification-it needs a garrison to make it thoroughly effective. There is this difference, however, that $\cdot a$ fire-resisting building can be made so effective in itself that a relatively small garrison can save it. In my judgment, a building thoroughly well constructed along the lines indicated in this report would stand in a conflagration such as that which occurred in San Francisco, preserve its contents, and suffer a loss to its own structure and finish not exceeding 15 per cent. Until a result approximating this degree of endurance is achieved, it is hardly fair to say that the "modern fire-resisting building" is a success, except in so far as it enables a sufficiently tall structure to be erected on a piece of valuable real estate to furnish an adequate return for the entire investment, and even this statement is true only as long. as the building does not happen to be attacked by a conflagration.

\section{EARTHQUAKE INSURANCE.}

It would seem that in a place like San Francisco it would be sound policy for the business men to form a mutual earthquake insurance company on lines similar to those of the mutual fire insurance companies. They should employ competent experts to draft specifications and evolve types of designs not in conflict with the municipal ordinances for buildings specially planned to resist earthquake. To be admitted to the benefits of the mutual earthquake insurance company an owner should be required to conform to the standard plans and specifications. In my judgment, there is every reason to believe that such an enterprise could be made successful and that it would result in having available at all times a fund for making good any earthquake damage. It is probable that the premiums that would have to be charged by such a mutual insurance company would be found to be no greater than those that are charged for fire risks in large cities.

\section{SUMMARY.}

It will be apparent that much of the information presented in a report like this one is necessarily hearsay. So far as the history of the fire is concerned, this indefiniteness can not be avoided, and the details of the damage itself could be verified only by a prolonged stay in the ruined city and a close inspection of the ruins of every building at every stage of the process of cleaning up. It is to be hoped that the technical men engaged on this work will keep a complete and accurate record of all details of every sort, which will be available for future reference. It is believed, however, that enough evidence was collected at first hand to abundantly justify every con- 
clusion and broad statement contained in this report. The only doubt in my mind is whether the damage may not have been really greater than it appears.

Extreme caution should be observed in drawing general conclusions from any individual case of damage in a great conflagration. For instance, the way in which misleading conclusions can readily be reached is indicated in the discussion of the relative merits of terra cotta and concrete for fireproof floor construction. The records of the fire, rightly read, would prove that both concrete and burned clay are efficient as materials, but that the method of application of both is open to severe criticism. That hasty and ill-founded conclusions have been reached is only too evident from the articles which have appeared since the San Francisco disaster.

It is also necessary that extreme caution should be observed in drawing conclusions in regard to the effect of the earthquake. Reenforced concrete proved itself superior to brickwork beyond any doubt. There is every reason to believe that for buildings of moderate height reenforced concrete can be so designed that it will be quite as efficient as a steel frame; but it should be remembered that this proposition was not proved, because there was no reenforced-concrete building of considerable height in the entire district affected. Again, the fact that steel frames stood up during the earthquake does not prove that they are earthquake proof. The framing of the tower of the Union Ferry Building suffered almost fatal damage, yet it stood up. The Call Building proved the efficiency of stiff and adequate steel. bracing; but many of the other commercial steel-skeleton buildings showed very clearly the need of it. The fact that some of the tall buildings are now out of plumb is no proof that they are damaged; very few such structures ever are plumb, and if the deviation is not very great it is quite possible, even probable, that the building was erected out of plumb. The condition of the masonry in wall piers, however, gives ground enough for uneasiness. It is safe to say that a well-braced steel frame is proof against ordinary earthquakes, but to point to the actual commercial steel-frame structure in San Francisco as a triumph of the ordinary type of steel frame, in advance of the careful detailed inspection of the steel work by competent engineers, is premature, to say the least. 


\title{
THE EARTHQUAKE AND FIRE AND THEIR EFFECTS ON STRUCTURAL STEEL AND STEEL-FRAME BUILDINGS.
}

\author{
By Frank Soule.
}

\section{THE EARTHQUAKE.}

\section{GEOLOGIC FEATURES.}

On the morning of April 18, 1906, central California experienced an earthquake, the most severe, as measured by its results, in the history of the State. The seismograph in the observatory of the University of California, at Berkeley, recorded the shock as beginning at 5 hours 12 minutes 6 seconds a. m., Pacific standard time, and as lasting for one minute and five seconds. Its severity was afterwards estimated and rated as IX in the Rossi-Forel scale of earthquake intensities. Other minor shocks followed immediately and at short intervals, so that before $7 \mathrm{p}$. m. of the same day thirty-one of these had been registered at the observatory. Slight shocks; coming successively after longer and longer intervals of time, were experienced during several weeks following, until finally the earth's crust in California seemed to have readjusted itself to new conditions of pressure and equilibrium. The material damage from the earth tremors was inflicted by the first great shock. The minor ones following wrought no injury, except to throw down a few tottering walls that had been racked by the original earthquake.

For many years the leading geologists in California have known that a rift, or line of dislocation in the earth's crust-called in common parlance an "carthquake crack"-starting near Point Arena, extends in a straight line, at least 400 miles in length, in a direction S. $35^{\circ}$ E. (fig. 1, p. 3). Passing under the ocean bed 8 miles west of the Golden Gate, the rift cuts the shore again at Mussel Rock, runs along the reservoir basins of the Spring Valley Water Company and over the Coast Range of mountains, ignoring surface topography in its course, and extends at least to Mount Pinos, in Ventura County, and probably still farther to Lake Elsinore, in southern California. This great "fault" gives abundant geologic evidence of having been, in the remote past, the locus of many distinct earthquake movements and disturbances. 
It was a rupture and slip along this fault, plainly evident for nearly 200 miles, that shook so violently the thousands of square miles of the earth's surface in central California. The first snap and movement of the crust were registered at the observatory of the State University as proceeding from south-southeast to north-northwest, or about parallel to the fault. This movement was there recorded as over 3 inches horizontally, and was accomplished, as estimated by the California earthquake investigation commission, in one second of time. The vertical movement at the same place and time was believed to be about 1 inch. Professor Omori, the distinguished Japanese seismologist, also estimated the vibration in San Francisco to be 3 inches in one second.

Instantly following this first snap were rebounds, reactions, and terranean reverberations from all parts of the greatly disturbed area on either side of the fault trace, which made the record on the seismograph resemble a tangled spider's web. It was this part of the earthquake-the temblors-that created and continued the racking vibrations, the twistings, and the wrenchings that brought down chimneys, walls, and towers.

Members of the California earthquake investigation commission advanced the belief that the first break, slip, and shock in the crust began at the northwest extremity of the fault trace, and that frorn this point the rupture and shearing extended progressively toward the southeast. This view seems to be borne out by later investigations, and certainly the greatest disturbances on the line of the fault were at and near its northern extremity. The earthquake was felt to a greater or less degree over a vast extent of territory, stretching from Coos Bay, in Oregon, to Los Angeles, in southern California, and from western Nevada over the greater part of middle California, and even out to sea. Although not noticeable to the senses, it was recorded on seismographs in Washington, D. C.; Tokyo, Japan; and Potsdam, Germany.

\section{A STUDY OF THE EFFECT OF NATURAL FEATURES ON THE INTENSITY OF DESTRUCTION.}

DISTANCE FROM THE FAULI LTNE.

The actual area of destruction was about 400 miles long (from north to south) and 50 miles wide on either side of the fault trace. The destruction wrought by the earthquake in its severe effects was proportional in a way to the nearness of the locality to the fault trace, but varied greatly according to the character of the rock and soil formation throughout the disturbed area.

Directly on the fault trace the disturbance and destruction were at a maximum. Many buildings and other structures were wrenched, 
twisted, and thrown down (Pl. $\mathrm{X}, B$ ); fissures were opened in the earth (Pls. III, IV) ; trees were uprooted and thrown to the ground, or snapped off, leaving their stumps in a standing position, or split from the ground up through the stock to the branches (Pl. II). Roads were ruined for long distances, bridges were thrown off their abutments (Pl. XI, A), and water pipes were twisted, telescoped, collapsed, or broken (Pls. IX; X, A). Along the seashore immense landslides occurred, throwing vast quantities of earth and rock into the sea. (See also Pl. VIII, B.)

The main pipe lines of the Spring Valley Water Company, which were depended on exclusively to supply the city of San Francisco with water, as well as the distribution system of this company in the city, were broken in many places, and the supply of water was absolutely cut off for a number of days after the earthquake (map Pl. LVI). The great mains leading from Pilarcitos, San Andreas, and Crystal Springs lakes were all badly broken (PI. LVII). The Pilarcitos conduit in particular, which ran almost along the fault trace, was completely ruined and rendered unfit for repair (Pl. IX). The great 44-inch water main crossing the San Bruno marsh was thrown down from its supporting trestles in a serpentine line, and broken in several places.

As the distance from the fault trace increased, the violence of the disturbance in a general way diminished, but this statement must be modified by saying that in cities and towns built upon the alluvial soil of valleys the destruction was at its greatest, as, for instance, at Santa Rosa, about 20 miles east of the fault trace, in the Sonoma Valley (Pls. XIV, $B$; XVII, $A$ ). This city, built upon a deep, alluvial soil, was more severely shaken and suffered greater damage, in proportion to its size, than any other town in the State. Scarcely a brick or stone building in the town was left standing, and 80 people were killed.

\section{SOIL FORMATION.}

The destruction wrought by the earthquake amounted to little or nothing in well-built structures resting upon solid rock, and, all other things being equal, increased in proportion to the depth and incoherent quality of the foundation soil. Thus dwellings in Berkeley, upon the solid rock, were scarcely disturbed, while those on the level plain of Oakland, 4 miles distant, were severely shaken and injured, as, also, were the buildings at Leland Stanford Junior University (Pls. XIV, $A$; XV; XVI; XVII, $B$; XVIII), 7 miles distant from the fault trace; at San Jose (Pls. XII, $B$; XIII, $B$ ), 13 miles distant; and at Agnew (Pl. XIII, $A$ ), 12 miles distant. The town of Salinas and the alluvial valley of Salinas River were also severely shaken. This region was fissured and disturbed more than any other district in the State.

7171-Bull, 324-07-10 
In order to get a fair understanding of the effects of the earthquake in San Francisco, a knowledge of the geologic formation and the different soils constituting the foundations of structures is necessary. The city and county of San Francisco comprise the northern extremity of a long, narrow peninsula, lying south of the Golden Gate, between the Pacific Ocean on the west and the southern half of San Francisco Bay on the east. (See map, Pl. LVII.) The boundary line between this county and San Mateo County lies about 8 miles south of the Golden Gate. The area of San Francisco County is $46 \frac{1}{2}$ square miles. The population of the city on April 1, 1906, was estimated to be 460,000 .

The site of the city has at least four different soil formations. Around the Bay of San Francisco, from Telegraph Hill to Mission Creek, which runs from west to east and empties into the bay, and on both shores of the creek is a strip which was originally mud flats and overflowed lands, having an area of about 354 acres. These tracts have been gradually filled in (especially on the bay shore and the northern Mission Creek sides), since the days of the American occupation, by encroachments on the water front, due to business and commercial pressure, and wharves and docks, warehouses, factories, manufacturing establishments, and large wholesale houses have been built on these filled-in lands. At the present time these large areas are for the most part included within the sea walls running around the officially established water front nearly as far as Mission Creek. They are known as "made lands," and consist of deep layers of mud, in many places saturated with salt water, and overlain by sand, trash, etc., which has been filled in upon them.

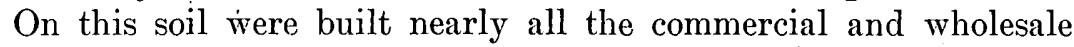
business structures of San Francisco-such as the Union Ferry Building-many large hotels, the post-office, the branch mint, and similar structures. On the Mission Creek side were originally very large areas of marshes that have been filled in with sand from adjacent hills. Adjoining all these made lands is the comparatively level ground, composed of a natural mixture of sand and clay, formed by the wearing of the hillsides and by the incoming of sands drifted from the seacoast. Upon this fringe of soil next to the made lands were built many of the largest hotels, tall office buildings, and expensive structures of brick, stone, and steel.

A ridge of rocky hills runs from the northeast corner of the city, or Telegraph Hill, southwestward along Russian Hill, Clay Street Hill, and so on, to Sutro Heights. These hills are composed largely of indurated clay, shale, and, on their highest summits, serpentine and other rocky formations. A ridge of sand hills runs through the western and southwestern portions of the city to the Pacific Ocean. 'The slopes and summits of the hills nearest the business portion of 
the city are closely built residence districts, and the areas toward the Pacific Ocean are covered with cottages, more and more sparsely placed, to the boundaries of the county.

Adjoining the business district on the southwest side, along Mission Creek, on the flat sand lots, was another thickly populated residence section known as "south of Market street." It was occupied almost exclusively by wooden buildings.

More than 90. per cent of the buildings in San Francisco were of wood. Almost all the brick, stone, and steel structures were in the congested business portions of the city, upon or very near the made land. Even in this district there was a large percentage of wooden buildings. High steel structures of the most modern type have been erected only recently in. San Francisco, and the number of them is small, not exceeding 50 .

The most destructive effects of the earthquake in San Francisco were experienced upon this made land. Wherever buildings were well founded on wooden piles deeply driven into the mud-as, for example, the Union Ferry Building-these foundations were disturbed but little or not at all; and where the superstructure had been well and strongly put up, practically no damage resulted. Only in poor foundations laid directly upon "filled-in." ground on the raft principle, or in buildings that were poorly constructed or underpinned or had a weak frame, poor brickwork, or brick laid dry in poor lime mortar, was there serious damage or collapse.

The Union Ferry Building (Pl. XLVI, A), with the exception of its high tower, was little injured, and the level of its floors was not perceptibly changed. At the same time, the streets at its front, which rested simply on the made soil, were rolled into waves 3 or 4 feet in height. So far as the writer is aware no foundations that had been properly established were in any considerable degree injured by the earthquake; nor was any structure of brick or stone, iron or steel, that was well designed and constructed, greatly damaged. Some chimneys and cornices were thrown down, but until the fire had passed over the region the structures remained ready for use. This statement applies especially to the wooden-frame structures throughout the residence part of the city, where the only losses were those of chimneys and plaster.

On the made land in the business portion of the city there had been erected in early days many light wooden buildings, which rested on simple timber underpinning founded on the filled-in material. Many of these structures collapsed, but this result was due to their imperfect foundations and weak construction rather than to the severity of the earthquake. Numerous structures in this district had been built of dry brick or stone laid in common lime mortar, and their beams, girders, and columns had not been anchored to the 
walls. Such walls commonly collapsed, and the brick were found afterwards with dry, clean surfaces, the mortar having no adhesion. (See Pl. XXI, A.) On the other hand, walls that had been laid in Portland-cement mortar, with brick, thoroughly wetted and all parts well bonded together, stood the trial perfectly and are standing to-day.

Tall, steel-frame, stone-exterior office buildings of the class A type that were founded either on well-driven piles or on concrete slabs suffered no very serious injury by the earthquake. With the exception of a crack here and there in a stone pier, arch, or stairway, or a block of veneer. loosened or dropped from a front, they remained entirely serviceable, so far as the earthquake effect was concerned. An excellent example of this class of buildings, and one that is exceedingly instructive, as it passed through the earthquake but escaped the fire that ravaged San Francisco, is the Union Savings Bank, in Oakland, at the corner of Broadway and Thirteenth street. This building is a steel-frame, stone-veneered structure, having 11 stories and a basement. It is founded upon separate concrete blocks and piers which rest upon a strong soil of mixed sand and clay. This structure was practically uninjured.

Buildings in San Francisco which rested upon foundations of sand in natural place were not injured by the shock, except where the sand was on a hillside or had opportunity to spread and flow. In such places buildings of either masonry or wood were badly shaken. Where the buildings rested upon good, hard soil, as on the hillsides or summits; practically no injury was done with the exception of the loss of chimneys and, in some buildings, of plaster. A first-class building of stone, brick, concrete, or steel frame in such situation seems absolutely proof against any earthquake of no greater severity than the one under discussion.

\section{THE FIRE.}

\section{GENERAL DESCRIPTION.}

Immediately after the first shock of the earthquake sixteen alarms of fire, from widely separated localities, were turned in to the central station. The causes of these fires were directly traceable to earthquake effects, such as the upsetting of oil lamps and oil and gasoline stoves, the contact of combustible material with lamps and gas jets, the rupturing of chimneys and flues, the scattering of chemicals, such as phosphorus, and the upsetting of boilers, furnaces, etc. It is claimed that currents of electricity did not originate any fire. Either the generators were disabled or the attendants switched off the currents. 
The death of Mr. Sullivan, the chief of the fire department, which was caused by the falling of a mass of brick from a chimney while he lay ill in bed, was a most unfortunate accident, as the city was thereby deprived of his excellent knowledge and skill as a fire fighter. The fire department, although it responded promptly to the calls and was composed of brave and efficient men, with excellent apparatus, was disconcerted by the loss of its chief and paralyzed in its action by the almost complete rupture and disintegration of the water system. The city mains were so thoroughly broken that in a short time not only could no water be obtained for the extinguishment of fires, but for a number of days little water could be had for domestic use, and the people were compelled to rely op a few wells that remained available.

In private dwellings incipient fires were quickly extinguished by individual effort; but, because of the early hour, the fires which started in the great downtown business houses, factories, etc., "south of Market street," grew to alarming proportions before anyone could reach and conquer them. With the exception of the private water: supplies, such as wells (see map, Pl. LVI), pumping systems, etc., possessed by a few establishments, there were no means of extinguishment. Within three hours after the earthquake nine fires were in full conflagration between "The Mission"a and the water front south of Market street. At first there was little or no wind to fan the flames, but the great heat soon drew in a current of air which continually increased, and, varying from one point to another, swept the flames first in this direction and then in that. By Wednesday noon the fire had consumed nearly a square mile of the city on the south side of Market street, and on the afternoon of the same day it broke across to the north side, in the vicinity of the high steel Call (Claus Spreckels), Examiner, and Chronicle buildings. Thence the fire veered with the wind, burning northward and westward through Chinatown, and joined its destructive energy with that of a separate column of fire that had swept up from the lower end of Market street. and the water front. The column, driven by the wind, ate its way rapidly through the residence portion of the city, which was built of wood and hence was consumed like tinder. Three hours after the conflagration had begun a corps of dynamiters was organized, but as no such body had existed in the fire department, it was necessarily composed of volunteers and amateurs. These men fought the flames with great bravery, but with little skill, and their endeavors to arrest the progress of the fire by throwing structures down in its path were

"a "The Mission" is a well-known locality in the city of San Francisco. It is the site of the original settlement and mission established by the Franciscan monks, and the old Mission Church still stands there (PI. XXIII, B), as the fire was checked at this point just in time to save it. 
futile until late on Thursday night, after a dynamite expert had been put in charge. A last stand was made in the western part of the city, at the broad and open street, Van Ness avenue. Here the dynamiters, aided by the shifting of the wind to the west, were able to stay the progress of the fire. Everything in the Mission district had been burned, except at places where the flames were checked by means of private water supplies. Although comparatively feeble, the fire continued in some parts of the desolated district until Saturday morning, April 22, when the last blaze was extinguished. The wharves and a fringe of buildings along the water front had been saved by means of engines and State fire boats drawing water from the bay.

The area of the burned district (see Pl. LVI) is 4.05 square miles, or 2,593 acres, and includes 490 blocks entirely burned and 32 blocks partially burned. These blocks were in two different classes, one being the "100-vara ${ }^{a}$ block," and the other the " 50 -vara.": Some structures along Mission Creek and a few residences on the summits of Telegraph, Russian, and Clay Street hills (Pl. LIV) escaped. The mint and a few other buildings were also saved by means of private water supplies.

Thus the greatest fire in the history of the world destroyed more than 4 square miles of closely built city property estimated at $\$ 500$,000,000 , half of which was insured; with the loss, it is believed, of about 800 human lives (though the official count is less).

San Francisco was little prepared to fight a conflagration under the existing conditions. Ever since the six devastating fires of the period from 1849 to 1852 the people had evidently relied on the excellence of the fire department (subsequently organized), the damp atmosphere, and the tradition that redwood, which composed the exterior of 90 per cent of the structures, would not burn. Dwellings were not protected against fire either from within or without, and the same may be said of most of the boarding houses and even of some of : the public hotels. There were few chemical extinguishers, private water supplies, or other fire apparatus in existence. In the congested business district buildings that had ample modern means of fire prevention within, or protection against fire from without, were the exception rather than the rule. Few buildings had metal shutters, wire-glass windows, sprinkler systems (interior or exterior), or private wells, tanks, or pumps. Some buildings where these preventives were installed were saved, although surrounded by fire.

Inflammable wooden buildings-remnants of the pioneer days of 1849-were scattered through the business districts and added fuel to the flames. The magnificent high steel structures that were gutted 
by the fire owe their desolation for the most part to their environment by these inflammable buildings.

There was no dynamiting corps in the fire deparment and no adequate salt-water system for fighting fires, although the city was almost surrounded by salt water, and there were no fire boats belonging to the department, and few cisterns in the streets or squares. Most of the streets were very narrow, and many of them were-lined by high wooden buildings. With the water mains and distribution system incapacitated by the earthquake, it is no wonder that the city burned; the only. wonder is that it had not burned before. This result had been prophesied by insurance inspectors many months previously.

\section{ABSTRACT OF REPORT OF ENGINEERS' COMMITTEE OF THE NATIONAL BOARD OF FIRE UNDERWRITERS.}

The Coast Review, an insurance paper, gives an abstract of the report and conclusions of the engineers' committee of the National Board of Fire Underwriters. This report was published in October, 1905 , many months preceding the occurrence of the great fire, and is epitomized as follows:

The area of San Francisco within the "fire limits" was 1.6 square miles. The "brick district" comprehended 0.95 square mile, and the "congested-value district" 0.49 square mile. The number of fires in the preceding nine years was moderate, but the average loss at each fire was two or three times the loss expected in cities having ordinary fire protection. The water supply was satisfactory in many respects, although the pressure (the average being 52 pounds) was too low for automatic sprinkler equipments, standpipes, etc. The fire hydrants were of an old style, and many water mains were too small. There were four water services, varying for districts of different levels. It was stated that the fire department was satisfactory in most respects, but that the building laws were not enforced thoroughly and impartially. The fire-alarm system was criticised adversely.

The "congested-value district" was bounded on the north by a mixed mercantile, warehouse, and dwelling section; on the west by a fashionable boarding-house, apartment, and residence district; on the south by a compactly built mixed district composed of dwellings and manufacturing and mercantile buildings, and on the east by the Bay of San Francisco. This district consisted of 101 blocks, containing 2,086 separate buildings, of which 2.2 per cent were fireproof, 68.3 were joisted brick, and 29.5 were frame buildings. There was only one sprinkler equipment in the district, and it was practically obsolete. Premises were generally clean and well cared for.

The "potential hazard" in the produce and commission district bounded by Battery, Washington, Drumm, and Commercial streets was said to be serious. The expert inspectors claimed to have found 
" conflagration breeders." In regard to the blocks north of Market street and between Powell and Taylor streets they reported: "This section contains more serious exposures and conflagration breeders than any other equal area in the city." They reported "frequent high winds," the absence of modern protective devices generally, the "probability feature" alarmingly severe, the elements of a " conflagration hazard" present to a marked degree, and the topography unfavorable. In fact, "San Francisco has violated all underwriting traditions and precedents by not burning up; that it has not done so is largely due to the vigilance of the fire department, which can not be relied upon indefinitely to stave off the inevitable."

This report was locally regarded as very severe, and in some respects-for instance, when referring to winds, redwood lumber, and hilly topography being unfavorable-as erroneous; but, unfortunately for San Francisco, the prophecy has come true.

\section{EXTRACT FROM A SAN FRANCISCO FIRE EXPERT'S REPORT TO THE BRITISH FIRE-PREVENTION COMMITTEE.}

George J. Wellington, who was born and reared in San Francsico, and therefore can not be accused of prejudice against that city, in his report to the British fire-prevention committee of London in 1906, says, among other things:

A glance at the city from a point of eminence shortly after the temblor had subsided at once disclosed the fact that San Francisco was doomed. Columns of smoke ascending from fires at many different points made apparent a condition that no fire department in existence could cope with, on account of the impossibility of assembling sufficient apparatus at each fire to control it, and particularly on account of the fact that there was little or no pressure in the bydrants.... Observation for six hours from the top of a tall office building failed to illustrate anything not already known to fire experts, and previously demonstrated at Baltimore and other places. Unprotected openings of brick buildings, improperly hung and uncared-for metal-clad sbutters, ineffective rolling and ordinary iron shutters, were conspicuous by their weakness. Exposed sides of hollow-tile fireproofing again cracked away; concealed piping again forced fireproofing away from steel members that it was intended to protect; metal-lath and plaster partitions again failed, and unprotected steel was warped and distorted, permitting floors to fall. Tall brick buildings with joisted interiors radiated heat to wooden cornices and window frames, which took fire.... In fact, everything that had been predicted by fire engineers occurred.

The bigotry of architects, the cupidity of contractors, and the penuriousness of owner's have laid the metropolis of the Pacific low. The work of intelligent architects came to naught against the creations of incompetent ones. The owners of well-constructed buildings were burned out by their criminally careless neighbors. In many instances talent was not engaged on account of its ability to construct permanently and well, but rather for its shrewdness in erecting structures that would earn the greatest returns for sums invested. Competi- 
tion in this respect has led to the use of inferior materials and the evasion of building laws and the underwiters' recommendations. San Francisco possesses building laws in plenty, which require enforcement rather than alteration. A valuable addition to present ordinances would be one similar to that in force in some European countries, which penalizes owner's for fires that escape from their buildings, affording protection to men disposed to build well.

\section{EFFECT OF THE LAYOUT OF THE CITY AND THE CHARACTER OF THE BUILDINGS.}

San Francisco, as already stated, is divided into three great districts. Market street, the great artery of the city, 120 feet wide, runs southwestward from the bay, and divides the city into two partsfirst, a level district on the south, largely filled with wooden buildings, factories, foundries, lodging houses, and the like, but around the bay extremity of the street covered to a considerable extent with buildings of brick, stone, or steel frame; second, the uneven and in its remoter parts hilly district on the north. This northerly portion is subdivided by Van Ness avenue, which separates the older residence district from the newer one on the west.

In the older section of the city, between Market street and Van Ness avenue, the streets had been established under the old Spanish system of "100-vara lots," as they are locally known, each block containing about 76,000 square feet. West of Van Ness avenue and south of Market street, in parts of the city more recently surveyed and built upon, the blocks are much larger, and-particularly along Market, Mission, and adjacent streets to the south-were built up with very long rows of buildings, many of them continuous for hundreds of feet. These blocks were so large that it was found necessary, or at least convenient, to subdivide many of them by narrow streets or alleys that permitted the ingress and egress of carts and drays. It was easy for the flames to pass across these narrow streets, and the heat was in many places so great that buildings on the opposite side of the street were ignited by the heated air without the passage of any flames.

More than 90 per cent of the buildings in San Francisco were of wooden-frame construction, and many of the new, modern, and socalled "fireproof" buildings were surrounded by frame structures of an old type, and, of course, were injured or destroyed by their combustion. The fire limits permitted these wooden structures to approach rather close to the business section; and in the congested business district at least 30 per cent of the buildings were of frame construction, some of them four or five stories in height. Outside of the congested district many business houses and almost all dwellings were frame structures. and except in the outskirts of the city 
were closely built in long rows extending over entire blocks. In the business district almost every separate structure was close to its neighbors. Wide, uncovered spaces separating buildings were; as a rule, confined to the outlying suburbs. In the compactly built district of wooden structures a house every three minutes was frequently the rate of destruction from the fire during the high wind that prevailed at times.

In the congested business district about 75 per cent of the streets were 60 feet wide, and a few (about 30 per cent) were at least 80 feet wide. These streets offered very little obstruction to the passage of the flames or heated air, and it was aided by the winds that were caused largely by the conflagration.

The height limit as e ablished by the city ordinances was 220 feet for buildings of class A, 100 feet for class B, 82 feet for class C, and 45 feet for frame buildings. Brick buildings with wooden joists were therefore allowed to be built to a height of eight stories if furnished with wire-lath and plaster ceilings, thus affording the fire admirable opportunities for destruction.

\section{BEHAVIOR OF STRUCTURAL STEEL AND STEEL-FRAME BUILDINGS SUBJECTED TO THE EARTHQUAKE AND FIRE:}

EFFECTS DUE PRIMARILY TO THE EARTHQUAKE.

\section{INTRODUCTION.}

Structural steel as a building material and as a principal stress resistant in high steel-frame buildings has greatly increased in favor since its entirely satisfactory behavior in the recent great vibrations in California; for while it possessed strength and stiffness to a satisfactory degree, it also displayed an amount of elasticity that avoided much shearing and fracture, even under the vibrations of the tallest steel-frame structures.

The behavior of structures of the various types in San Francisco and elsewhere in the area destructively affected by the earthquake was in strict accordance with the merits of their foundations, design, materials, and workmanship. The so-called fireproof buildings within the area most affected by the earthquake, and afterwards, in San Francisco, burned over, did not exceed 60 in number. Among these buildings were 8 having steel frames and hollow-tile floor arches, 29 or 30 having steel frames with reenforced-concrete floor arches, and 2 having reenforced-concrete frames-one of these of imperfect design. There were 6 unfinished buildings with steel frames, and 10 having brick walls and fireproof floor arches. 


\section{FOUNDATIONS.}

It is believed that every building whose foundations were well and strongly established-upon deep piling, as, the Union Ferry Building and the Merchants' Exchange; with reenforced-concrete slab, as the Call Building; upon separate concrete piers or grillages resting upon good beds having a uniform load per square foot, as the Union Savings Bank in Oakland; or upon any other type of excellent foundation-escaped injury by the earthquake to the foundations themselves, nor did the superstructure owe any damage to inefficiency in those foundations.

The central portion of California was subjected to a severe earthquake in 1868, and has, on a number of occasions since, been slightly shaken by earthquake shocks, but many architects and engineers, and the people generally, had become so accustomed to these slight movements of the earth's crust that little attention was paid to them, and, so far as the writer can learn, architects had believed that in establishing solid foundations for high steel buildings, with good anchorage and bracing, adequate to take care of extreme wind force, they had sufficiently guarded against the effects of any earthquake vibrations which might occur. As a matter of fact, the provisions thus made seem to have been ample and safe so far as any disturbance of the foundations or any lack of support of the superstructure has been detected. Notwithstanding the severe vibrations these tall buildings have been called upon to endure, they have remained plumb and very slightly damaged by the earthquake.

STRUCTURAL-STEEL FRAMES EXPOSED TO VIBRATORY MOTION.

As stated by' A. O. Leuschner, secretary of the California earthquake commission, and also by Professor Omori, the distinguished seismologist of Japan, the vibratory motion in Berkeley and in San Francisco was approximately 3 inches in a horizontal direction and about 1 inch vertically, the time of the first oscillation being one second. This is understood to be the vibration on very hard soil or solid rock. Where the soil was softer and less coherent the waves became longer and the movement slower.

This vibratory motion had a tendency to move the foundation of a high building and the basement immediately in connection with it forward and back, and perhaps to move some of its columns in opposite directions, although this is not certain. At any rate, it apparently had the effect, owing to the inertia of the mass of the upper part of the building, of bringing a maximum bending moment to bear on the frame at some point between the basement and the top 
of the building-to speak roughly, somewhere near the middle stories. It also seemed to have the effect of producing a horizontal shearing stress in the frame, particularly above and near the basement. The frames in these high buildings seemed to be the most severely wrenched, and the exterior walls, stairways, linings, etc., most injuriously cracked in these middle stories. For example, the magnificent eighteen-story Call Building seemed to be well braced against bending moment and shear, but the eyebars from the tenth to the sixteenth floor and the transverse wind bracing are reported to be somewhat buckled, the maximum occurring on the thirteenth floor. The braces were warped on all four sides of the building, and there was also probably some.slight distortion of the steel frame from the tenth to the thirteenth floors. The exterior veneer of stone remained practically intact up to the tenth floor, above which, up to the sixteenth, there was an increasing amount of damage, some of the stone being considerably out of place. (See also p. 146.) The same thing practically can be said of the new Chronicle Building, the damage to the stonework of which can be noted by a close inspection of $\mathrm{Pl}$. XXX, $B$. The earthquake proved the absolute necessity of bracing steel-frame buildings with diagonal braces, so far as the requirements of use will allow. The Mutual Savings Bank and the Shreve and Atlas high steel-frame buildings have such bracing and remained entirely plumb after the earthquake. The St. Francis Hotel and the Call Building were somewhat similarly braced and were also left in reasonably good condition.

Some architectural authorities assert that wind bracing put in liberally for an allowance of 30 pounds pressure per square foot will amply care for earthquake vibrations of an intensity equal to those of April 18, 1906. Undoubtedly many of the high steel buildings in San Francisco were designed without reference to earthquakes, but they have nobly withstood their effects, and steel frames have proved themselves entirely adapted to earthquake countries. A careful inspection of the high steel frames in San Francisco shows that they suffered comparatively little injury, and that this injury was confined to the shearing of rivets and connections, particularly in the lower stories and on the ground floors, and to some buckling of braces.

After the earthquake, bolts and rivets in the Union Trust Building were found to be loose, and some were sheared off. This damage was due apparently to faulty construction, careless workmanship, and the insertion of field bolts, in some places, instead of rivets. It was shown that the rivets, connection joints, etc., in these steel-frame structures are of vital importance, and that in order to resist earthquake vibrations they should be made as strong and effective as possible, particularly at the basement and first floor. 
The stone exteriors of all the high steel-frame buildings were to a greater or less extent cracked or injured under the action of the earthquake. In some places, owing probably to imperfect bond between the veneer and the steel frame, the stone veneer was displaced and the walls were bulged outward; in others, blocks were thrown to the ground and bricks or arch stones from windows and other exterior openings were dropped out of place. This disintegrating effect had its maximum in the intermediate stories between the top and the base of the building, a very good example being the Union Savings Bank in Oakland. This eleven-story steel-frame, stoneveneer structure gave opportunity for careful and comprehensive study of earthquake effects independently of fire, since it is really the only high steel-frame structure in the disturbed area which was not subjected to fire. In this building the steel frame is intact and uninjured, so far as can be ascertained. The marble. veneer along the stairways and corridors and the sandstone exterior, particularly in the fourth, fifth, sixth, and seventh stories, were somewhat cracked and disturbed, indicating not only a bending but a shearing action; and the brick in the arches in some of the windows in these stories have dropped to the ground. Otherwise the building escaped damage, and it has been continuously in use since the earthquake.

The Aronson Building, at Third and Mission streets, had stone piers running from the bed up to the street level. These were badly wrenched and cracked by sheer action, and in the ninth story two courses of stone in the arches above the soffit course were badly cracked, apparently for the same reason. In the Call Building, where the stonework ends at the sidewalk level, the corner piers were not found to be cracked, but in the James Flood Building (Pls. XXXIII, $B$; XXXV, $A$ ), where the stonework extends to the bottom of the basement, the corner piers were cracked by earthquake action.

RELIABILTTY OF S'TRUCTURAL STEEL.

Structural steel is a very reliable material. It is produced and also placed in position by high-class skilled labor and is not subject to the flaws which sometimes appear in concrete work as a result of poor quality of labor and inefficient inspection. Builders in this country have had much experience in the use of structural steel, and feel sure of what it will do and for what it stands. It is no longer: in the experimental stage as to resistance either to earthquake tremors or, when properly fireproofed, to conflagration. Constructors in San Francisco feel that this material has safely and triumphantly passed through a most trying ordeal, 
EFFECTS OF THE FIRE.

\section{BUILDINGS.}

Structural steel in the steel-frame buildings subjected to the terrific heat of the great conflagration behaved satisfactorily wherever it was properly and amply protected by any method adopted for fireproofing. In no instance that has come under the observation of the writer has the steel been injured or deformed where such fireproofing was of the proper kind and remained intact after the earthquake. Unfortunately, in many places there was practically no fireproofing whatever, or it was very poor in design or workmanship, or both, and as a consequence failed miserably. Columns were softened and buckled. Girders were softened to such a degree that they sank by their own weight, some pulling after them the walls into which they were built, others falling into the fiery furnace below, as in the Cowell Building (Pl. LI, $B$ ), where the fireproofing eitherwas lacking or proved defective in the fire. In such places the columns were buckled and some of them telescoped, thus removing all support for the floors above. In other buildings where the fireproofing was fairly good and effective, as in the James Flood and the Call buildings, the structure remained ready for rehabilitation. Although all the steel girders or columns that were subjected to intense heat on account of lack of fireproofing did not fall, yet many of them were rendered unfit for further use.

Prominent among the steel structures was the eighteen-story Call Building, with dome and lantern, the architectural pride of the city. This building took fire through a tunnel leading from the power house in the rear of the building, across Stevenson street. The fire was drawn in by the draft up the 18 stories of the elevator shaft, which acted like an enormous chimney, the flames being sucked up to the topmost story with great force and rapidity. The heat, of course, became intense, and all combustible matter on the interior of the building was quickly consumed, but the fireproofing, although not perfect in design and execution, so far protected the steel frame that it remained. only slightly damaged and ready for refitting. The marble lining of the walls and corridors, and the glass in the exterior and interior windows, were all destroyed, and the metal trimmings were to a considerable extent melted or ruined. But the steel frame and stone exterior, with the exception of that on some of the middle stories, remains little injured, and parts of the building are continuously in use.

In the same way the James Flood Building, one of the newest and largest steel-frame structures, excellent in design and first-class in workmanship, was fairly well fireproofed; and although gutted by 
the fire, it is being rapidly refitted for store and office occupation. The Western Pacific Bank reoccupied its old quarters on the first floor of this building almost immediately after the fire.

FIREPROOFING:

GENERAL CONDITIONS.

It can be truthfully stated that perfect fireproofing of buildings in San Francisco, even in those of the newest and most modern type, was the exception and not the rule. The bent or broken columns and the distorted or disfigured steel girders in many of the burned buildings demonstrate this fact (Pl. XXVII, $B$ ). Wherever structural-steel framework was covered with fireproofing material of the best design, executed with conscientious, skillful workmanship, the steel remained uninjured after the fire.

The lessons taught by the great Chicago and Baltimore fires had been applied by but few of the architects of San Francisco, on account of cost restrictions insisted on by owners, and very much of the damage inflicted on these high-class structures during the conflagration is directly traceable to the imperfect fireproofing put in, or to the entire absence of fireproofing. Some of the failures were evidently and directly attributable to poor workmanship.

CONCRETE.

There are two opposing parties in the matter of fireproofing in San Francisco-those who have favored the hollow-tile system, and those who believe in concrete as the best fireproofing material. The Bekins 'Van and Storage Company's warehouse, the only building of considerable size in the city constructed of reenforced concrete, has already been mentioned as resisting the action of the earthquake and fire. In this building the concrete acted as a perfect fireproofing protection for the steel.

Good Portland-cement concrete has won a triumph for itself in fireproofing in San Francisco, for wherever well made and properly laid upon the steel girders or columns, it protected the metal. In very hot fires the exterior portions were disintegrated, and in some places the whole mass was cracked, necessitating removal, but the fireproofing it furnished during the conflagration was excellent. Examination showed also that it protected well against rust. The heat to which it was subjected was very great, in places common mortar being fused and ironwork in walls melted.

The steel beams and girders in the St. Francis Hotel, the Merchants' Exchange, the Mutual Savings Bank, and other similar structures that were thoroughly fireproofed with concrete endured the fire exceedingly well. 
The weight of Portland-cement concrete is a drawback, and, moreover, concrete is expensive when well made and applied. Cinder concrete was well esteemed for fireproofing for floors, but the scarcity of good cinders in the city rendered its general employment impracticable.

TERRA COTTA.

As fireproofing for floors terra-cotta tiling. has not given universal satisfaction. It is lighter than concrete, but the wrenching of buildings during the earthquake opened many of the joints and the mortar was destroyed-as in the Mills Building, a large ten-story steelframe structure of the older type, having self-supporting walls. The mortar joints in the tiling were started by the earthquake, and the mortar was disintegrated by the fire, the floors being destroyed and the lower surfaces of the tiling badly spalled. The same effect was noticeable to a certain extent in the excellent Union Trust, Crocker, and James Flood buildings. In the last named the flooring was fireproofed with terra-cotta arched tiles, covered with concrete on top and finished beneath by an efficient ceiling plastered on wire lath. The fireproofing was less injured in this building than in almost any other.

Terra-cotta fireproofing of columns was in many buildings a failure, not so much on account of the nature of the material as because of its insufficiency in quantity and poor or imperfect method of application. Wooden studs were in many places put behind the terra cotta. These burned out quickly, leaving the material insupported. Pipes and wires were run up between the column and the fireproofing, and the twisting or expansion of the pipes caused by the earthquake movement broke the protecting cover. Imperfect junctions with ceilings above or floors beneath were common. That such imperfect construction should never be adopted has been fully demonstrated in San Francisco.

Porous terra cotta has been found more satisfactory than the hard and glazed varieties. For inclosing columns, the round porous forms have proved more stable and efficient than the rectangular ones, as shown in the Spring Valley Water Company's building (Pl. XLV, $A$ ) and the Aronson Building (Pl. XXVII, $B$ ).

PLASTER AND METAL WORK.

Common plaster on wire mesh, metal lath, or expanded metal was very generally used for the fireproofing of columns, partitions, and the like, on account of its cheapness, but was a failure when subjected to a hot fire, as proved in the Hotel Fairmount (Pl. XXXIV), the Hotel Hamilton, and several other buildings. This failure was much more noticeable where only a single wrapping or thickness of the wire 
mesh, etc., was used than with the double wrapping. But even the latter proved to be too weak and disintegrable to pass successfully. through a severe earthquake or a fire and a strong stream of water from a fire hose. The plaster quickly cracks and falls away from the metal. No doubt these materials will be used in the future by owners demanding cheapness of construction; but they will satisfy the requirements only in cases of mild exposure. Good gravel concrete in place of the plaster, if of considerable thickness, has been found to give better results.

The failure of the plaster and metal method and some other methods of fireproofing in San Francisco is directly traceable to the commands of owners to their architects to cheapen as far as practicable the fireproofing and the construction generally, in order to receive greater interest on their investments. Much of this cheapening has been done in spite of the protests of the designer, and it is in an entirely wrong direction; for rates of insurance are largely reduced with improvements in fireproofing, and as the cost of the steel frame and its proper fireproofing seldom exceeds 27 per cent of the cost of the building, it seems wise to protect the other 73 per cent with adequate materials.

BRICKWORK.

In some buildings in San Francisco, brick laid in rich Portlandcement mortar has been found to be an excellent fireproof covering; but it is objectionable on account of the bulliness of the brick and the rusting of the steel, as in basement stories. Good brick withstood the severe fire well, and where laid in rich cement afforded a strong fireproof wall or pier. At least 4 inches of brickwork was found necessary, and a layer of concrete 3 inches in thickness between that and the steel was a great improvement and served well to protect the steel from rust. But this method will probably not be followed in general, on account of weight, bulk, and expense. Hollow brick and tiling were efficient also when properly and liberally used, porous tiles proving to be the better.

The well-known Palace Hotel was built about thirty years ago, a few years after the earthquake of 1868 , and before the introduction of steel-frame structures and concrete steel. It was intended to be earthquake proof as well as fireproof, and was built with very heavy walls of brick, most of them being 2 feet or more in thickness, laid in cement mortar, and strongly braced by many cross and partition walls. In the brickwork, at every 3 or 4 feet in height, were laid bands of iron, riveted together at their ends and crossings. This building, although of the old type, successfully endured the great earthquake, its walls being practically uninjured (Pl. XXX, $B)$;

7171-Bull. $324-07-11$ 
and although gutted by the fire, which gained access through the .unprotected windows and wooden casings, was so strong on its foundations that very vigorous blasting operations were required to throw down its walls.

\section{REENFORCED CONCRETE.}

There was in San Francisco at the time of the earthquake only one building of considerable size constructed of reenforced concrete. This fact was due to the opposition of certain labor unions to the use of this material in place of brick and stone.

The building referred to is that of the Bekins Van and Storag'e Company, at 190 West Mission street (Pl. XXVII, A). This building had outside walls of brick, but was massively constructed on the interior with columns, beams, and floors of reenforced concrete. It was originally intended to carry it to a height of four stories, but on account of the earthquake, which occurred during construction, the building was finished to include only the second story. At the time of the fire the permanent doors of iron were not in place, and the fire gained access to the front or south room, where very slight damage was inflicted. The entire main interior and the goods stored therein were unharmed, and the building has been in continuous use since completion. The brick building adjoining, however; was badly injured by the earthquake and was afterwards burned.

\section{LESSONS FROM THE VARIOUS TYPES OF BUILDINGS.}

Great destructive earthquakes have seldom occurred twice in the same locality during centuries of time, but, so far as man knows, one may occur at any time anywhere on the earth's surface. On the other hand, destructive conflagrations in cities have happened many times, but most of them might have been avoided by wise and adequate provision for fire prevention, protection, and extinguishment.

In San Francisco the earthquake could not have been averted, but its disastrous effects on structures could have been prevented by the use of proper materials correctly applied in the execution of skillful and scientific designs, carried out by good conscientious workmen under honest and able supervision. The city's official inspection has usually been very inefficient.

The buildings in California that were ruined or badly injured by the last earthquake may be divided into four classes:

The first class comprises buildings of a public character, such as city halls ( $\mathrm{Pl}$. XXXI), court-houses (Pl. XXXIX, $A$ ), asylums, public schoolhouses, etc., which were badly desibned and constructed or for the construction of which insufficient funds had been voted, so that the materials and workmanship, under imperfect inspection, or 
worse, were of very poor quality. In contrast to such construction were the United States Government buildings-the mint and the appraisers' (or customs) building (Pl. XXVIII, $A$ ), in San Francisco, and the post-office building in Oakland-all of which were either entirely uninjured or very slightly injured by the earthquake. These buildings were well designed and constructed with the best materials and workmanship, upon foundations that had been tested and found strong and satisfactory. The results to both of these classes of buildings were fully to be expected.

As a second class of buildings that suffered badly may be grouped those of the oldest type of wooden structure in San Francisco, lightly resting upon slim wooden underpinning, which stood upon soft and unstable soil or loose, unconsolidated sand. Such houses went down at the first shock, as one would naturally expect. In contrast to these flimsy structures are the thousands of more substantially constructed wooden buildings that still stand intact, except as to chimneys and some plastering, all over the unburned part of the city. These structures were built fairly well and upon stable foundations; and the writer believes from his personal observation that no wellfounded and well-constructed building of wood in San Francisco was injured to a greater degree than those just mentioned. In a country subject to earthquakes a strongly framed and well-founded wooden house, not exceeding three stories in height, with nondisintegrating plaster and finish, light tile chimneys, and ample fire prevention and protection, would seem to be the ideal type of residence structure.

Experience shows that buildings constructed with exterior brick walls laid in common mortar, with timber columns and girders, tied and braced little or not at all, constitute a third class of buildings which are nonresistant to a severe earthquake, particularly if they are erected upon a poor foundation. Even if the girders and columns are of metal, they are pulled apart, and the walls fall inward or outward during the shock. Only rich Portland cement, laid with wetted brick, and strong joists, ties, and anchorage, endured the stress.

The behavior of the high steel-frame office buildings, which constitute the fourth class, has shown that in order to resist perfectly the bending moments and shears induced by the swaying due to the earthquake movement, such buildings should be stiffened in their joints and connections by the best riveting combinations, and $\cdot$ knee and other bracing, particularly at or near the ground floor. This requirement is of the utmost importance, and so also is the one that the swaying referred to should be diminished by the liberal introduction of diagonal and wind bracing throughout. The proper bracing in the lower stories has in some buildings been omitted, on the demand of 
owner or lessee, to afford more glass or light space, but such design has a weakening effect, and should be discouraged. The Marston Building, on Kearney street, is an object lesson in this respect. On the other hand, the Whittell Building, on Geary street, near Union square, is commended for its deep plate girders and heavy steel generally. It stood well, and no rivets were sheared. Columns, exterior and interior, in steel-frame buildings, should in future be put in more liberally on the first and second stories, and the strongest joints and connections should be adopted in order to resist the bending and shearing. These improvements will greatly. stiffen the steel frame, and prevent the cracking of the walls. The Kohl Building, thus stiffened by lattice girders on all floors, was uninjured in its exterior stonework and brickwork, although built upon the edge of the made ground along the old shore line. With such strengthening the high steel structures will safely endure an earthquake of even greater severity than that of April 18, 1906. This kind of building has proved its worth and reliability, and minor improvements, as advocated, will produce an enduring structure.

In a fifth class are to be placed, but not as failures, concrete and reenforced-concrete structures. These have become popular with a large number of designers in San Francisco, on account of the strength claimed for them, and on account of the indestructibility, facility of construction, and fire and rust protection that their materials afford. Unfortunately for San Francisco, there were very few structures of concrete or reenforced concrete in the city at the time of her great trial; but these few behaved well during both the earthquake and the resulting fire. Therefore, although such structures are admittedly new and comparatively experimental on the Pacific coast, the confidence reposed in them has already led to the designing and construction of a number of large buildings of this type for public or business purposes. At present the sentiment is to limit them to a height of six or eight stories, on account of their experimental character and because of the fear that greater height would permit a reversal of stress, due to earthquake and wind force in their reenforced girders. It is agreed that the columns should be reenforced with steel and braced together wherever possible; that the girders should be similarly reenforced for tension and shear, and made, so far as practicable, continuous over the columns; and also . that the joints and connections should be strongly stiffened and the curtain walls strengthened by a reenforcement.

Mill construction with brick will undoubtedly be utilized in many buildings for a considerable time to come, but the lesson has been taught that the materials used should be first-class pressed brick, well wetted, and cement mortar, and that all parts should be thoroughly 
tied and anchored together. San Francisco's experience has proved that this rule is a most important one to follow in all brick and stone construction, and its neglect in the past has resulted in much loss and ruin.

\section{FIRE-FIGHTING APPARATUS AND FIRE-RESISTING MATERIALS.}

The damage inflicted on San Francisco from the direct and immediate effects of the earthquake was relatively small, being estimated at only 3 to 10 per cent of the total loss; but a subsequent and indirect effect was to paralyze the water supply and its distributing system, start a great conflagration and render impossible its extinguishment with the means at hand, cause the death of at least 600 human beings, burn approximately $\$ 500,000,000$ worth of property, render homeless and miserable 200,000 people, and inflict remoter damages to business, commerce, and labor, only to be estimated in the future. Inasmuch as it can be plainly seen, by looking backward, that nearly all of this destruction and suffering might have been prevented by wise foresight and provision, it is felt that a warning should be sent to all the cities in the world. Any city that disregards this warning will be guilty of a great crime.

San Francisco should have had separate and ample water mains entering the city on several independent lines from different sources of supply, and numerous distributing reservoirs on the hills in various parts of the city, always well filled, independent and yet with a distributing system meshing the entire area, with its pipes so joined or valved that they could be separated or united as desired. There should have been in that city, almost surrounded by salt water, a separate system of flexible salt-water mains for fire and sewer purposes, and numerous large cisterns in her streets, laid in reenforced concrete, with somewhat flexible lining and pipes. These cisterns, only a few blocks apart, should have been filled at all times with salt water. There should have been many wide streets-like Van Ness avenue, where the fire was finally checked-and many large squares, the city being thus divided into numerous fire districts. The fire department should have included a dynamiting corps of experienced fire fighters, and a number of fire boats always. ready along the water front and among the shipping. None of these things did San Francisco have. With these means available, probably this story of the greatest fire in history would never have been written.

Of a building's entire fire risk, that from fire within the building is estimated, on the average, at 40 per cent, the other 60 per cent of the risk being from exterior fires. This risk for interior fires should 
be reduced to a minimum by ample provision for fire prevention. As far as practicable, combustible material should be eliminated. Several of the fine so-called fireproof buildings in San Francisco were injured chiefly by the burning of their wooden trim, floors, doors, office furniture, papers, books, carpets, rugs, etc. - Wooden floors have proved to be dangerous and objectionable; but in some places noncombustible wood may be used for them and for the interior trim, as, for example, where the heat could never be very great. Metal trim, doors, windows, sash, and casings, together with plate glass, or, better, wire glass, may confine a fire to a single room, preventing a general combustion. Adequate fire-extinguishing apparatus-such as fire hose, always connected with good water pressure, wells with automatic pumps, and tanks in the basement or upon the roof, with pipe connections-was lacking in nearly all of San Francisco's buildings, even in those of the highest class. In the California Electric Company's building the standpipes, with attached hose, the well, pump, and tank in the basement, and the roof tank, together with the metal sash and the wire-glass windows, proved the value of such a private system, saving that property from the hot ${ }^{\circ}$ fire around it, though every adjacent structure was burned. As this building was not fireproof, the value of the fire-extinguishing system can be well understood, and had all the large establishments been equally well equipped the conflagration would have been quickly checked and a vast amount of property saved. Automatic sprinklers connected with the abovementioned plant will afford excellent fire protection within and will greatly reduce insurance rates.

While the fire danger from exterior fires to a given building is ordinarily estimated at 60 per cent, this risk practically becomes 100 per cent, of course, in a great conflagration. In San Francisco little protection from exterior fires had been adopted. There were few metal shutters or steel roller shutters, and most of those were of imperfect design, proving unsatisfactory when tested. The openings in walls were fatal points of weakness in all the great buildings. Wire-glass windows, though few in number, behaved well, but wooden instead of metal sashes were great sources of fiery contagion. Metal covering over wooden doors and window frames was generally inefficient. Ordinary glass. was quickly cracked by heat from the exterior; the sashes took fire and the flames rushed in through the openings, consuming all combustible material within. Many of the best buildings were gutted in this manner. Had they been furnished with metallic shutters of the best design, with wire glass in metal sashes, and with cornice and other exterior sprinklers, supplied by a private water plant, they certainly might have been saved. Thus the employees of the United States mint (Pl. XXXVIII), with a 
scanty private supply of water, made a desperate and gallant fight from the roof of the building and within, and saved it, little injured.

As most metallic shutters rapidly deteriorate with time, rust, and weather, and often become jammed so that they will not close, many architects prefer wire glass in hollow metallic sash and window sprinklers. This combination has proved effective.

San Francisco's experience indicates that wells and elevator shafts, running up through many stories, should be guarded by brick or reenforced-concrete walls, fitted with double metal rolling doors, bolted to the walls to allow for expansion, or with automatic sliding doors and wire-glass partitions. There was little or no provision for cutting off the draft of air that will ascend through such a shaft during a fire, and great destruction resulted in consequence. The Call Building took fire from the power house behind it, on the other side of Stevenson street, the heat being drawn through the tunnel to the elevator shaft, up which it rushed with the fierce draft given by the 18 stories, breaking glass and burning doors, furniture, trimmings, and office contents. The Telephone Building, on Bush street (Pl. XLI, A), met a similar fate, being consumed from within. This new structure was claimed to have the best fire protection in the city.

The importance and value of real protection will be appreciated when it is stated that a third-class building with a complete fireprevention plant is insured for less than a first-class one that does not have it. This fact should be understood by all owners. Moreover, all parts of an establishment should be equally protected, for the fire may begin anywhere. The new Telephone Building was burned owing to the nonobservance of this rule, catching fire through the inprotected wooden back door of the basement. The structure was fitted with "tin-clad shutters" and wire glass on the side and rear openings and with steel rolling shutters in front. The.fire broke through the rear wooden door into two well shafts and a corridor and, rushing upward, consumed every floor. The building was destroyed by a fire that entered through a single unprotected opening. The tin-clad shutters were destroyed and much of the wire glass was melted or broken by the hot fire. The rolling shutters in front still hung, but were bent so that the windows were exposed.

Concrete floors with metallic-mesh reenforcement are strongly recommended for strength and fireproof character. Noncombustible wooden floors, doors, and trim were installed in a few buildings, and under ordinary conditions would probably have limited the destruction to "one-room fires," but the heat was so high, and in general the bulk of papers, books, and furniture so great; that all were consumed. A noninflammable substitute for woodwork and trim generally is greatly to be desired. 
Double windows of wire glass in hollow metallic frames are recommended, or where such material would be objectionable by cutting off the view, double plate glass is considered next best. Interior doors should be of metal, or at any rate metal covered, in fireproof buildings, and the light for corridors and halls should come through wire glass. As the installation of wire glass, metallic rolling shutters, and metal sash involves only a small percentage of the cost of the building, and as these materials have proved to be of such excellent service as fire protection when of the best quality and workmanship, a wise economy demands their use in every important fireproof building.

Capitalists and owners must understand that perfect.fire protection for structural steel is necessarily expensive. Any so-called fireproofing that is cheap and flimsy is a delusion and will not serve. The application of an effective method insures permanence of the structure and at the same time greatly reduces the rates of insurance. Steel columns may be well fireproofed by surrounding them with the best quality of stone or cinder concrete 4 inches in thickness, or by 3 inches of either when hollow tiling is put on the exterior.

A 3-inch porous terra-cotta tiling, wrapped on the outside with wire, and with metal mesh used around the bed course of the column, has proved efficient. The mortar of the tiles should contain a large proportion of cement, and the tiles should be strongly anchored to the columns to prevent their falling away in earthquake or fire and so leaving the steel exposed.

In the great fire, decorations, trim, inflammable oil paints and varnishes, in office buildings, aided materially in spreading the flames. A noninflammable water-color paint that will endure washing has been recommended.

Fire walls of brick, extending above the roofs of buildings, were effective in resisting the spread of the fire; but the support derived from metal bands and anchors was neglected in many such walls, as in much other masonry in San Francisco; a large number of them fell, therefore, during both the earthquake and the fire, particularly those laid in common mortar. This was also a common fate of unsupported gables and towers. Walls that were well anchored, as in the Union Trust Building, remained in perfect condition.

Cast-iron columns in some buildings endured the earthquake and the fire fairly well, but undoubtedly would have been broken or shattered had cold water been thrown upon them in the midst of the great heat. They should no longer be used, for at present they cost more than steel for an equal factor of safety, and their connections are clumsy and weak.

Structures made of concrete blocks were as a r'ule greatly damaged 
or even ruined by the earthquake, owing to imperfect anchorage and failure to cohere at their joints (Pl. XVII, $A$ ).

Granite, sandstone, and marble were badly cracked and spalled by the fire, much of the marble crumbling to powder. The granite piers in the front of the Hobart Building were nearly all chipped away, and they are now reenforced by new temporary supports.

Chemical fire extinguishers were effectively used immediately after the earthquake in some of the uptown residences, thereby preventing an increase in the number of fire centers at the beginning of the conflagration. It is possible that numerous chemical engines and locally installed chemical extinguishing plants in the downtown districts might have greatly limited the spread of the flames, despite the dearth of water.

\section{FINAL CONCLUSIONS.}

\section{EARTHQUAKE PROTECTION.}

A proper foundation, stable and firm, is of vital importance, and particularly on soft, marshy, or made ground (Pls. XLIII, B; XLIV, A). Anchoring, bonding, and tying should be practiced with exactness in all masonry. Steel framing should be made heavier rather than lighter, and joints, connections, bracing, and flooring should be strongly united. Girders and columns should be made very stiff and, where practicable, continuous.

FIRE PROTECTION.

The lessons taught by the great fires of Boston, Chicago, and Baltimore have been verified by San Francisco's experience.

Fireproofing should be of the most perfect type, and no reasonable expense should be spared in its installation.

Roofs, roof appurtenances, and skylights should be given ample protection against fires from without. A great excess of fire hose and apparatus, beyond ordinary needs, should be available. A strong bond for fireproof tiling, etc., for both girder and column protection, is essential. Protection for front windows, as well as for side and rear ones, is of vital importance. Good protection for steel frames and steel roof trusses in attics or other exposed or unusual places should be provided. Liberal use should be made of fire retard, ant in windows, doors, transoms, etc. Wise and liberal use of concrete and reenforced concrete for girder and column fireproofing has proved its saving quality. Interior fire protection and prevention by wells, pumps, sprinklers, and water tanks vastly lessen fire risk. 


\section{ACKNOWLEDGMENTS.}

Special acknowledgment is due to the following gentlemen, who have courteously aided in the preparation of this paper with information and photographs: T. P. Woodward, city engineer of San Francisco; Charles Derleth, jr., associate professor of civil engineering in the University of California, and secretary of the Structural Association of San Francisco; A. O. Leuschner, professor of astronomy, University of California, and member of the California earthquake investigation commission; also Oscar Maurer, O. V. Lange, and Willard P. Worden.

Thanks are also due the Structural Association of San Francisco, the California earthquake investigation commission, the American Builder's Review and its Engineering Supplement, and the New San Francisco Magazine. 


\section{LIST OF PAPERS RELATING TO THE EARTHQUAKE AND FIRE.}

American Society of Civil Engtneers. Report of a general committee and of six special committees of the San Francisco association of members of the American Society of Civil Engineers. The effects of the San Francisco earthquake of April 18, 1906, on engineering constructions: Am. Soc. Civil Eng., Proc., vol. 33, no. 3, pp. 299-354, 31 pls., 3 figs. March. 1907. Discussion by Edwin Duryea and others: Idem, vol. 33, no. 5, pp. 537-547, 1 pl., May, 1907.

BaUER, L. A. Magnetograph records of earthqualies, with special reference to the San Francisco earthquake, April 18, 1906: Terrestrial Magnetism and Atmospheric Electricity, vol. 11, no. 3, pp. 135-144, 2 figs., September. 1906.

and Burbank. J. E. The San Francisco earthquake of April 18, 1906, as recorded by the Const and Geodetic Survey magnetic observatories: Nat. Geog. Mag., vol. 17, no. 5, pp. 298-300, May, 1906.

Branner. John C. The California earthquake: movements along the Santa Cruz fault line: Eng. News, vol. 55, no. 20, p. 542, May 17, 1906; Palo Altan, May 1, 1906.

Carer, Everetr P. The great fault of Califormia and the San Francisco earthquake, April 18, 1906 : Jour. Geog., vol. 5, no. 7, pp. 289-301, 6 figs., 1906.

Discusses the faulting which produced the San Francisco earthquake and displacements along the line of fricture.

Christr. S. B. Some lessons from the [San Francisco] earthquale: Mg. and Sci. Press, vol. 92, no. 17, pp. 273-274, April 28, 1906.

Cooper, A. S. The [San Francisco] earthquake explained: Mrg. and Sci. Press, vol. 92; no. 24, pp. 401-402, June 16, 1906.

Davidson, George: Points of interest involved in the San Francisco earthquake: Am. Phil. Soc., Froc., vol. 45, pp. 178-182, 1906.

Davison, C. The San Francisco earthquake of April 18: Sci. Am. Supp., vol. 61. no. 1586, pp. 25416-25417, May 26, 1906.

Derleth, Chardes, Jr. Report [on the San Frincisco earthquake] : Eng. News, vol. 55, no. 18, pp. 503-504, May 3, 1906; no. 19, pp. 525-526. May 10, 1906.

Some effects of the San Francisco earthquake on waterworks, street sewers, car tracks, and buildings: Eng. News, vol. 55, no. 20, pp. 548-554, 20 figs., May 17, 1906.

The destructive extent of the San Francisco earthquake of 1906: Eng. News, vol. 55, no. 26, pp. 707-713, 17 figs., June $28,1906$.

Engineering News. The San Francisco disaster; earthquake and fire ruin in the bay counties of California : Eng. News, vol. 55, no. 17, pp. 478-480, 1. fig., April 26, 1906. 
Fuller, M. L. Comparative intensities of the New Madrid, Charleston, and San Francisco earthquakes (abstract): Science, new ser., vol. 23, pp. 917-91s, June 15,1906 .

Gallowar, J. D. The recent earthqualie in central California and the resulting fire in San Francisco: Eng. News, rol. 55, no. 19, pp. 523-525, 13 figs., May 10,1906 .

Gilbert, G. K. The cause and nature of earthquakes: Mg. and Sci. Press, vol. 92, no. 17, pp. 272-273, April 28, 1906.

Heilprin, Angero. The concurrence and interrelation of volcanic and seisnic phenomena: Science, new ser., vol. 24, pp. 545-551, Nov. 2. 1906.

Ingaris, A. O. Earthquakes and their probable origin: Northwest Mining Jour., July, pp. 2-12, 14 figs., 1906.

Presents a detailed discussion of the Facifio coast earthquakes from 1888 to 1898 .

Lawson,. Andrew C., and others. Preliminary report of the [California] State earthquake investigation commission: Mg. and Sci. Press, vol. 92, no. 24, pp. 399-401, 4 figs., June 16, 1906 ; Sci. Am. Suppl., vol. 61, no. 1590, pp. 2548225484, Jume 23, 1906 ; Science, new ser., vol. 23, pp. 961-967, June 29, 1906.

Includes various data relating to the geologic structure of the State of California and to the earthquake of April 18, 1906.

Leuschner, A. O. The [San Francisco] earthquake: Mg. and Sci. Press, vol. 92, no. 17, p. 274, April 28, 1906.

Marvin, C. F. The record of the great [San Francisco] earthquake written in Washington by the seismograph of the U. S. Weather Bureau: Nat. Geog. Mag., vol. 17, no. 5, pp. 296-298, May, 1906.

Mulne, J. Seismological investigations. Eleventh report of the committee: Brit. Assoc. Adv. Sci., Rept., 1906, pp. 92-103, 1907.

Contains references to Nortli American eartbquakes.

Moone, C. E. Earthquake effects at Santa Clara, Palo Alto, and San Jose, Cal. : Eng. News, vol. 55, no. 19, pp. 526-527, 4 figs., May 10, 1906.

OмоRi, Fúsakichi. Observations of distant earthquakes: Mg. and Sci. Press, vol. 92 , no. 24, pp. 397-39S, June.16, 1906.

Includes observations on the San Francisco earthquake.

On the great earthquake of April 18, of San Francisco, 1906: Jour. Geog. (published by the Tolyo Geog. Soc.), vol 18, no. 215. pp. 764-777, November, 1906. [In Japanese.]

- Note on the San Francisco earthquake of April 18, 1906: Publications of the [Japan] Earthquake Investigation Committee in Foreign ranguages, no. 21, Appendix II, 3 pp., 1 pl., Tokyo, 1906.

On the estimation of the time of occurrence at the origin of a distant earthquake from the duration of the first preliminary tremor observed at any place: Imperial Earthquake Investigation Committee, Tokyo, Japan. Bull., vol. 1 , no. 1 , pp. 1-4, January, 1907 .

Includes time data regarding the San Francisco earthquake of April 18, 1906.

Preliminary note on the cause of the San Francisco earthquake of April 18, 1906: Imperial Earthquake Investigation Committee, Tokyo, Japan, Bull., vol. 1, no. 1, pp. 7-25, 6 pls., 9 figs., January, 1907.

Preliminary note on the seismographic observations of the San Fran- 
cisco earthquake of April 18, 1906: Imperial Earthquake Investigation Committee, 'Tokyo, Japan, Bull., vol. 1, no. 1, pp. $26-43,6$ pls., January, 1907.

Tabulates seismographic records of the Sin Francisco earthquake made at various earthquake-observation stations and discusses the rate of transmission.

- Comparison of the fatults in the three earthquakes of Mino-Owari, Formosa, and San Francisco: Imperial Earthquake Investigation Committee, Bull., vol. 1, no. 2, pp. 70-73, 8 figs., 1907.

Ransome. Frederick Leslie. The probable cause of the San Francisco earthquake: Nat. Geog. Mag., vol. 17, no. 5, pp. 280-296, 11 figs., May, 1906; Mg. and Sci. Press, vol. 92, no. 24, pp. 396-397, 1906.

Describes the geologic structure of the region surrounding San Francisce, Cal.

Redway, Jacques W. Some notes on the San Francisco earthqualke: Geog. Jour., vol. 29, pp. $436-440,6$ figs., 1907.

Reid, Harry Fielding. Records of seismographs in North America and the Hawaian Islands. No. I1I: Terrestrial Magnetism and Atmospheric Electricity, vol. 11, no. 4, pp. 1S5-197, December, 1906.

[Rickard, T. A.] The [San Francisco] earthquake: Mg. and Sci. Press, vol. 92, no. 17, pp. 270-272, April 28, 1906.

After the [San Francisco earthquake] disaster: Mg. and Sci. Press, vol. 92, no. 18, pp. 287-288, May 5, 1906 .

Former earthquakes and their discarded lessons: Mg. and Sci. Press, vol. 92, no. 18, pp. 289-290, May 5, 1906.

- and others. After earthquake and fire. A reprint of the articles and editorial comment appearing in the Mining and Scientific Press immediately after the disaster at San Francisco, April 18, 1906. San Francisco, Mining and Scientific Press, 1906. 194 pp., illus.

A reprint of papers appearing in the Mining and Scientific Press in the issues of April 28, May 5, and June 16, in the main relating to the San Francisco earthquake.

SEe, T. J. J. Thê cause of earthquakes, mountain formation, and kindred plenomena connected with the physics of the eirth: Am. Phil. Soc., Proc., vol. 45, pp. 274-414, 17 figs., 1906.

Stonms, W. H. Earthquake lines: Mg. and Sci. Press, vol. 92, no. 1.8, p. 2\$9, May 5, 1906.

Tamer, Stephen. Some local effects of the Sim Frincisco earthquake: Jour. Geol., vol. 14, no. 4, pp. 303-315, 9 figs., 1906 .

Describes the faulting which caused the earthquake and its movements as shown by various local displacements.

Weatherbe, D'Arcr. First observations of the [San Francisco earthquake] catastrophe: Mg. and Sci. Press, vol. 92, no. 17, pp. 275-276, April 28, 1906. 



\section{N D E X.}

A.

Academy of Sciences, damage to views of _-___._. Pls. XXIV, XXV Acknowledgments to those aiding--- 63-

Ajtna Building, damage to -- 31-22, 76-77 views of ---- PIs. XXIV, XXV, XXIX Agnew, insane asylum at, damage to 22,133 damage to, cause of Air shafts, danger from__-_._-_. 155 view of _._._._. XIIX

Albert Pike Memorial, damage to--- 26 Alluvial soil, buildings on, damage

to, view of: PI. XII slipping of, view of P.I. VIII See also vade ground; Settling of soil.

Appraisers' warehouse, damage to -32 , $77-78$ view of iil. XXVIII Arches, behavior of, views show:

ing -_..- I I XVIII, Xx Arches, ilon, expansion of _-_. $36,87-88$ Aronson Building, damage to $78-79,145$ view of l'. XXVII Attics, floors of, danger in_-_-_-_-- 122

B.

Baltimore, fire at, heat of 68-69.

fire at, loss in

rebuilding of

raults in

70

Basement floor, apparent pushing up of -

Bekins Van and Storage Co.'s building, character of ... 109, 150

damage to_....... 33, 109, 147, 150 view of _-_el. XXVII

Isending moment, maximum, point of application of -....- 15 . $75-76,143-144$

Ferkeley, damage at__-__-_-_-_- 25. 133 Tibliography of earthquake_-_-_ 159-16.1

Bolinas Lagoon, fissures at, views of _._._. PI. IV

Bracing, importance of 24-25. 26, $35 . \quad 57$. 59, 124-125, 144, 151

instances of $106-107$
Bracing. lack of, results of, views showing --_ I'ls. XVI, XVIII Brick buildings, effect of earthquake on - 57 , $73-75,110,185-156,151$ effect of earthquake on, view showing PI. Xxvill

See also Brickwork.

Bricks, arch, buildings of, survival of -

Frickwork, comparative behavior of reenforced concrete and _-_._-_._._. XIV

cracks in_-__________ 57, 74-75 view of

effects of earthquake on $74,75,88,94-95,102$, $106,110,130,148-14$ ! views showing -.- Pls. XII. XXXXII, XxxVII.XLi, LII effects of fire on $70,72,88,92,95,156$ views showing -...- Pls. XL, LII essentials of _-_-_._-_ 59, 152-15? fireproof vault of, view of _-_- 1. LII. freproofing by use of, in partitions___._._. 52,72 Sce also Brick buildings; Bricks, arch.

Bridges, damage to__._.___- $20,116,133$

damage to, view showing___.- r'l. XI liryant street, settling in -._-_-_- 26 Fuilding code, character of._-_._ 50-51.

Buildings. Sec Brick buildings; Structures; 'Tall buildings: Wooden buildings.

Tiullock \& Jones Building, damage

view of to-_- $33,80-81$

Burned district, map showing- P'is. LVI, I.VII

Butler Building, damage to views of _....... l'ls. NXx, NxxII

\section{C.}

California Casket Co.'s building, damage to

damage to, view of _-_-_-_ Fl. Xxix California . earthquake investigation commission, personuel of _- 2 
California Electric Co.'s building, fire protection of --_-- $\mathbf{1 5 4}$

Call Building, damage to $144,145,146,155$ description of _._._._._._._. 34,81

Cast iron, objections to see also Columns.

Cathedral, St. Dominic, damage to $-{ }_{--} \quad 27$

Ceilings, behaviol of _ passim 31-48, 76-10s behavior of, views showing-Pls. XXVI, XXXV recommendations on_..._._. 121

Cemeteries, damage in

Charleston earthquake, cause of

Chemical extinguishers, value of _... 157

Chimneys, damage to .. 21, 24, 100, 111-112 Sce also Smokestacks.

Chittenden, railroad bridge at, damage to

Chronicle Building, damage to-..- 35 , 83-84, 144 view of Pl. XXX

Cinder concrete. Sce Concrete.

City hall, damage to____ $35-36,69,84-89$ description of _._._._._._. $\$ 4-\$ 6$ l'estoration of, cost of _._._._ 89 ruins of, views of _- Pls. XXVI, XXXI

College Hill reservoir, conduit to, damage to

Columns, failure of, through fire-- passim $30-48,72,78-104$

failure of, through fire, views showing-- Pls. XXVI, XXVII.

XXXIV-XXXVI,

XL, XLVIII-I, fireproofing of damage to, by earthquake $\quad \pi t$ failure of, through fire $30-4 S, 72,7 S-104$ views showing--- Pls. XXIV, XXVII, XXIV-XXVI, XL, XLIII

recommendations on_____._- 55,72 see also r'ilasters.

Commissary building. See Ntna Building.

Concrete, behavior of, in earthquake. see Concrete, reenfor ced.

behavior of, in fire 31-33, $48-44,46,52-55,72-74,79$ 103-104, 119-121, 147-148 views showins-- Pls. XXIV, XXV

Concrete, reenforced, comparative behavior of brickwork and, view showing - P1. XIV behavior of $33,44,75,77,80-\$ 2,87-88$ $97,108,113,130,150,152$ views showing_........ Fls. XX, XXIII, XXV, XXVI, XXVII example of. See Bekins Van and Storage Co.

merits of $120-121,125-126,150,152$ opposition of union labor to .. 60 , 126,150
Page.

Concrete buildings, behavior of _..- 15, 24, $29-30,33,75,113,150,152$

Conclete dam, view of..._....... Fl. XI Concrete-block buildings, damage to $24-25$,

$113,114,156-157$ damage to, views showing -- Pls. XVII,

$\mathrm{XIX}$

Conduits and mains, damage to $-\ldots$ 1. -19 ,

$115-116$

damage to, views showing-- Pls. $I X, X$ map showing__._._._._. Pl. T.VII repairs to 117-118

Construction, defects of, wide prevalence of .............

rigidity of, necessity for, in high structures _._...... 15, 59

Court-house, Santa Rosi, ruins of, view of _._._.... Pl. XIV

Cowell Building damage to_._._._ 89.146 view of _-_________._. Pl. LI

Cracks, earth, character of _._. 7 view of _____. IV

Cracks, masonry, character of__ $26,57,74-75$ views of _._._._._. Pls. XXII,

XXX, XLII, XLIV, LIII

Crocker Building, damage to_-_- $36,89-90$ view of _._. Pl. LII

Crocker Estate Building, damage to $\quad 90$ view of - Pl. XXvilI

Crystal Springs Lake dams, immunity of view of _.

Custom-house, United States. Seo Appraiser's warehouse.

Cyclorama, collapse of _.____ 29-30, 109 views of _..._._. Pls. XXII, XXIII

D.

Dilms, damage to _- 18-19, 21, 114-115, 116 safety of view of .............. $\mathrm{XI}$ See also Reservoirs.

Dewey monument, damage to..--_ 90 view of _._._.

Doors, metal-covered, efficacy of --.- $\quad 94$

Dore street, settling in_._._._._._. 26 settling in, view of._-_._._. PI. VI

Dynamiting, damage done by _...- 1.01. damage done by, view showing _._. inefficacy of -

\section{E.}

Warth, flow of $7-9$ flow of, results of, views of -- Pls. V, VII, VIII, XLII, XIilII. See also Settling of soil; Made ground.

liarth waves, propagation of - $10-11,12-13$ velocity of ................. 17

Earthquakes, aftermath of........ 59 causes of damage by, minimization of 150,157 insurance against _..._... 129 nature of. 
Darthquakes, prevalence of, on $\mathrm{Pa}$ cific coast _-_._-_ $15,16,143$ protection against ${ }^{\circ}-\ldots$ $56-59,116-118,124-126,157$

Sec also San Francisco earthquake; San Francisco, earthquake in.

Elevator shafts, danger from

Limanuel Synagogue, damage to -.view of - I'l. XXI

Emporium, damage to_._._. $36 ; 78,90-91$ views of -_._._._._. XXXII

Explosions, volcanic, earthquakes caused by

F.

Falrmount Hotel, damage to 37,92 view of Pl. XXXIV

Pault scarp, description of

Fault trace; antiquity of appearance of

views of character of, diagram showing conduit crossing, views of _-- Pls. IX, $\mathrm{X}$ description of _._._._._._. 4-0 dam on, effects of earthquake on

views of distances from, to towns, etc...earth movement along ......... $5,17,20,132-133$

views showing _........ Pls. I, I I extent of _... fence crossing, view of _-_._._- I'l. map of

mapping (previous) of -.-.-.-offset in

views of reservolrs on, damage to _._._- 10-19,

$114-115$

road crossing, view of _...... Pl. I telescoping along, view showing - Fl. IX See also Faulting.

Faulting, earthquakes due to_- $2,10,15-16$ prevalence of, on I'acific coast. place of, surface or subterranean

time required for-_-_-_-_-_-_-sce ulso Fault trace.

Fire. protection against_-__-___- 51-56, $119-124,126-129,157$

See also San Francisco, fire in; San Francisco fire.

Fire extinguisher's, chemical, value

Fire Underwriter's, National Board

Fireproof buildings in San Franconditions surrounding____._ 50,64 damage to protection of of of, report of, on fire hazard in San Francisco

$64,139-140$ cisco, character of _-_ $\quad 52$

7171-Bull. 324-07- 12
Fireproofing, cost of general inadequacy of _-- 119, 146, 147 imperfections of, in San fran.

cisco_- 52-54, 71-74, 147-150

insurance rates reduced by _._. 155 materials for-_._-_-_ 52-54, 147-150 protection afforded by, pèrcentage of recommendations concerning --- 55 $119-122,157$

Sec also Brick; Concrete ;

Metal laths; Tiies, etc.

l'issures, creation of .......... 133 views of -

Flood Bulding. see James lilood Building.

flloors, behavior of _-_-_-_-- passim 31-48 7:3, 76-108

behavior of, views showing- I'ls. XXVI, XXVII; XXIX

recommendations on _._._. 125,155

Fortifications, damage to___._._. 63,114

Foundations, importance of _._._. 57, 59, $133,135,143,151$

Frame buildings. See Wooden'buildings.

\section{G.}

Geologic formations, character of, influence of -..- 1.2, 133-130

Cilbert, G. K., photographs by III-VIII

report by, on the earthquake as a natural phenomenon. 1-13

work of -

Girders, fire protection of

Girls' high school, damage to__._- 26-27 Glass, wire, behavior of ${ }_{--} 80,123,154,156$ behavior of, view showing _._. Ii: IS Golden Gate I'ark, damage in Government lulldings, damage to $-32,42$, $44-45,69,78,151:$ views of XXXVII, XLII, XIIV Ciranite, damage to_._....... 53; 92,157 damage to, views showing- l'Is. XX't'

XXYYi

Grant Building, damage to_._-_ 37-38, 93 Gravity, earth movement due to _.._ 8 Gravity waves, propagation of $10-11,12-18$ Greek 'Theater, immunity of

H.

Hahnemann Medical College, damage to

Ilayward Building, damage to....--

Hibernia Savings and Loan Society's building, damage to

view of

High school building, Sin Jose, diamage to, view of:- Til. XH1

Himmelwright, A. I. A., phótograph by _... Pl. XX'xvI 
. . Page.

Hobart building, damage to._-_._- 38-39 view of _._._._._._. PXXVI

lollow tile. Sec Tiles.

Holmes, J. A., preface by _._._._. XI-xIr

Horne store, Pittsburg, comparison of fires at Emporium and.

I Iotel Hamilton, damage to

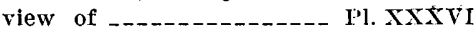

House, splitting of ........... 20 splitting of, view showing

Howard street, ruined buildings on, view of _._._._._. Pl. LIII settling in _._-_-_-_._-_._- 26 view showing _._._._. PI I

Humphrey, R. L., experience of --- xI maps by _-_._._._. I'ls. LVI, LVII photographs by _._._. Pls. II, VI, XXXV, XXVII-XXX, XXXIVXLV, XLVIII, L, LII-LIII

report by, on effects of earthquake and fire on structures and structural materials ...... 14-61

work of

\section{I.}

Illustrations, sources of -

Insurance, earthquake, need for ---- 129 Iutensity, earthquake, definition of distribution of . - . factors governing -...-- 132-136 maximum of, region of -- $2,4,132-133$ scale of _._. variations in

Inyo earthquake, cause of _-_._...- 2 Iron arches, expansion of

J.

Jackson Brewing Company's building, damage to view of _._. XXXVII James Flood Building, damage to -- 37 , $78,92-93,145,146-147,148$ views of _.___- Pls. XXXIII, XXXV Japan, gravity waves in Jerkiness, causes of . Justice, Fall of, at San Francisco, damage to

view of _-...._. Pls. XXXV, XXXIX

Justice, Hall of, at San Jose, wreck of, view of

K.

Kamm Building, damage to__-_- 39-40, 98 Kelly, William, information from_-- 124 Key monument, damige to view of Pl. XX

Kobl Building, damage to $\ldots . \ldots 40,94,152$ I.

Laboi unions, attitude of $60,126,150$

Lake Honda reservoir, conduit to, destruction of _._._- $1 \mathrm{~s}$

diamage to 19,115
Landslips, production of

Laths, metal. See Metal laths.

Lawson, A. C., faults traced by _-_- 16 photographs by _..... Fls. VIII, XIII

Lee Brothers, building of, view of _ Pl. XVII J.eland Stanford Junior University, damage to $75,112-114,133$

damage to, views of. Pls. XIV-XVIII geologic conditions at_........ 15 Leuschner, A. O., on San Francisco earthquake _._._..._. 143 Iife, loss of Light-houses, damage to._....... 63 I.os Gatos, tunnel near, damage to

M.

Made ground, conduits in movement of _.____ $8,13,15,21,133$ effect of, on structures___. 15 , $19,26,56,115-116,133,135$ views of ... Pls. V, VI sewers in See also Settling of ground; Earth.

Mains and conduits, damage to $115-116,133$

damage to, views of _._._-_ Pls. IX, $\mathrm{X}$ repair of _._. Majestic Theater, damage to _._._. 40 view of _._._._._._. PXXIX Marble, destruction of ...____._ 53,157 Marston Building, lessons from_-_- 152 Marx, C. D., and Wing, C. B., report of _-_

Masonry. See Stonework; Brickwork.

Materials, structural, behavior of $71-76$

See also particular materials; Structures, artificial.

Mercantile 'Trust Co.'s building, damage to

Nerchants' Exchange building, damage to _._._._ 41, 94-95

view of _._._._. PI

Metal (expanded) and plaster, fireproofing by _-..-..- 40 , $45,47,93,104,119,148-149$

partitions, ceilings, etc., of _..- 44 $47,77,90,104$ Metal laths and plaster, behavior of, views showing-- Pls. XXXIV, XLI, XLVIII

fireproofing by ........... 38 $39,73-74,93,148-149$ partitions and ceilings of _..- $43,46,92$ Mill construction, definition of -..- 66 failure of _.....- $36,90-91,152-153$ view showing _._-__- Pl. XXXI

Mills Building, damage to_- 41-42, 78, 148 damage to, views of ..-- Pls. XL, XLV Mills College for Girls, damage to damage to, view of _._._._._. Pl. XX 
Mint, United States, damage to $\quad 42$, $95-96,154-155$ view of Fl. XXXVIII

Mission, The, section of city known as

Mission Dolores, new, damage to ... old, view of _._._._._._. PxIIt

Mission street, earth slip on, view showing _._._._. Fl. XIII

Monadnock Building, damage to_-_- 42,96

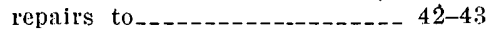

Nonterey, damage at

Monterey.Bay, effects of earthquake

$$
\text { at - }
$$

Mosaic cellings, behavior of .......

Mountain-making forces, earthquakes due to

See also Tectonic earthquakes.

Mud, movement of See also Earth.

Murphy Building, damage to

view of

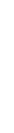

Mutual Life Building, damage to _.. 43, 96 view of _._._._._._._. PIII

Mrutual Savings Bank, damage to_-- 108

$$
\text { N. }
$$

New Madrid earthquake, cause of -Ninth street, earth flow on, view of

$$
\text { O. }
$$

Oakland, damage at $25,112,133$ Omori; F., on earthquakes_._- $59,132,143$ Ornamentation, loss on

$$
\text { I. }
$$

Facific States Telephone and Trelegraph Co.'s building, damage to_ $43-44,96-97,155$ view of -

Fajaro River, rallroad bridge over, damage to damage to, view of _._._. XI XI

Palace Hotel, damage to views showing -...- Pls. XXX. LII

Falo Alto, damage at geologic conditions at_-....- 15 See also Leland Stanford Junior University.

Partitions, behavior of. See Metal laths; Terra cotta ; Tiles, etc.

general character of ---- 52, 72-73, 94 recommendations concerning--- 55 , $125,127-128$

Pike (Albert) Memorial, diımitge to 26 Pilarcitos conduit, damage to 18,$115 ; 133$ damage to, views showing-- PIs. IX. $\mathrm{X}$ Pilasters, shearing of stripping of, view showing__._ Pl. XII Plles, buildings on, damage to_... 28, 135 Pipes on columns, damage due to $52,80,148$

Plaster of Paris, effect of fire on -._ 31 effect of fire on, view showing- Pl. XXV
Plastering, imperfections of 88 Plumb, difficulty of building in- $82-83,130$ Point Arena, fault trace at_._..._ 2 fault trace at, map showing--- $\quad 3$ Point Delgada, fault trace at_..._. r'oint Reyes, fault trace near, views of _. I'ost-office building, damage to $97-103$

settlement at _..._.

views of _.... I'Is. XIII, XIIII, XLIV Fublications on earthquake, list of - 1.59-1.61

\section{R.}

Rafters, thrust of, damage from_-- $\quad 114$ damage from, view showing-- Pl. XIX Rallroads, damage to _._._._._._- 20,21 damage to, view showing _-_-_- Pl. XI Records, hall of, San Francisco, damage to..._. 36,89

Records, hall of, Santa Rosa, ruins of, view of._._._-_. PI. XIV

Redwood, damage at

Reed, S. A., on fire in telephone building -_._._._. 97

Reservoirs, damage to Sec also Water-supply systems.

Rhythm of earthquake, character of -

Rialto Building, damage to._._._.- $45,10 \mathrm{z}$ view of _._. XI. XVIII

Rivets, importance of _._._._. 144 shearing of, view showing- Pl. XLVII Roberts, J. W., aid of._._._. 44, 97-98

\section{S.}

Safes, failure of

failure of, view showing__._._. Pl. LII Sailor's' Home, damage to........ 27

St. Dominic Cathedral, damage to_- 27

St. Francis Hotel, damage to 103-104

Saliuas, damage at _._._._. 21,133 geologic conditions at__._._._- 15

Salinas River, effects of earthquake near _._._._._._._. 21, 133

effects of earthquake near, view showing _._._._. Pl. VII

Salt - water mains, establishment of _._._._._. $117,139,153$

San Andreas dam, damage to_- 18-19, 115

San Francisco, area of _._._._._. 134 building code in $-50-51,59-60,65-66$ buildings in, character of .... 30,50 , $52,59,65,134-136,139-142$ classes of _-_._._._. $65-66$ relative damage to fire underwriters' report: on --.-- 49-50, $64,139-140$ height of _..._._._. 142 recommendations, for $\ldots$._. 124-129. See also Structures, artificial.

description of earthquake in, damage by $72,112,142-145$ 
Sau Wrancisco, earthquake in, damage by, reasons for $-26,58,142$ earthquake in, damage by, relation of fire damage and _-_._-_ 66, 74, 158 effect of, on walls. See Crincks.

lessons of $56-59$ loss of life in_-___- $59-60,153$ see also San Francisco earthquake.

fire department of $51,140,153$ chief of, death of - 137

fire hazard in, underwriters' report on $-49-51,64,139-140$ fire in, normal loss by _._- 49, 1.36, 1.39 normal loss by, reasons for - _. _._._._. 138-139

See also San Francisco fire.

fireproof buildings in, behavior of. See Fireproof: buildings.

foundation material of _-- $25,134-136$ map of, showing burned area _ Pl. I,VI showing whole city, burned area, water conduits. etc_-_-_._. IVII

panorama of Pl. T.V

population of 134

rebuilding of -_-_- 59-60,61, 116-1.17

recommenditions for _..- 124-129 surviving buildings in, descriptions of ...... 31-48, $\dot{7} 6-112$ view of, from line and Powell streets from Telegraph Fill _._. Pl. LIV water supply system of _-__-_-_ 17-18, $19-20,50,139$

damage to causes of _-_._. 19 future prevention of $-19-20$, 55,153 fire underwriters report on $\quad 50$, 117. 139 map showing _._._._._. PI. LVII recommendations on _._. 117, 153

San Francisco earthquake, beginning of, point of

bibliography of _._-_-___-_ 159-161 caluse of _ 2,132 consideration of, as a natural phenomenon _...... 1-13 damage by $30-48,72-116,150-152$

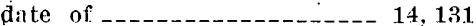
divection of ...______ 17,132 duration of _..._._._. 16. 131-132 effect of, on surface material__ 7-9 extent of ___._-_-__- 2,4,10,16, 132 map showing 3 intensity of. See Intensity. movements in, character of --- 10-12,

direction of 17,132 extent of sce also Fault trace.
San Francisco earthquake, publications on _._._. 159-161. shocks in, number of ____._. 16, 131 . velocity of _._._._._. 17 vibrations in ...........- 10-12, 17 See also Fault trace; Faulting; San Francisco, earthquake in ; and particular towns.

San Francisco fire, comparison of other fires and...... 51 damage by $69-108,126-127,146-150$

insurance for

loss from__. relation of earthquake damage and $\ldots \ldots \ldots, 74,152$

See also structures, artificial.

description of

fireproof buildings in. See Fireproof buildings.

heat of lessons of _......... loss from_.._.

magnitude of._......... 49, 137-138

maps showing-_- I'Is. I.VI, IVII

wind caused by___________ 137

See also San Francisco, fire in.

San Prancisco Gas and Flectric Light Co., buildings of, damage to

San Jose, damage at damage at, reasons for._..... 22

views showing_-_- Pls. XII, XIII geologic conditions at__-_.-... 15 reservoir of, damage to San Juan, fault trace at........- 2 San Mateo, dam neal, escalpe of.--_ 19 dam near, view of._..._._... Pl. XI Sandstone, damage to Santa Rosa, damage at__._._._ 24-25, 133 damage at, reasons for....... 25 view showing._...._-_._. PI. XIV geologic conditions at._._._.- 15 Sinta Rosa Valley, earthquake in -- 4 Saratoga reservoir, damage to_-_-_ 21, 116 Schussler, Herman, aid of Scott Building, damagre to Searsville dam, immunity of $\ldots \ldots \ldots$ 19, 115 Security Savings Bank, damage to _- 46 Settling of soil__-_________-_ $9,21,44$ effect of views of

VI, VIII, XXV, XIII, XIIV See also Made ground; Earth.

Sewell, J. S., experience of photographs by -........- I'ls. XXI. XXV, XXVI, XXVIII, xxx, xxxII, xxxIII, xxxy, XxxviII, XXXIX, XLIII, XLIV, XLIX, LV

report of, on effects of earthquake and fire on buildings, engineering structures, and structural materials_________ 62-130

work of 
Page.

Sewer's, recommendations regarding_ 118 Shafts, air, danger from view of

155

Shutters, importance of - 122-124, 154-155 use of, in San Francisco _... 123-124

Sloane Building, damage to_-_-_-_ 47, 104 view of Fl. XLIX

Slow-burning construction. See Mill construction.

Smokestacks, damage to 112 views of _._._._._. Pls. XIII, IIII

Soil. Sec Earth; Made ground; Settling.

Soule, lrank, experience of photographs by

Pls. IX, XII, XXXI, LIII, LIV leport by, on the earthquake and fire and their effect on structural steel and steel-frame buildings _._._.

Southern Facific Railroad, damage to -

damage to. view showing _._._. Pl. XI

Spreckels (Claus) Building. Seo Call Building.

Spreckel's sugar mill, damage to _..._. 21

damage to, view showing__._- Pl. XII spring Valley Water Co., building of, damage to

building of, damage to, views of._-_. Pls. XLV, I, vault in

conduits and mains of, damage to _-__-_._- 62-63, 115-116 damage to, views showing _...... Fls. IX, X, XI dams of, damage to_____ 62, 114-115 Stairways, behavior of

Stanford University. See Leland Stanford Junior Uni versity.

Steel, structural, reliability of --- 145-146

Steel bands, effect of fire on effect of fire on, view showing _._._._._... Pl. XXIX

Steel buildings, effect of earthquake on $130,136,142,144,151-152$

effect of earthquake on, views showing--- Pls. XV, XXXII

effects of fire on $76-112,146-147$

view showing _._______ Pl. LI fireproofing of. See Fireproofing.

joints in, damage at

Stone buildings, effect of earthquake on -

57. 58, 74, 75, 85, 112-11:

effect of earthquake on, view showing
Srone-veneer buildings, damage to $\ldots-22-24$,

$58,113,145$

Stonework, effect of earthquake on $\quad 53$, $74,75,145$

effect of earthquake on, views showing- I'ls. XXXII, XI.IV effect of fire on, views show ing -.. Pls. XXXVII-XXXIX essentials in Stow I ake, bridge over, immunity . of _-_._. 30

Structural materials, behavior of--- 51-55, $71-76$.

See also particular materials. Structures, artificial, classes of, relative damage to $74-75, \quad 150-152$ cracks in $26,74,75$

defects prevailing in comparative endurance of, view showing - - X'l. XIII

essentials of, for resisting earthquake and fire.--_-- 15 , 56-59, 116-11.8, 124-126. 157

failures of, causes of _-_.- $58,150-152$ fire risk of _........... 153-154 protection of, against file._. $51-56$, $119-124,126-129,157$ against outside fires_____ $54-55$ surviving, descriptions of -_-_-- 31-4.8 susceptibility of, to earthquake_ 12 , 15,75 water supply for._._. 54-55, 122, 128 Sec also Concrete; Stone; Tall buildings, etc.

Structures, artificial, in San Francisco, effect of eirthquake and fire on $69-112$

See also purticular structures.

structures, artificial, outside San Francisco, effect of earthquake on $63,112-116$

See also particular places.

Subtreasury, 'United States, damage to

Surface material, movements of ---- 7-9

Synagogue Emanuel, damage to -.- 26 view of

\section{T.}

Tall buildings, properly built, safety of _-_._._. $58,75,129,152$ recommendations on Tanks, survival of, view showing Fl. XIII wrecking of _..._._._._. 21,116 Tectonic earthquakes, character of -- 15-16 Temperatures, range of Terra cotta, ornamental, failure of, view. showing-_.. Pl. XXVIII See also Tiles, terra-cotta.

Thiele Building, destruction of -.-- 24 ruins of, view of 
Tie lack of results of riews showing - _._._. Pls. XVI, XIX value of, view showing_-_._- Pl. XVII Tiles, terra-cotta, behavior of, in floors, partitions, etc $35-48,73-95,101-$ $102, \quad 105, \quad 130$ behavior of, views showing - Pls. XLV; XIIX, L fireproofing by --_.-_-_-_-_-- passim $32-37,46-54,70-95$, $119-120, \quad 148, \quad 156$ failure of, consequences of, views showing _- Pls. XXVI, XXVII, XL, XLII, XLV

quality of, on Pacific coast__._- $\quad 52$ use of, in San Francisco_ 120-121, 148 varieties of 148 Tomales Bay, mud bottom of, gravity waves in.

mud bottom of, shifting of

views of Pls. VII, VIII

Trees, splitting of 20,133 splitting of, view showing

PI. II

Trim, loss on _._._.__ 52-53, 127, 154 Tunnels, railroad, damage to 20,62

$$
\text { I. }
$$

Union Ferry Building, damage to $---28-29$ 1.05-107, 135 damage to, views showing - Pls. XLVI,

XLVII

Union Savings Bank, damage to _- 136, 145

Union 'Trust Co.'s building, damage to _...-_-_._- 47-48, 108 view of

University Mound reservoir, conduit to and mains from, damage to

\section{$\mathrm{V}$}

Valencia street power station, damage to, view showing. Pl. LIII

Vandervoort Brother's' building, destruction of

view of _._._. XIX

Vaults, failure of _._._._._ $53,69-71,124$

failure of, views showing-- Pls. XXIX,

LII

survival of, view showing_-_. Pl. LII

Vibrations, character of -... 10-12 direction of _............... 17 propagation of, velocity of
Volcinic action, earthquakes due Page. to _........ 2, 15-16 Volkman building, damage to _..... $4 \mathrm{~s}$

W.

Walker, M. I., information from

Water, effect of ear thquake on individual supply of _._._._. 54-55, $122,128,154$ ease of obtaining, in Sin Francisco _-..... 122

Water-supply systems, character of $17-18$, $19-20,21,139$

damage to S-21, 117 prevention of _. $55,56,117-118,153$ reasons for._.......... 19

Water tower, damage to

Waves. See Earthquakes.

Wellington, G. J., report of, on fire - -

Wells-Fargo Building, damage to_-_ 48 views of _._._._._. Pls. XLIX, LII

Whittell Building, lessons from _.-_ $\quad 152$

Wind, production of, by fire -..-_- 137

Wind bracing, earthquake shocks taken up by _...-_-_ 144

Wing, C. B., and Marx, C. D., report of -

Wile glass, behavior of _-_ $80,123,154,156$

behavior of, view showing - 1'l. XLIX

Wire lath and plaster, fireproofing by_ $38,41,48,94,119,148-149$

fileproofing by, failure of, view showing ..... Pl. XXXVI

partitions of

Wooden buildings, effects of earthquake on $57,60,110,135,151$

essentials in____..._._._._. 59, 111

ruins of, views of

Woodwork, loss on

Woodwork, metal-covered, behavior of _..... $40,53,154,156$

Wrights, house near, splitting of --- 20 house near, splitting of, view showing _._._._._. Pl. $\mathbf{X}$

tunnel near, damige to._._._-_ 20

I.

Young Building. See Etna Building. 


\section{CLASSIFICATION OF THE PUBLICATIONS OF THE UNITED STATES GEOLOGICAL SURVEY.}

[Bulletin No. 324.]

The publications of the United States Geological Survey consist of (1) Annual Reports, (2) Monographs, (3) Professional Papers, (4) Bulletins, (5). Mineral Resources, (6) Water-Supply and Irrigation Papers, (7) Topographic Atlas of United 'States-folios and separate sheets thereof,'(8) Geologic Atlas of United States-folios thereof. The classes numbered 2, 7, and 8 are sold at cost of publication; the others are distributed free. A circular giving complete lists can be had on application.

Most of the above publications can be obtained or consulted in the following ways:

1. A limited number are delivered to the Director of the Survey, from whom they can be obtained, free of charge (except classes 2, 7, and 8), on application.

2. A certain number are delivered to Senators and Representatives in Congress for distribution.

3. Other copies are deposited with the Superintendent of Documents, Washington, D. C., from whom they can be had at prices slightly above cost.

4. Copies of all Government publications are furnished to the principal public libraries in the large cities throughout the United States, where they can be consulted by those interested.

The Professional Papers, Bulletins, and Water-Supply Papers treat of a variety of subjects, and the total number issued is large. They have therefore been classified into the following series: A, Economic geology; B, Descriptive geology; C, Systematic geology and paleontology; D, Petrography and mineralogy; $\mathrm{E}$, Chemistry and physics; F, Geography; G, Miscellaneous; H, Forestry; I, Irrigation; J, Water storage; K, Pumping water; I, Quality of water; M, General hydrographic investigations; N, Water power; O, Underground waters; P, Hydrographic progress reports; $Q$, Fuels; R, Structural materials. This paper is the first in Series $R$ and bears the following title $(\mathrm{B}=$ Bulletin $)$ :

\section{SERIES R, STRUCTURAL MATERIAIS.}

B 324. The San Francisco earthquake and fire of April 18, 1906, and their effects on structures and structural materials; reports by G. K. Gilbert, R. I. Humphrey, J. S. Sewell, and Frank Soule, with preface by J. A. Holmes. 1907. 170 pp., 57 pls.

Correspondence should be addressed to

The Director,

United States Greological Survey,

Washington, 1). C.

August, 1907 . 


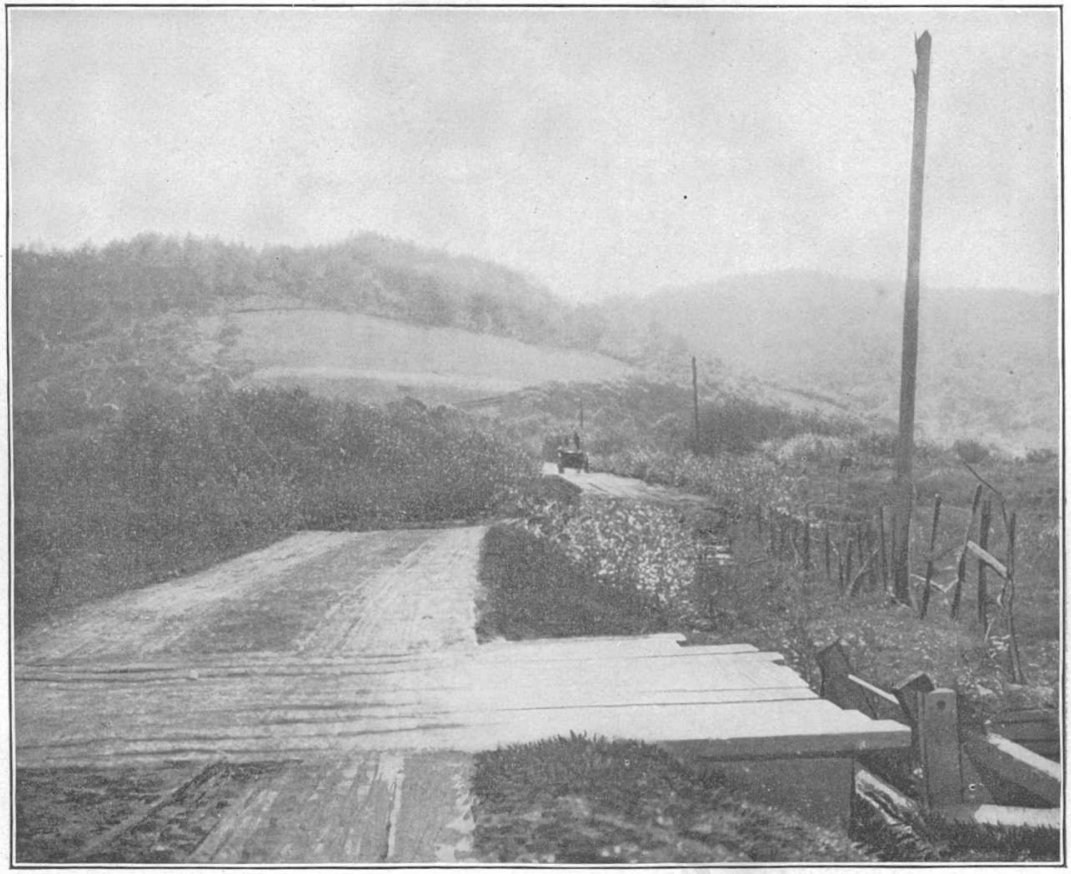

A. ROAD CROSSING FAULT TRACE NEAR POINT REYES STATION. Looking southwest. Offset, 20 feet. Photograph by G. K. Gilbert.

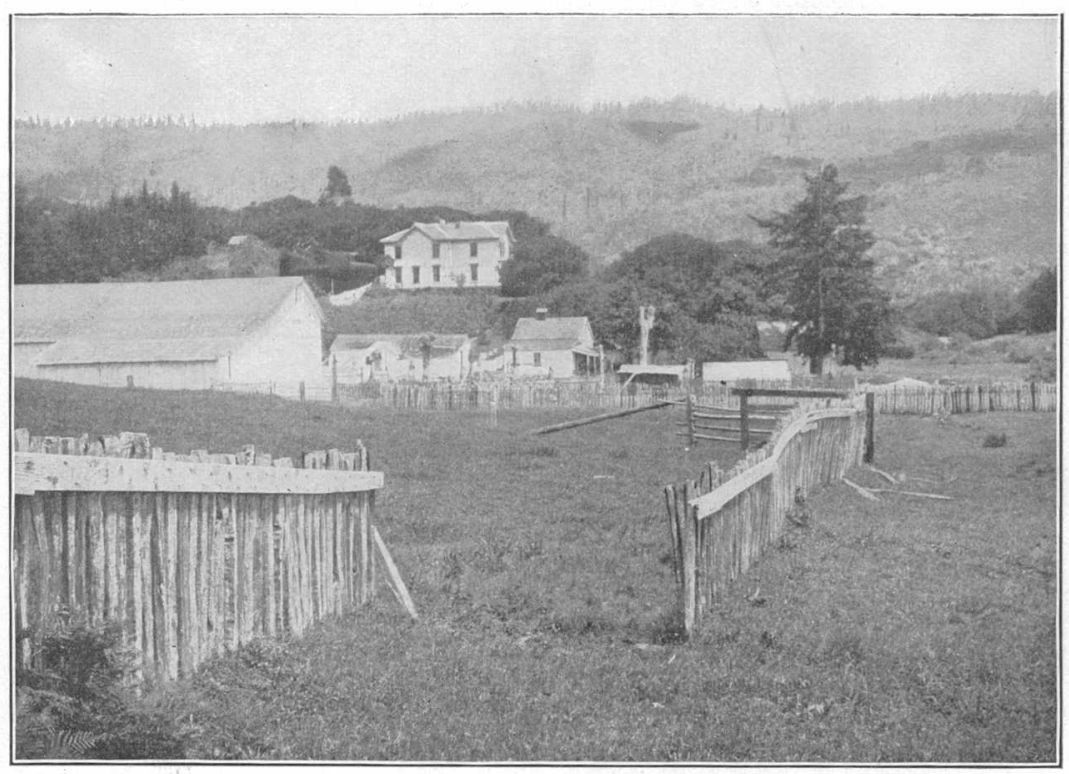

B. FENCE PARTED BY EARTHQUAKE FAULT.

The fault trace or fracture accompanying the earthquake is inconspicuous, although the horizontal displacement is considerable. Photograph by G. K. Gilbert. 


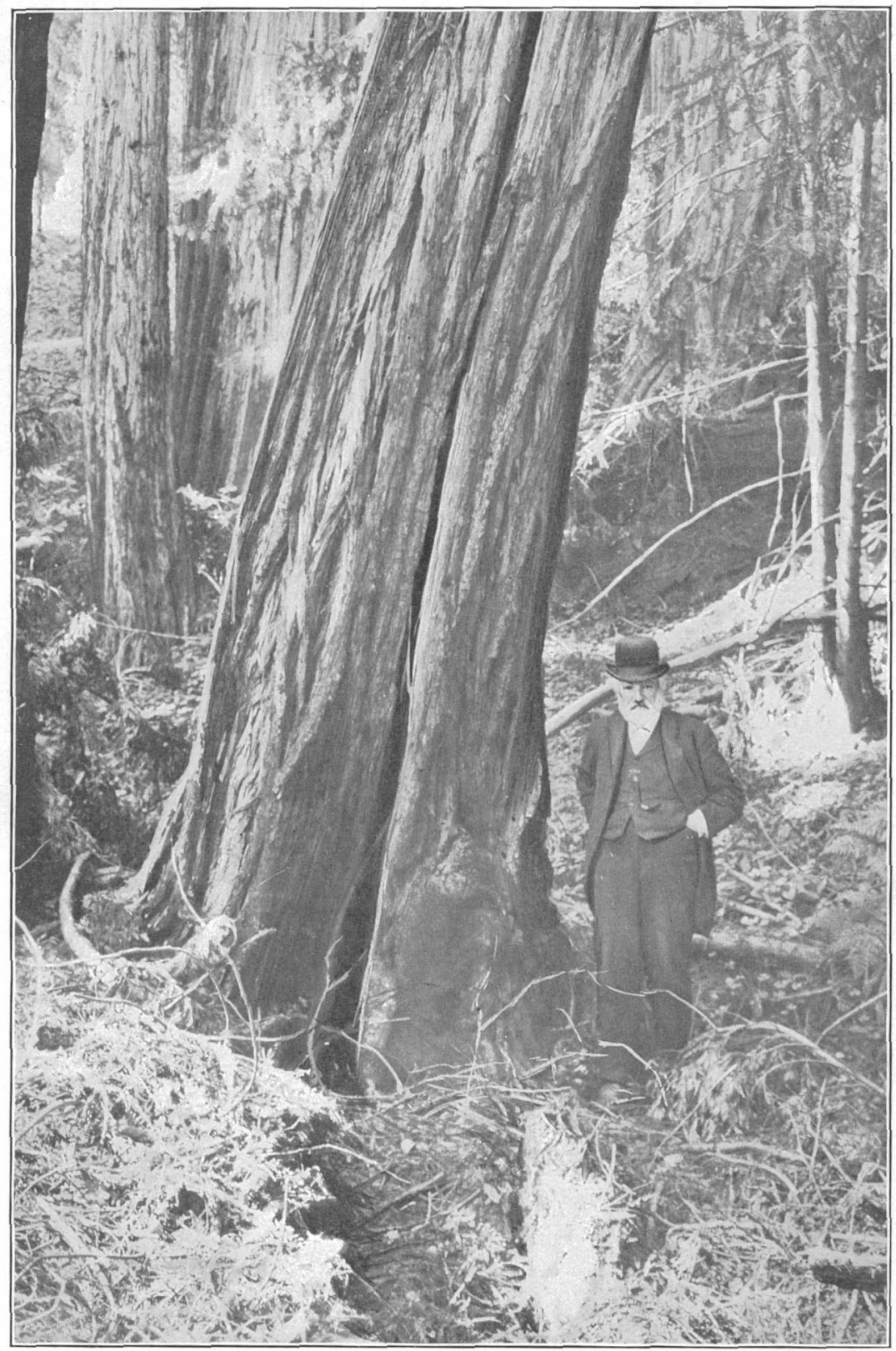

REDWOOD TREE 6 FEET IN DIAMETER ON LINE OF FAULT SOUTH OF FORT ROSS.

The tree was split to a height of 35 feet, although the horizontal displacement was slight. The opening is wedge-shaped at the base, running from a width of 8 inches on the side shown to a fine crack on the farther side. Photograph by Richard L. Humphrey. 


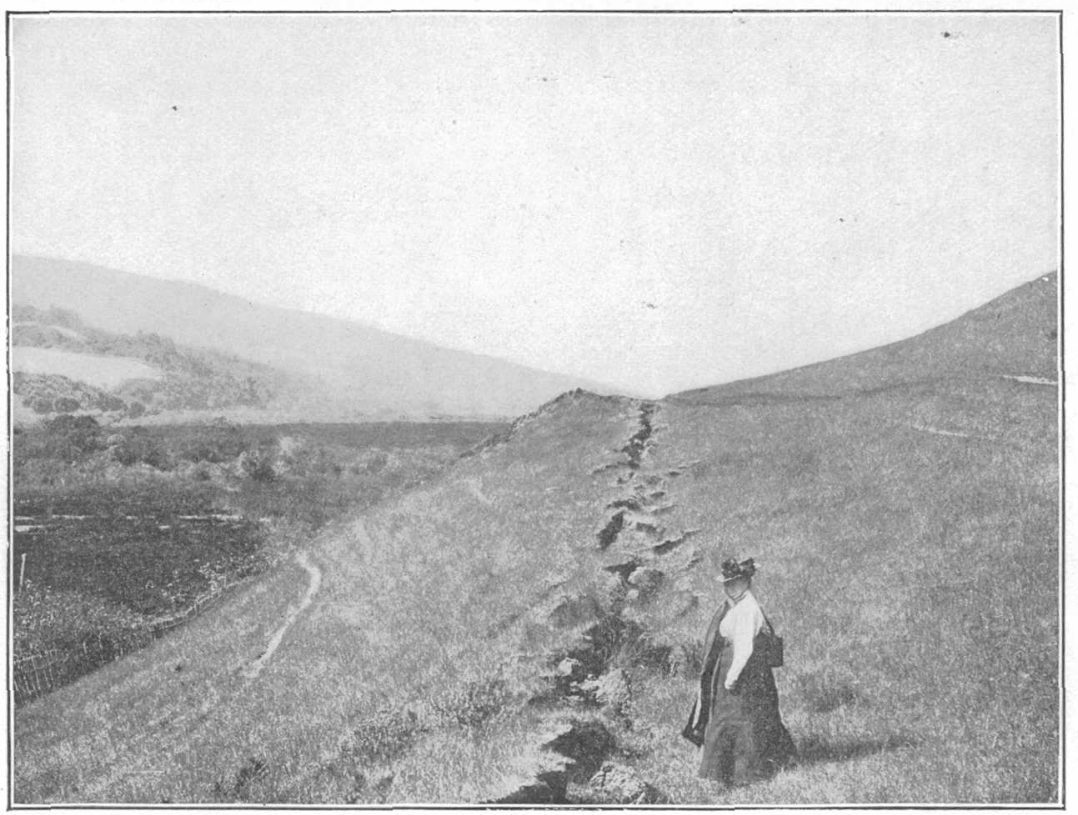

$A$

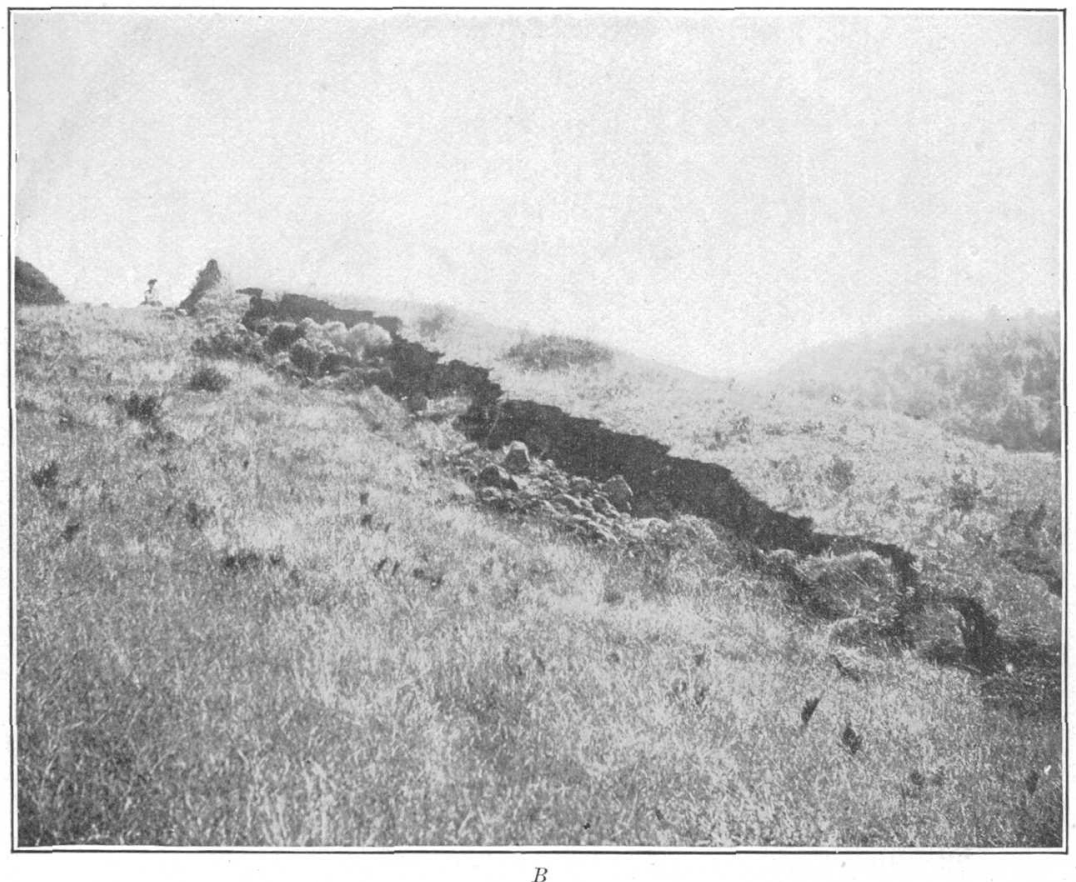

THE FAULT TRACE NEAR POINT REYES STATION.

A, Looking northwest; $B$, Looking southeast. Photographs by G. K. Gilbert. 
BULLETIN NO, 324 PL. IV

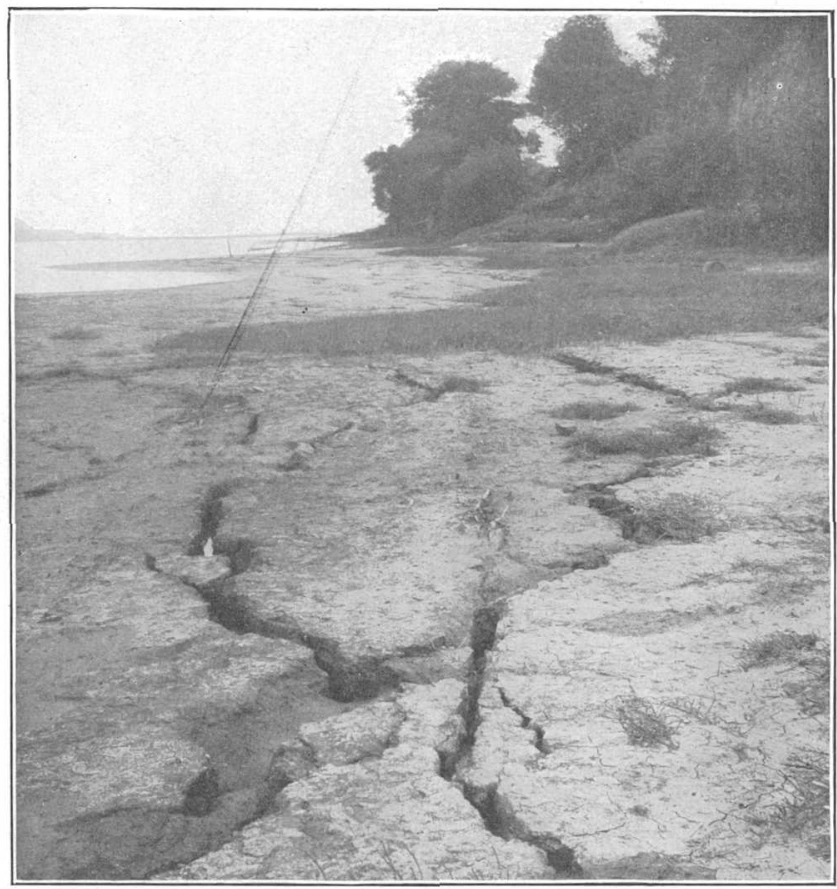

A. SECONDARY CRACKS, SHORE OF BOLINAS LAGOON.

Photograph by G. K. Cillbert.

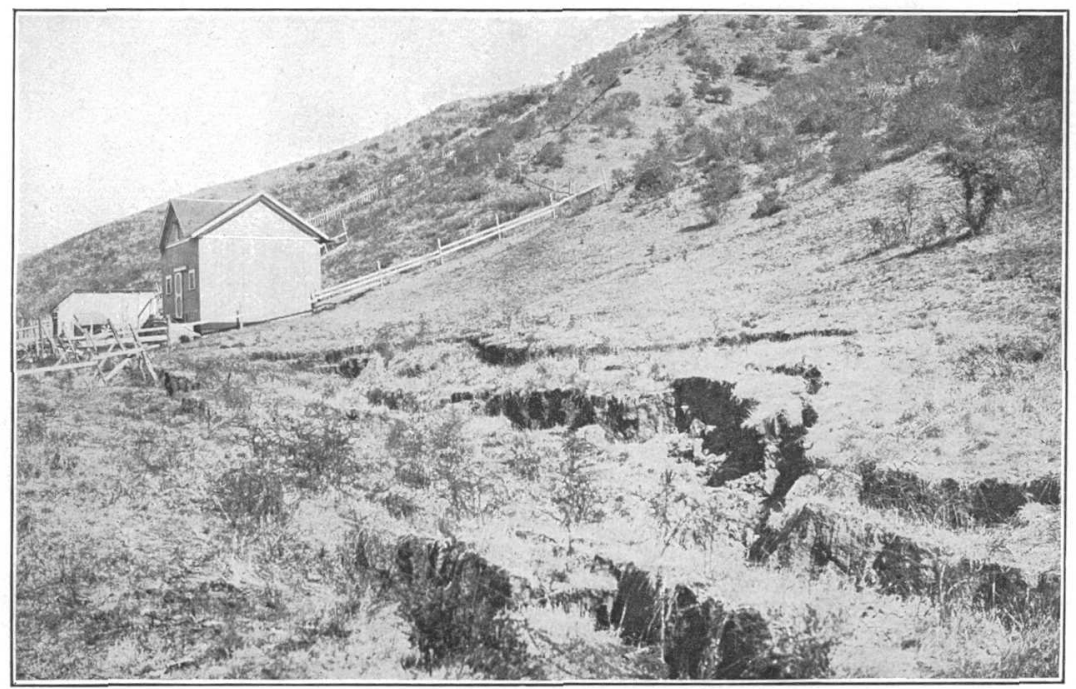

B. SECONDARY CRACKS, WITH SETTLING, BOLINAS.

Photograph by G. K. Gilbert. 


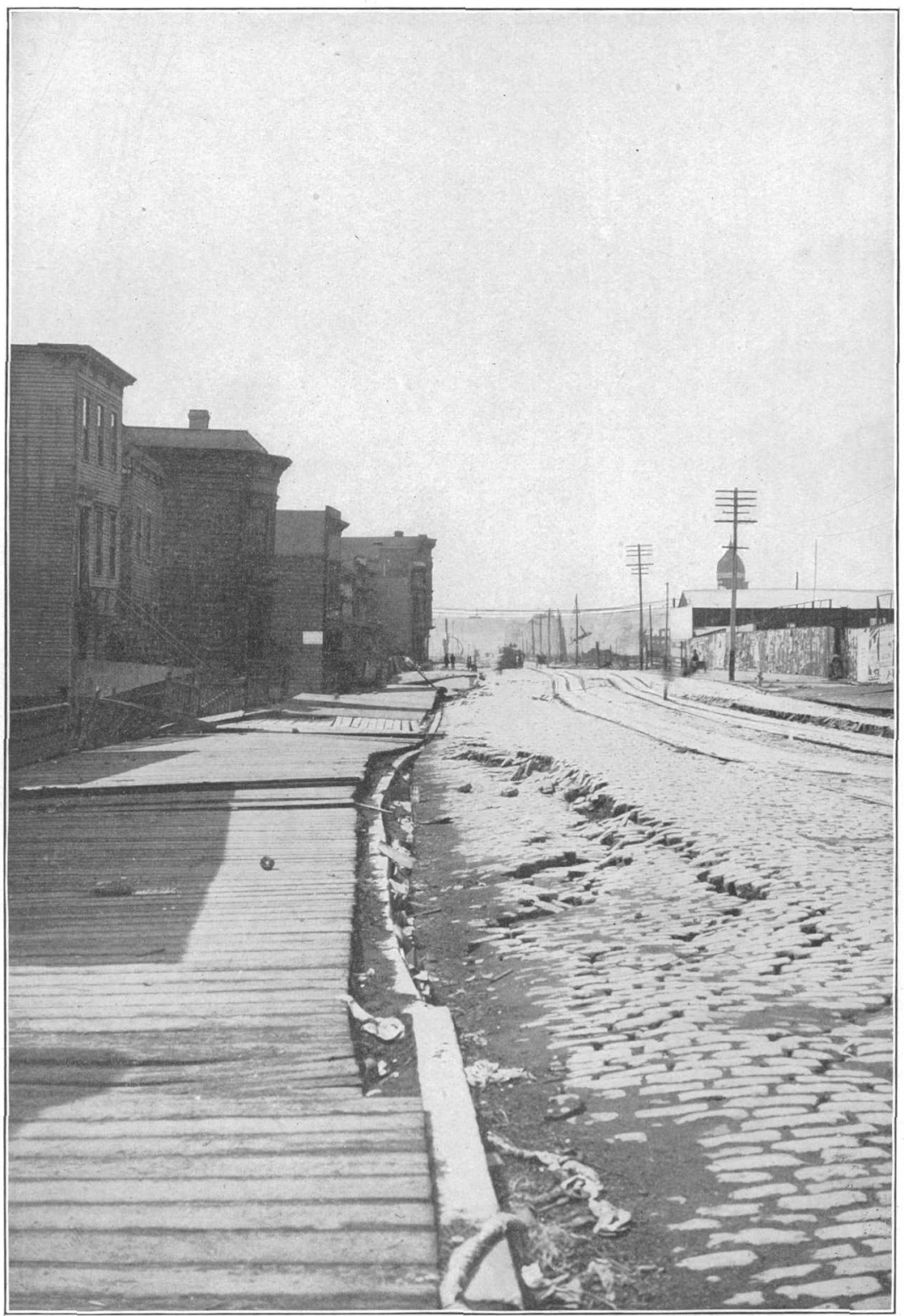

RESULTS OF EARTH FLOW, NINTH STREET, SAN FRANCISCO.

Photograph by G. K. Gilbert. 


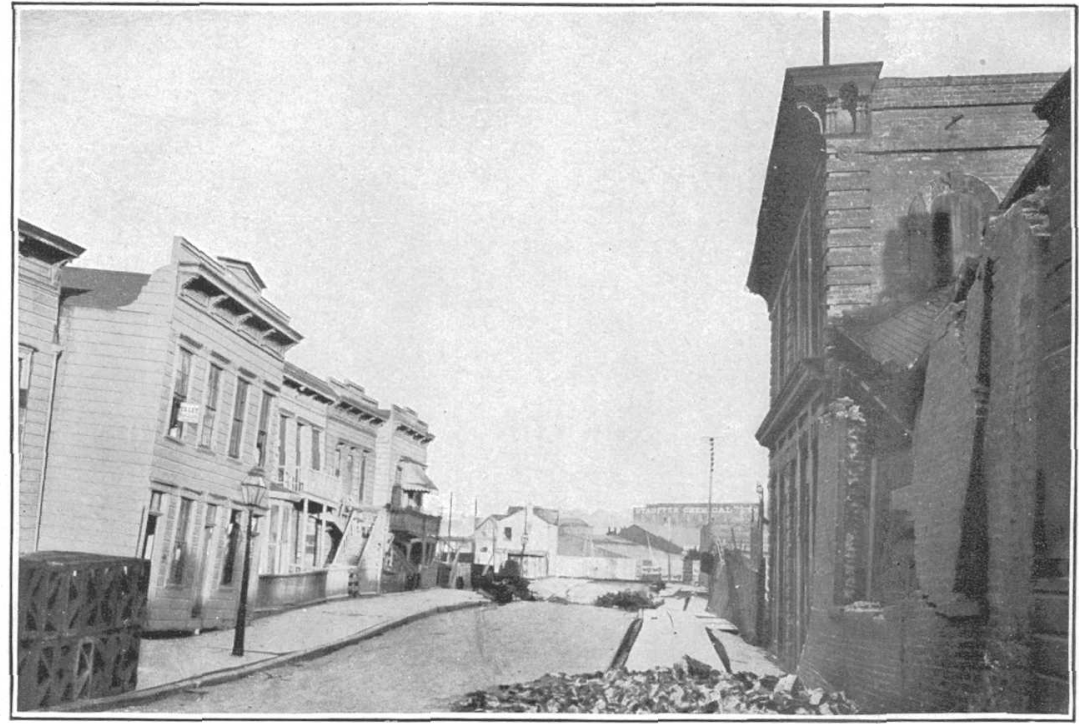

A. SETTLING (5 FEET) ON DORE STREET, BETWEEN BRYANT AND BRANNAN STREETS, SAN FRANCISCO.

Photograph by Richard L. Humphrey.

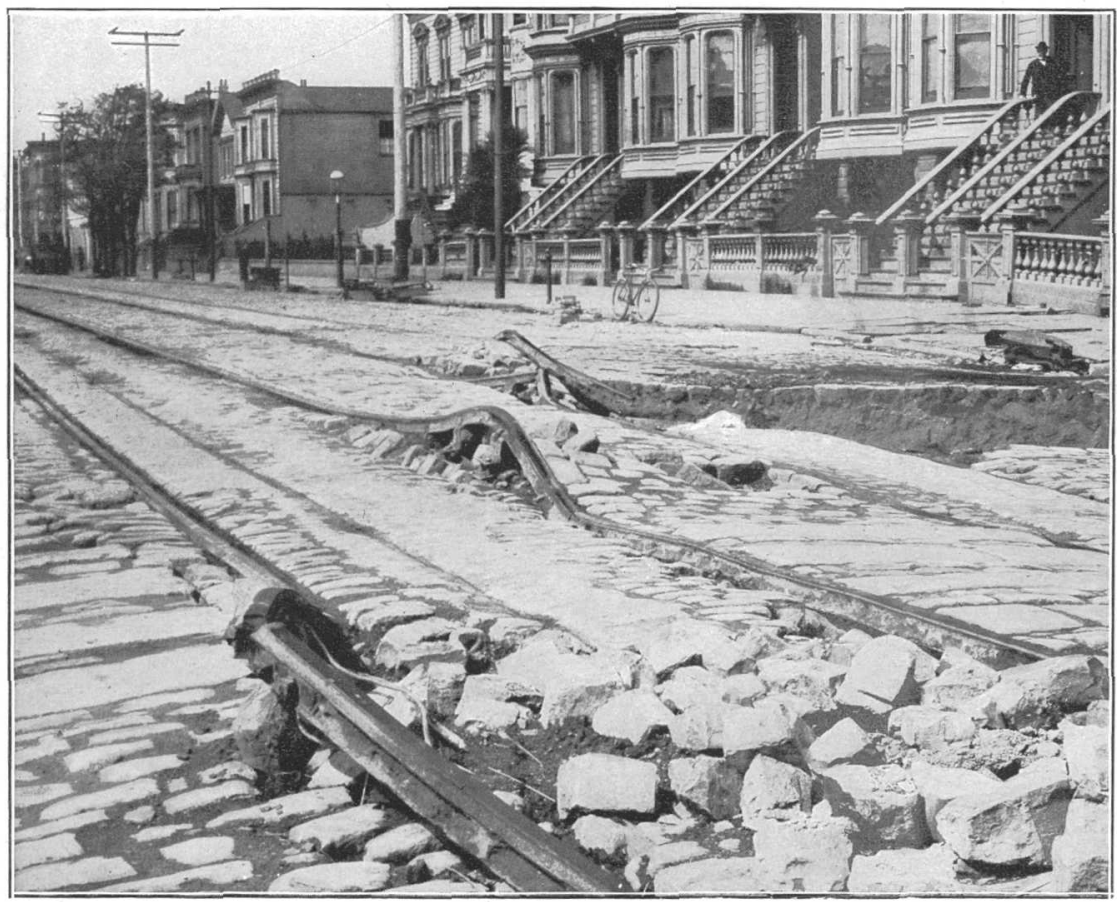

B. BUCKLING CAUSED BY EARTH FLOW, HOWARD STREET, SAN FRANCISCO.

Photograph by G. K. Gilbert.

EARTHQUAKE EFFECTS ON MADE GROUND. 


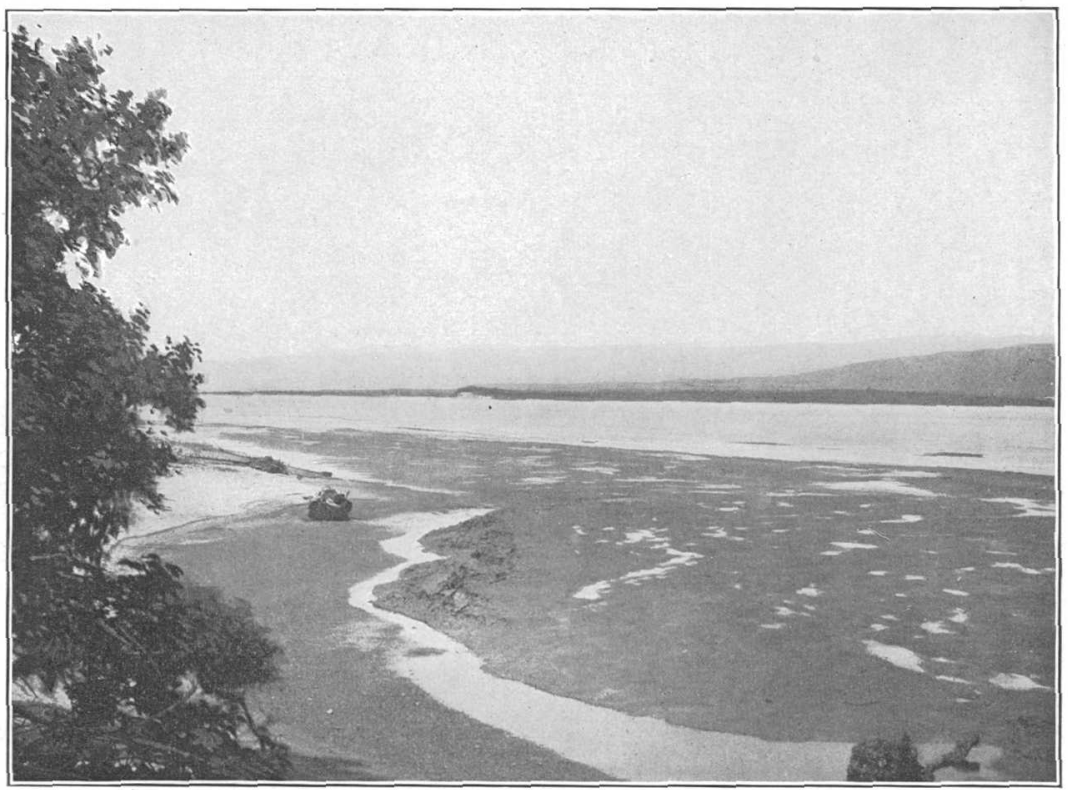

A

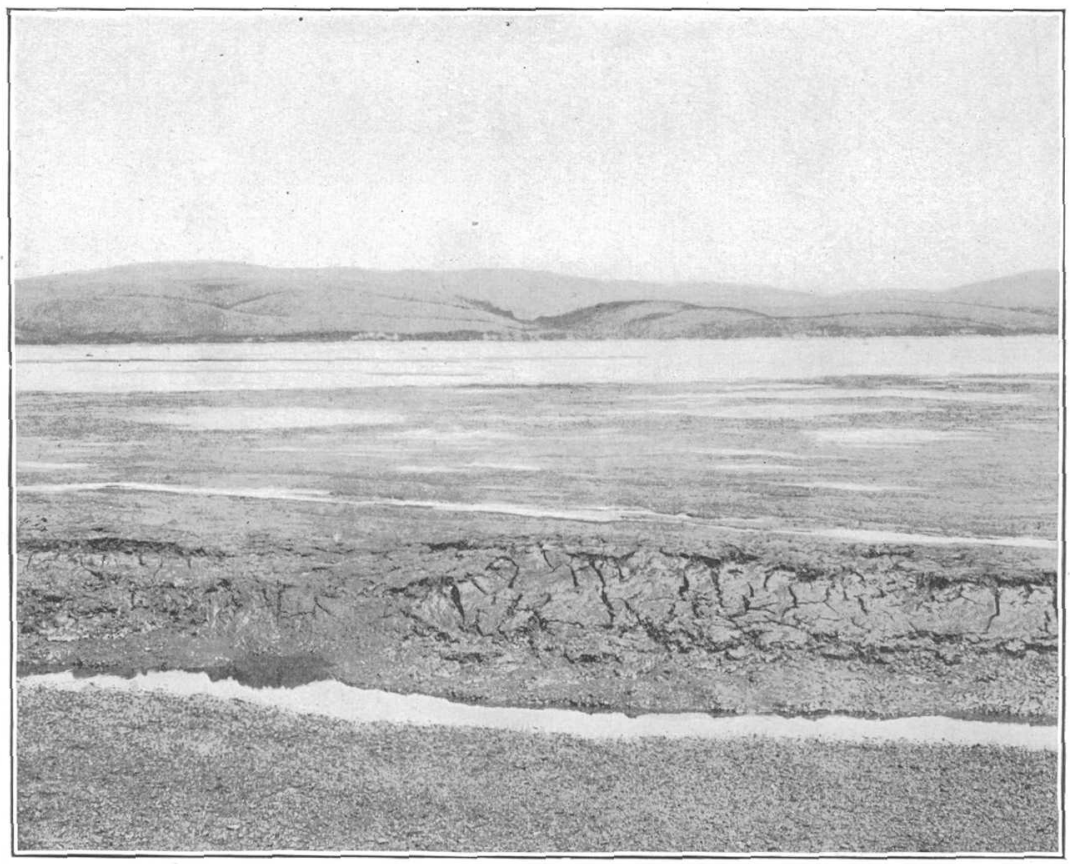

B

SHIFTED BOTTOM OF TOMALES BAY.

A. General view; l, Edge of new shoal. Photographs by G. K. Gilbert. 


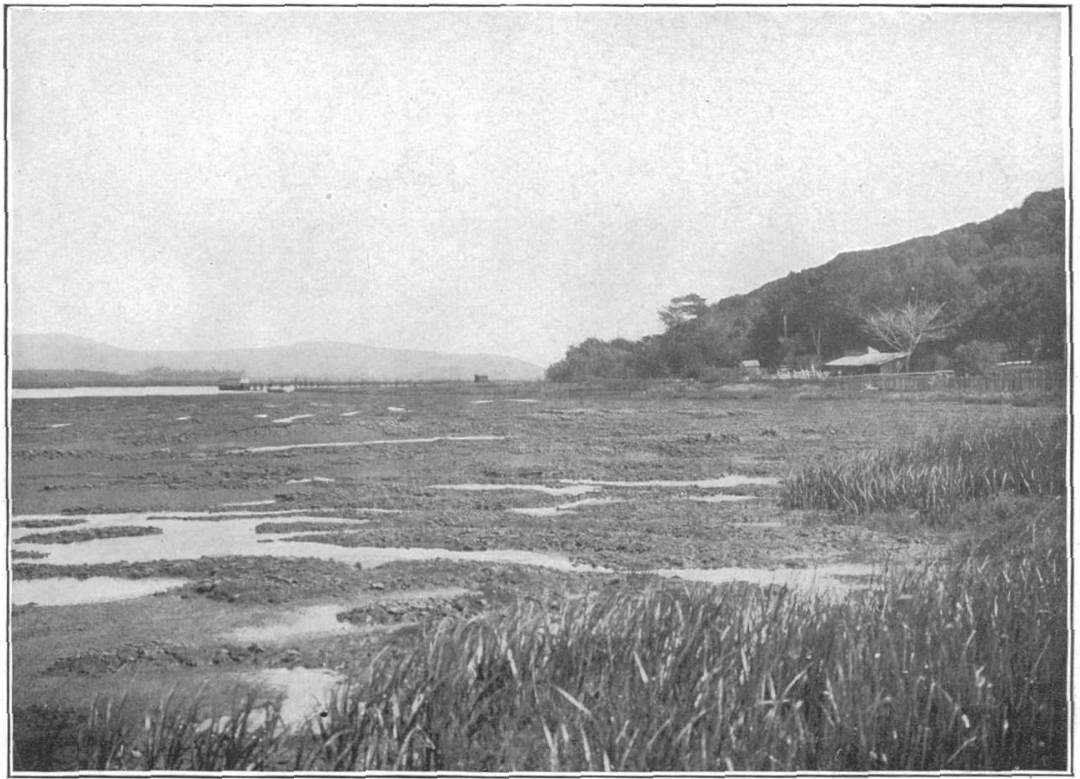

A. EARTHQUAKE RIDGES ON TIDAL FLAT, TOMALES BAY.

Photograph by G. K. Gilbert.

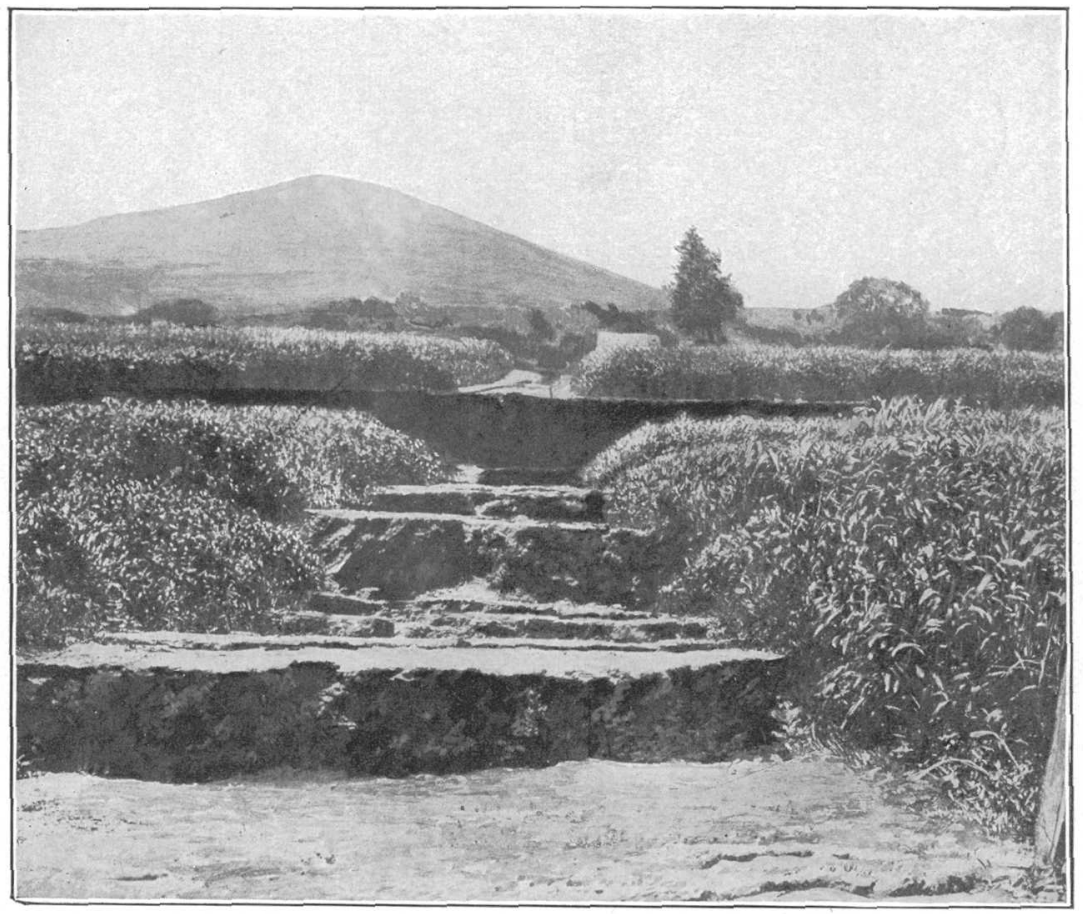

B. SLIPPING OF ALLUVIAL SOIL TOWARD SALINAS RIVER.

Grain field adjoining road along river between Spreckels's sugar mill and Salinas. Photograph by A. C. Lawson. 


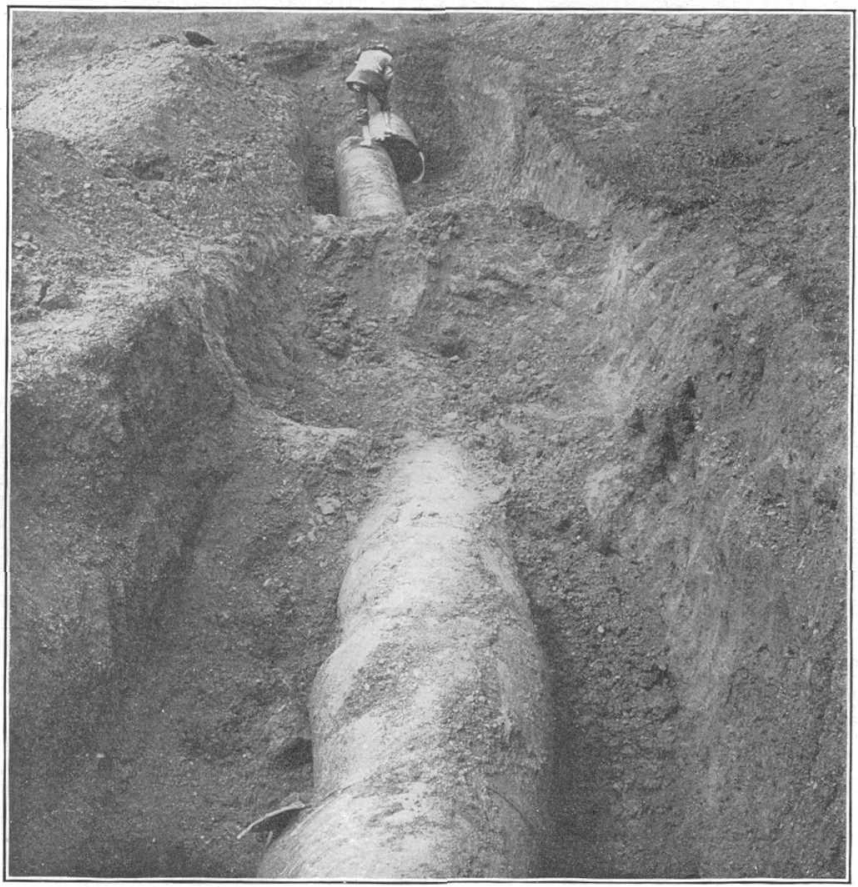

A

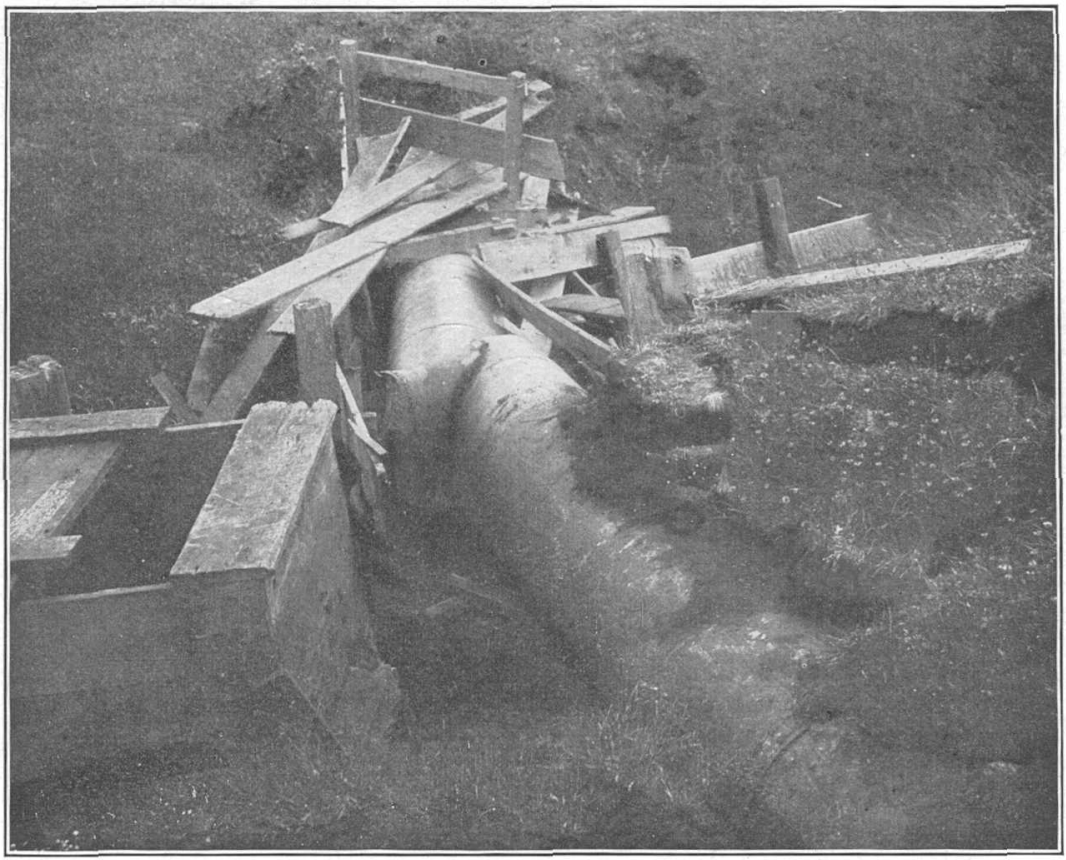

B

DAMAGE TO PILARCITOS 30-INCH PIPE LINE BY EARTHQUAKE.

$A$, Offset; $B$, Telescoping. Photographs submitted by Frank Soulé. 


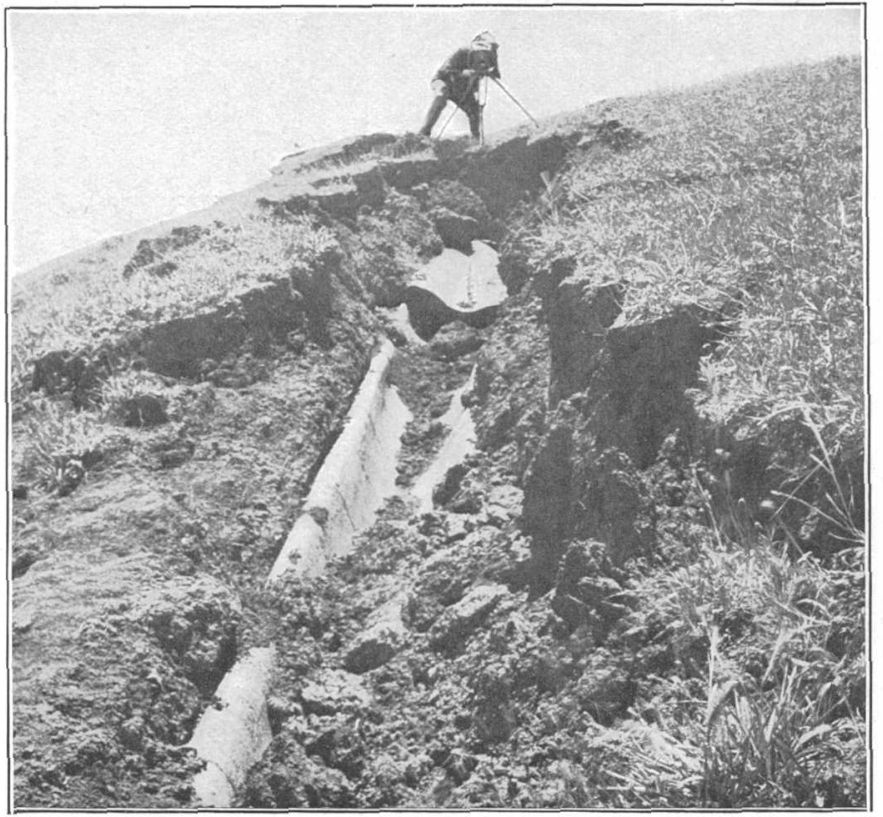

A. COLLAPSED PILARCITOS 30-INCH WROUGHT-IRON PIPE LINE, NEAR TRESTLE CROSSING THE FAULT

The slip produced a compression on the pipe line which buckled it, thereby throwing down the trestle support. The consequent parting of the pipe line suddenly released the water from the pipe, causing a vacuum which brought about the collapse. Photograph by Richard L. Humphrey.

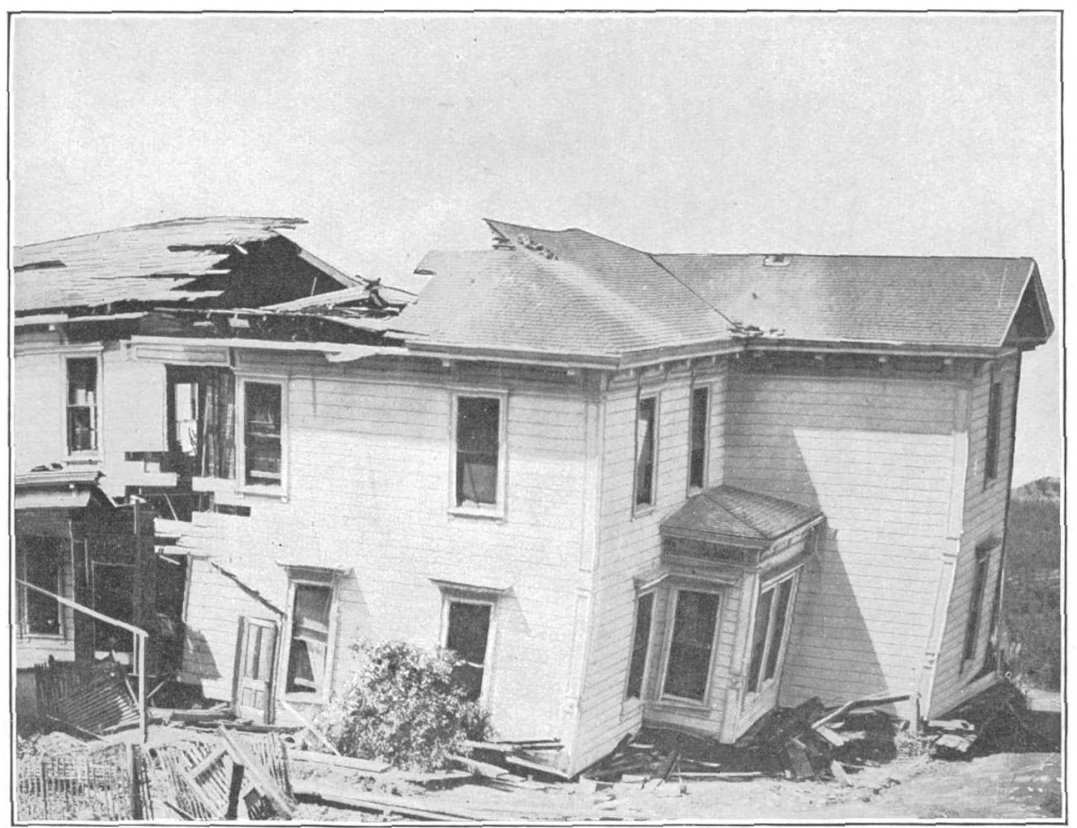

B. HOUSE ON LINE OF FAULT, TORN ASUNDER BY EARTHQUAKE. Near Wrights Station, on Southern Pacific Railroad. Photograph by Richard L. Humphrey. 


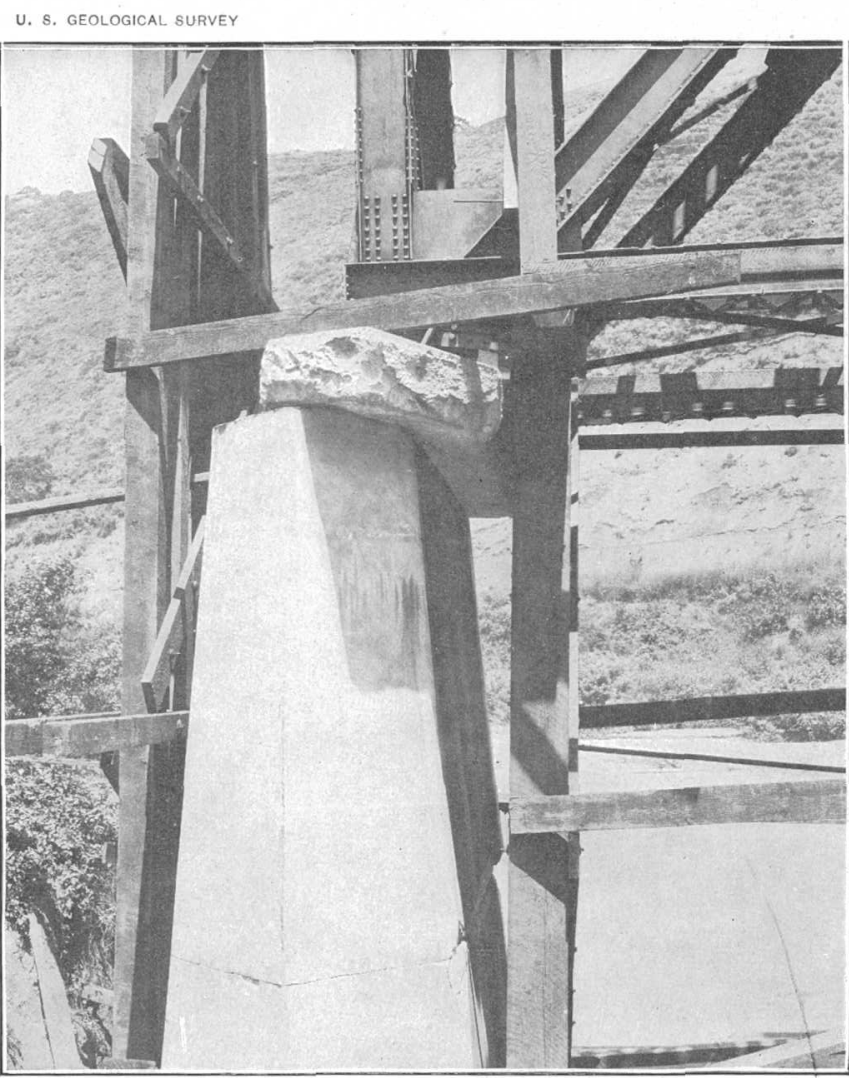

A. RACKING AND SPALLING OF CONCRETE PIER DUE TO EARTHQUAKE. Near south abutment of Southern Pacific Railroad bridge over Pajaro River. Photograph by Richard L. Humphrey.

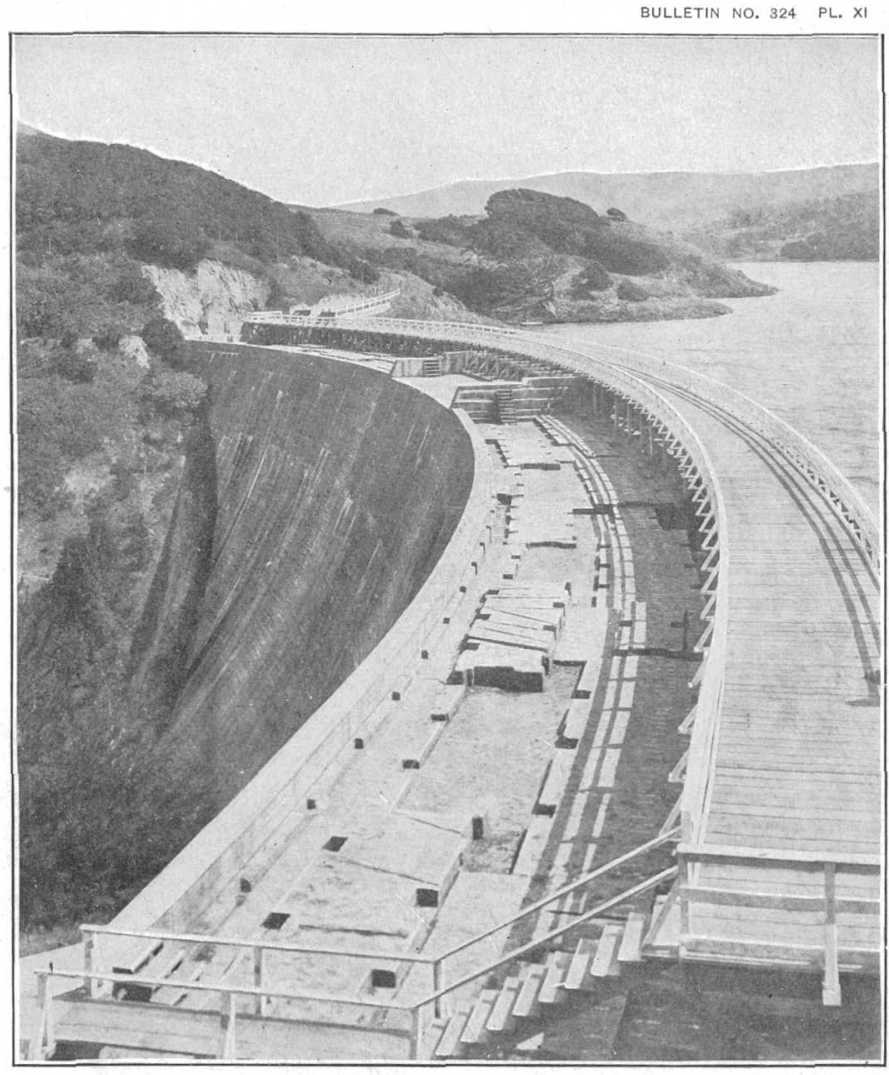

B. ENDURANCE OF CONCRETE DAM NEAR FAULT TRACE, AT CRYSTAL SPRINGS LAKE, SAN MATEO:

Photograph by Richard L. Humphrey. 


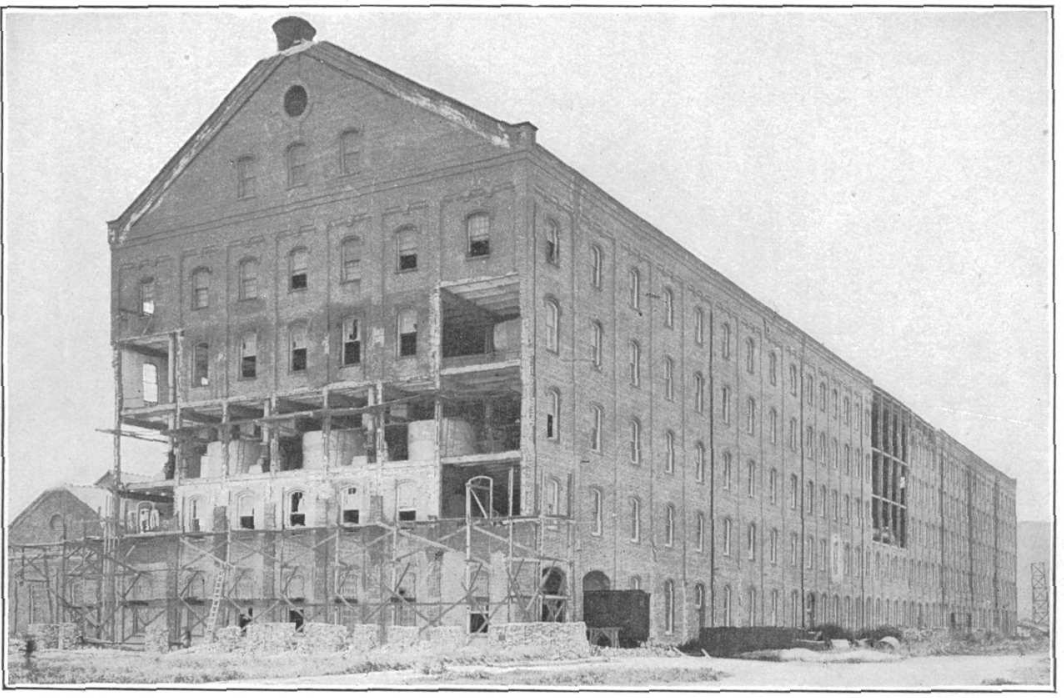

A. EFFECT OF EARTHQUAKE ON THE END AND THE INSUFFICIENTLY BRACED CENTRAL PORTION OF A BRICK BUILDING, SPRECKELS'S SUGAR MILL, ABOUT 4 MILES SOUTH OF SALINAS.

Note the stripping of brick pilasters from steel columns. Photograph by Richard L. Humphrey.

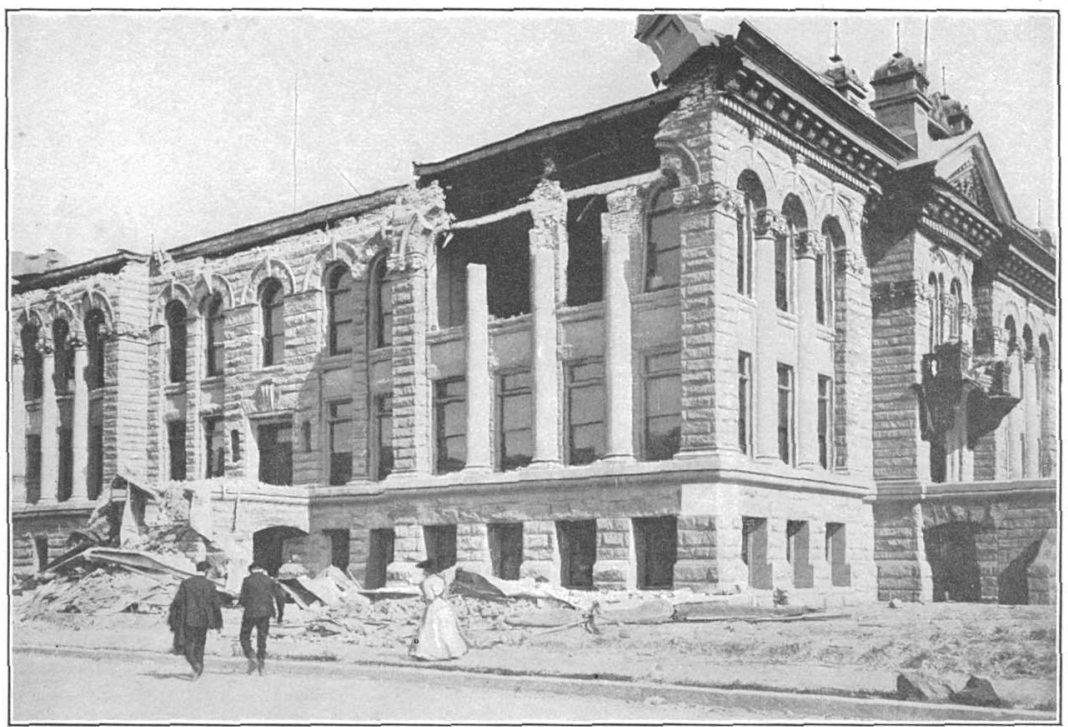

B. EARTHQUAKE WRECK OF NEW HALL OF JUSTICE, SAN JOSE, BUILT ON ALLUVIAL SOIL. Wrack due to poor quality of stonework and unnecessarily massive construction. Photograph by Frank Soulé. 


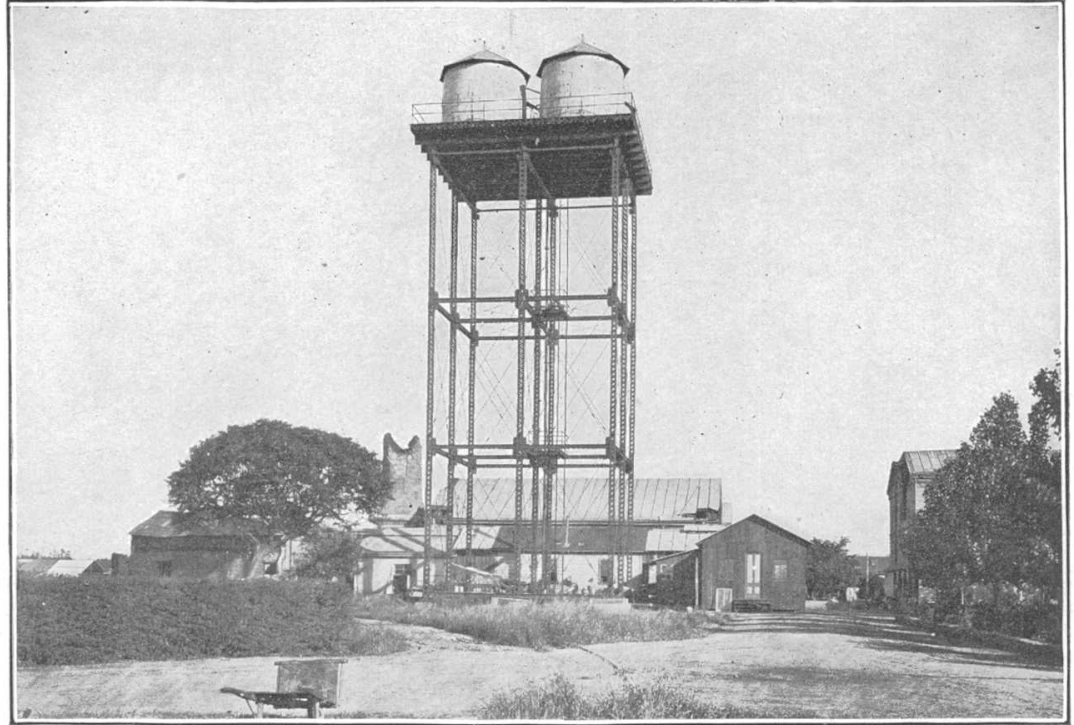

A. COMPARATIVE EARTHQUAKE ENDURANCE OF DISSIMILAR STRUCTURES, AGNEW INSANE ASYLUM, NEAR SAN JOSE.

Tanks on steel trestle, undamaged, and circular brick stack, collapsed. Photograph by Richard L. Humphrey.

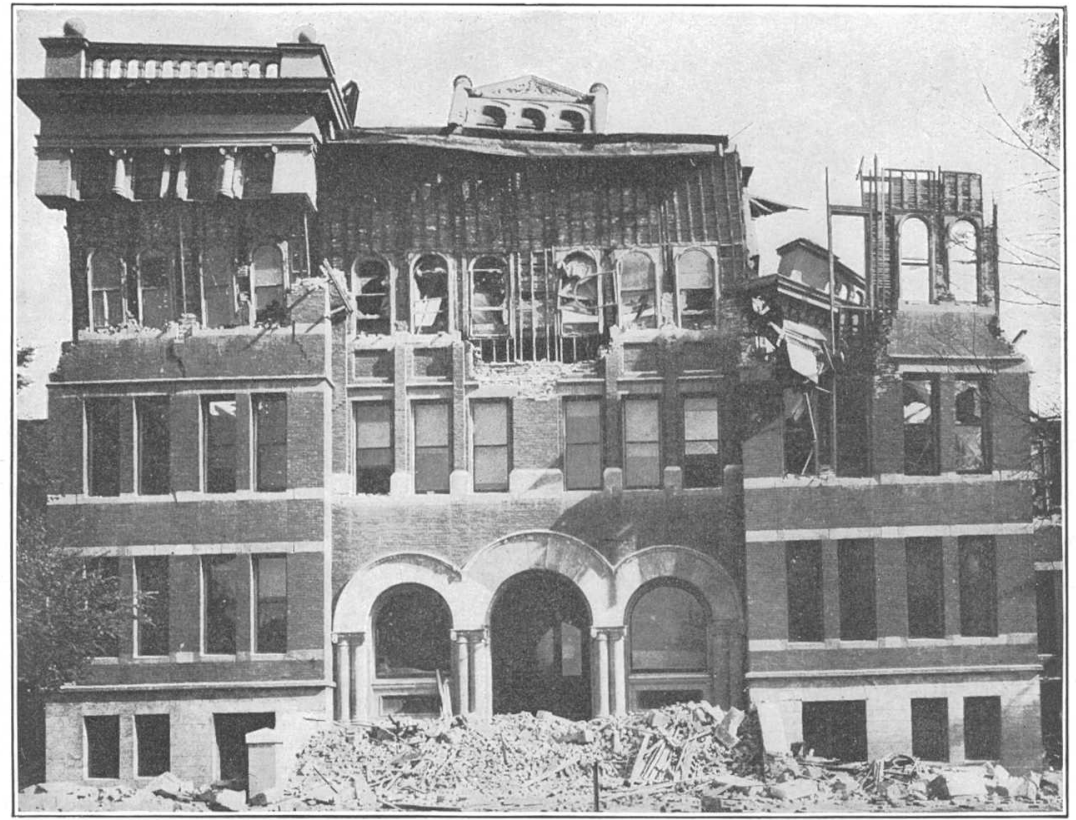

B. EARTHQUAKE EFFECT, HIGH SCHOOL BUILDING, SAN JOSE.

Photograph submitted by Frank Soulè. 


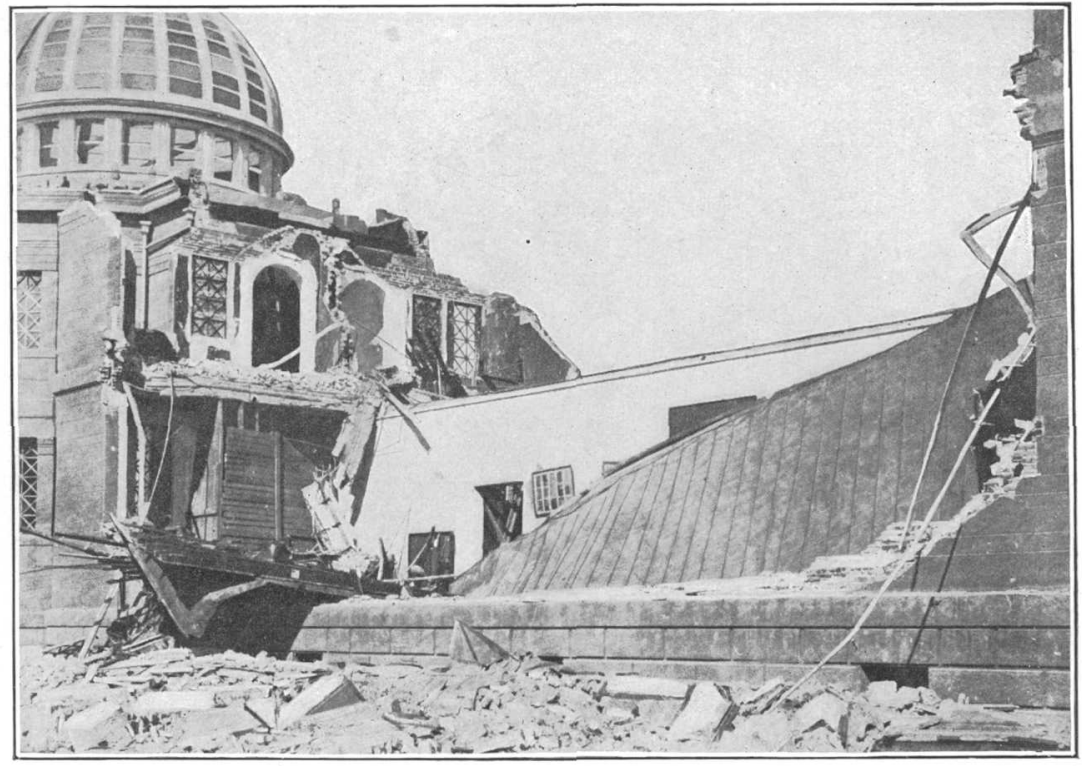

A. COMPARATIVE BEHAVIOR OF REENFORCED CONCRETE AND BRICKWORK UNDER EARTHQUAKE VIBRATION, MUSEUM, LELAND STANFORD JUNIOR UNIVERSITY.

The central portion, of reenforced concrete, was undamaged, but the brick wings collapsed. Photograph by Richard L. Humphrey.

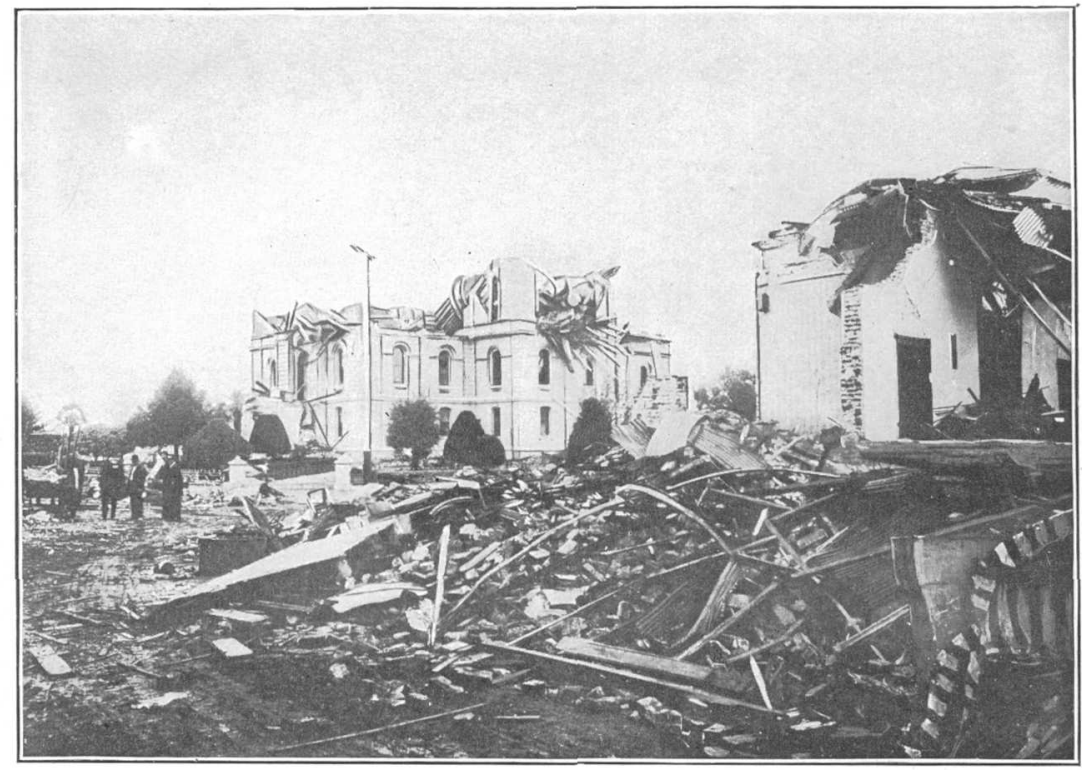

B. COMPLETE WRECK BY EARTHQUAKE, COURT-HOUSE AND HALL OF RECORDS, SANTA ROSA.

Wreck due to light wooden framing, insufficierit bracing, and poor mortar. Photograph submitted by Richard L. Humphrey. 


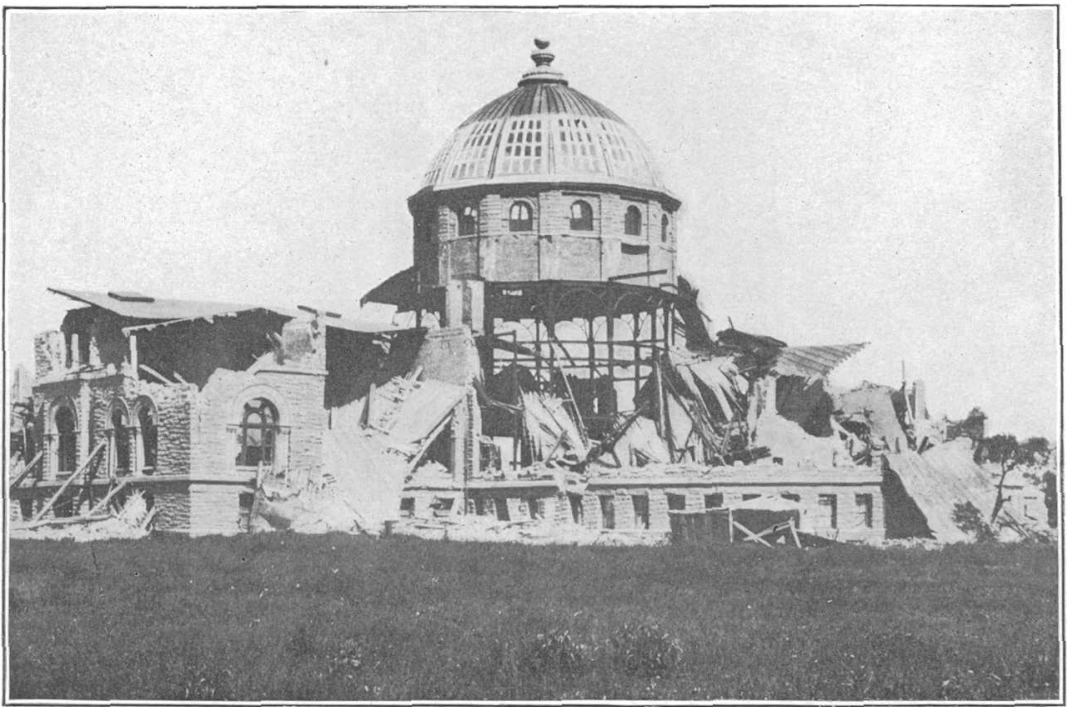

A. UNDAMAGED STEEL FRAMEWORK SUPPORTING DOME OF LIBRARY

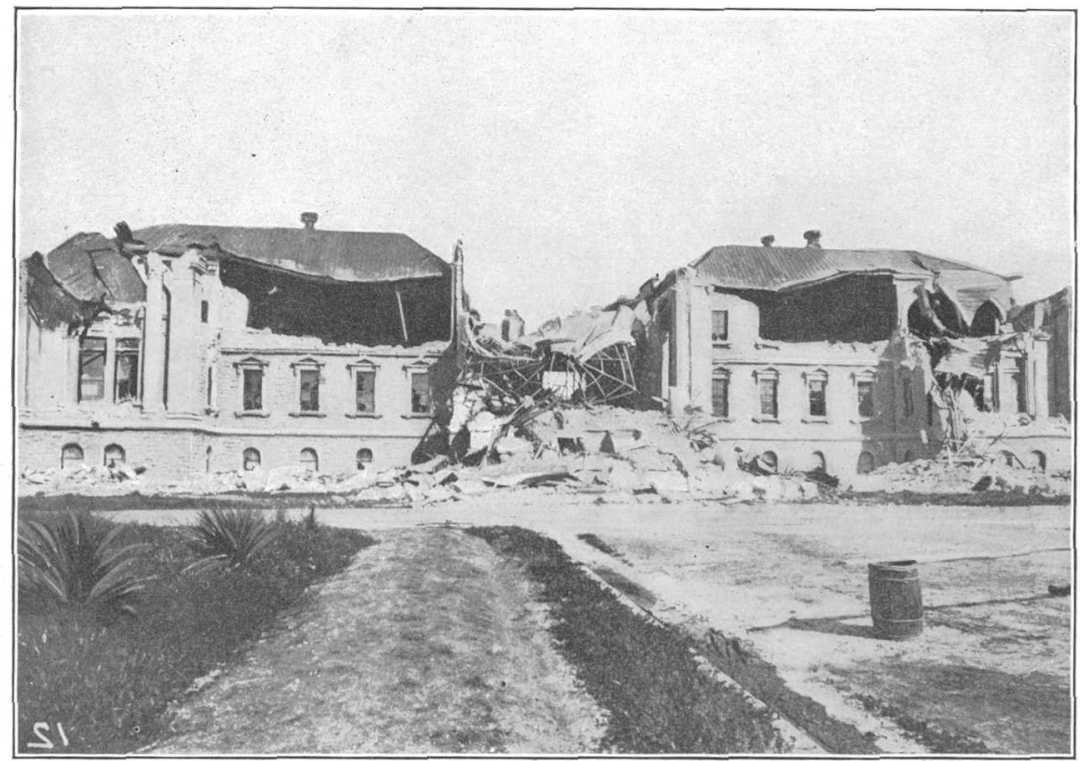

B. COLLAPSE OF BRICK WALLS, CAUSING DESTRUCTION OF STEEL SKELETON DOME OF GYMNASIUM.

ENDURANCE OF STEEL FRAMEWORK AS AFFECTED BY METHOD OF SUPPORT, LELAND STANFORD JUNIOR UNIVERSITY.

Photographs by Richard L. Humphrey. 


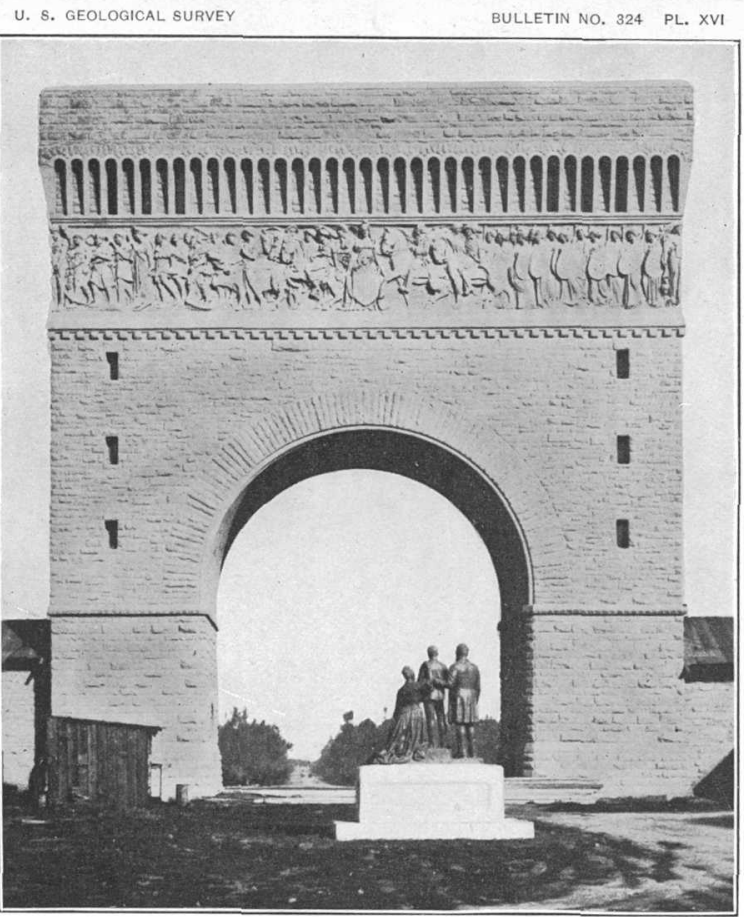

$A$

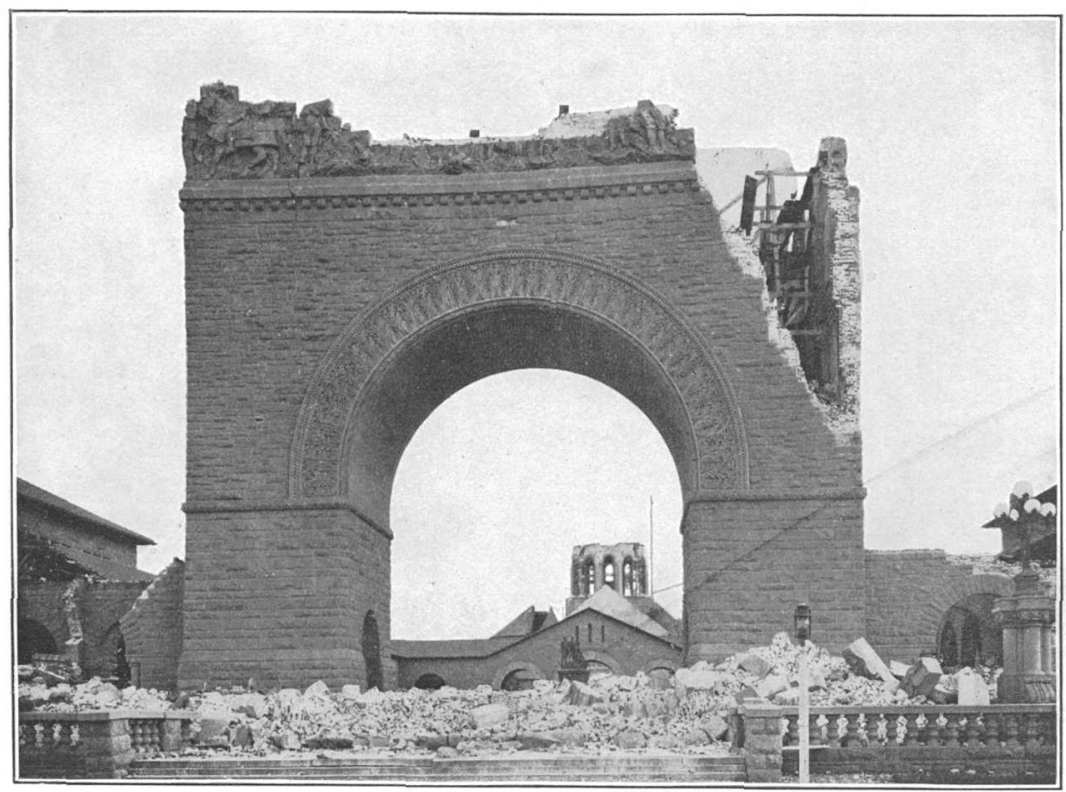

$B$

MEMORIAL ARCH, LELAND STANFORD JUNIOR UNIVERSITY.

$A$, Before the earthquake (photograph submitted by Richard L. Humphrey); B, Earthquake effect (photograph by Richard L. Humphrey). The beams designed to stiffen the walls were not tied to them and helped to batter them down when the shock came. 


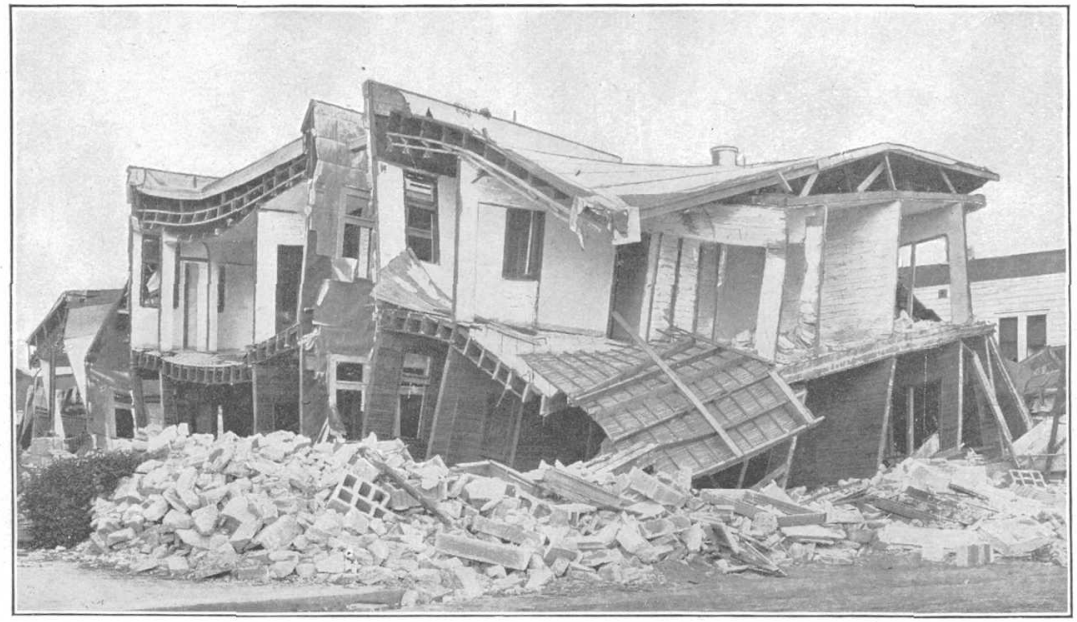

A. COLLAPSE DUE TO LACK OF TIE BETWEEN WALLS AND FRAME, THIELE BUILDING (CEMENT BLOCK), PALO ALTO.

Photograph by Richard L. Humphrey.

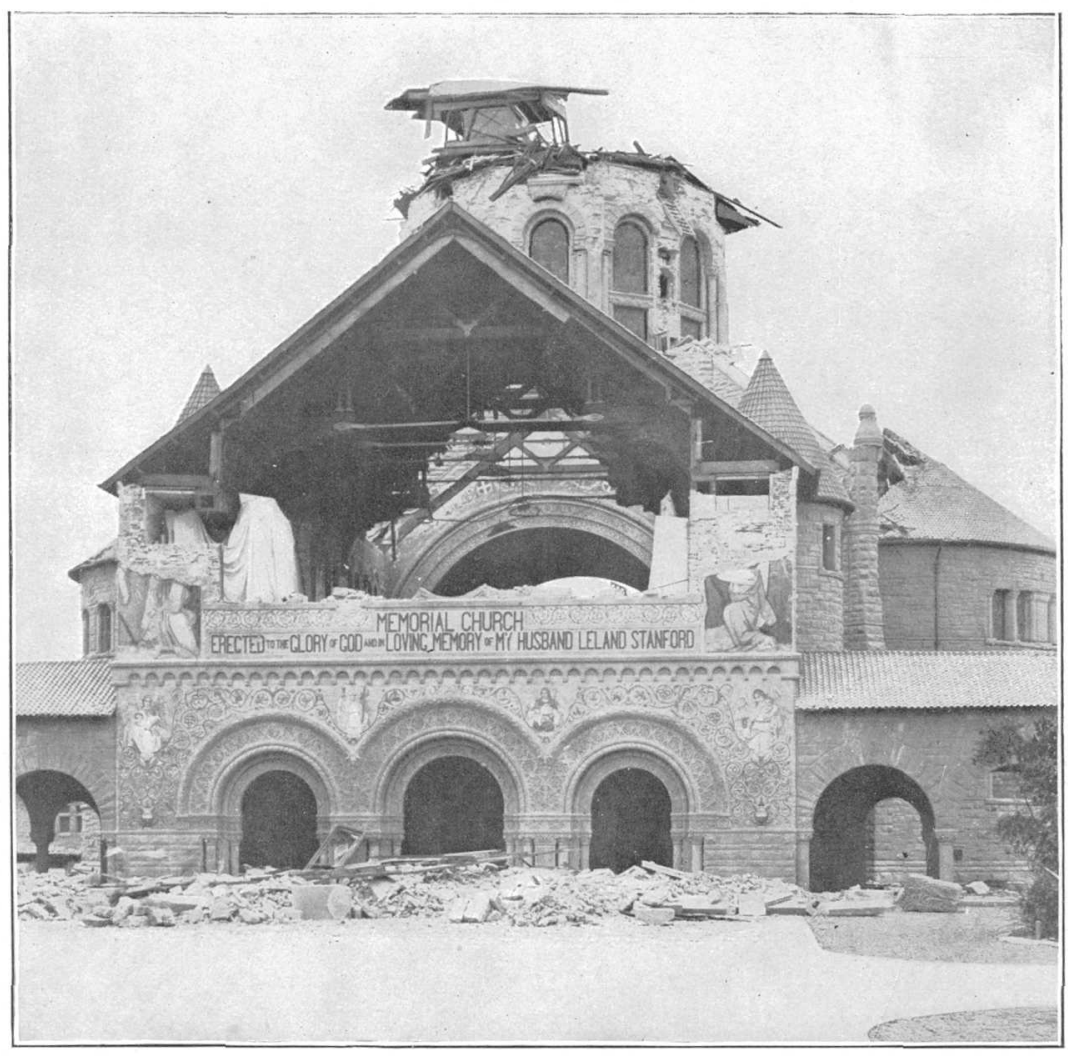

B. COLLAPSED TOWER AND GENERAL EARTHQUAKE WRECKAGE, MEMORIAL CHURCH, LELAND STANFORD JUNIOR UNIVERSITY

Photograph by Richard L. Humphrey. 


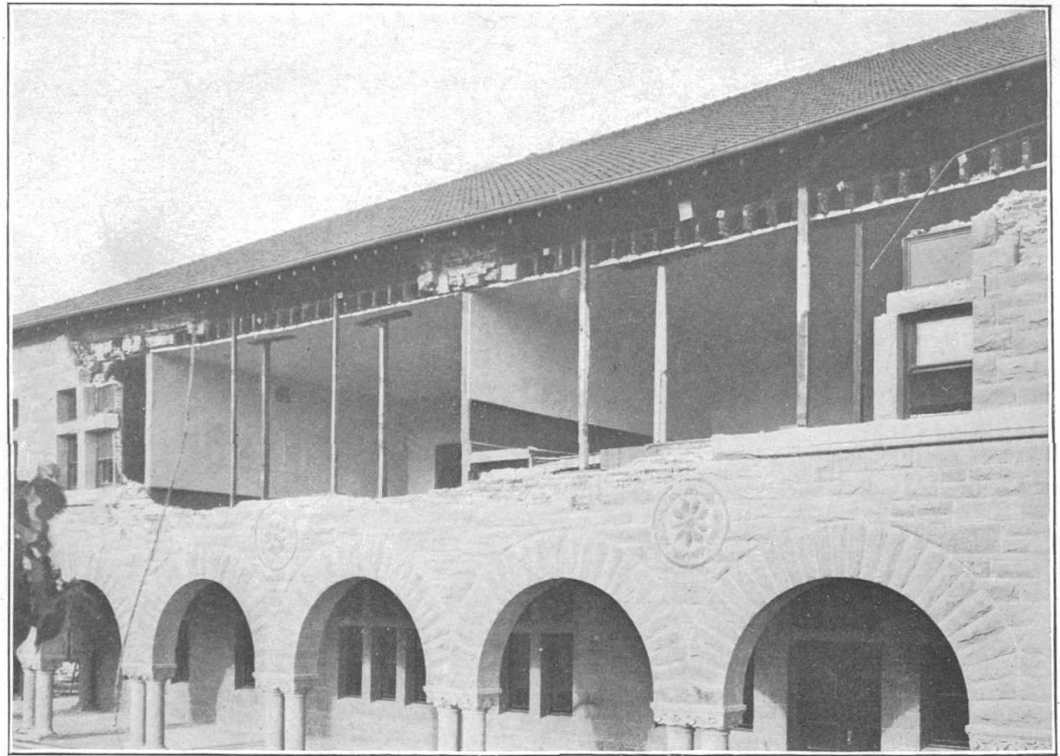

A. EARTHQUAKE DAMAGE DUE TO LACK OF TIE AND BRACING, GEOLOGICAL DEPARTMENT, LELAND STANFORD JUNIOR UNIVERSITY.

Photograph by Richard L. Humphrey.

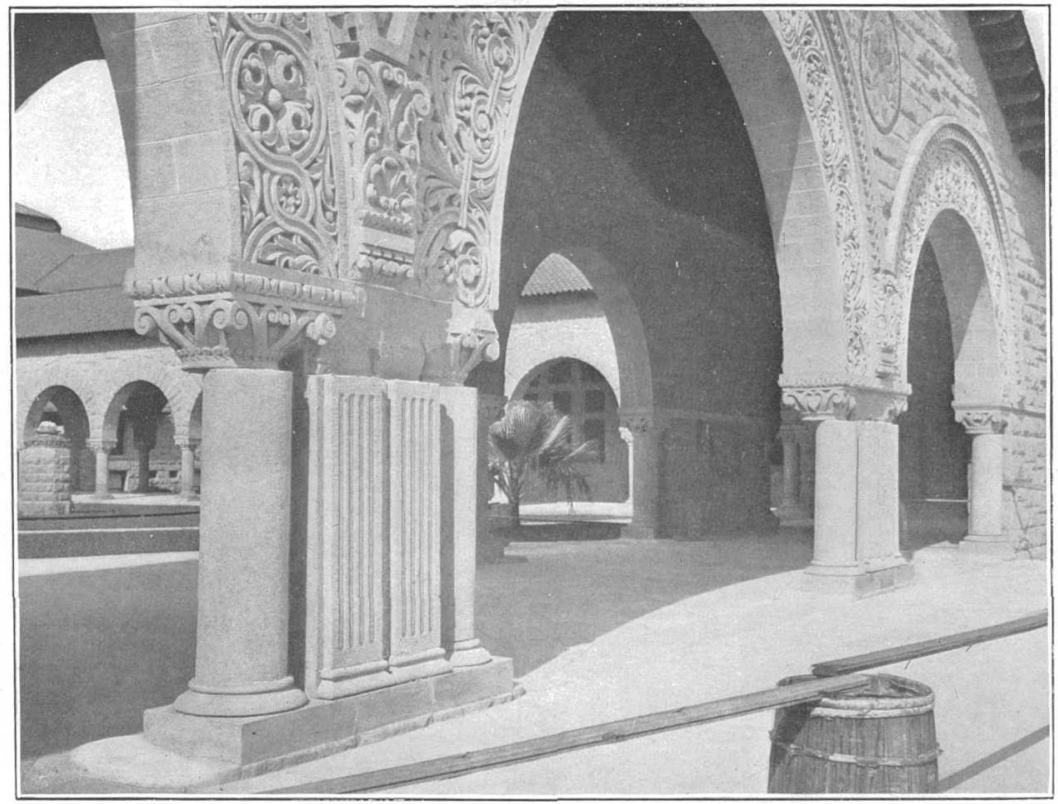

B. EARTHQUAKE EFFECT ON ARCHES, LELAND STANFORD JUNIOR UNIVERSITY. Spalling of caps and movement of upper part of columns. Photograph by Richard L. Humphrey. 


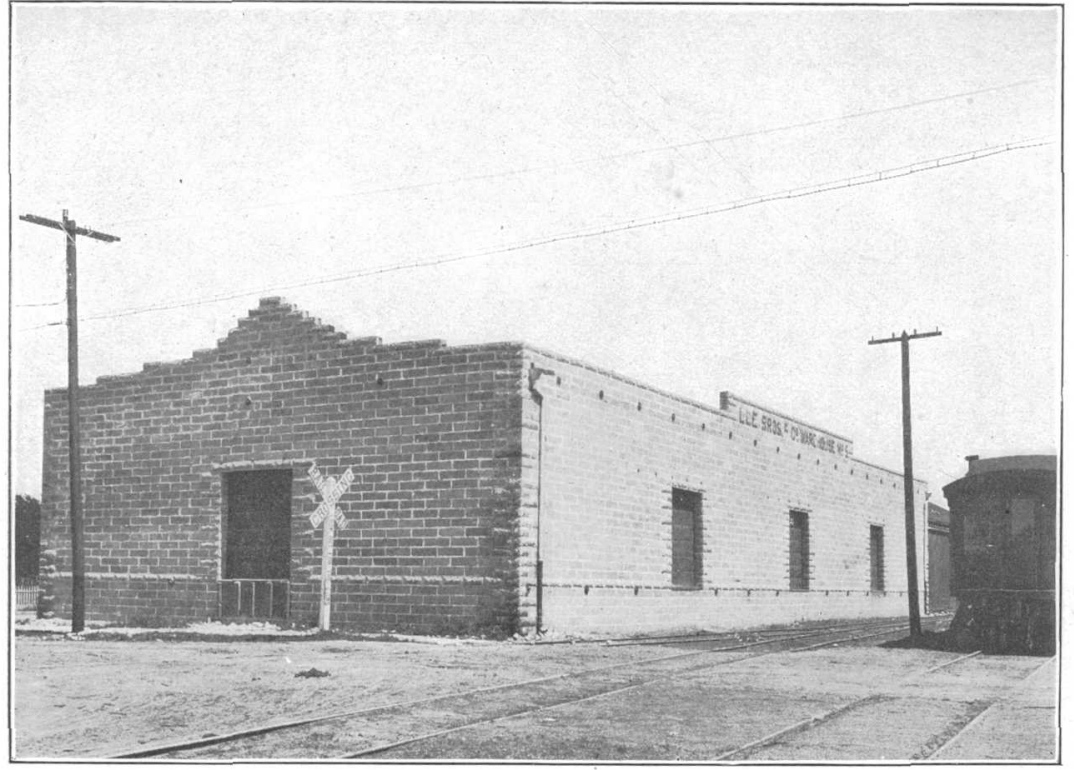

1. ENDURANCE OF WALLS TIED TOGETHER WITH STEEL RODS, LEE BROTHERS' WAREHOUSE, SANTA ROSA.

Slightly damaged at cornice. The few blocks which were thrown down by the earthquake were replaced previous to the taking of the photograph.

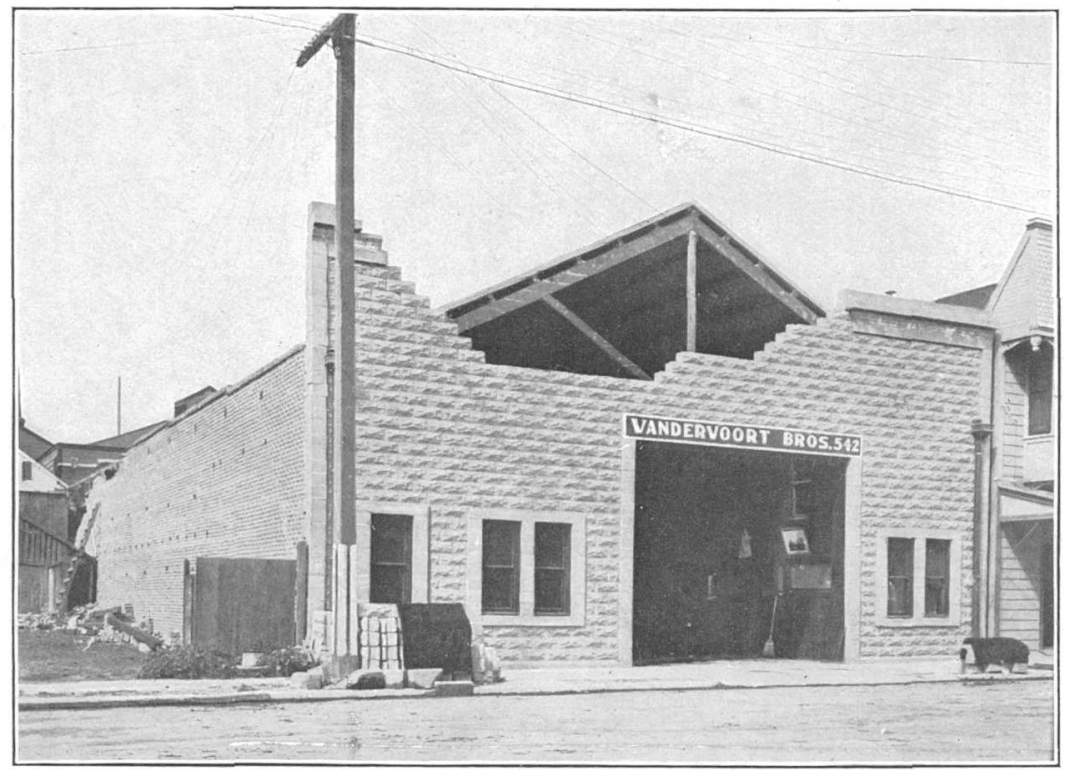

B. WALL THROWN DOWN BY EARTHQUAKE VIBRATIONS OF ROOF TRUSSES WHICH WERE NOT TIED TO WALL, VANDERVOORT BROTHERS' LIVERY, PALO ALTO.

EARTHQUAKE EFFECTS ON CEMENT-BLOCK. WALLS.

Photographs by Richard L. Humphrey. 


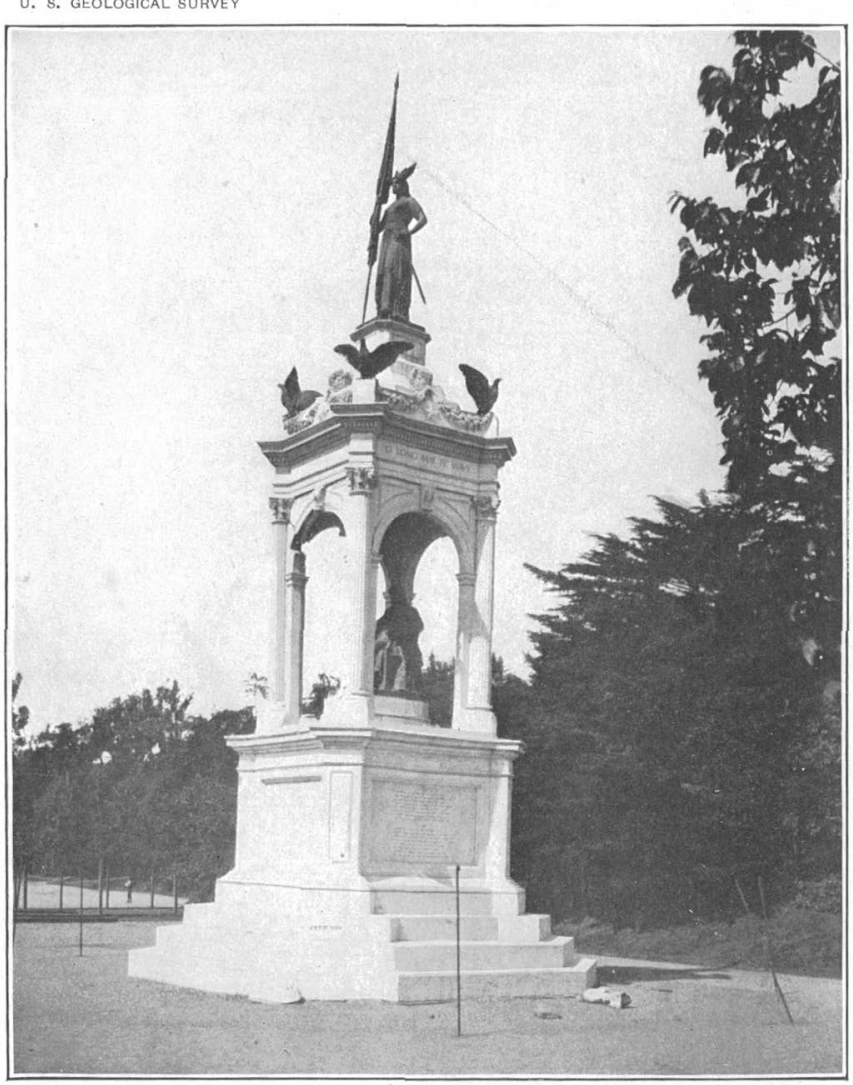

A. LOOSENING OF ARCH STONES AND SPALLING OF COLUMNS BY EARTHQUAKE, FRANCIS SCOTT KEY MONUMENT, GOLDEN GATE PARK, SAN FRANCISCO

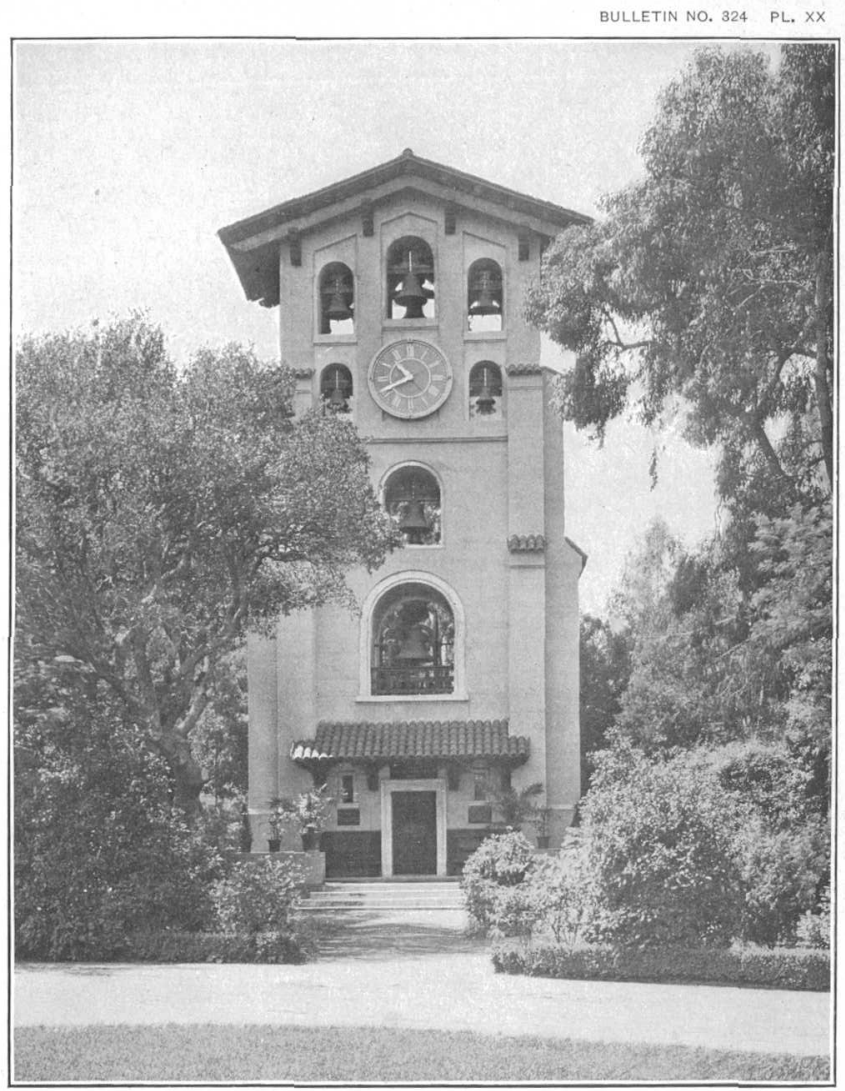

B. UNDAMAGED REENFORCED-CONCRETE STRUCTURE AT MILLS COLLEGE, NEAR OAKLAND. Bell tower, within a few feet of a brick building that was badly racked by the earthquake.
Photograph by Richard L. Humphrey. 


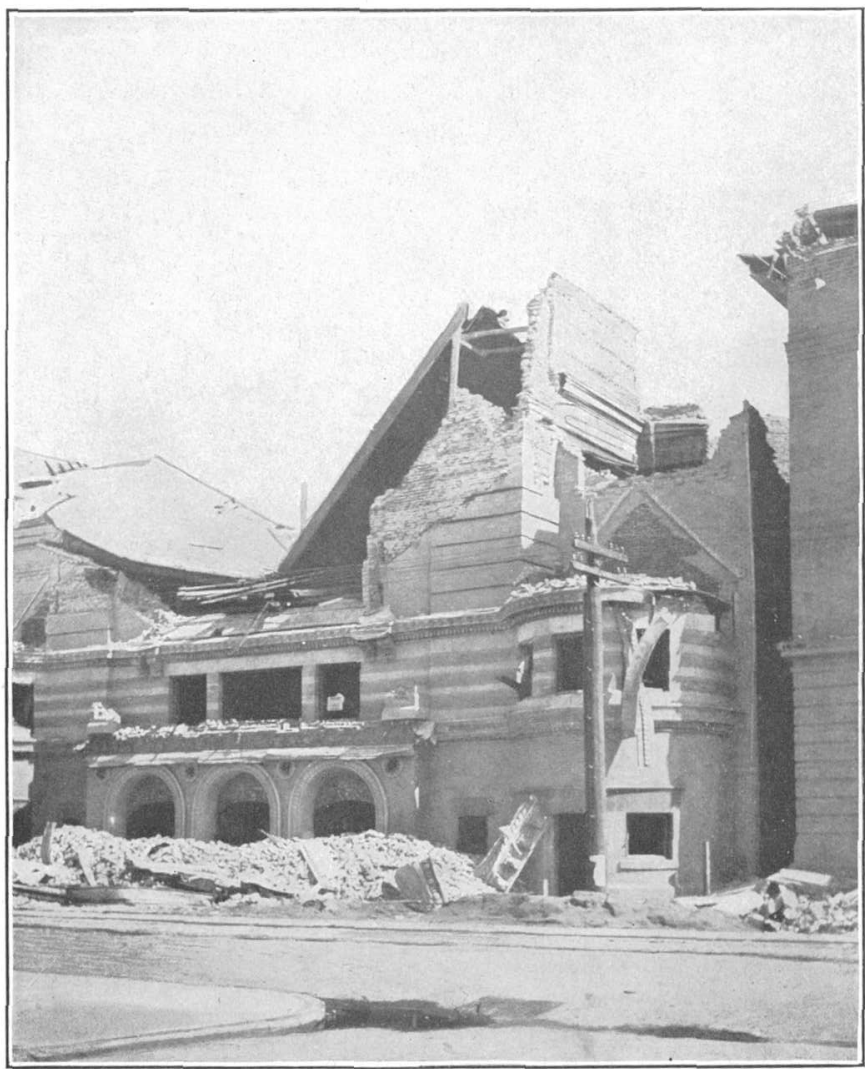

A. RACKING OF NEWLY CONSTRUCTED BUILDING, SYNAGOGUE GEARY AND FILLMORE STREETS, SAN FRANCISCO.

Note the separation of the brick veneer from the backing; also the racking of the wall at the corner. Photograph by John Stephen Sewell.

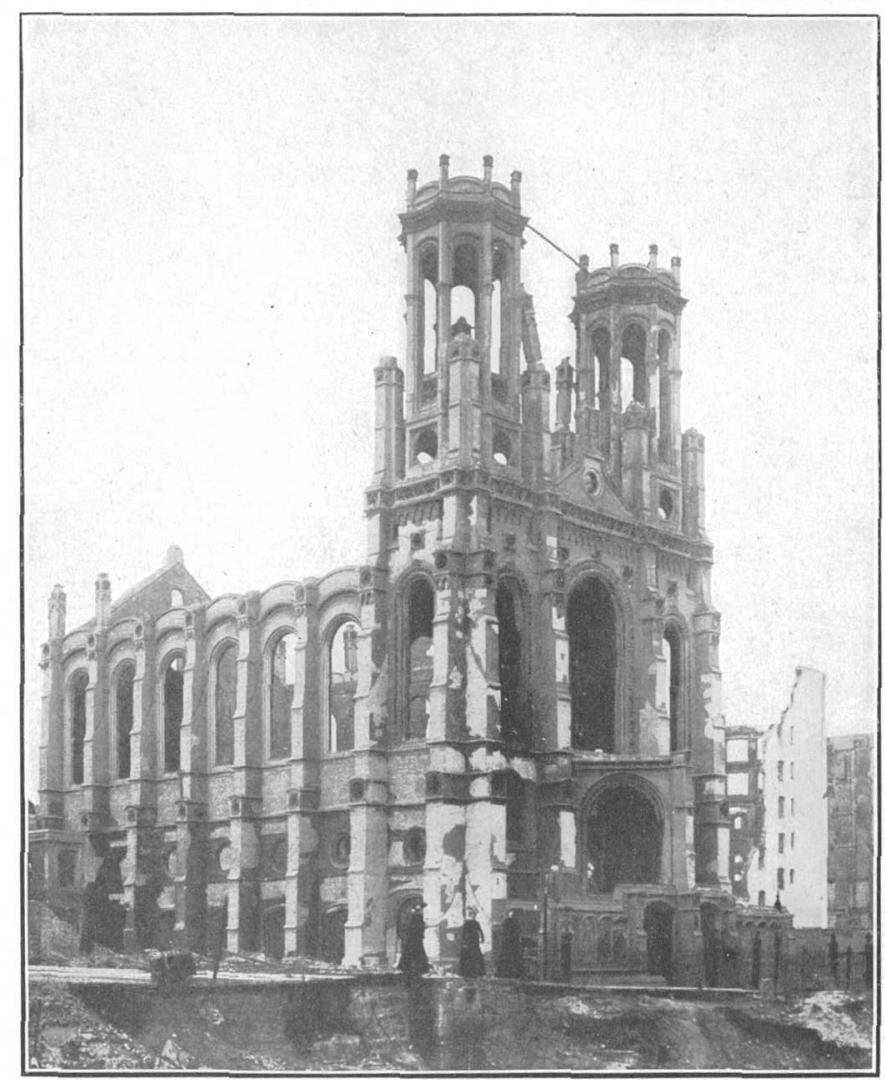

B. GOOD EARTHQUAKE ENDURANCE OF BUTTRESSED WALLS, SYNAGOGUE EMANUEL, SAN FRANCISCO.

Photograph submitted by Richard L. Humphrey. 


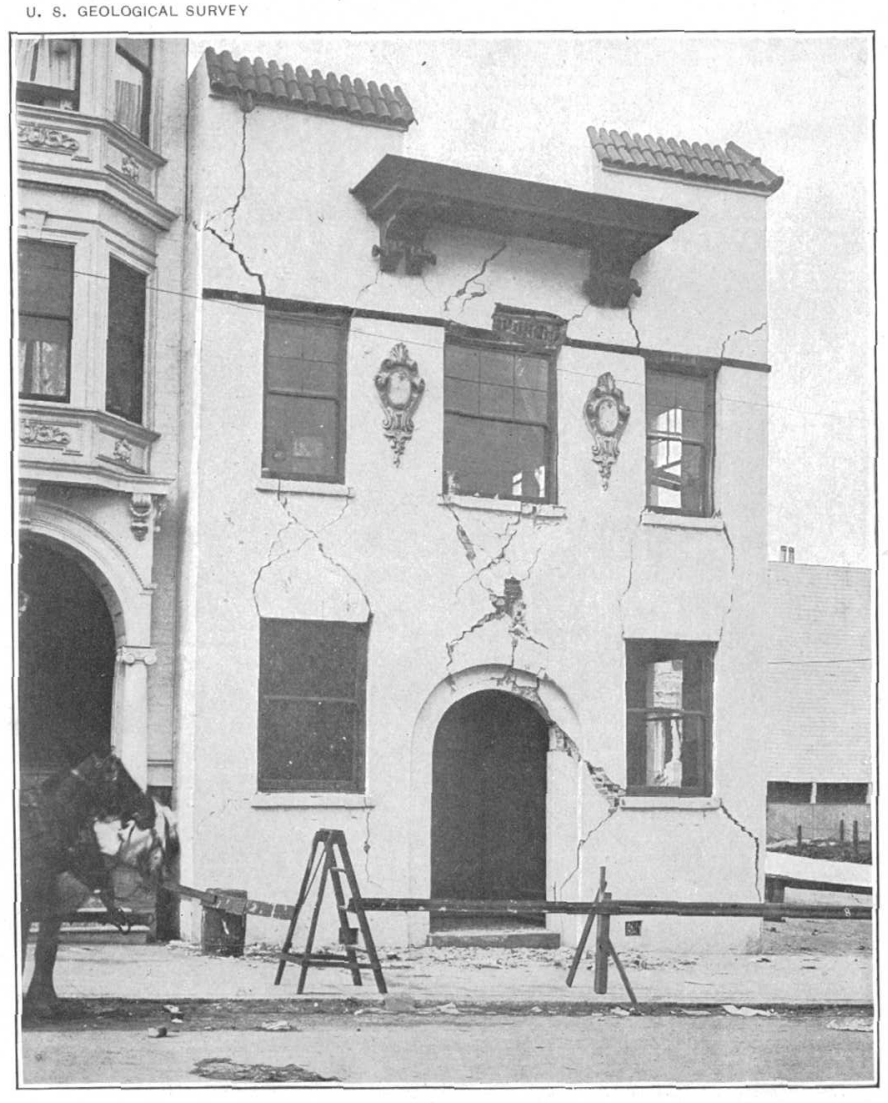

A. X CRACKS IN BRICKWORK, CAUSED BY ROCKING, HOUSE IN SAN FRANCISCO.

Photograph submitted by Richard L. Humphrey.

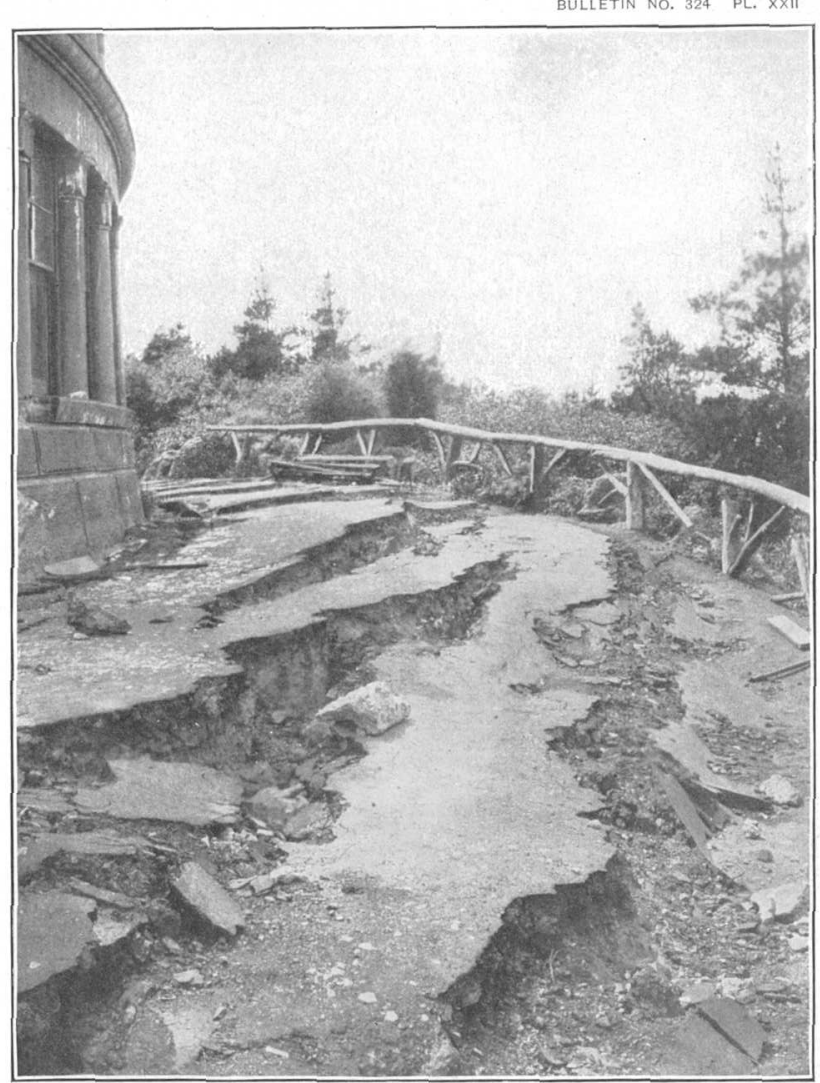

B. SLIP OF FOUNDATION OF CYCLORAMA, STRAWBERRY HILL, GOLDEN GATE PARK, SAN FRANCISCO, CAUSING COLLAPSE OF THE STRUCTURE. Photograph by Richard L. Humphrey. 


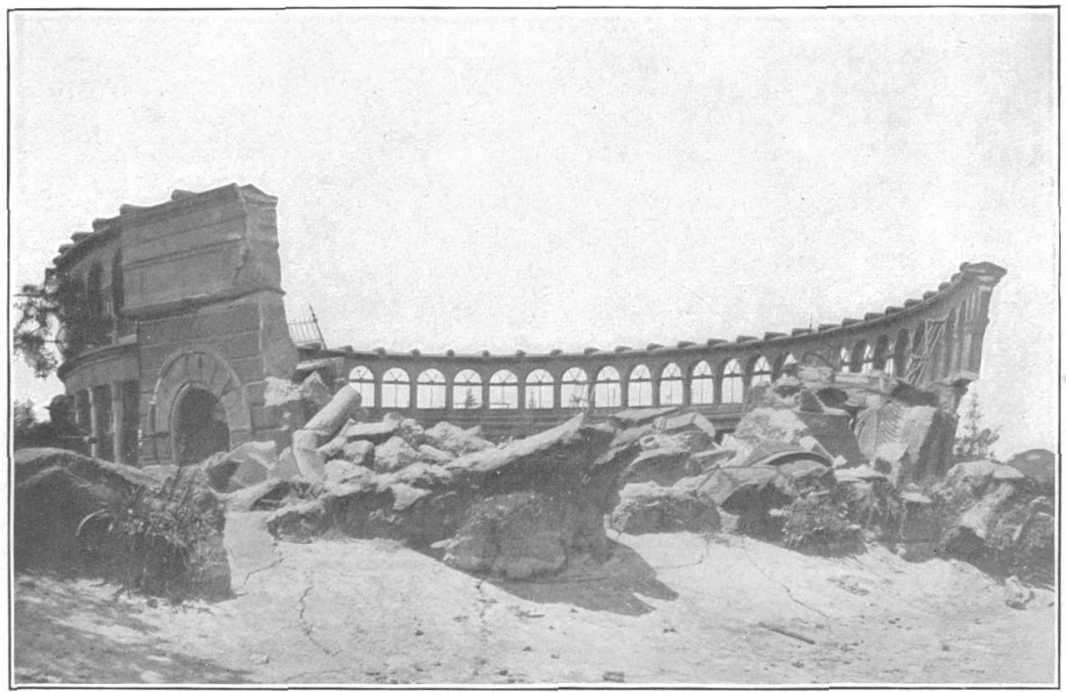

A. EARTHQUAKE EFFECT ON STRUCTURE OF REENFORCED CONCRETE OF POOR QUALITY. Cyclorama, Strawberry Hill, Golden Gate Park, San Francisco. Photograph by Richard L. Humphrey.

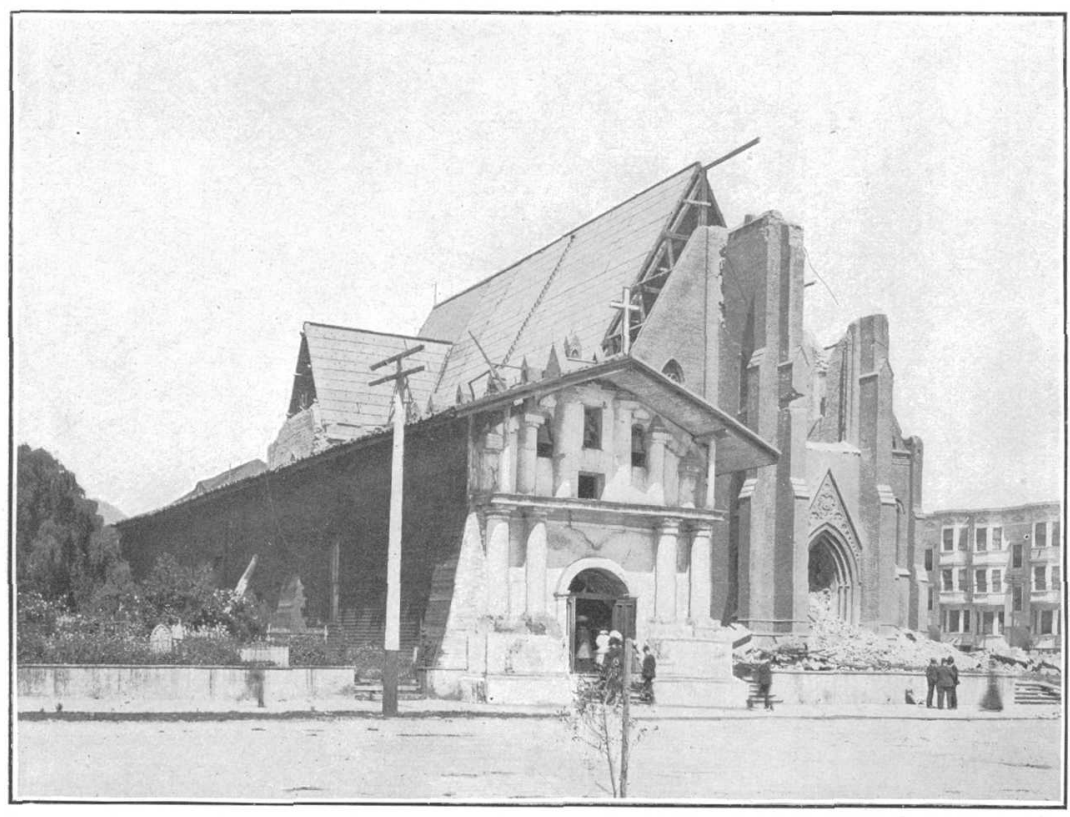

B. EFFECT OF EARTHQUAKE ON ADJACENT BUILDINGS OF DISSIMILAR TYPE AND CONSTRUCTION.

Old Mission Dolores, San Francisco, undamaged. Tower of new church adjoining was so badly damaged that it had to be taken down. Photograph by Richard L. Humphrey. 


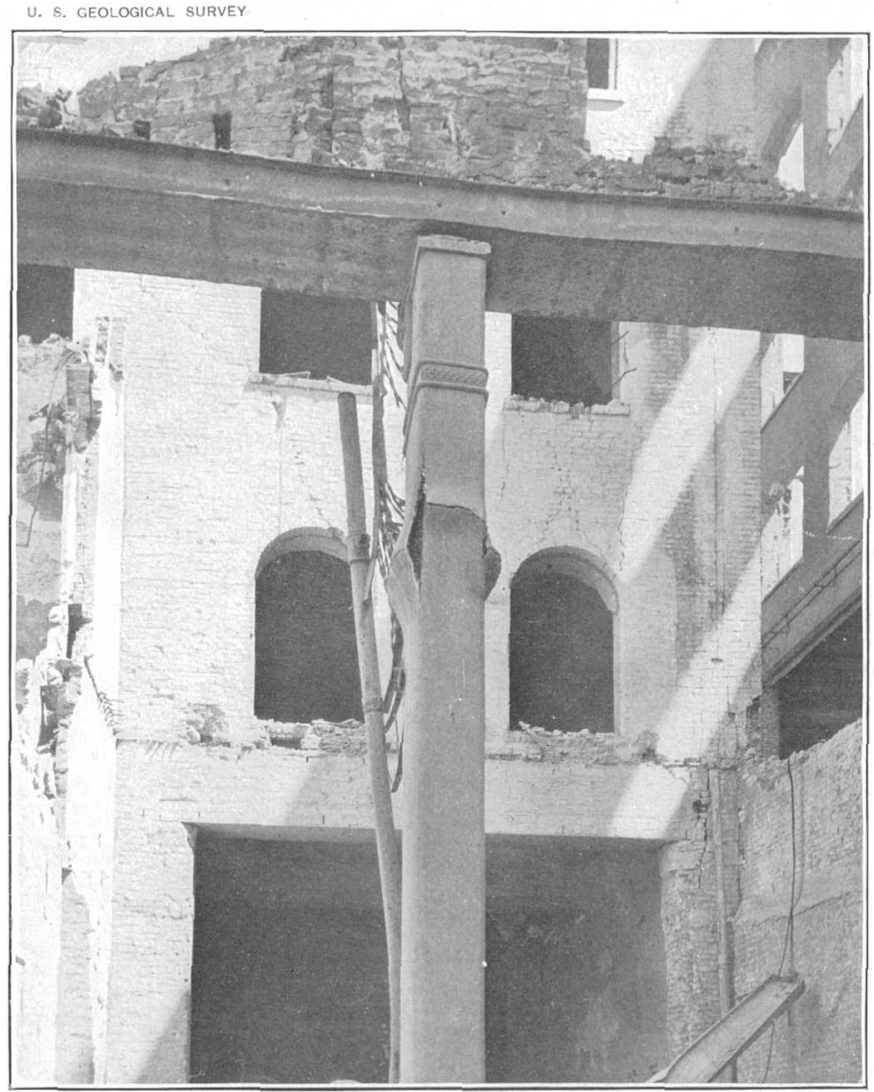

A. FAILURE OF CAST-IRON SHELL OF CONCRETE-FILLED CAST-IRON COLUMN BY FIRE, ACADEMY OF SCIENCES BUILDING, SAN FRANCISCO.

The concrete core supports the load. Note also the effect of the earthquake on the brick wall in the rear. Photograph by Richard L. Humphrey.

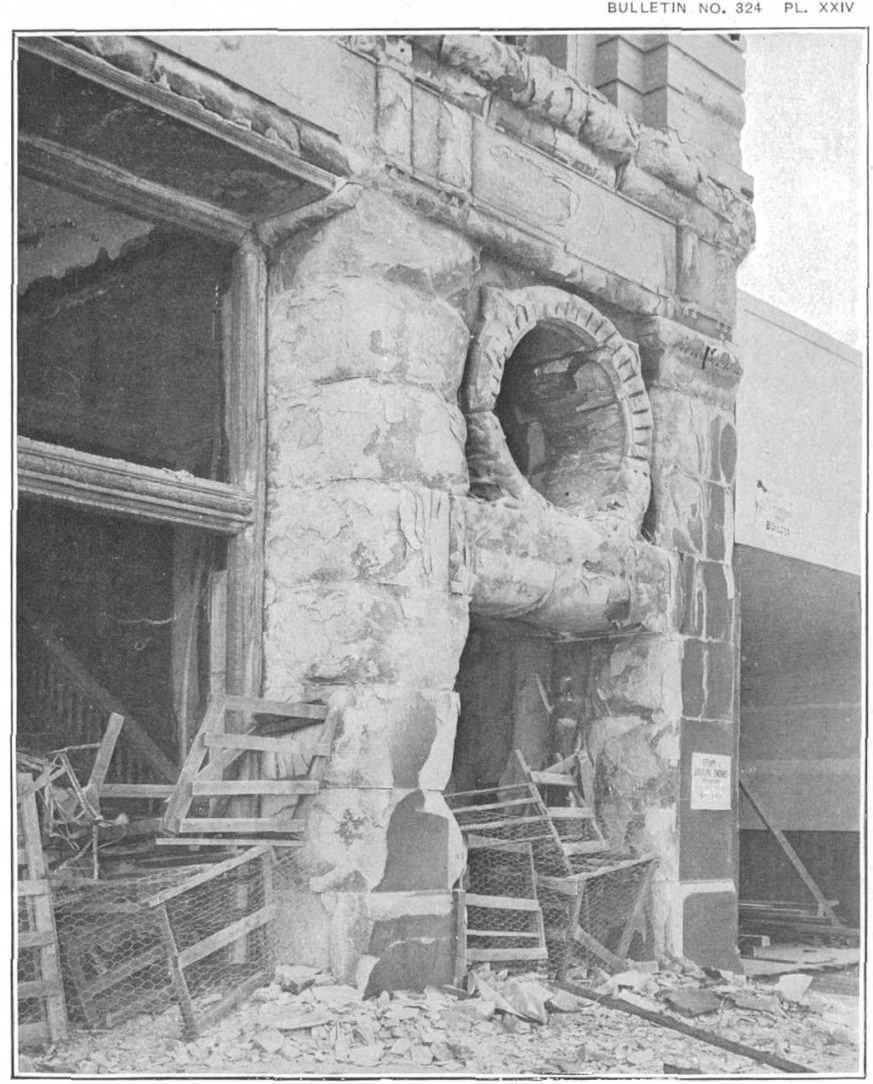

B. SPALLED GRANITE, MARKET STREET ENTRANCE OF EETNA BUILDING, SAN FRANCISCO.

Photograph by Richard L. Humphrey. 


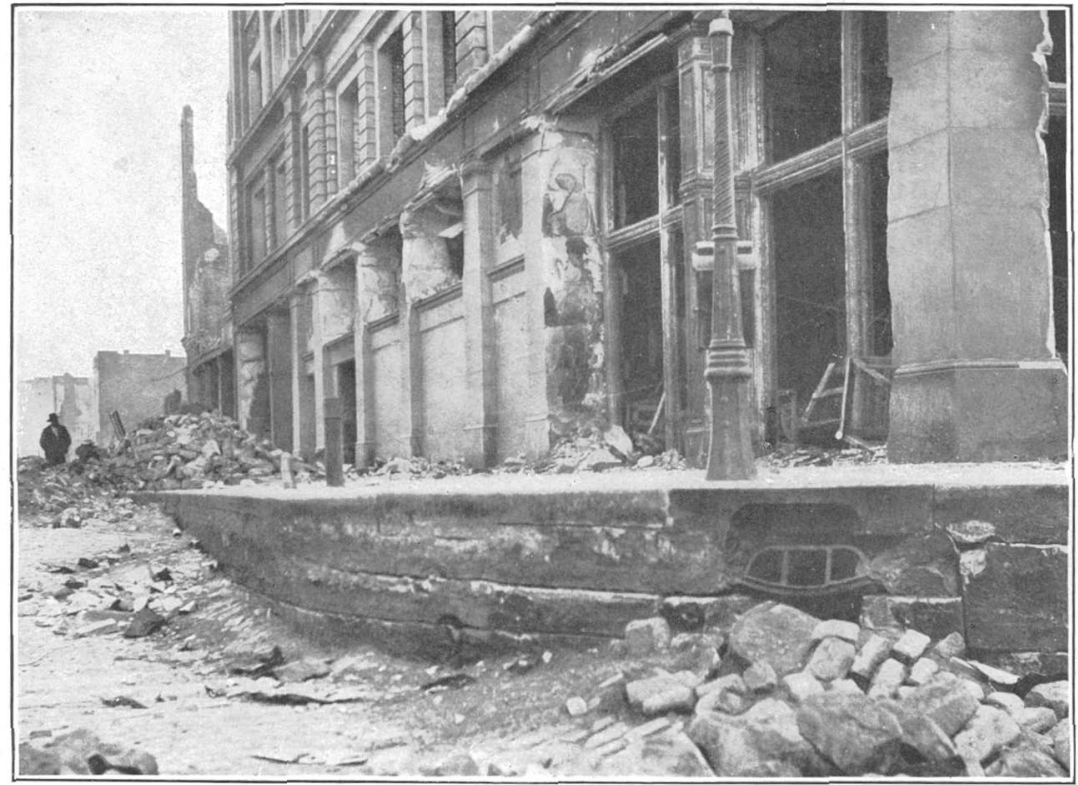

A. SUBSIDENCE OF STREET IN FRONT OF FETNA BUILDING. SAN FRANCISCO.

Photograph by John Stephen Sewell.

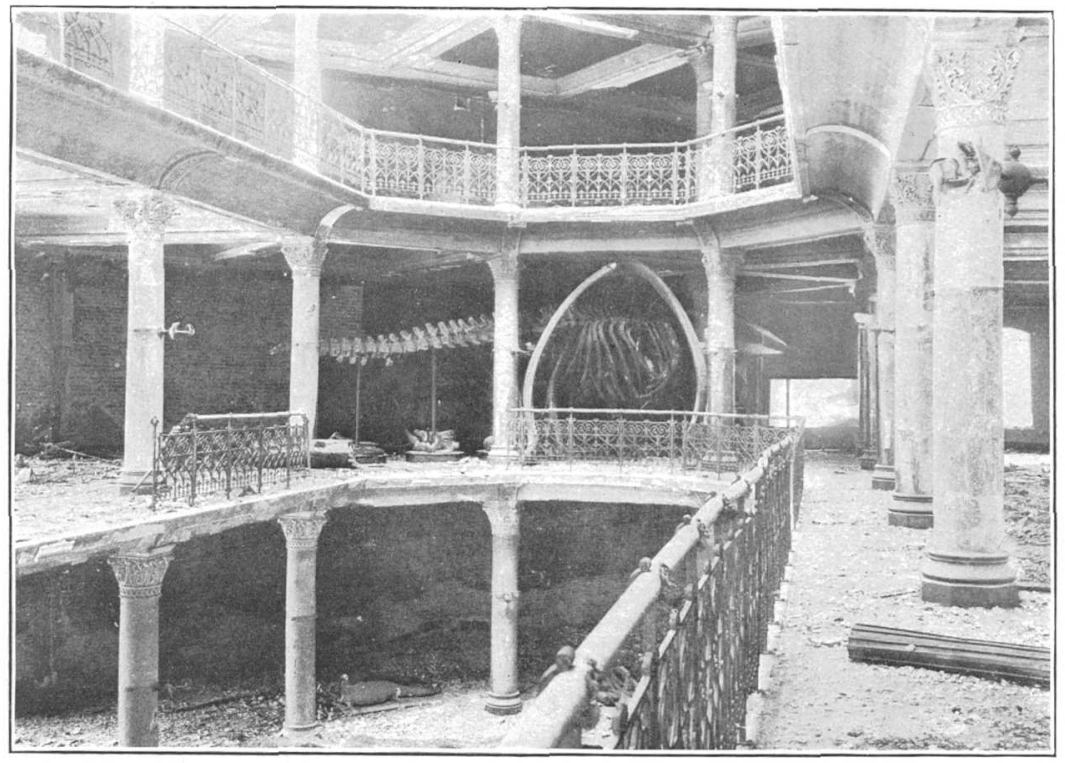

B. FIRE ENDURANCE OF CONCRETE, ANNEX OF ACADEMY OF SCIENCES BUILDING, SAN FRANCISCO.

Reenforced-concrete floors and concrete-filled cast-iron columns with plaster covering. Photograph by Richard L. Humphrey. 


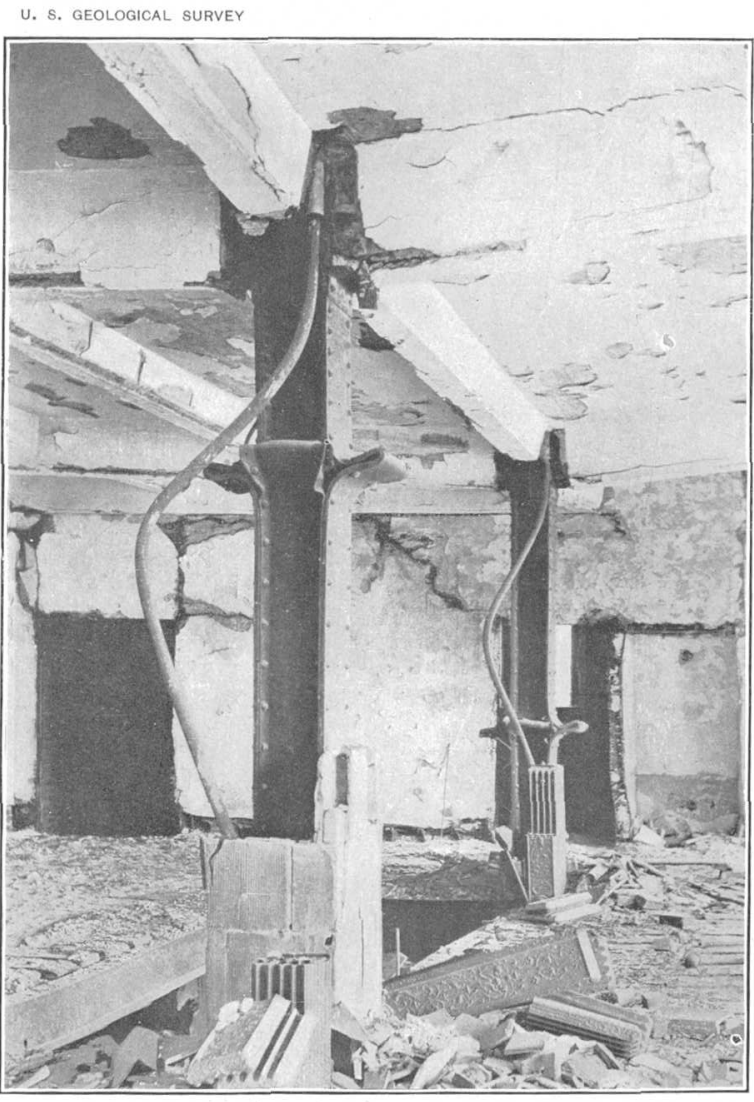

A. BUCKLED COLUMNS AND COLLAPSED FLOOR PANEL, BULLOCK \& JONES BUILDING, SAN FRANCISCO.

Photograph by John Stephen Sewell.

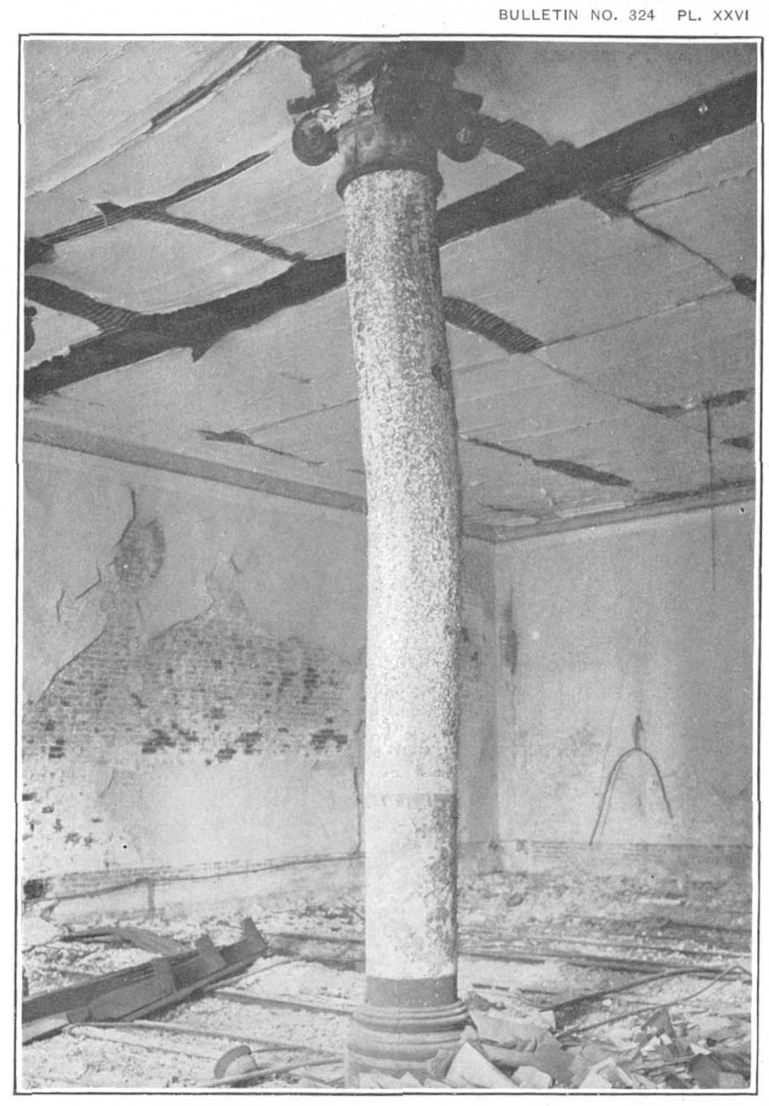

B. INCIPIENT FAILURE OF NAKED CAST-IRON COLUMN IN CITY HALL, SAN FRANCISCO.

Ceiling on the point of falling. Photograph by John Stephen Sewell. 


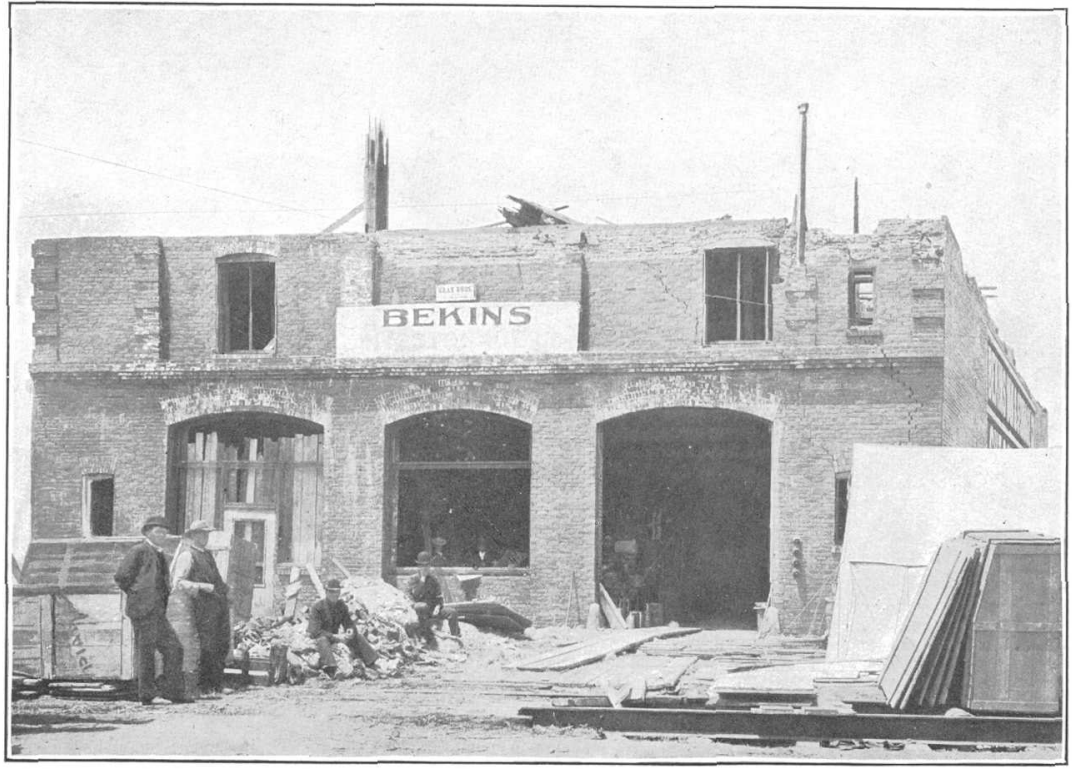

A. EARTHQUAKE ENDURANCE OF REENFORCED-CONCRETE BUILDING, BEKINS VAN AND STORAGE COMPANY'S WAREHOUSE, SAN FRANCISCO, UNDER CONSTRUCTION.

The only building of pure reenforced-concrete type in the city. The brick walls composing the shell of the building were cracked, but the reenforced-concrete floors and columns were uninjured. Photograph by Richard L. Humphrey.

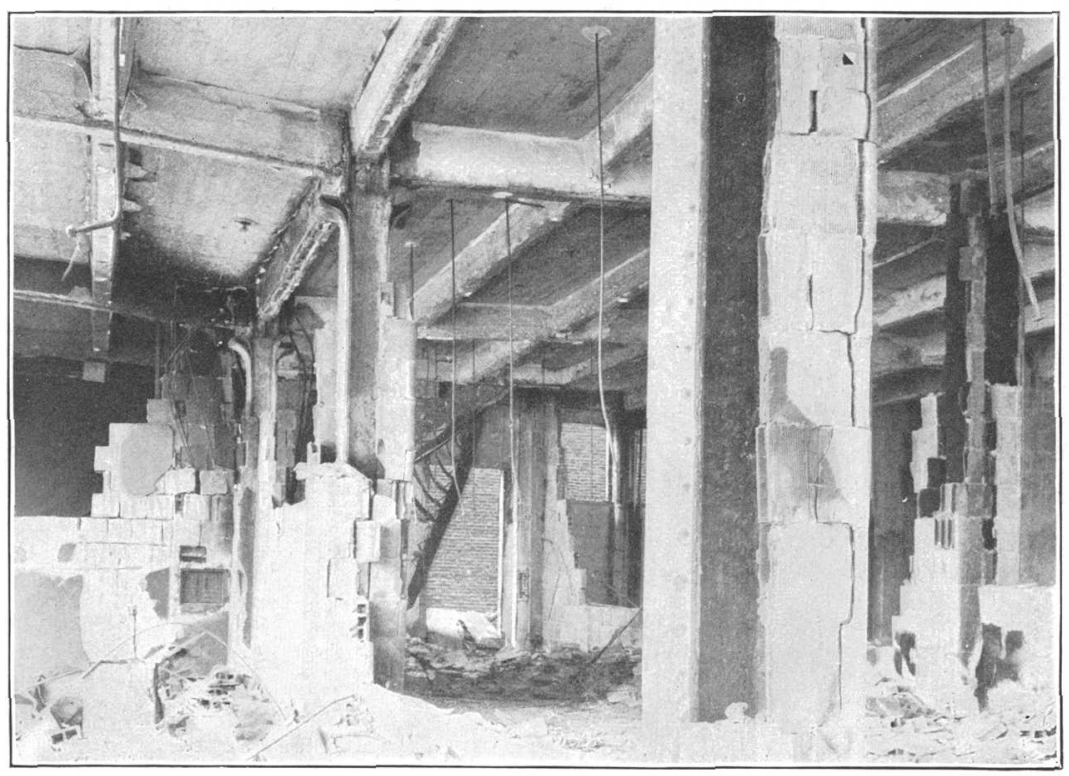

B. FAILURE OF TERRA-COTTA COLUMN COVERINGS, RESULTING IN BUCKLED COLUMNS ENDURANCE OF CINDER-CONCRETE FLOORS; CENTER OF GROUND FLOC?, ARONSON BUILDING, SAN FRANCISCO. 


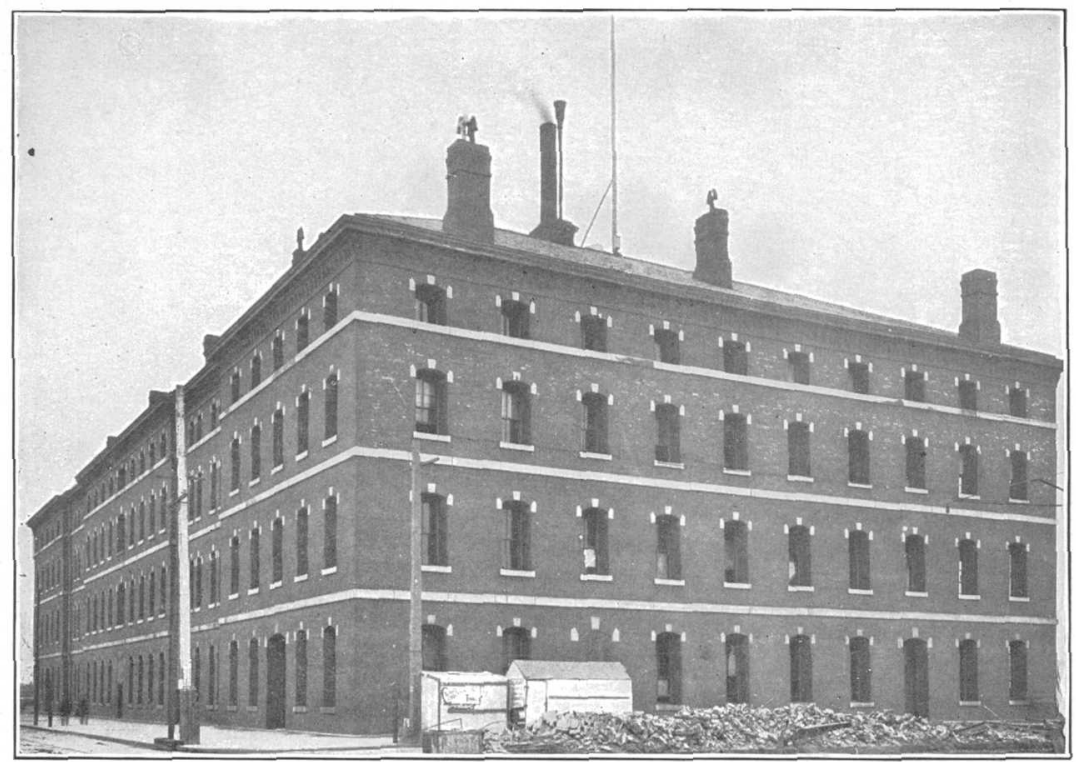

A. EARTHQUAKE ENDURANCE OF A WELL-CONSTRUCTED BRICK BUILDING: APPRAISERS' WAREHOUSE, SAN FRANCISCO.

The walls were built with full-header courses and show only a few slight cracks, although the building was located on alluvial soil. Photograph by Richard L. Humphrey.

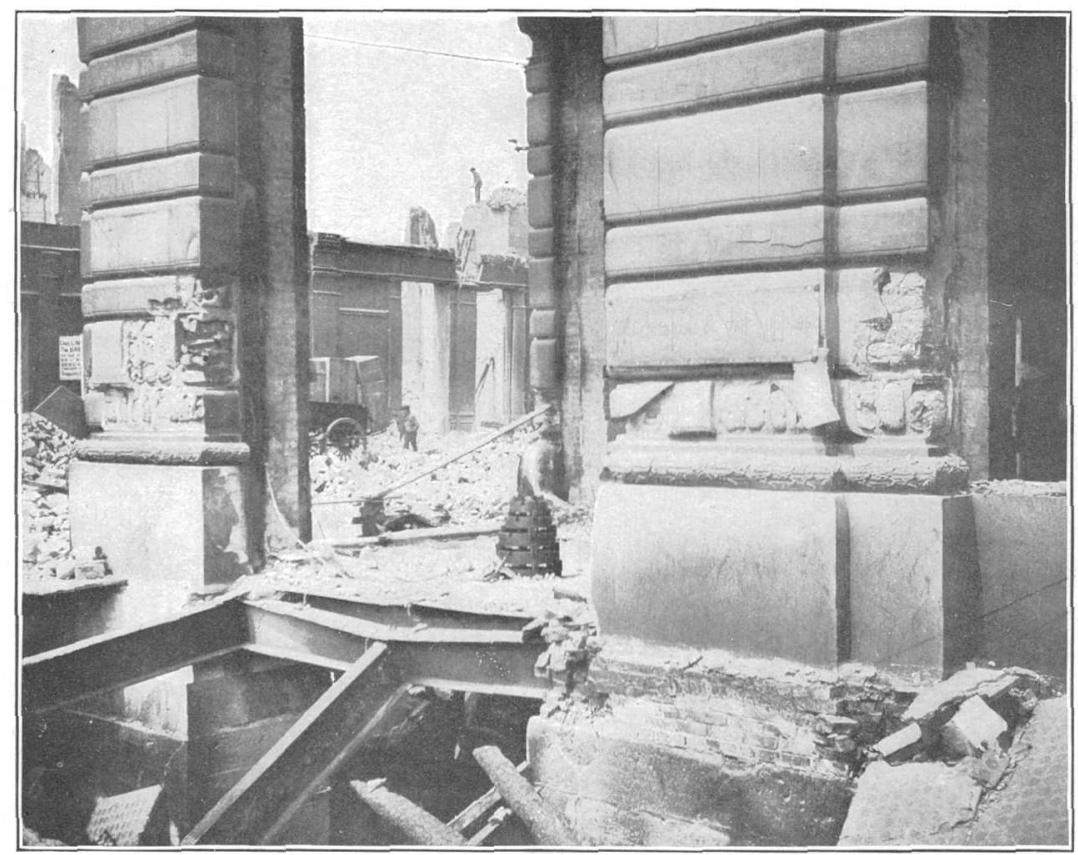

B. FAILURE OF ORNAMENTAL TERRA COTTA, CROCKER ESTATE BUILDING, SAN FRANCISCO.

This terra cotta failed, though solidly filled with brick mortar. The damage shown was probably due to fire, although darnage of this kind was caused by both earthquake and fire. Photograph by John Stephen Sewell. 


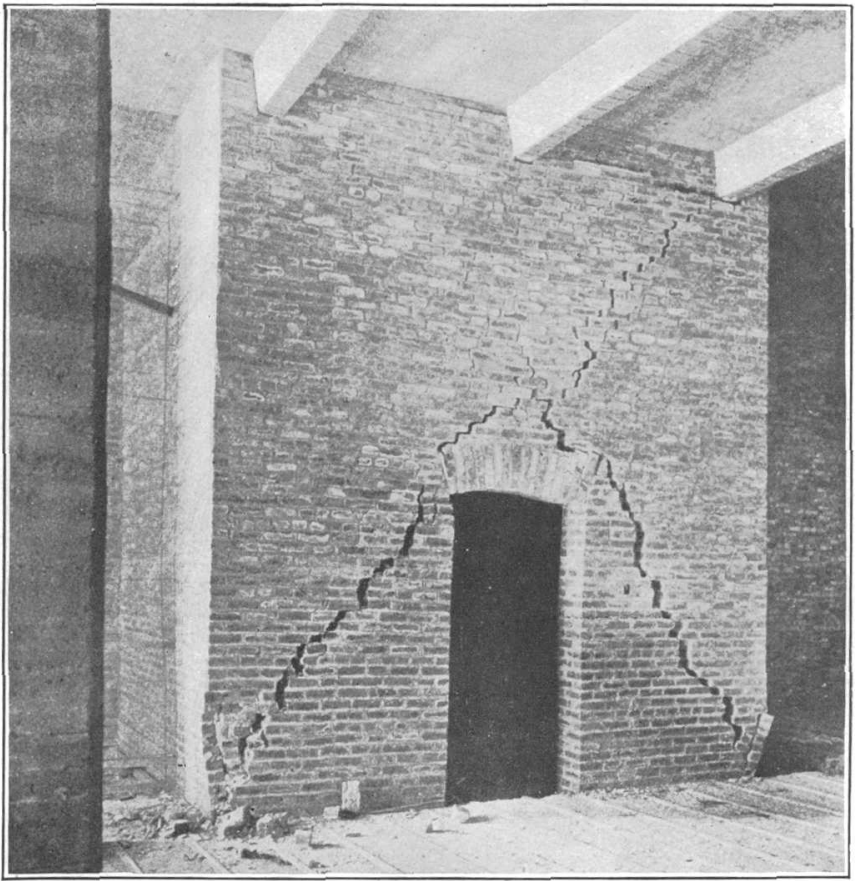

A. EARTHQUAKE CRACKS IN WALL OF VAULT, CALIFORNIA CASKET COMPANY'S BUILDING, SAN FRANCISCO.

Photograph by Richard L. Humphrey.

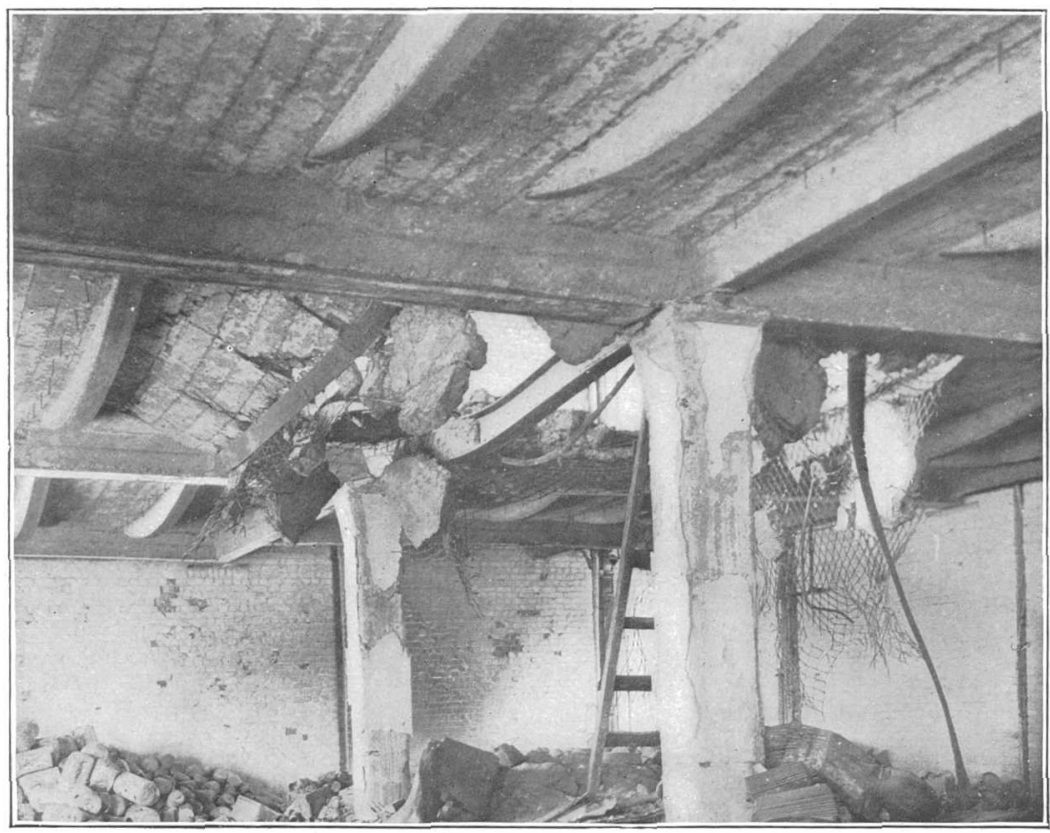

B. COLLAPSE OF FLOOR PANEL, CAUSED BY LOAD FALLING FROM A FLOOR ABOVE, THIRD FLOOR OF AETNA BUILDING, SAN FRANCISCO.

The failure of the upper floor was due to the softening by heat of reenforcing steel bands. Photographs by Richard L. Humphrey. 


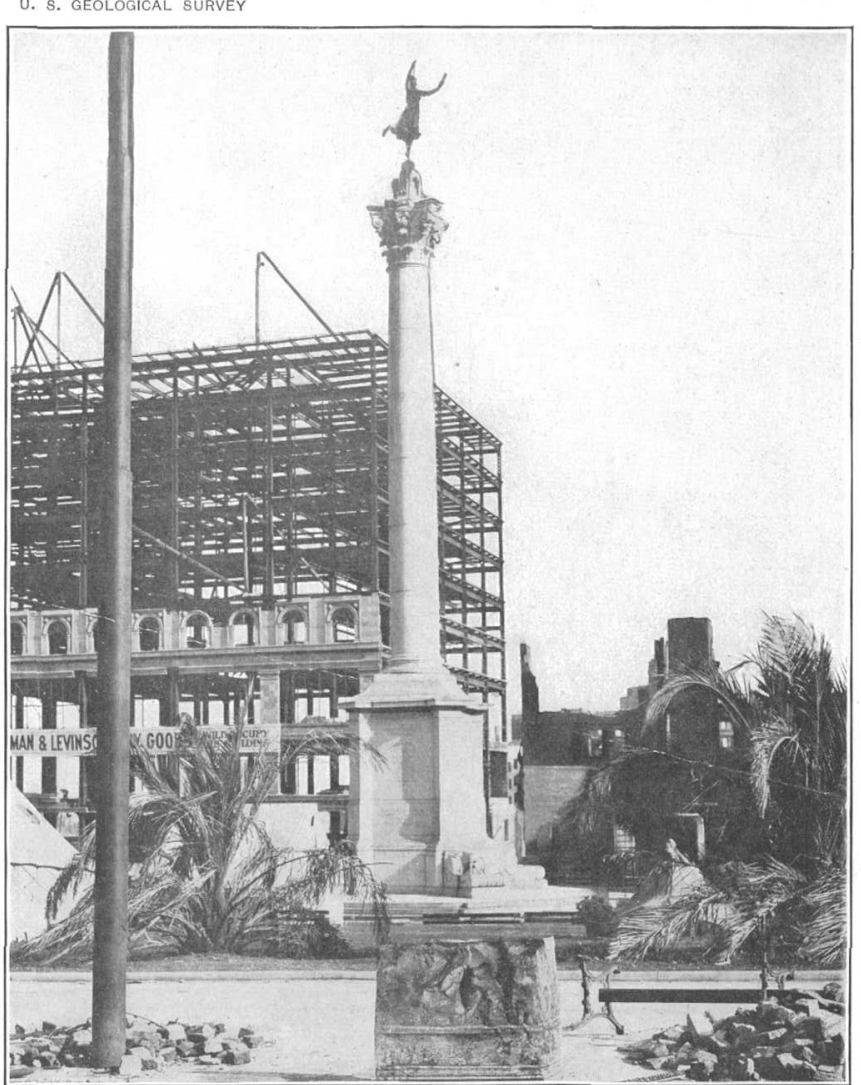

A. EARTHQUAKE DAMAGE MINIMIZED BY SPECIAL CONSTRUCTION, DEWEY MONUMENT, SAN FRANCISCO.

The drums on the shaft were displaced slightly, but were kept from falling by a stee core. Photograph by John Stephen Sewell.

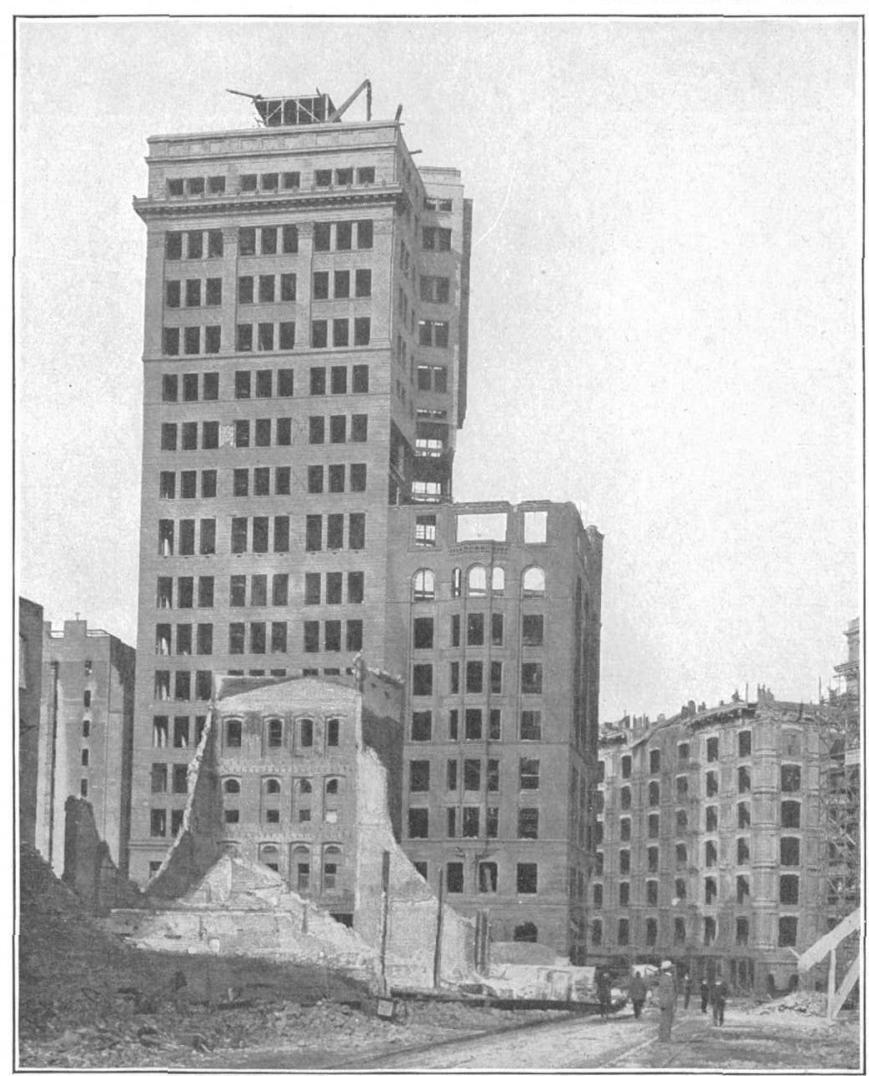

B. $X$ CRACKS IN WALLS, DUE TO ROCKING OF BUILDING BY EARTHQUAKE, CHRONICLE BUILDING AND ANNEX, SAN FRANCISCO, LOOKING EAST.

The Palace Hotel (at the right) was completely gutted by fire, but the walls remained in good condition. Photograph by Richard L. Humphrey. 


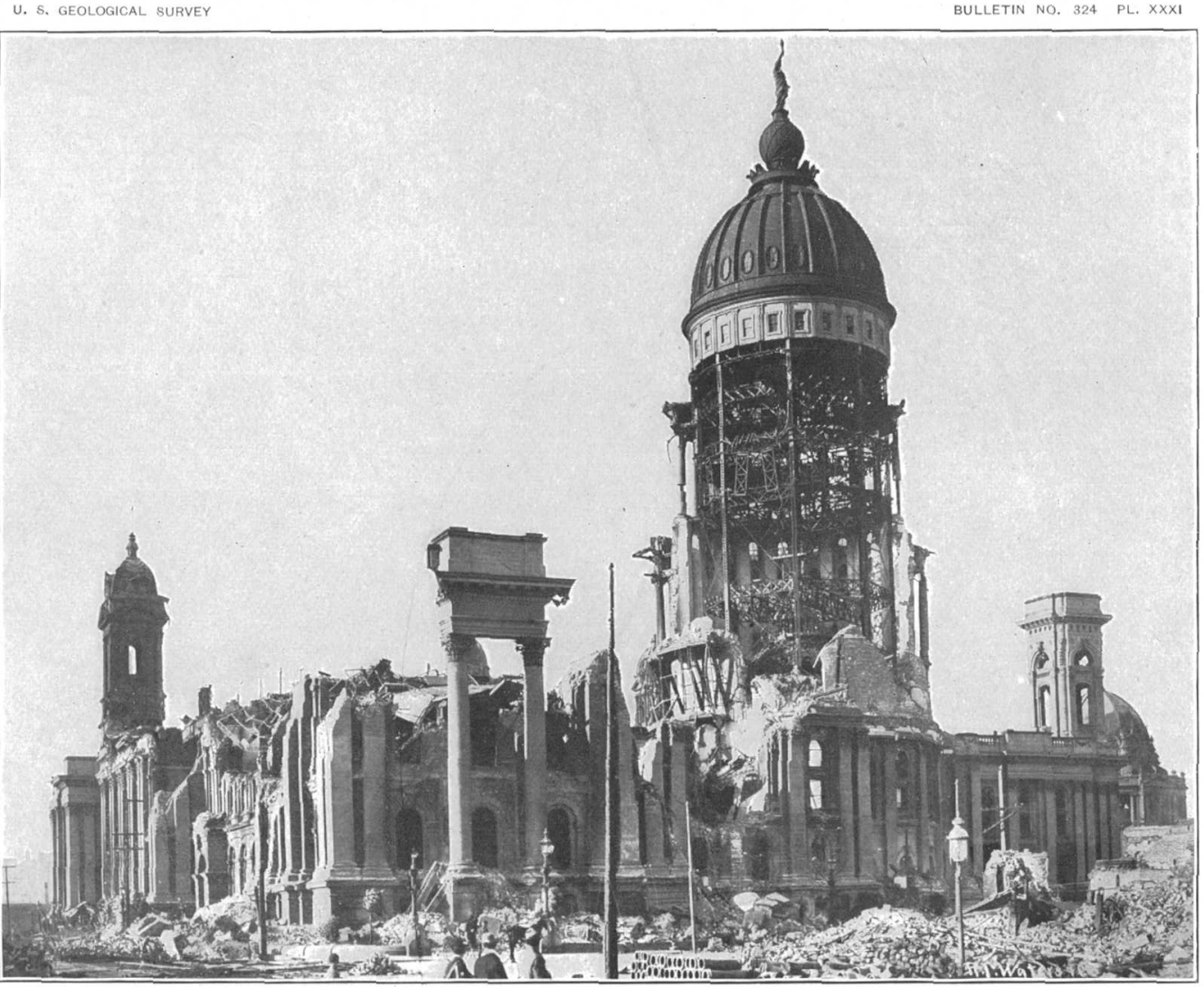

RUIN OF THE $\$ 7,000,000$ CITY HALL, SAN FRANCISCO, BY EARTHQUAKE AND FIRE. 


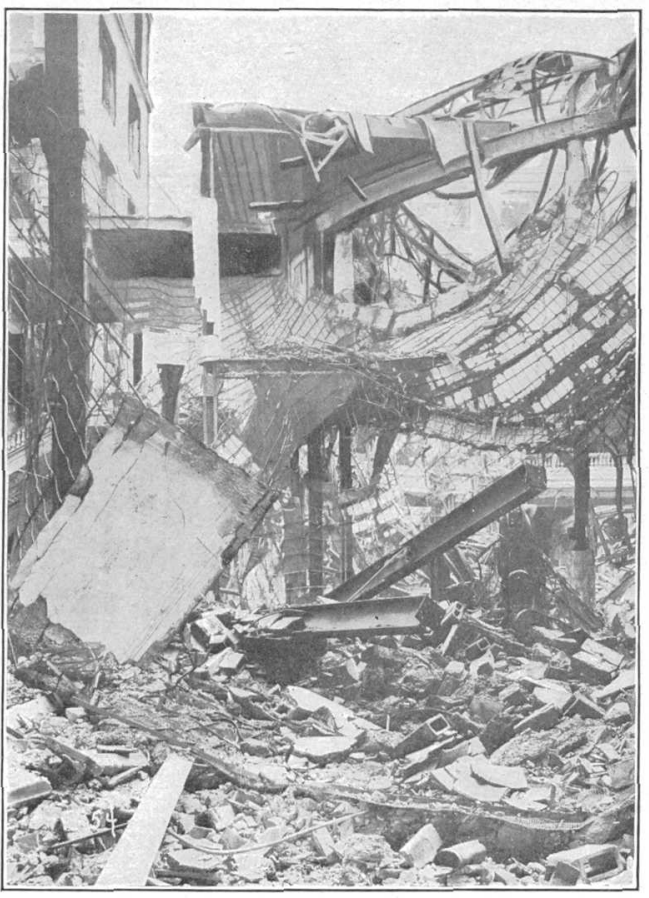

A

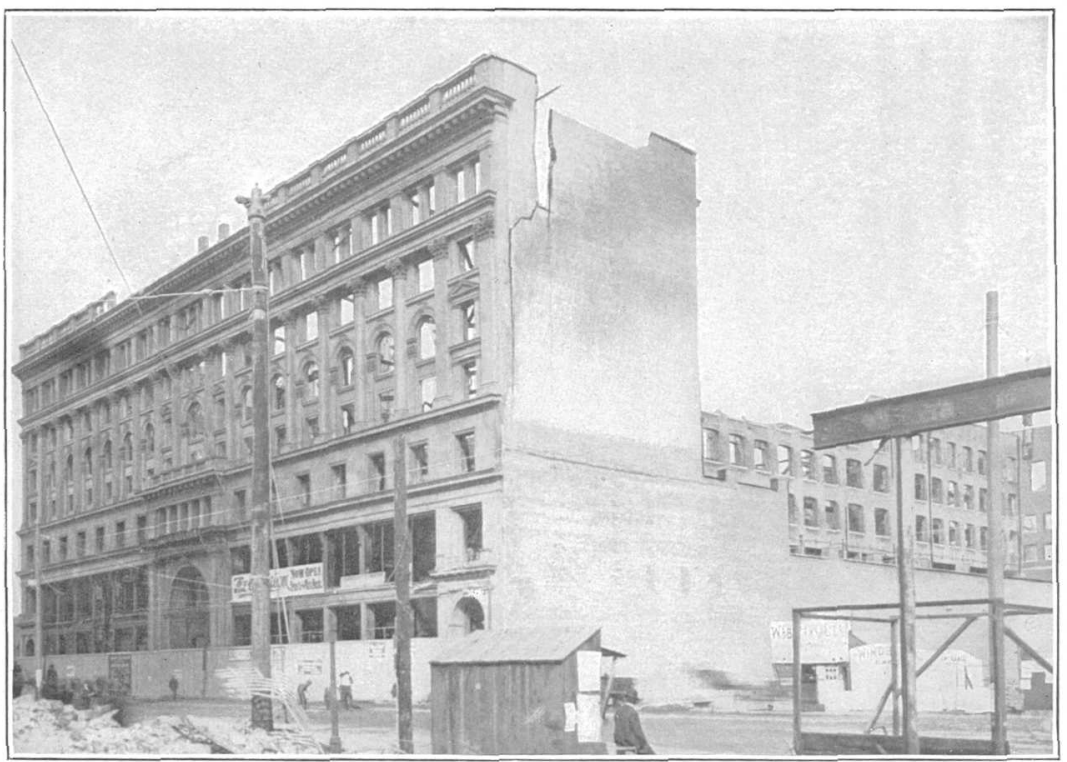

COMPLETE FAILURE OF SLOW-BURNING WOOD CONSTRUCTION, THE EMPORIUM, SAN FRANCISCO.

A large department store. A, Interior (photograph by John Stephen Sewell); B, Exterior (photograph by Richard L. Humphrey). 


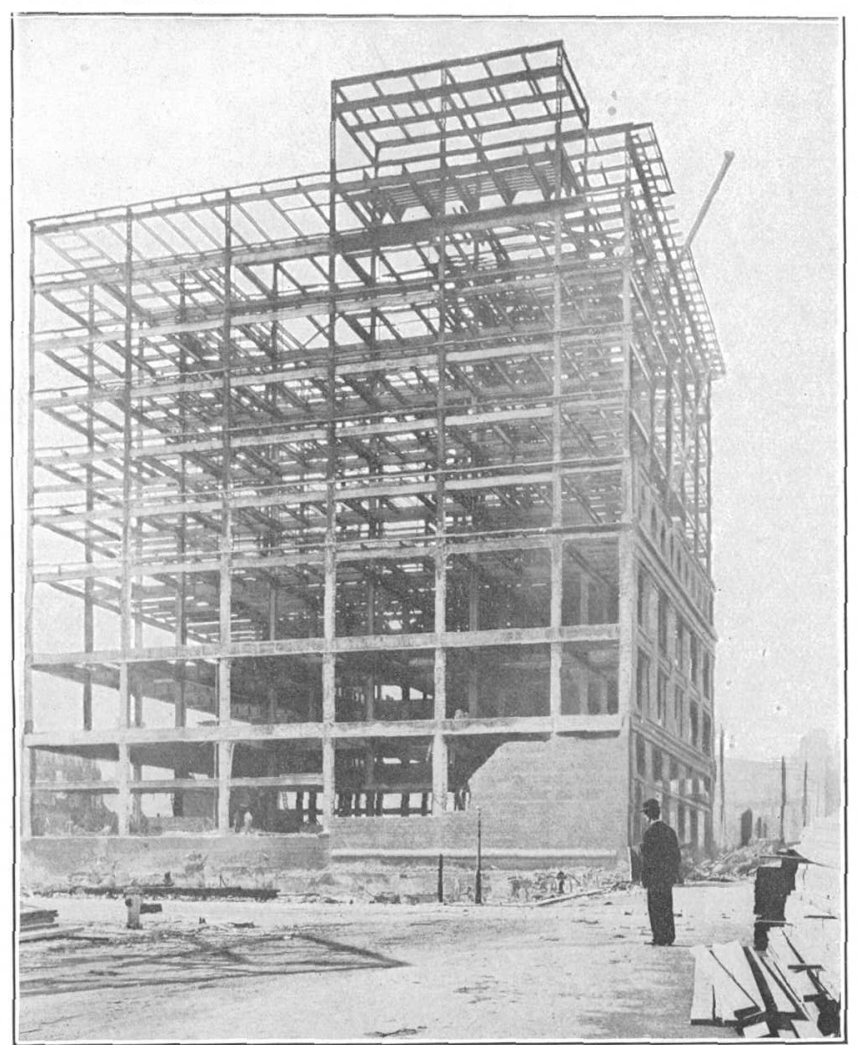

4. BEHAVIOR OF STEEL FRAME BUTLER BUILDING (INCOMPLETE), AT THE SOUTHWEST CORNER OF GEARY AND STOCKTON STREETS, SAN FRANCISCO.

Walls taken down in places because of earthquake damage, although damage to stee by earthquake and fire was nominal. Photograph by John Stephen Seweil,

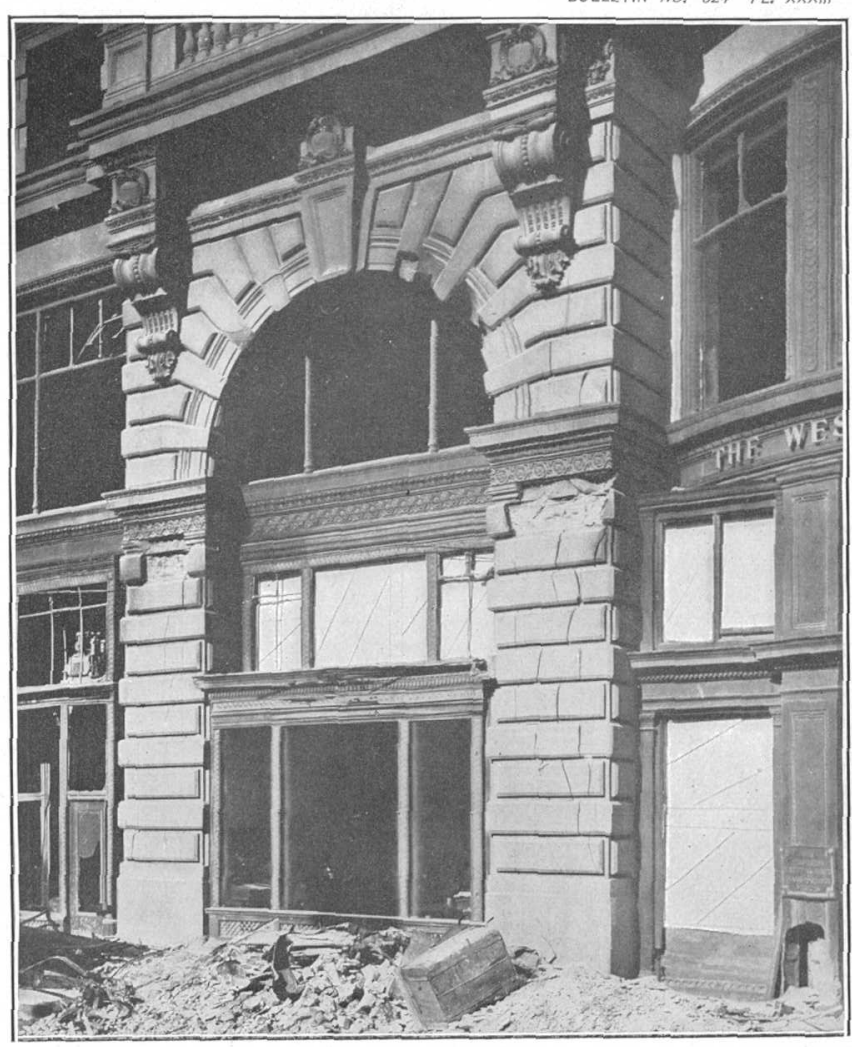

B. EARTHQUAKE DAMAGE TO STONE PIERS, JAMES FLOOD BUILDING, SAN FRANCISCO.

Photograph by John Stephen Sewell. 

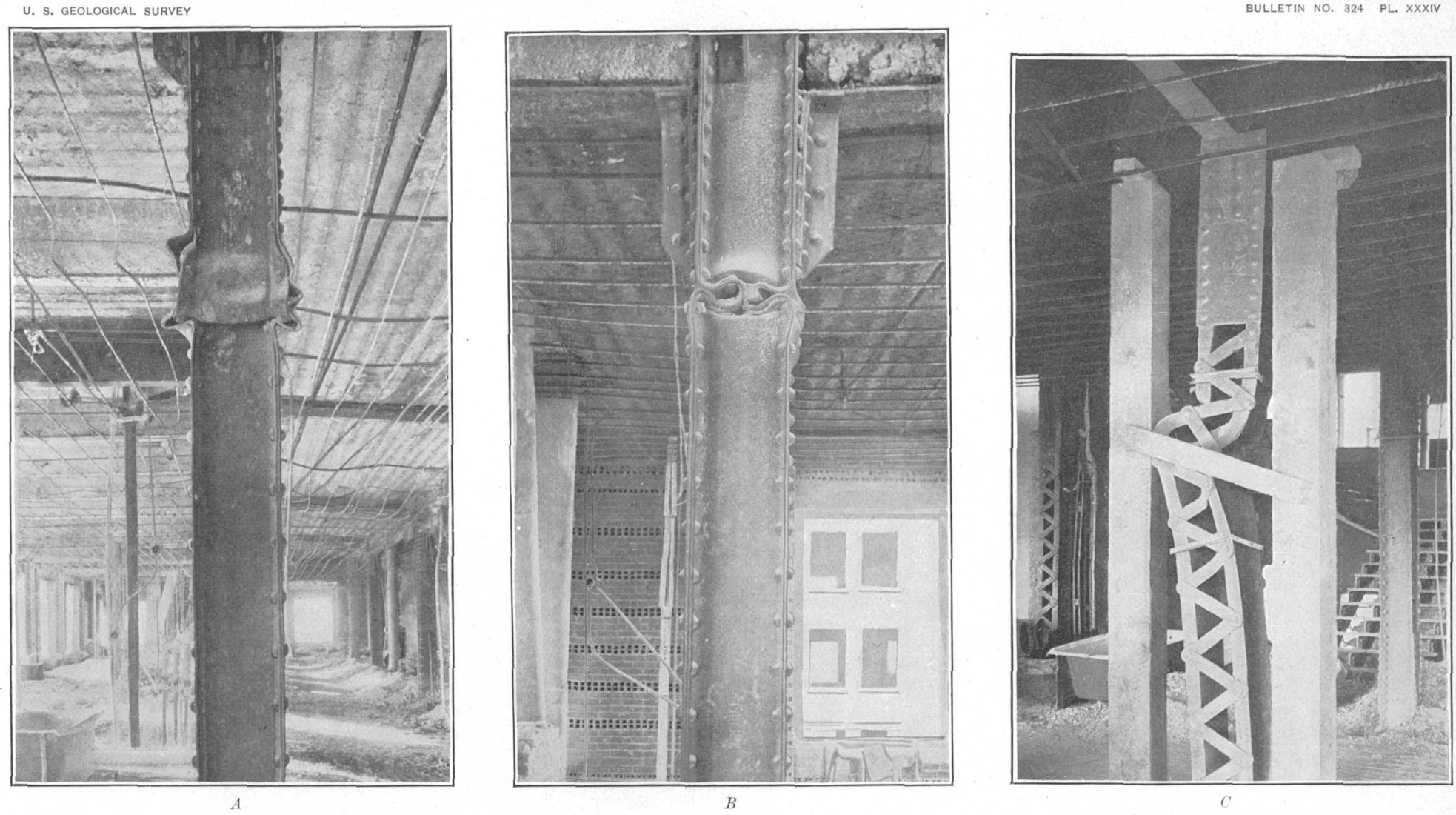

BUCKLING OF COLUMNS DUE TO FAILURE OF PLASTERED METAL-LATH FIREPROOFING, FAIRMOUNT HOTEL, SAN FRANCISCO.

The method of fireproofing was to inclose the column between the metal lath forming the partitions. Photographs by Richard L. Humphrey. 


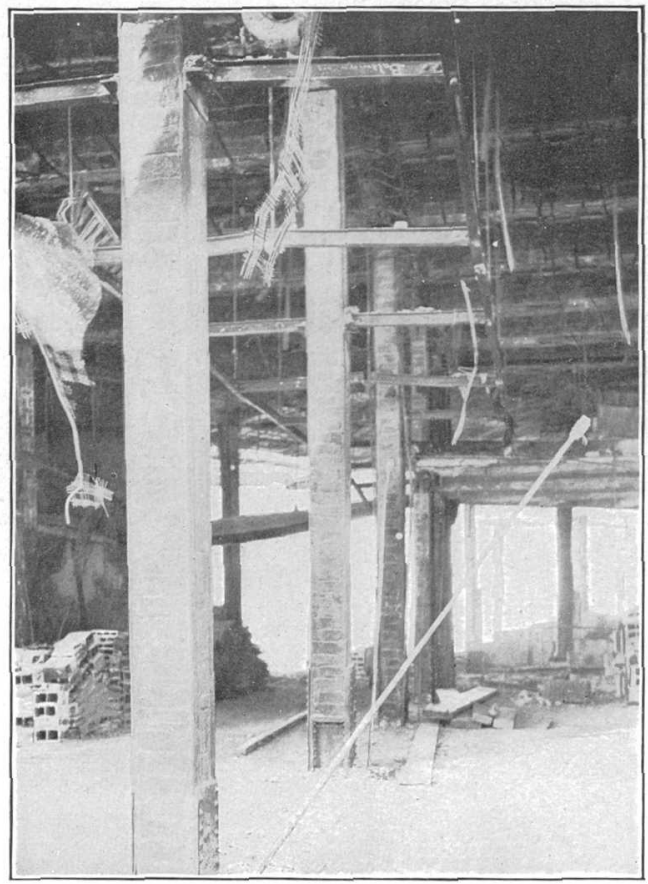

A. INCIPIENT BUCKLING OF COLUMNS FROM HEAT, FIRST STORY, JAMES FLOOD BUILDING, SAN FRANCISCO.

The brick filling probably saved the columns from fatal buckling or collapse. Photograph by John Stephen Sewell.

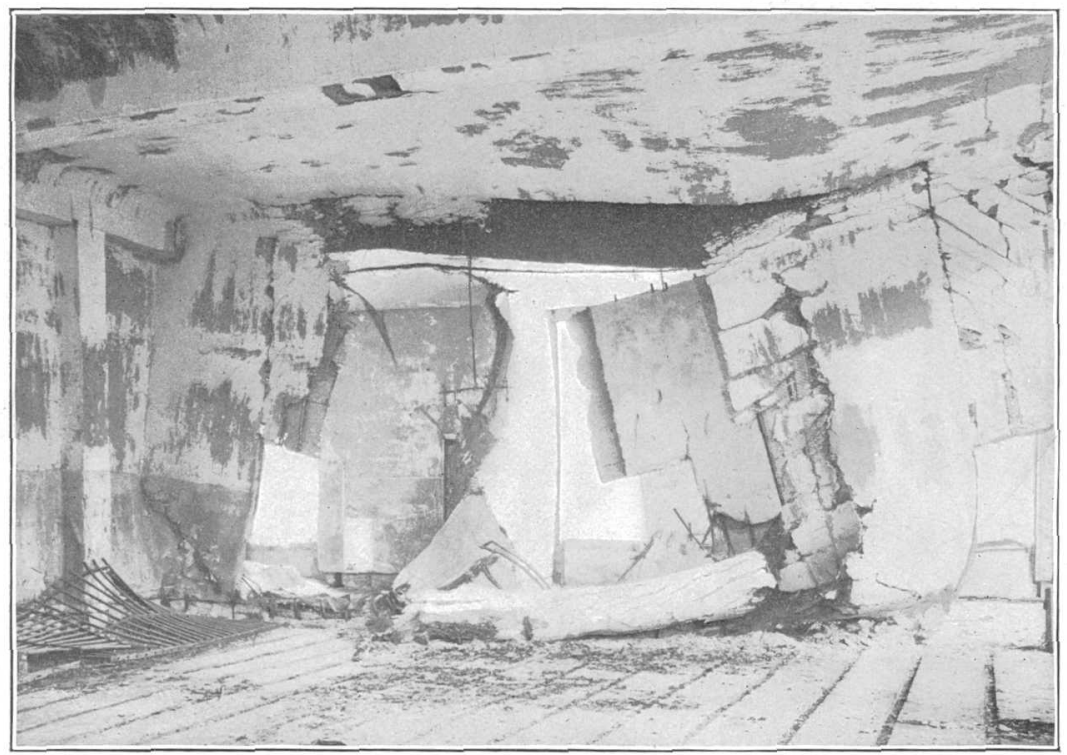

B. FAILURE OF SUSPENDED CEILING, HALL OF JUSTICE, SAN FRANCISCO.

Photograph by Richard L. Humphrey. 


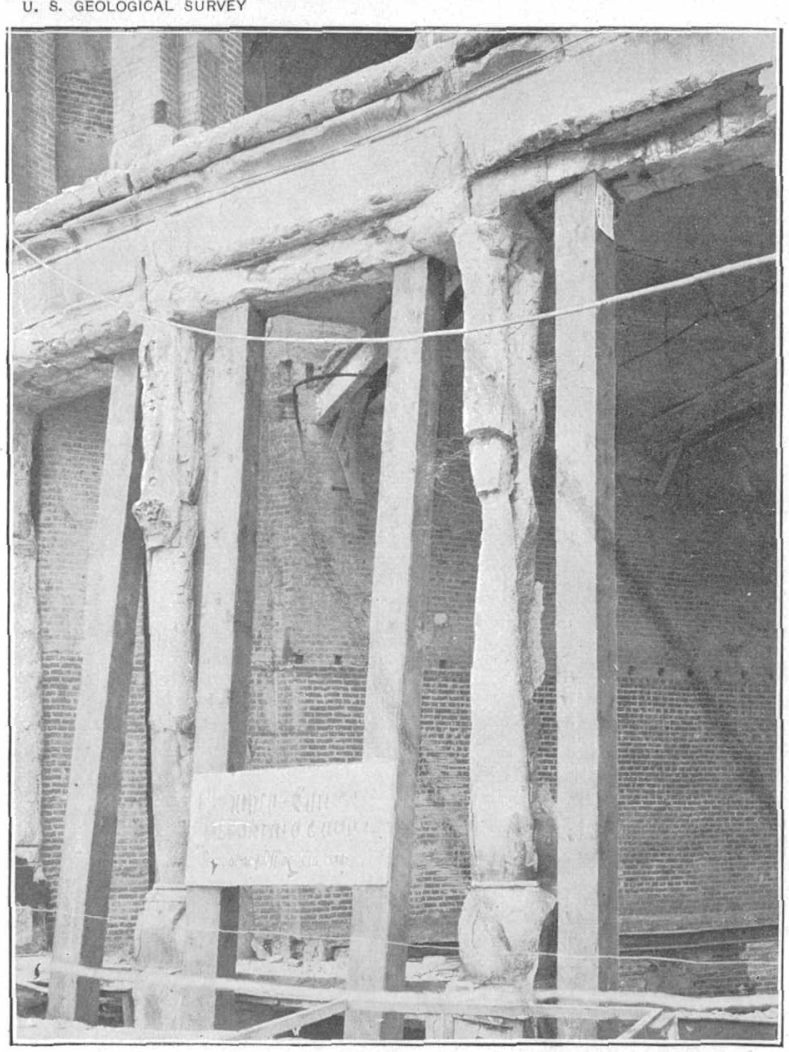

A. GRANITE COLUMNS SPALLED BY FIRE, HOBART BUILDING, SAN FRANCISCO.

Photograph by Richard L. Humphrey.

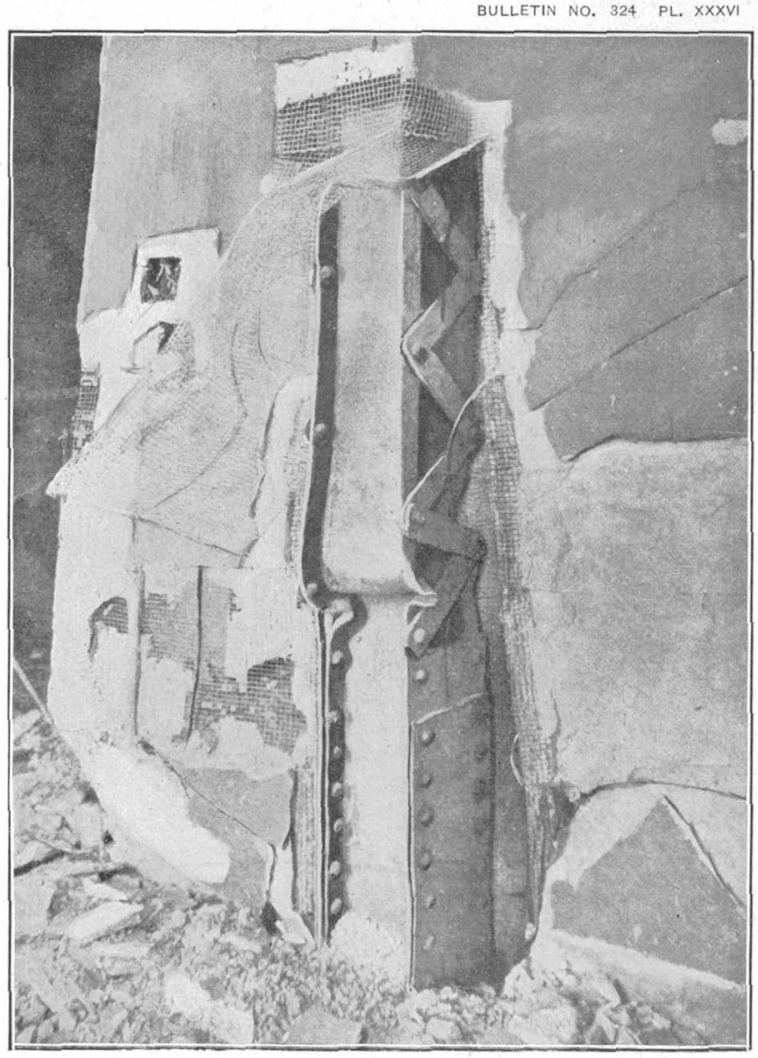

B. BUCKLING OF COLUMNS DUE TO FAILURE OF WIRE-MESH-AND. PLASTER FIREPROOFING, HOTEL HAMILTON, SAN FRANCISCO.

The fireproofing on either side shows the general condition in which it was left by the fire. It was stripped away from the column just before the left by the fire. It was stripped away from the column just before the
photograph was taken in order to show the buckling. Photograph by A. L. A. Himmelwright. 


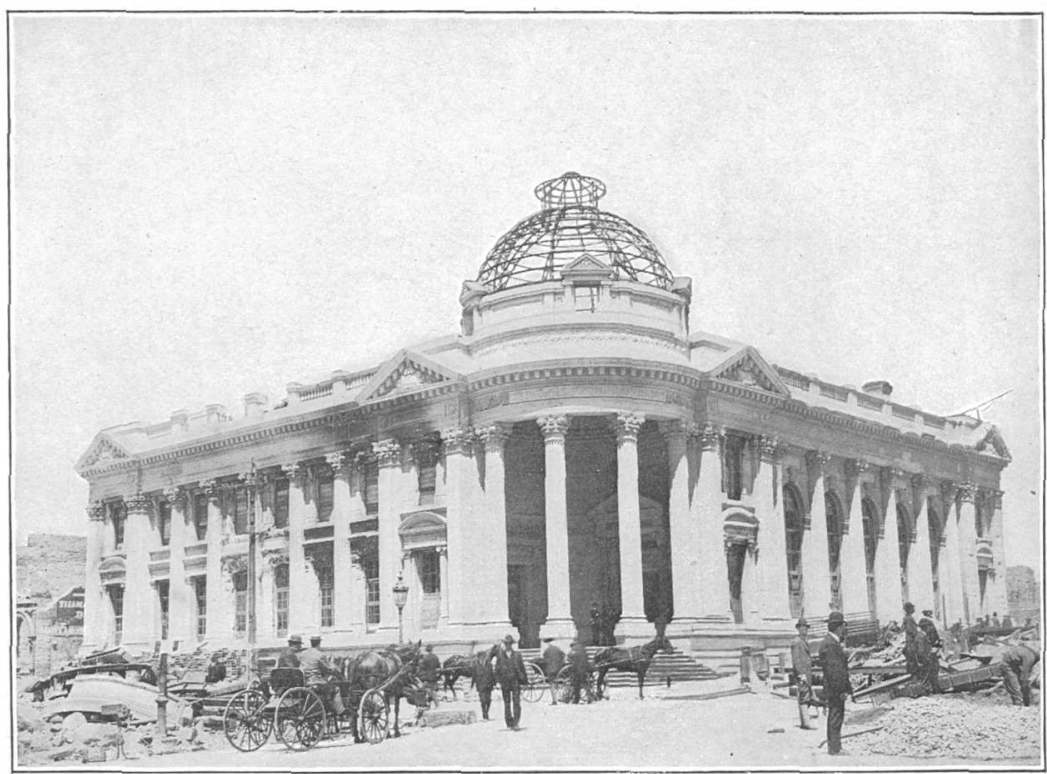

A. STONEWORK SPALLED BY FIRE, HIBERNIA SAVINGS AND LOAN SOCIETY'S BUILDING, SAN FRANCISCO.

Photograph by Richard L. Humphrey.

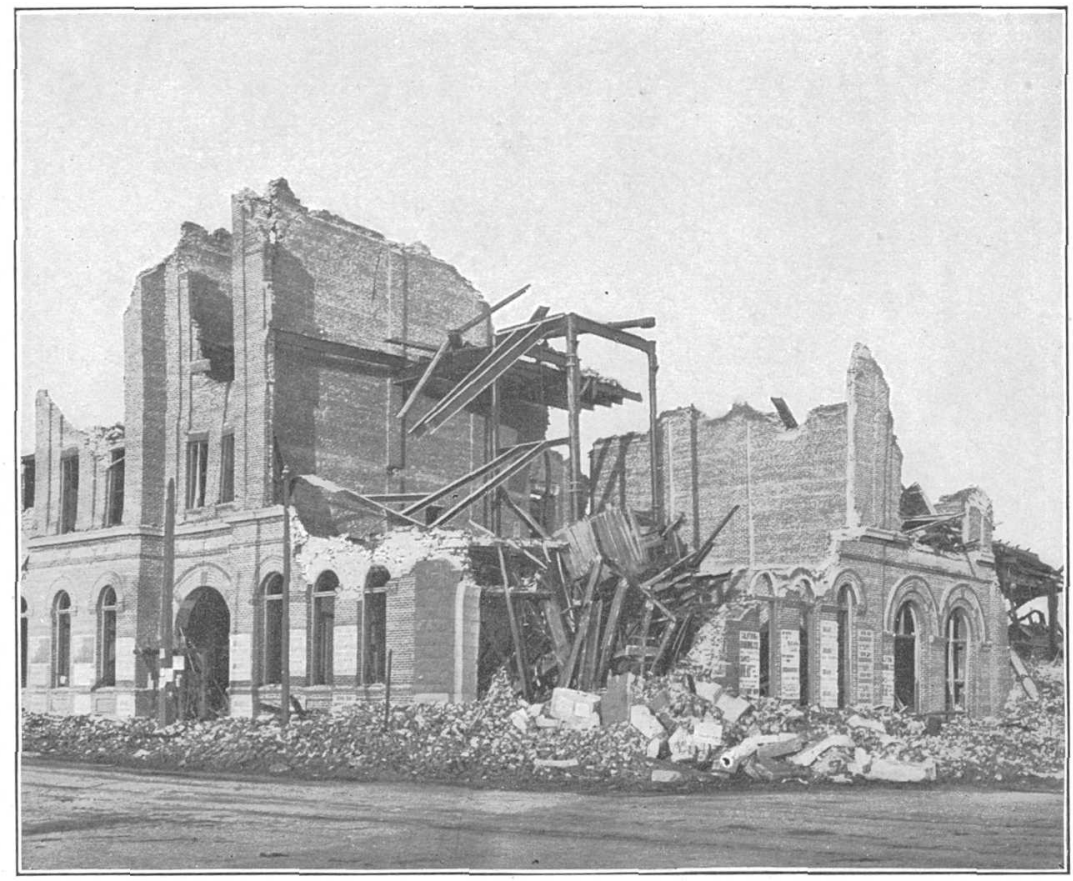

B. EARTHQUAKE DAMAGE, JACKSON BREWING COMPANY'S BUILDING, SAN FRANCISCO.

Light walls, badly bonded and laid up with poor lime mortar, and flimsily constructed steel work. Photograph by Richard L. Humphrey. 


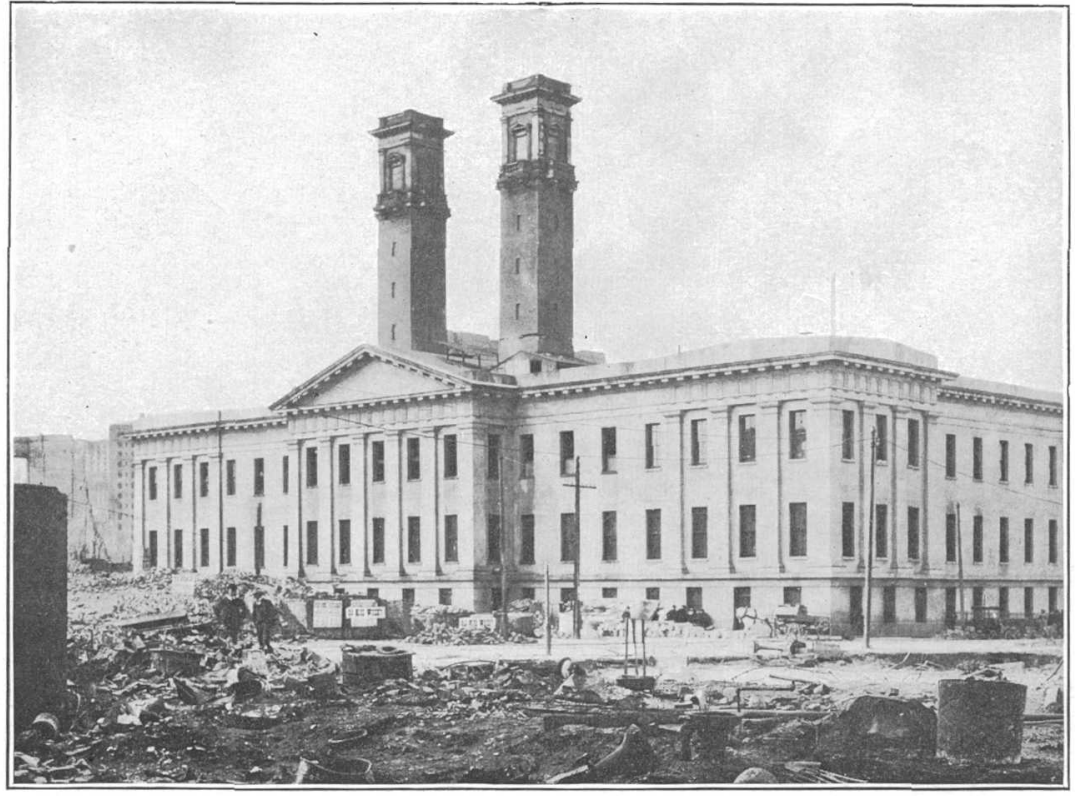

A. GOOD EARTHQUAKE ENDURANCE OF A BUILDING OF THE MONUMENTAL TYPE: UNITED STATES MINT, SAN FRANCISCO.

Showing only slight damage to brick stack, probably due to earthquake. Photograph by John Stephen Sewell.

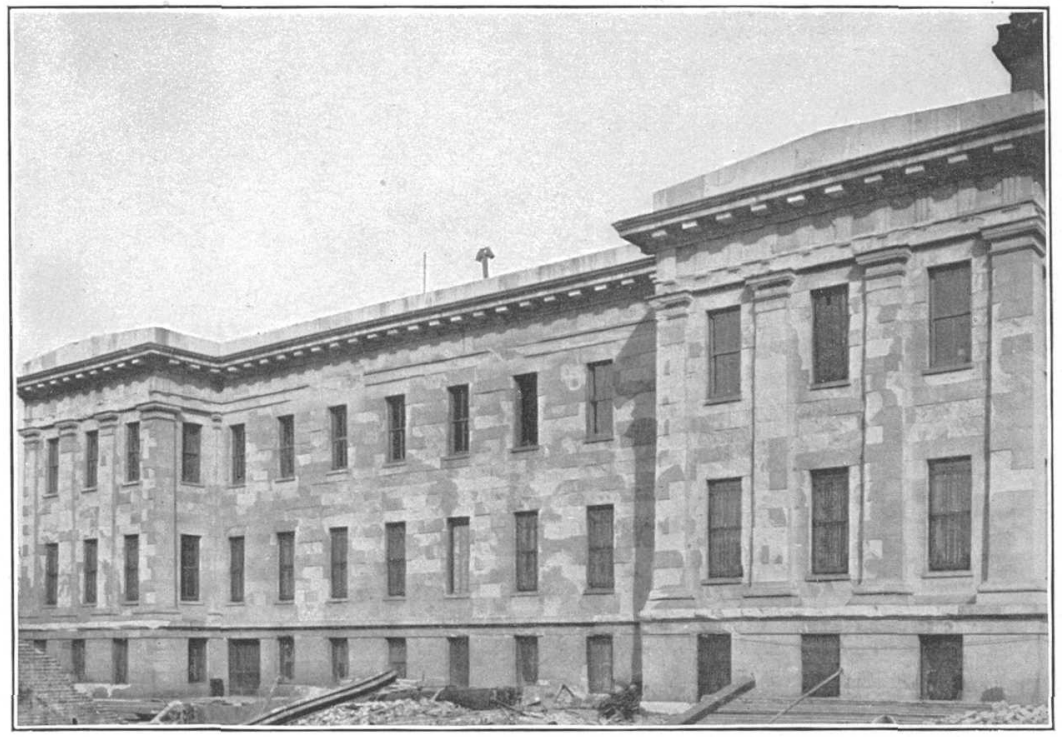

$B$. SPALLING OF STONEWORK BY FIRE, NORTHWEST FRONT OF UNITED STATES MINT. Photograph by Richard L. Humphrey 


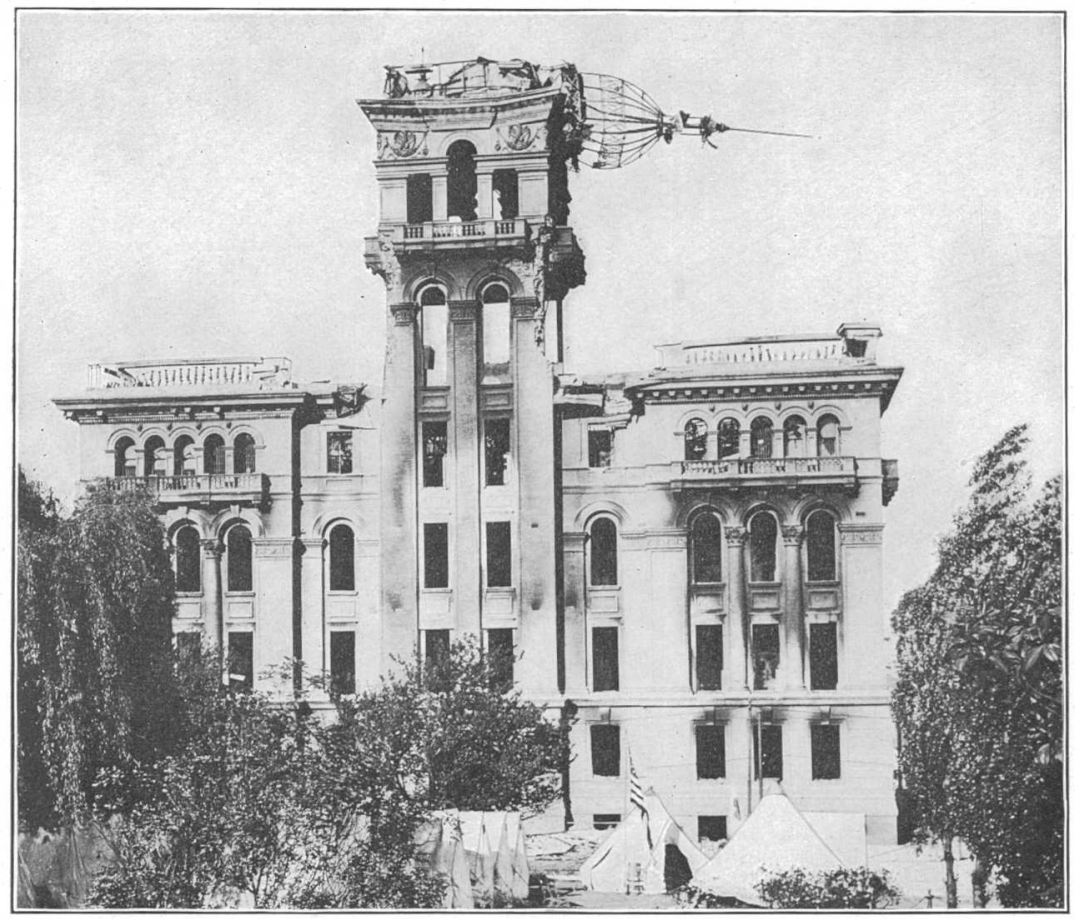

A. WRECKED TOWER AND SPALLED STONEWORK, HALL OF JUSTICE, SAN FRANCISCO. Photograph by John Stephen Sewell.

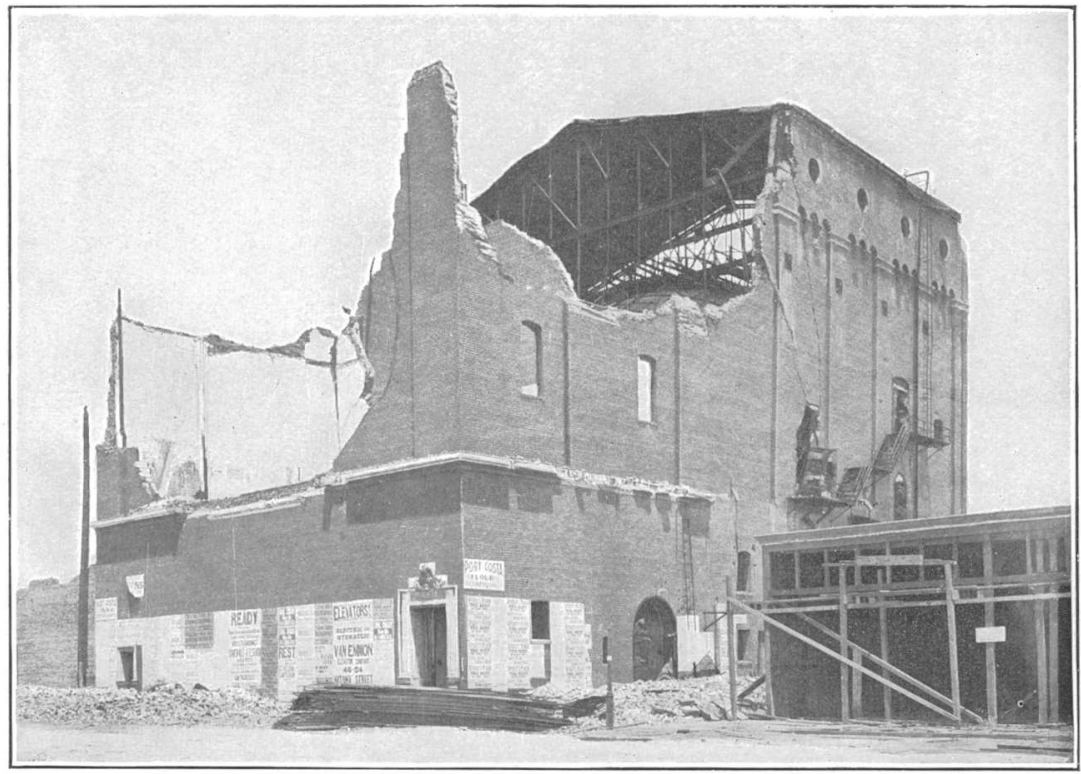

B. COMPLETE WRECK by EARTHQuake, DUE TO POOR DESIGN, MAJESTIC THEATER, SAN FRANCISCO.

Photograph by Richard L. Humphrey. 


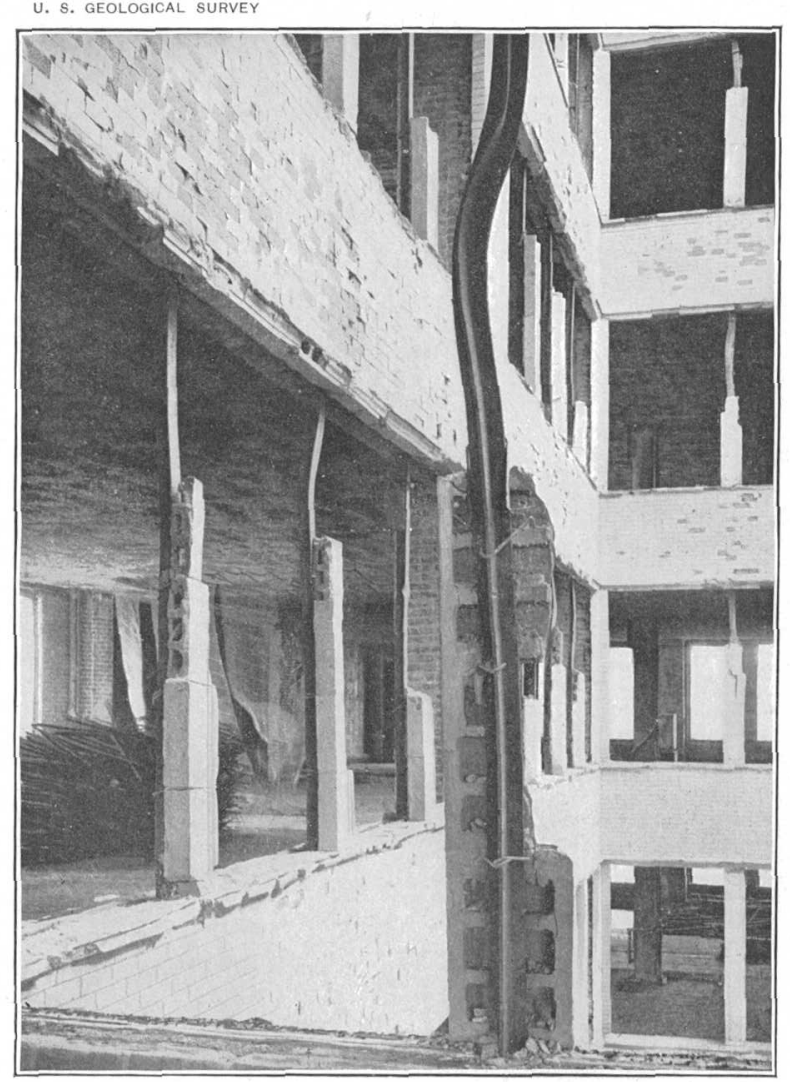

A. SPALLING OF ENAMELED BRICK IN LIGHT WELL, AND FAILURE OF FIREPROOFING OF WINDOW-FRAME SEPARATORS, MERCHANTS EXCHANGE BUILDING, SAN FRANCISCO.

Photograph by Richard L. Humphrey.

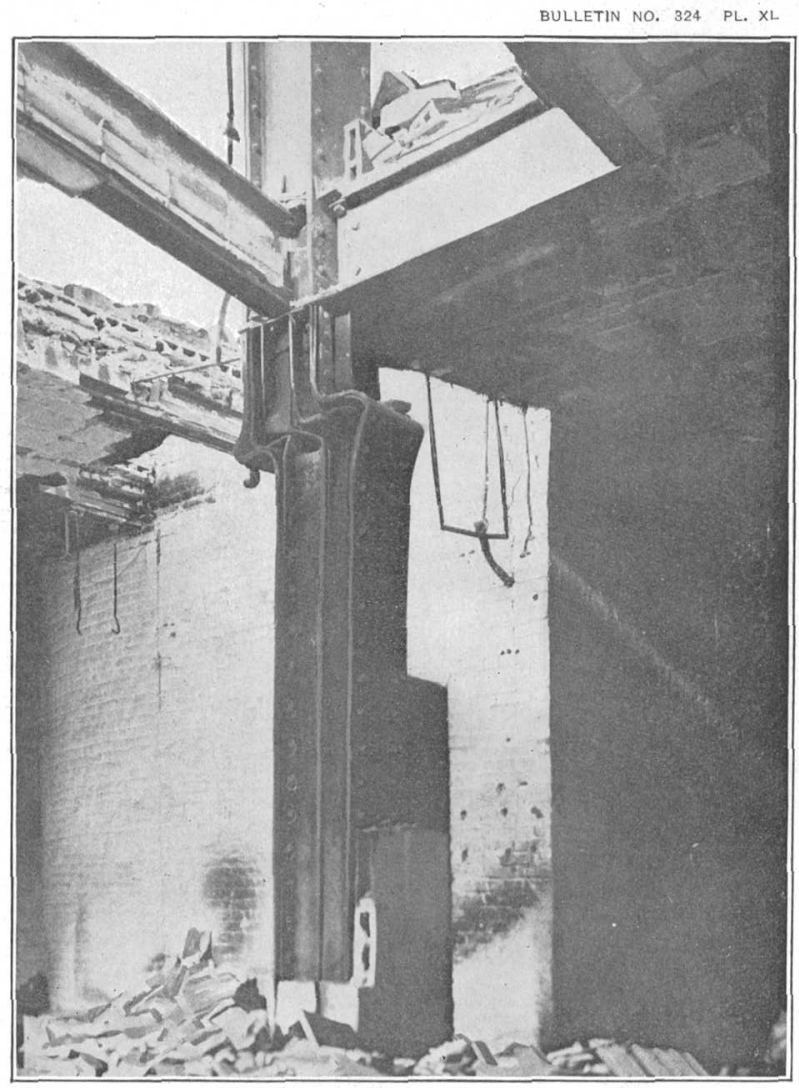

B. BUCKLING OF BASEMENT COLUMN DUE TO FAILURE OF TERRACOTTA COVERING IN FIRE, MILLS BUILDING, SAN FRANCISCO. Photograph by Richard L. Humphrey. 


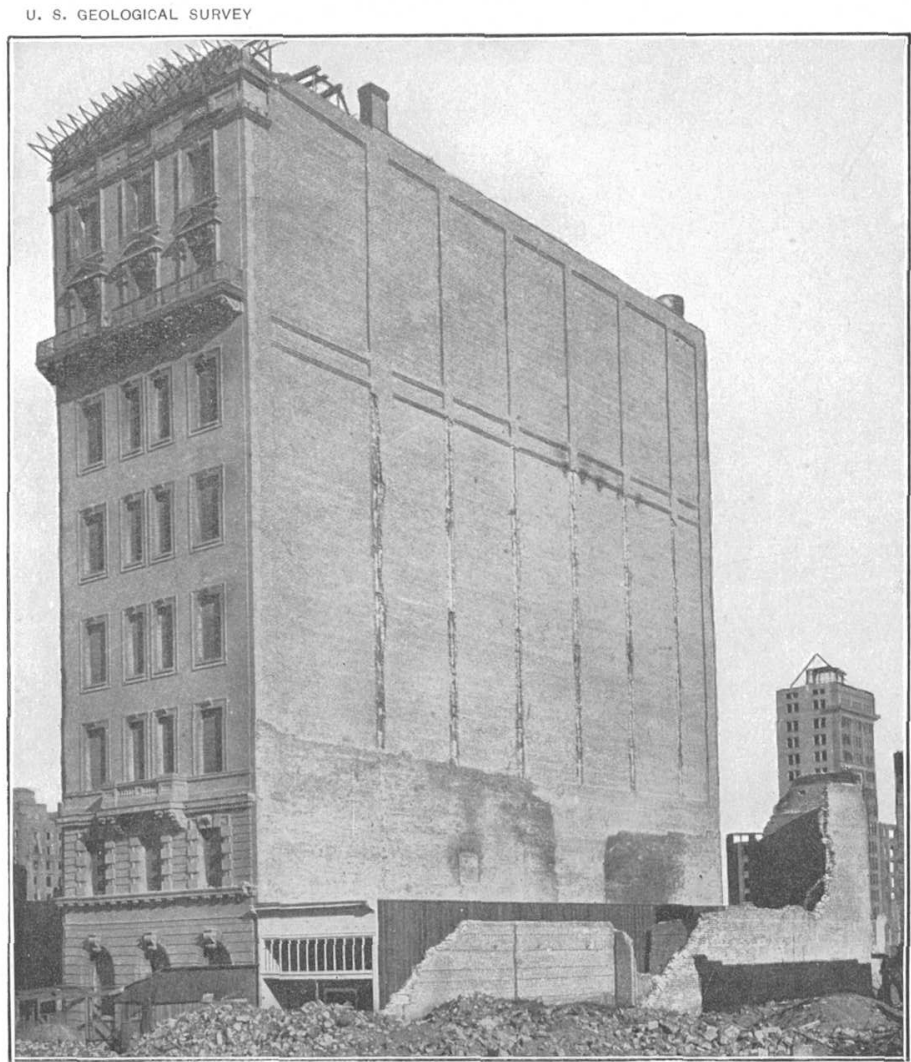

A. ENDURANCE OF A WELL-PROTECTED BUILDING SUBJECTED TO SEVERE HEAT, MAIN EXCHANGE OF PACIFIC STATES TELEPHONE AND TELEGRAPH COMPANY, SAN FRANCISCO.

Rolling shutters, self-supporting brick walls, concrete floors, and concrete protection for columns and girders, Photograph by Richard L. Humphrey.

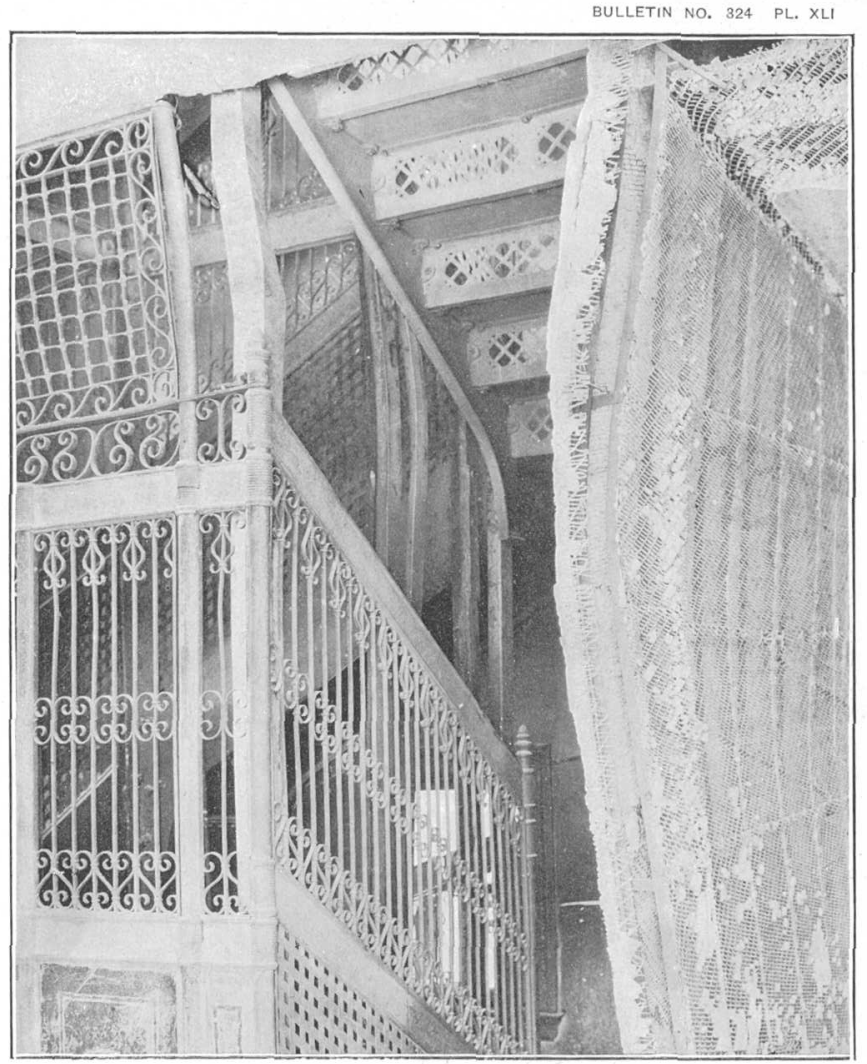

B. WARPING OF PLASTERED METAL-LATH COVERING BY FIRE, MURPHY BUILDING, SAN FRANCISCO.

Photograph by Richard L. Humphrey. 


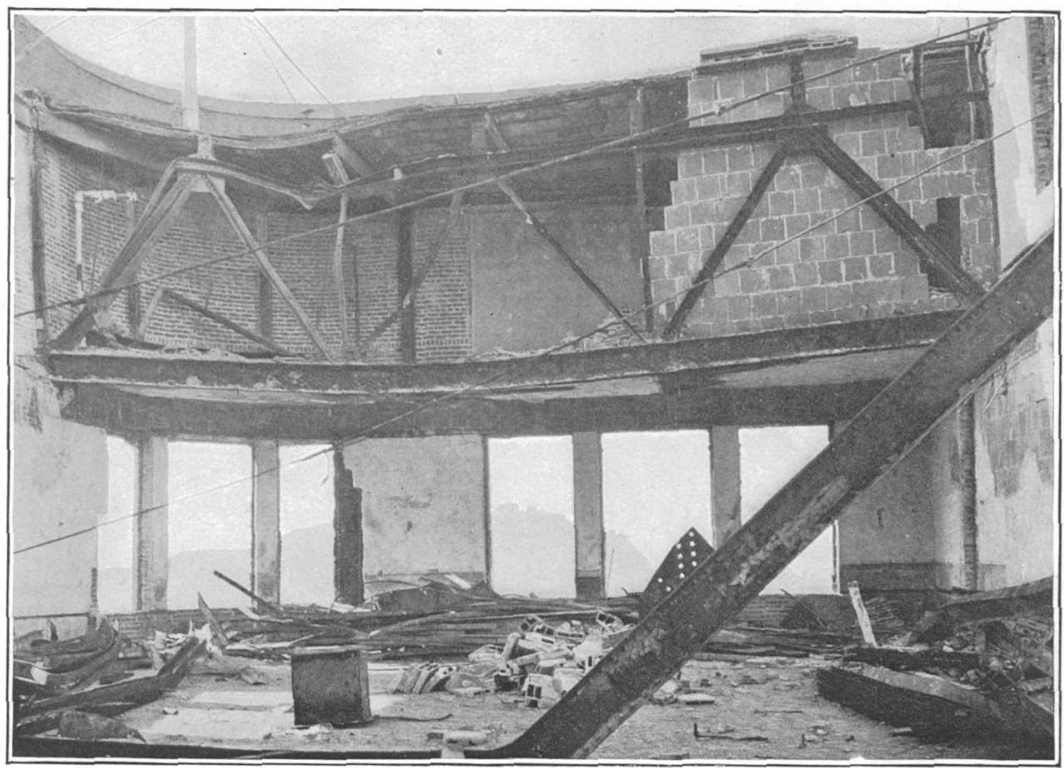

A. ROOF TRUSSES DAMAGED BY HEAT, THROUGH FAILURE OF TERRA-COTTA COVERING, MUTUAL LIFE BUILDING, SAN FRANCISCO.

Photograph by Richard L. Humphrey.

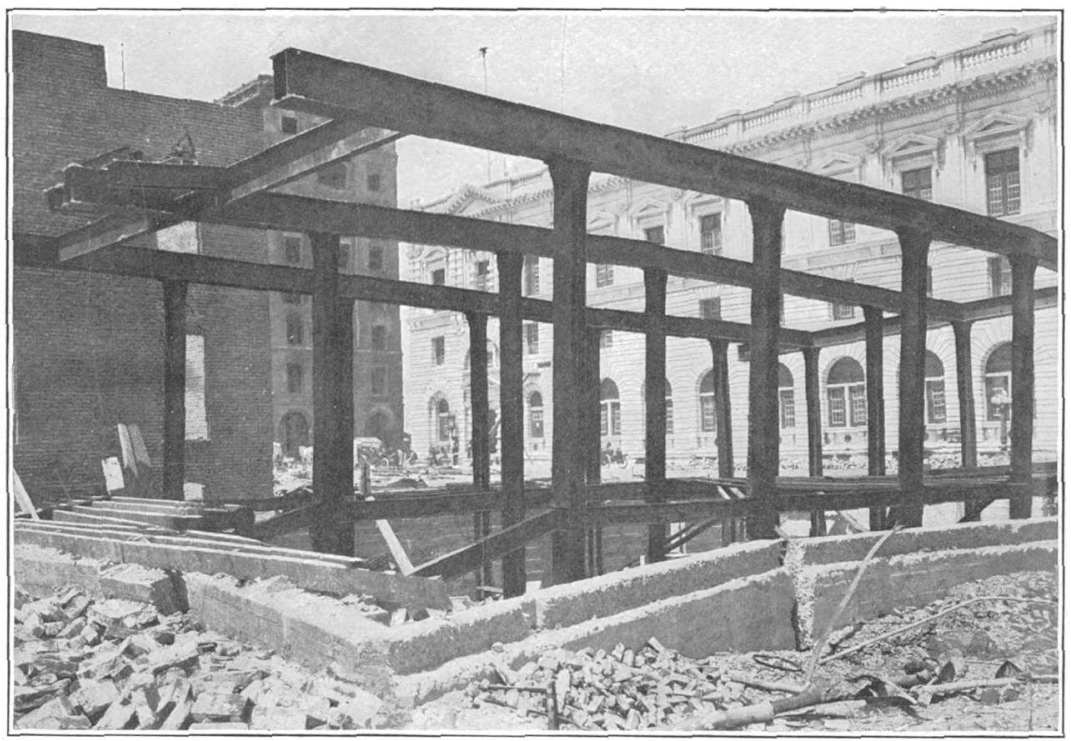

B. EFFECT OF SETTLING OF GROUND SUBJECTED TO EARTHQUAKE VIBRATIONS, STEEL-FRAME BUILDING UNDER CONSTRUCTION.

The concrete basement walls were not reenforced. Post-office in the background. Photograph by Richard L. Humphrey. 


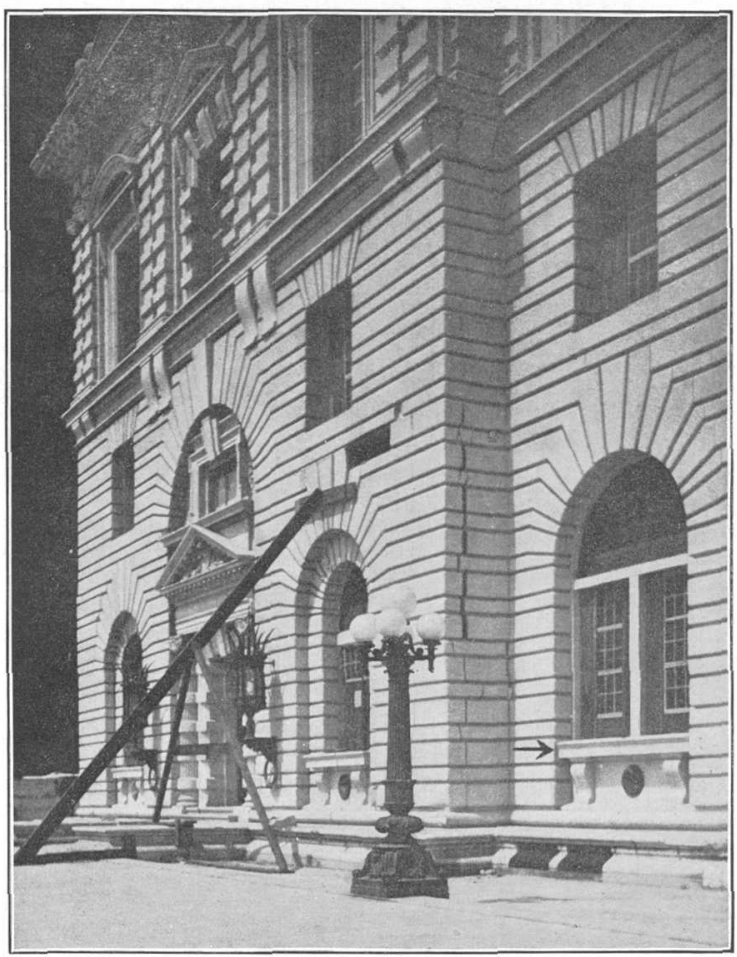

A. CRACKS IN MASONRY, PAVILION OF POST-OFFICE, SAN FRANCISCO.

The window reveal and sill were jostled together by the earthquake at the point indicated by the arrow. Photograph by John Stephen Sewell.

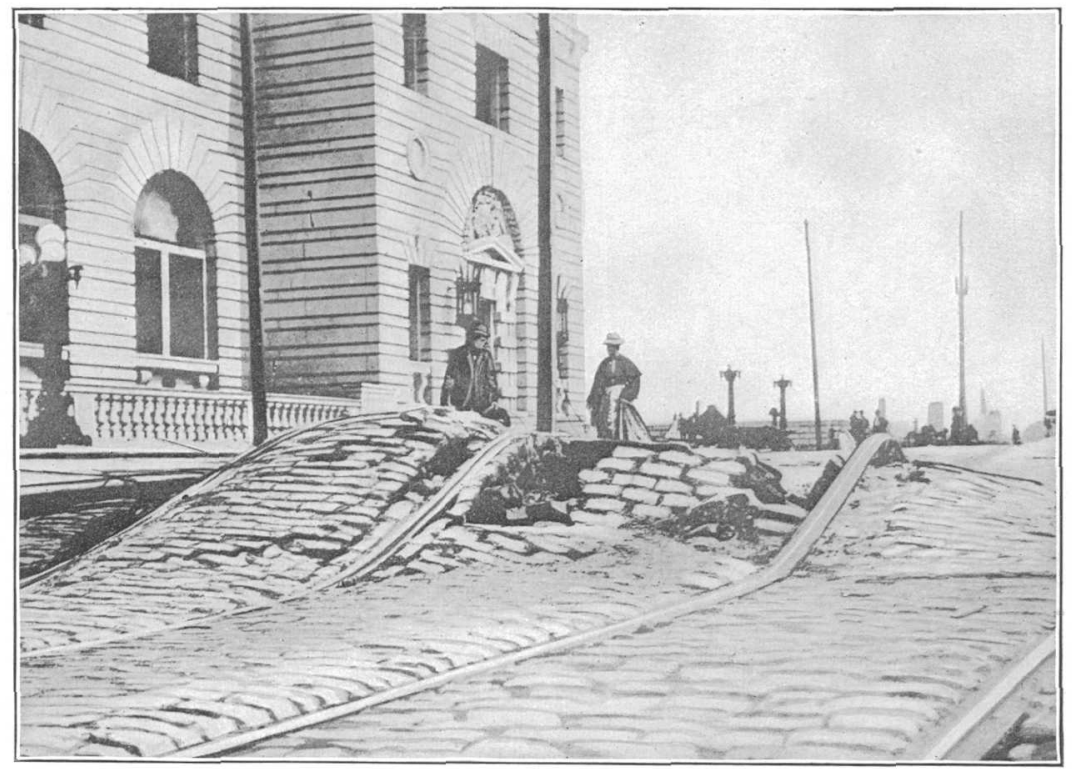

b. EFFECT OF SLIP, MISSION STREET, SAN FRANCISCO.

Corner of post-office building at the left. Photograph submitted by Richard L. Humphrey. 


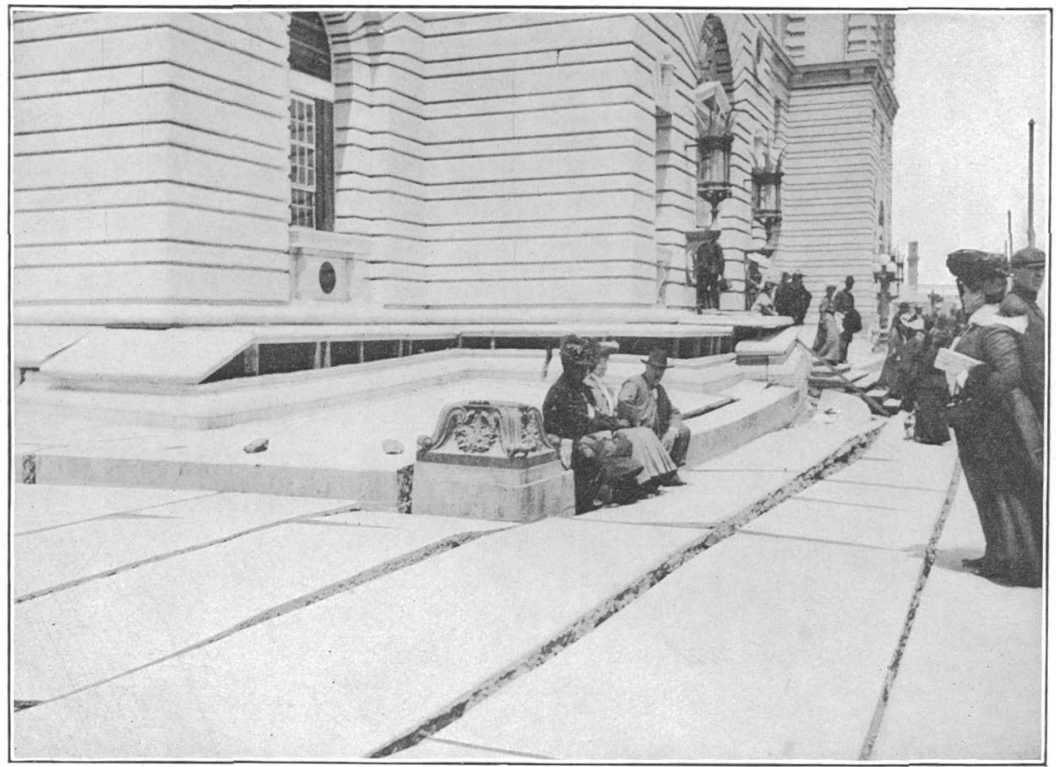

A. CRACKS IN MASONRY AND SETTLING OF OUTER TERRACE, POST-OFFICE BUILDING, SAN FRANCISCO.

The surface of the street went down at this point at least 4 feet. Photograph by John Stephen Sewell.

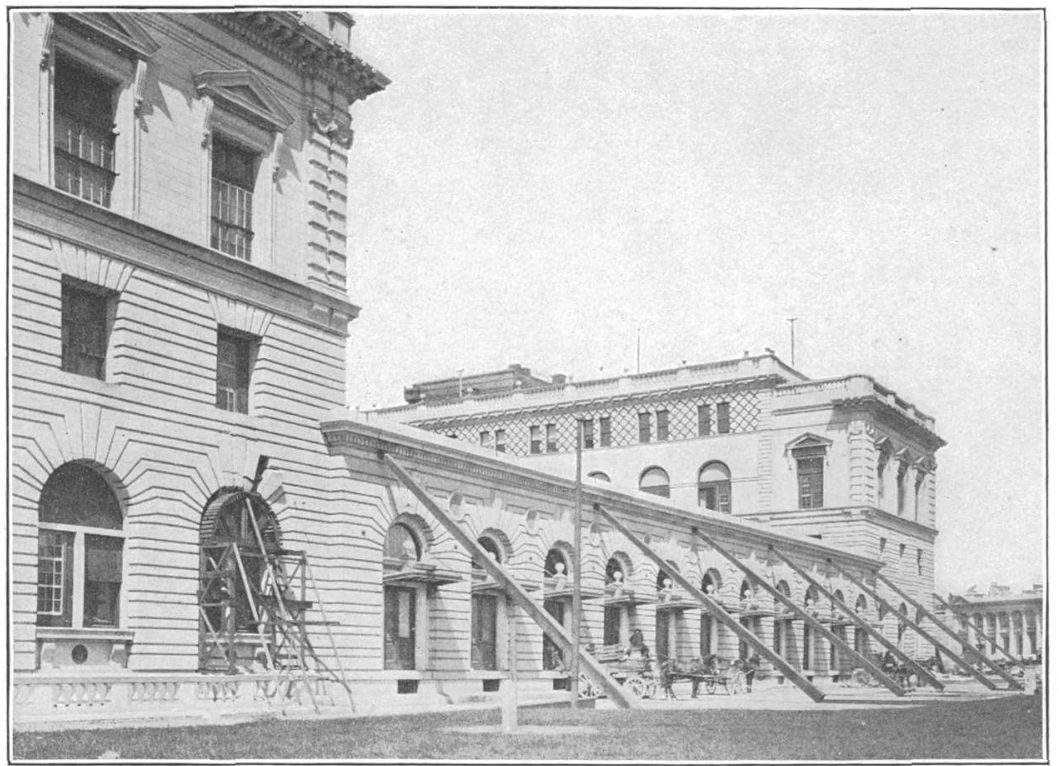

B. EFFECT OF EARTHQUAKE IN LOOSENING STONEWORK, NORTHEAST FACE OF POST-OFFICE BUILDING.

Photograph by Richard L. Humphrey. 


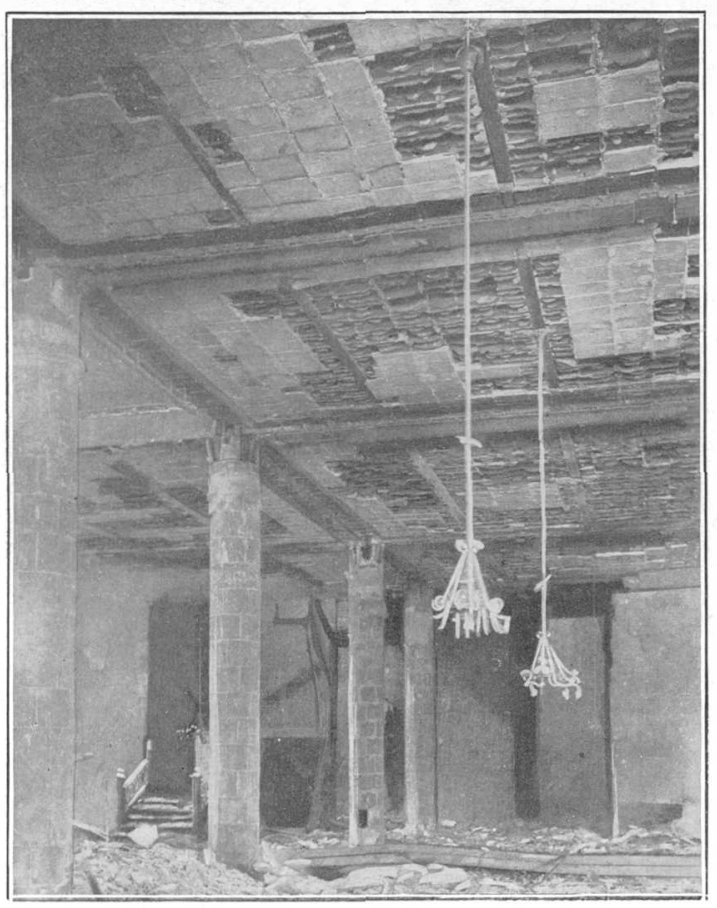

A

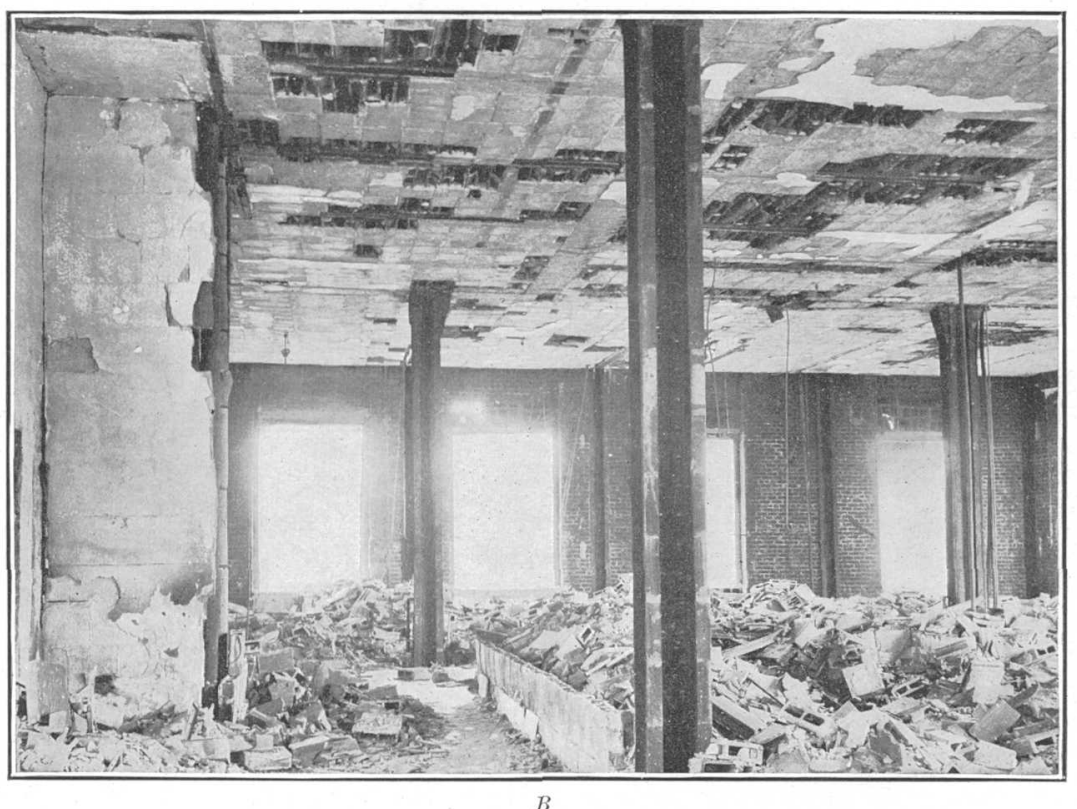

FAILURE OF HOLLOW TERRA-COTTA TILE FIREPROOFING.

$A$, First story of Spring Valley Water Company's Building, San Francisco (photograph by John Stephen Sewell); $B$, Mills Building, San Francisco (photograph by Richard L. Humphrey). The lower webs of the floor tiles were spalled or taken entirely off by the fire. 


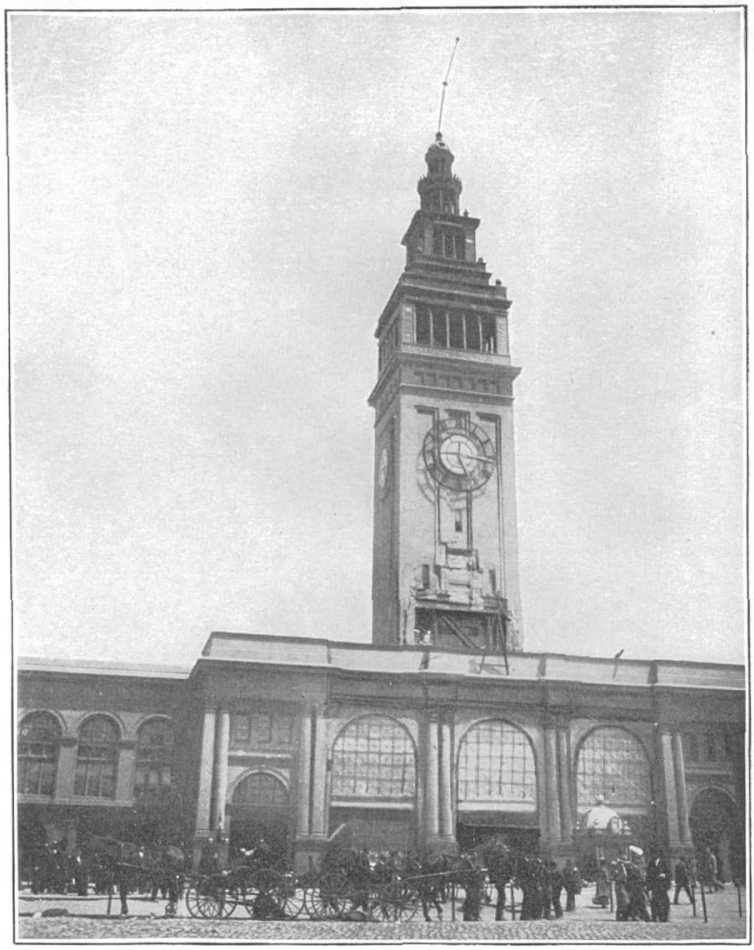

A. BRICKWORK THROWN DOWN BY EARTHQUAKE VIBRATION, TOWER OF UNION FERRY BUILDING, SAN FRANCISCO.

Note bending of time-ball shaft. Photograph submitted by Richard $L$. Humphrey.

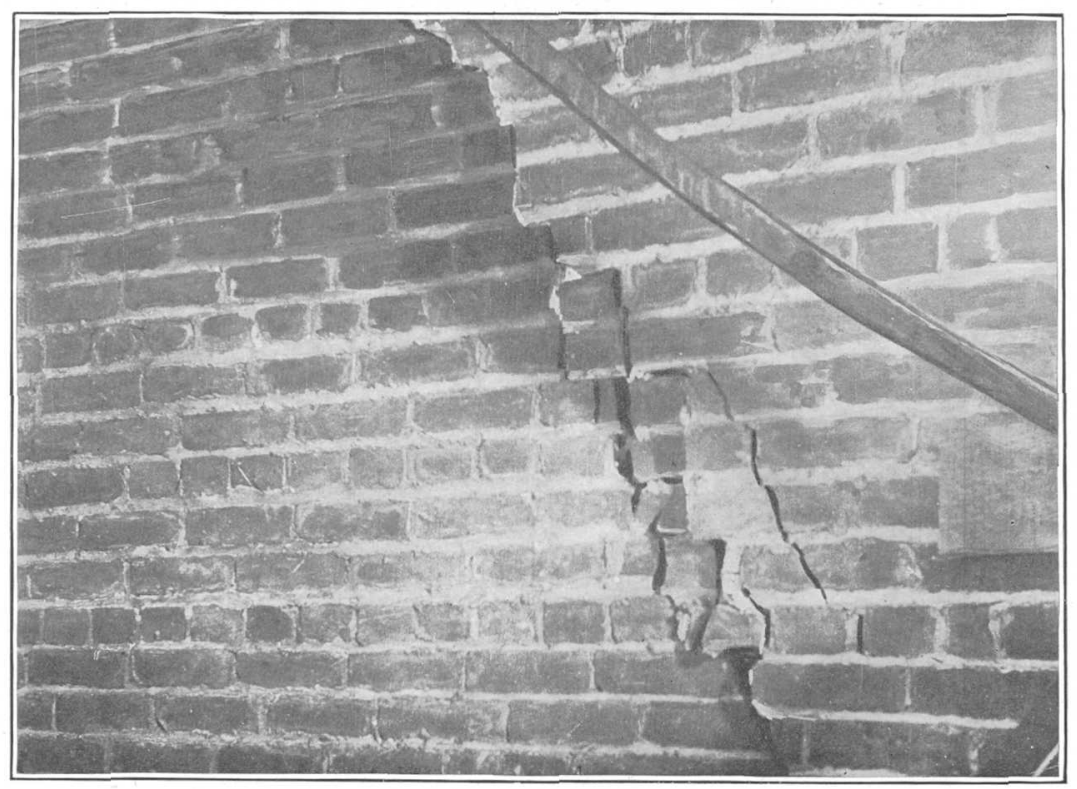

B. EFFECT OF SEVERE SHAKING ON WELL-BONDED BRICKWORK FILLED WITH GOOD MORTAR, TOWER OF UNION FERRY BUILDING.

Note sagged tie-rod, stretched by the racking of the structure. Photograph by John Stephen Sewell. 

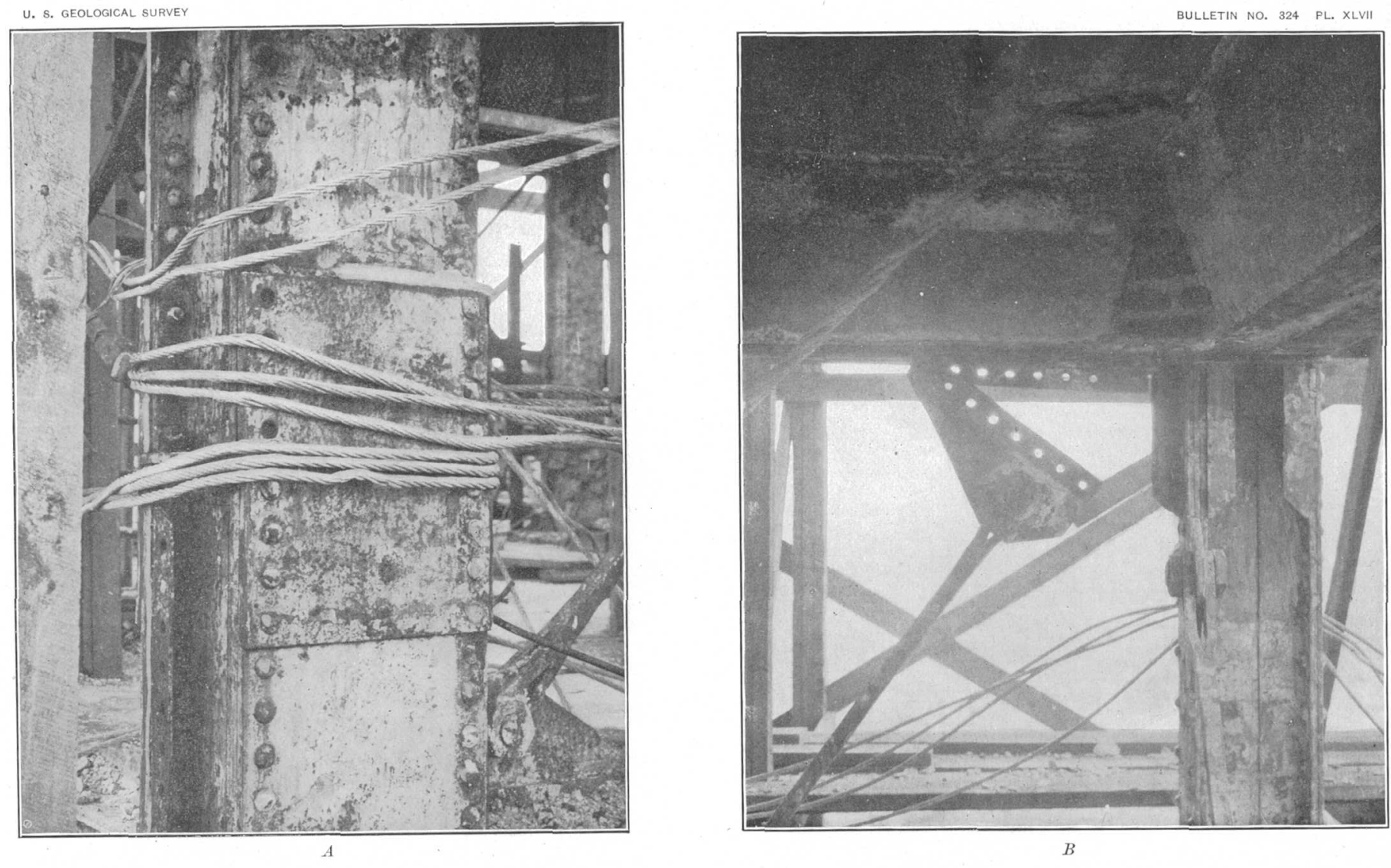

SHEARED RIVETS, TOWER OF UNION FERRY BUILDING, SAN FRANCISCO. 


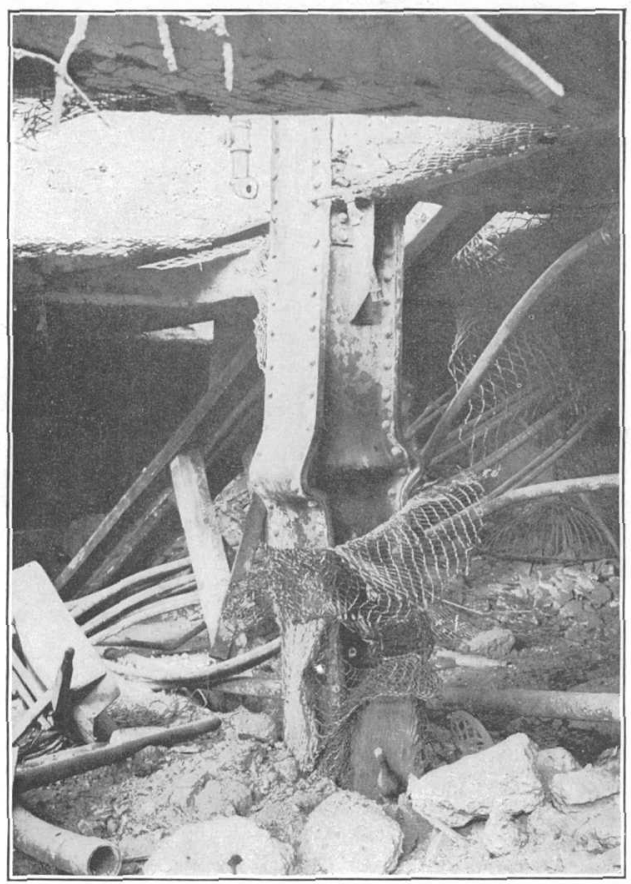

A. BUCKLING OF BASEMENT COLUMN DUE TO FAILURE OF PLASTERED METAL-LATH FIREPROOFING, RIALTO BUILDING, SAN FRANCISCO

Photograph by Richard L. Humphrey.

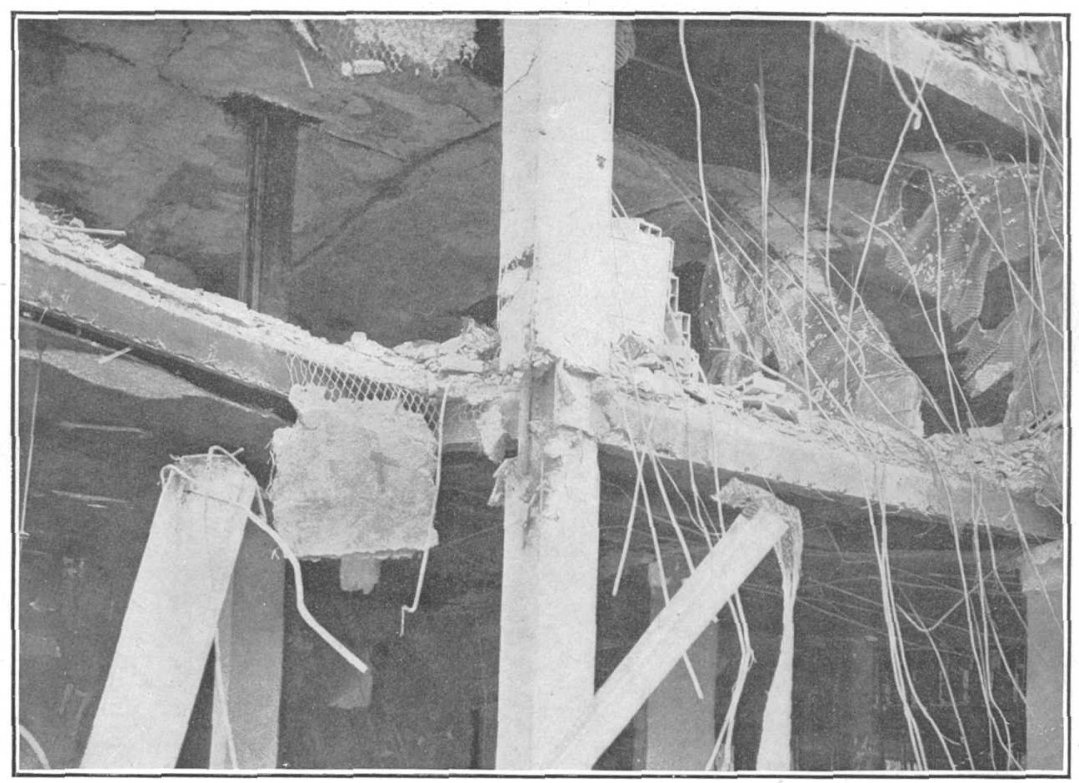

B. DAMAGE SAID to haVe BEEN CAUSEd bY DYNAMITE, RIALTO BUILDING.

Photograph by John Stephen Sewell. 


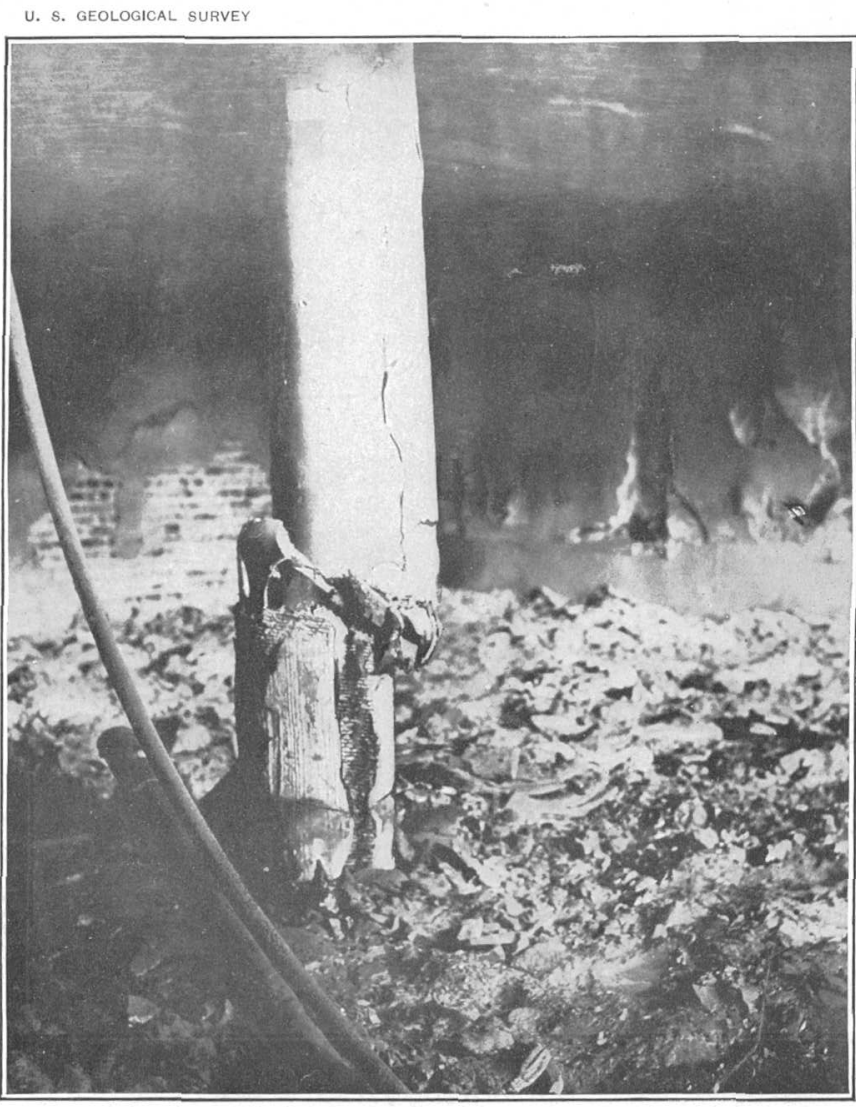

A. FAILURE of BASEMENT COLUmN DUE to FIRE, SLOANE BUILDING, SAN FRANCISCO.

Photograph by John Stephen Sewell.

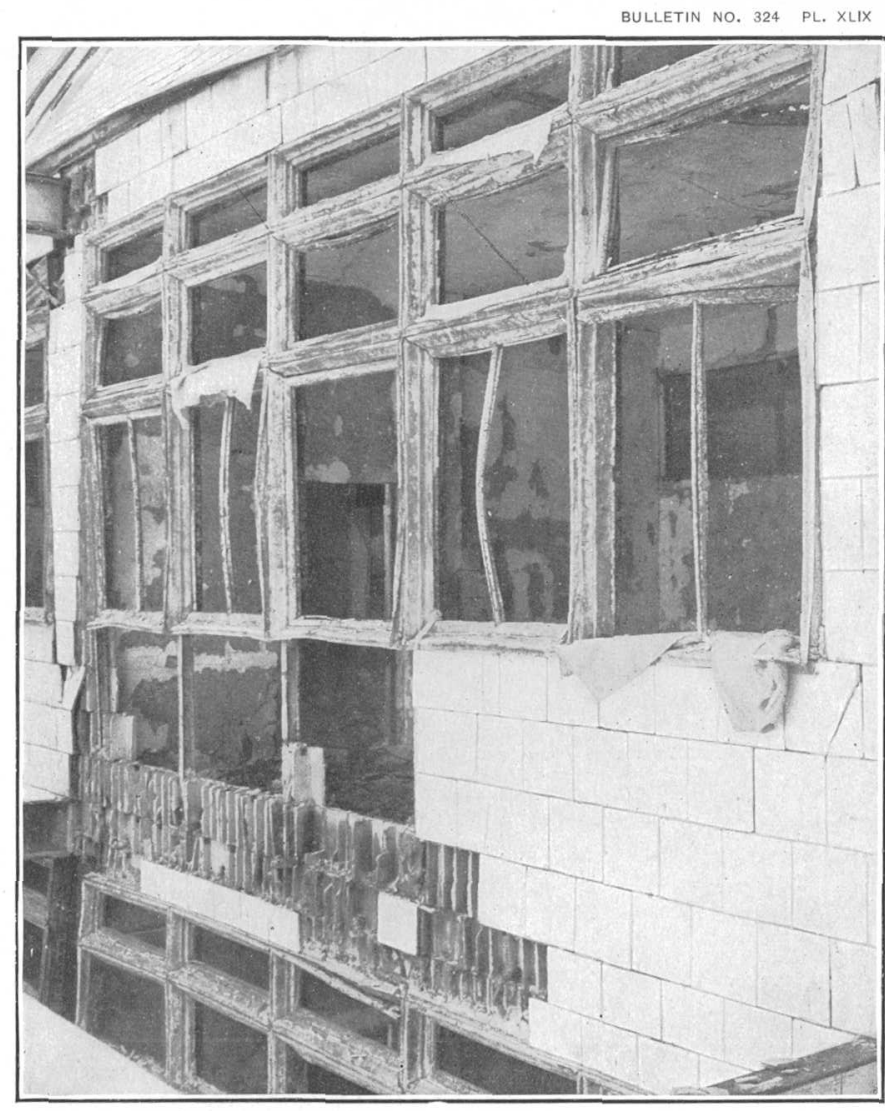

B. FAILURE OF TERRA-COTTA TILING AND METAL-FRAME WIRE-GLASS WINDOWS BY FIRE, LIGHT-WELL COLUMN, WELLS-FARGO BUILDING, SAN FRANCISCO.

Photograph by Richard L. Humphrey. 


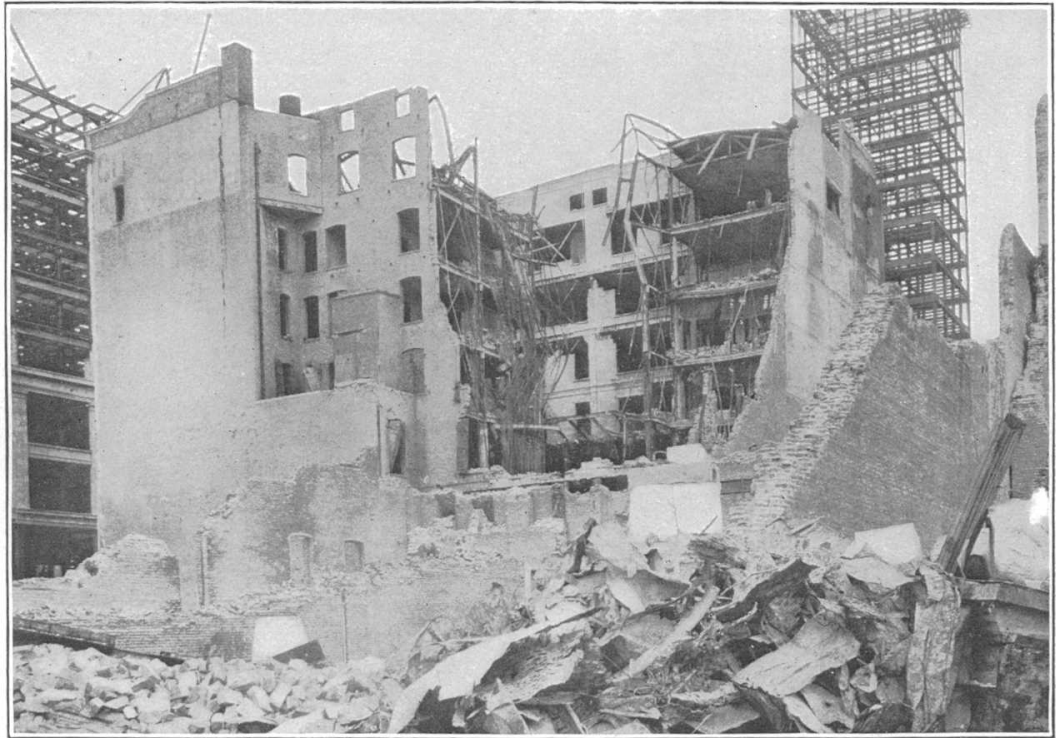

A. COLLaPSE of BUILDING DUE TO BUCKLING OF COLUMNS, SPRING VALLEy WATER COMPANY'S BUILDING, SAN FRANCISCO.

Photograph by Richard L. Humphrey.

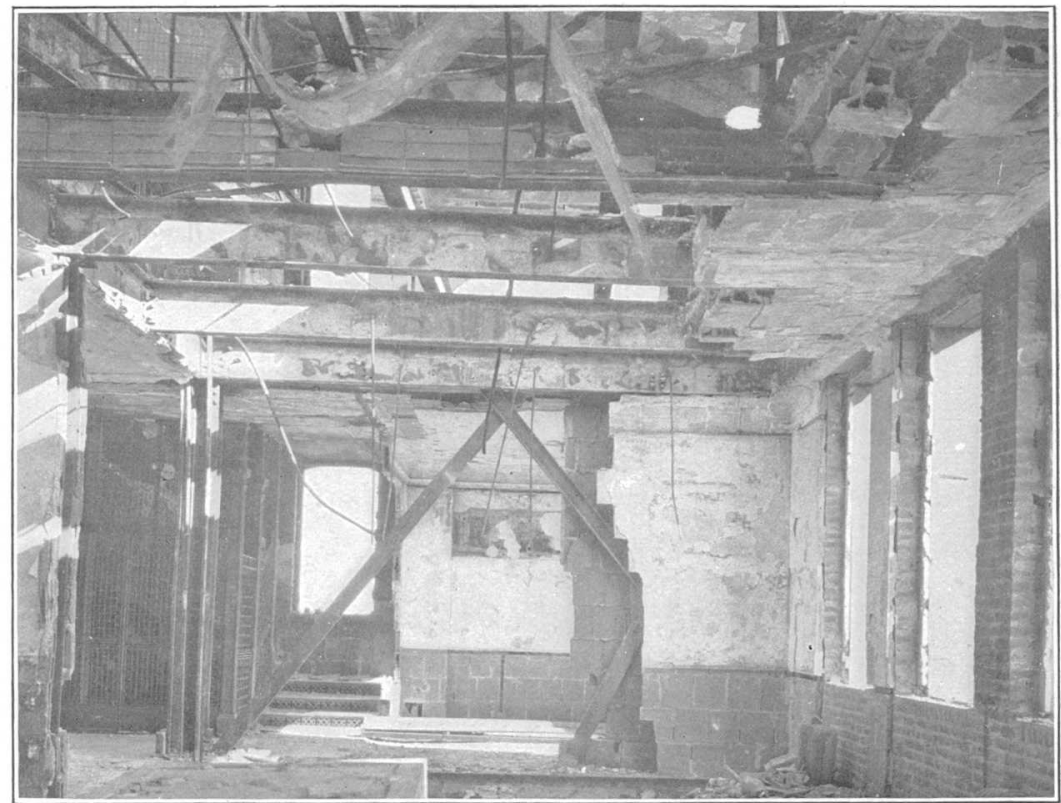

B. FAILURE OF TERRA-COTTA TILE COVERING IN FIRE, UNION TRUST COMPANY'S BUILDING, SAN FRANCISCO.

Photograph by Richard L. Humphrey. 


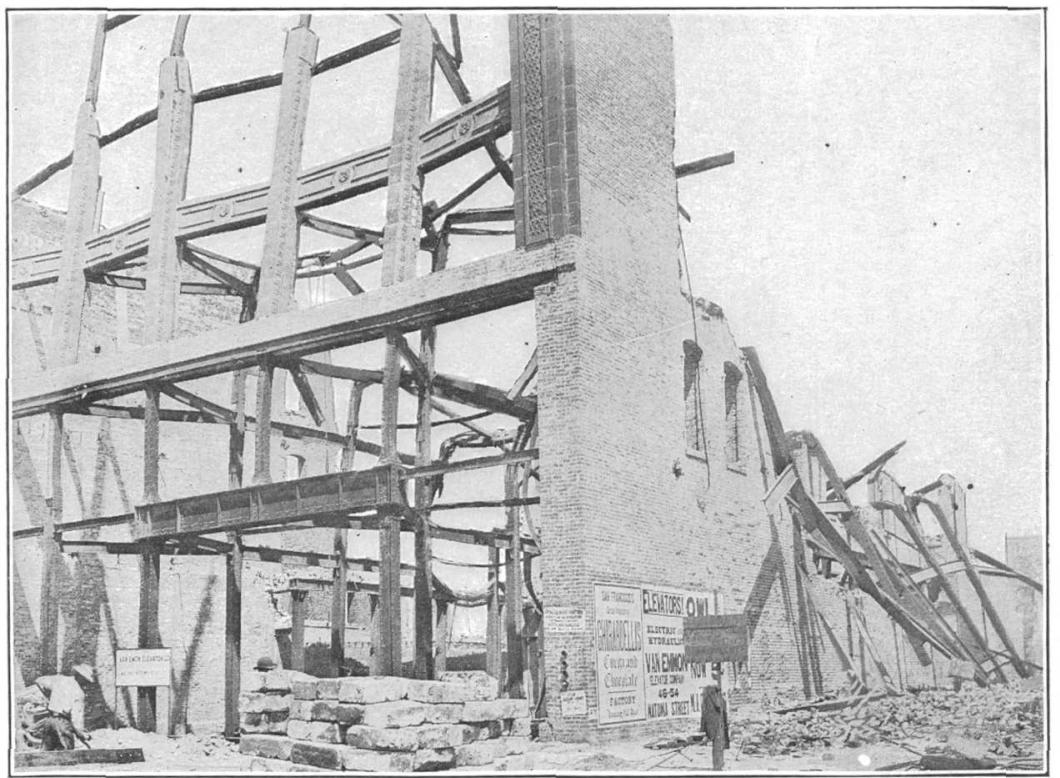

A. AN UNFINISHED STEEL SKELETON, WITH NONFIREPROOFED STEEL WORK.

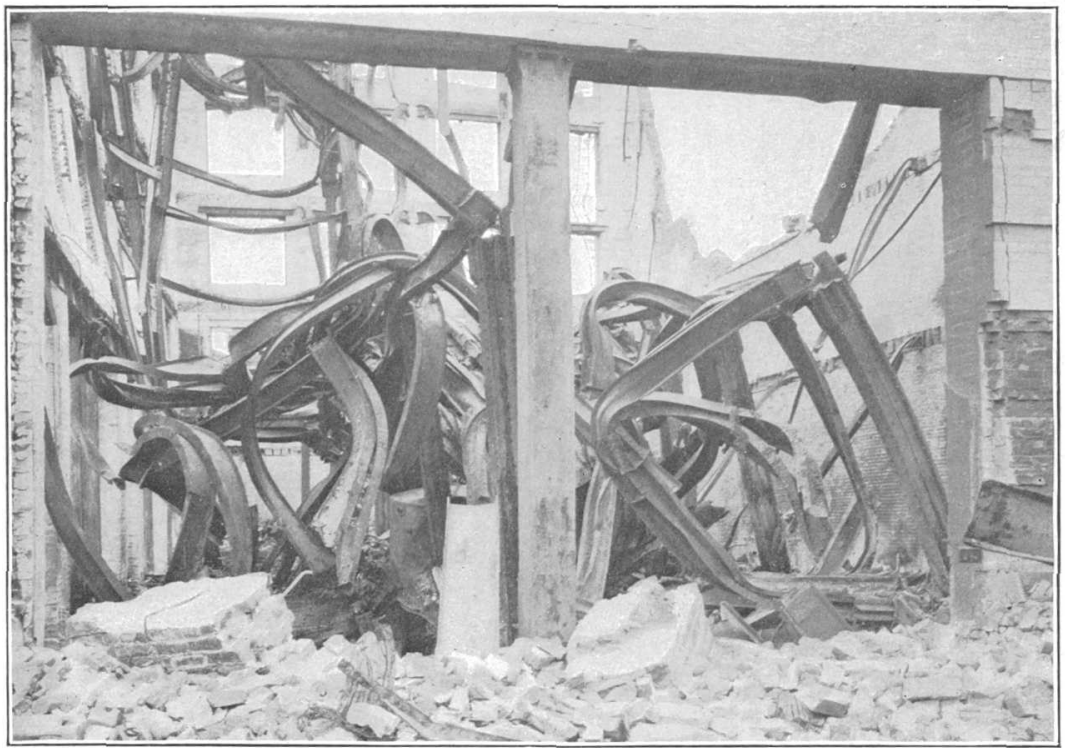

B. UNPROTECTED STEEL FRAME AND GENERAL FLIMSY CONSTRUCTION, COWELL BUILDING. EFFECTS OF HEAT ON STEEL WORK, SAN FRANCISCO. 


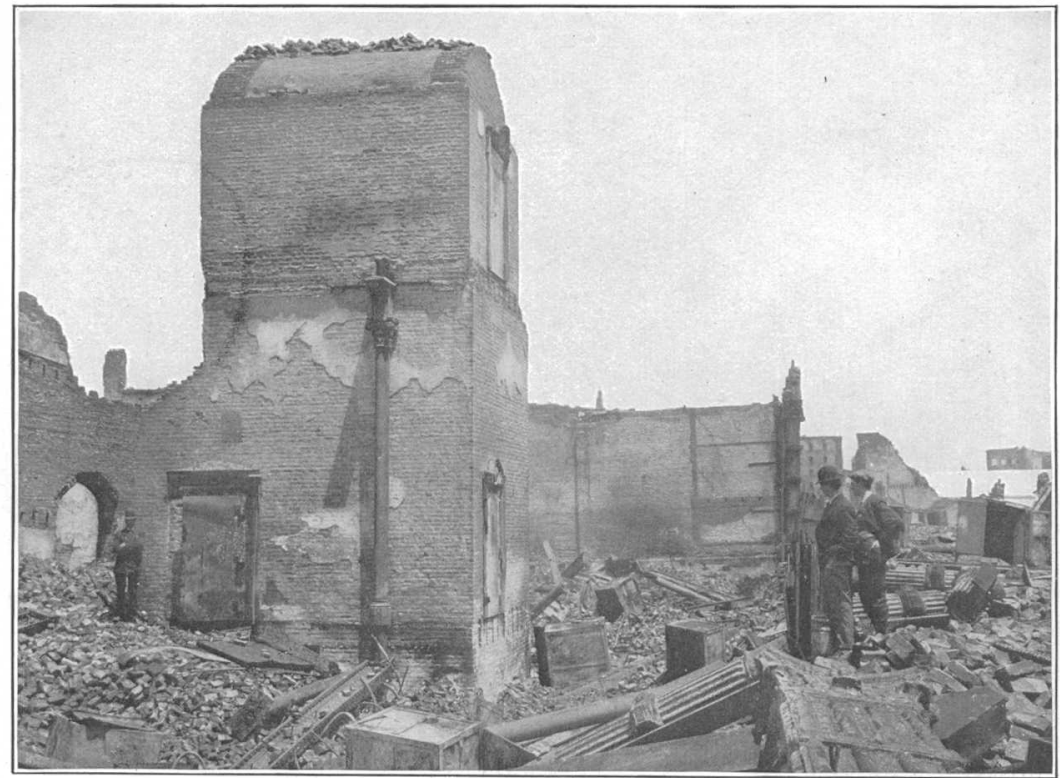

A. ENDURANCE OF BRICK VAULT

This vault, which was in the original Wells-Fargo Building, San Francisco, passed the fire test satisfactorily, although the building was completely destroyed. Note the defective steel "fireproof" safes near by Photograph by Richard L. Humphrey.

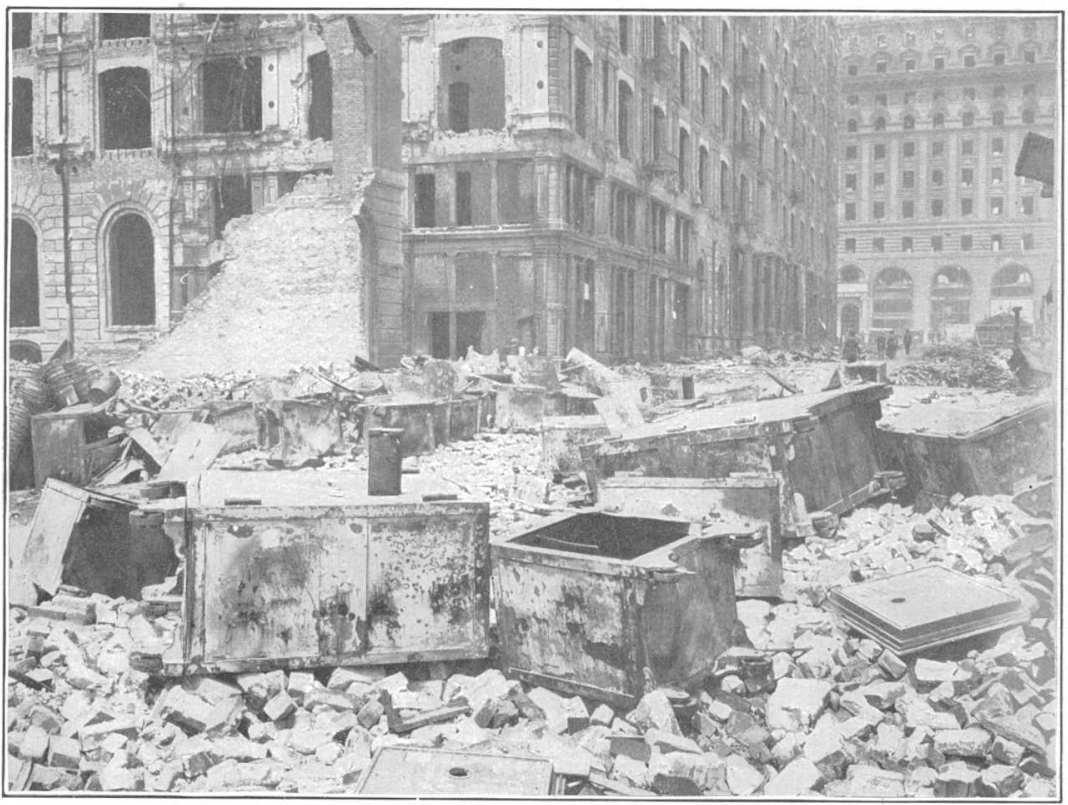

13. ABSOLUTE FAILURE OF SO-CALLED "FIREPROOF" SAFES.

In the rear are the Palace Hotel (at the left) and the Crocker Building (at the right). Photograph by Richard L. Humphrey. 


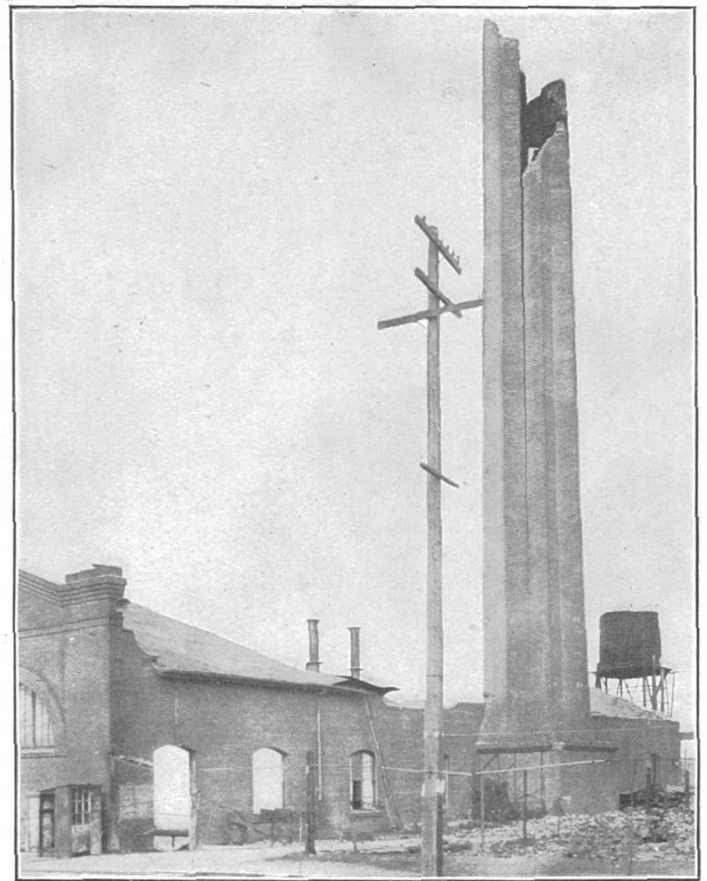

A. EARTHQUAKE DAMAGE TO BRICK STACK OF STAR SECTION, VALENCIA STREET POWER STATION, SAN FRANCISCO

Showing peculiar crack in reentrant angle. Photograph by Richard L. Humphrey,

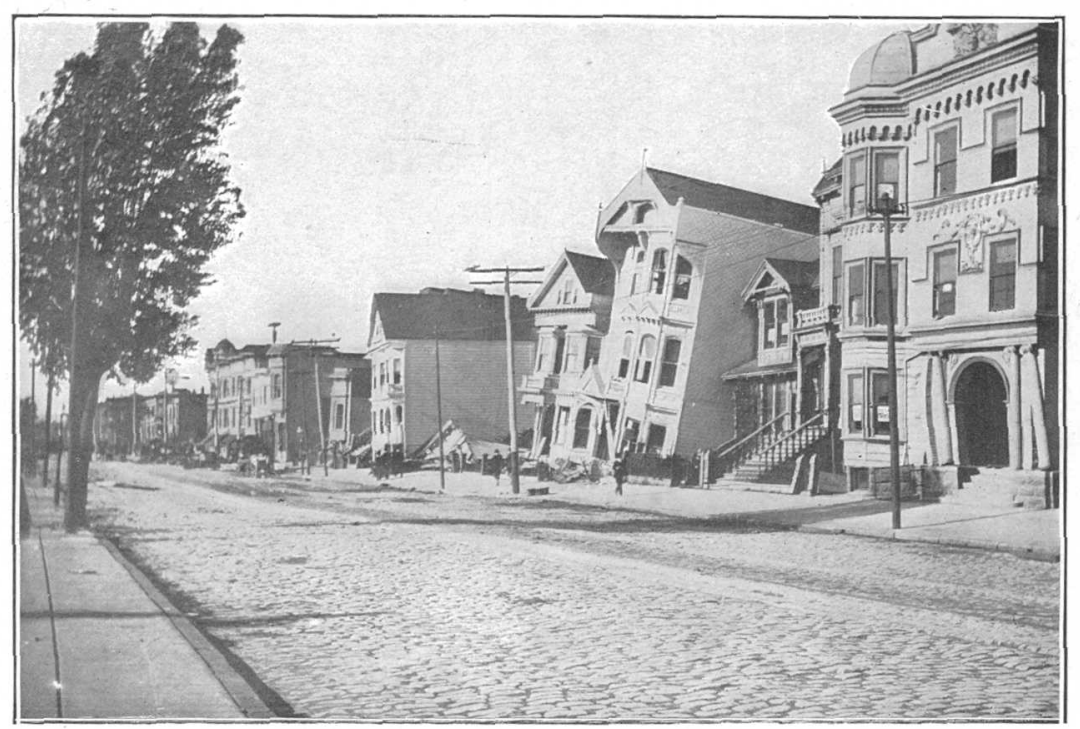

B. GENERAL EARTHQUAKE EFFECT ON FRAME BUILDINGS SITUATED ON ALLUVIAL SOIL, HOWARD STREET, SAN FRANCISCO. 


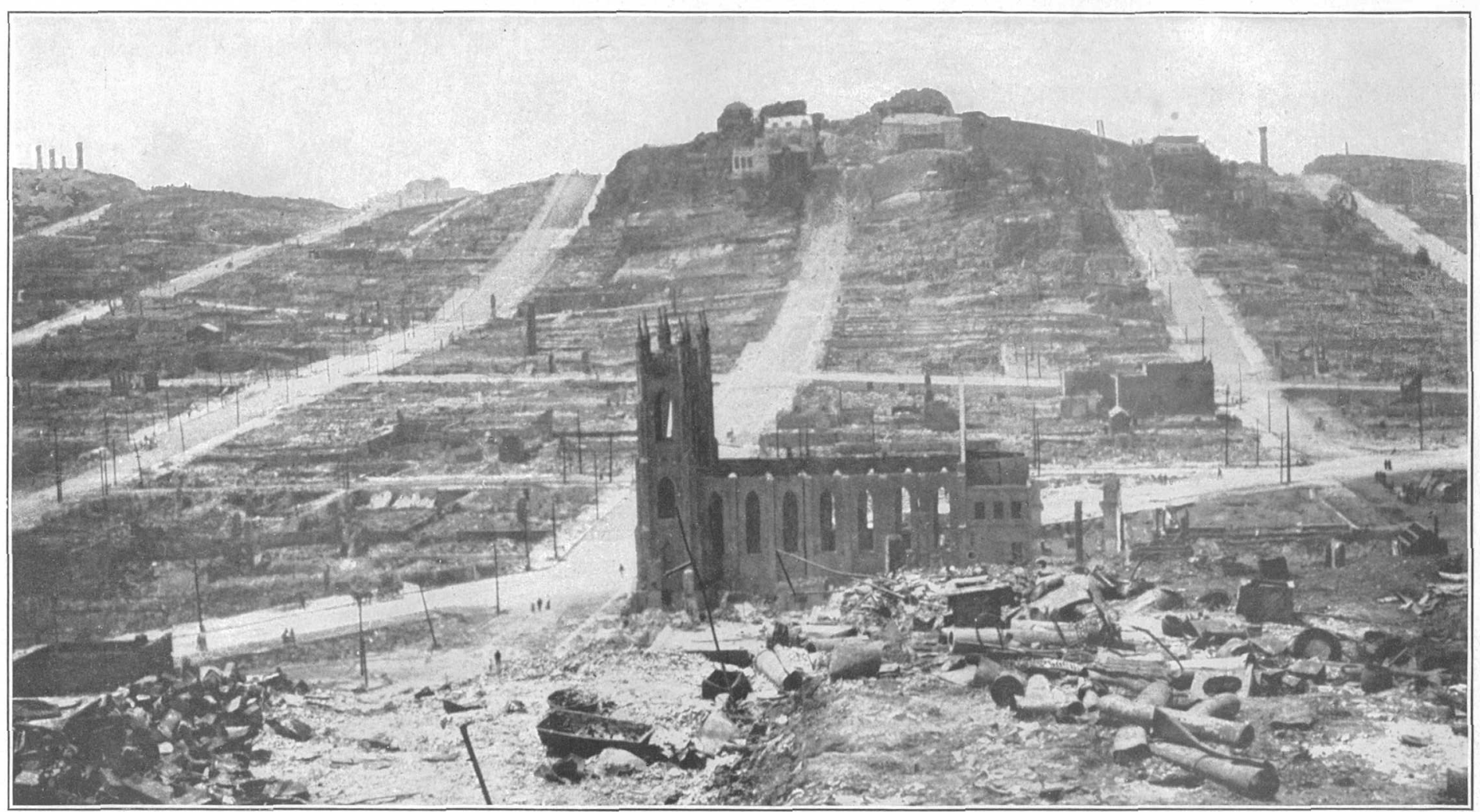

DESTRUCTION BY FIRE, SAN FRANCISCO.

View looking west from Telegraph Hill, showing unburned houses on summit of Russian Hill. St. Francis Roman Catholic Church, with its excellent brick walls, in the foreground. Photograph submitted by Frank Soulé. 


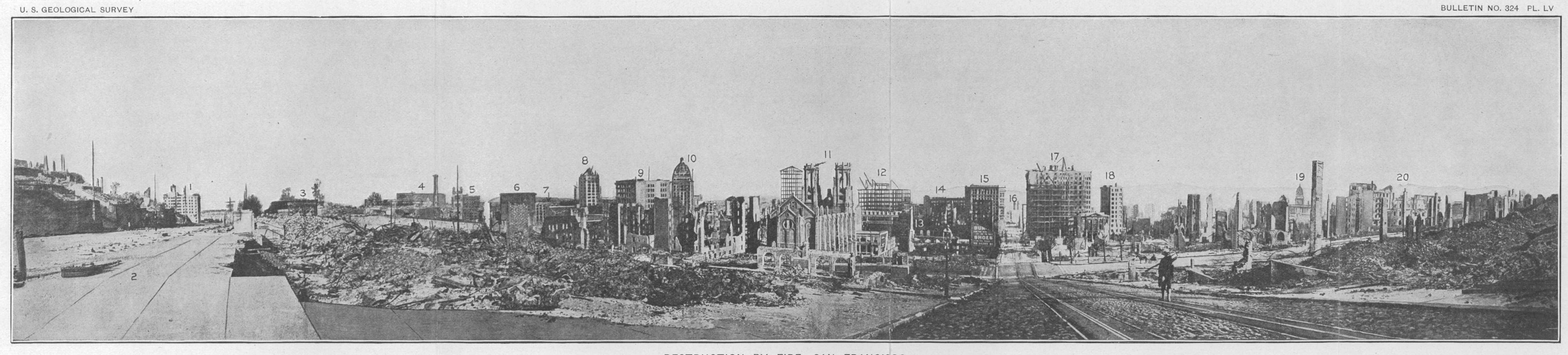

DESTRUCTION BY FIRE, SAN FRANCISCO

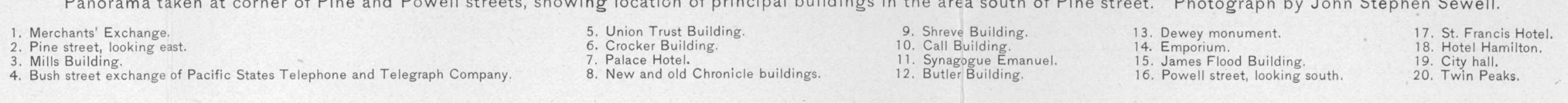

